Movimentos Docentes Comunidade Movimentos Docentes Comunidade Movimentos Docentes Comunidade Movimentos Docentes Comunidade Movimentos Docentes Comunidade Movimentos Docentes Comunidade Movimentos Docentes Comunidade Movimentos Docentes Comunidade Movimentos Docentes Comunidade Movimentos Docentes Comunidade Movimentos Docentes Comunidade Movimentos Docentes Comunidade Movimentos Docentes Comunidade Movimentos Docentes Comunidade Movimentos Docentes Comunidade Movimentos Docentes Comunidade Movimentos Docentes Comunidade Movimentos Docentes Comunidade Movimentos Docentes Comunidade Movimentos Docentes Comunidade Movimentos Docentes Comunidade Movimentos Docentes Comunidade Movimentos Docentes Comunidade Movimentos Docentes Comunidade Movimentos Docentes Comunidade Movimentos Docentes Comunidade Movimentos Docentes Comunidade Movimentos Docentes Comunidade Movimentos Docentes Comunidade Movimentos Docentes Comunidade Movimentos Docentes Comunidade Movimentos Docentes Comunidade Movimentos Docentes Comunidade Movimentos Docentes Comunidade Movimentos Docentes Comunidade Movimentos Docentes Comunidade Movimentos Docentes Comunidade Movimentos

\title{
Caderno de Resumos
}

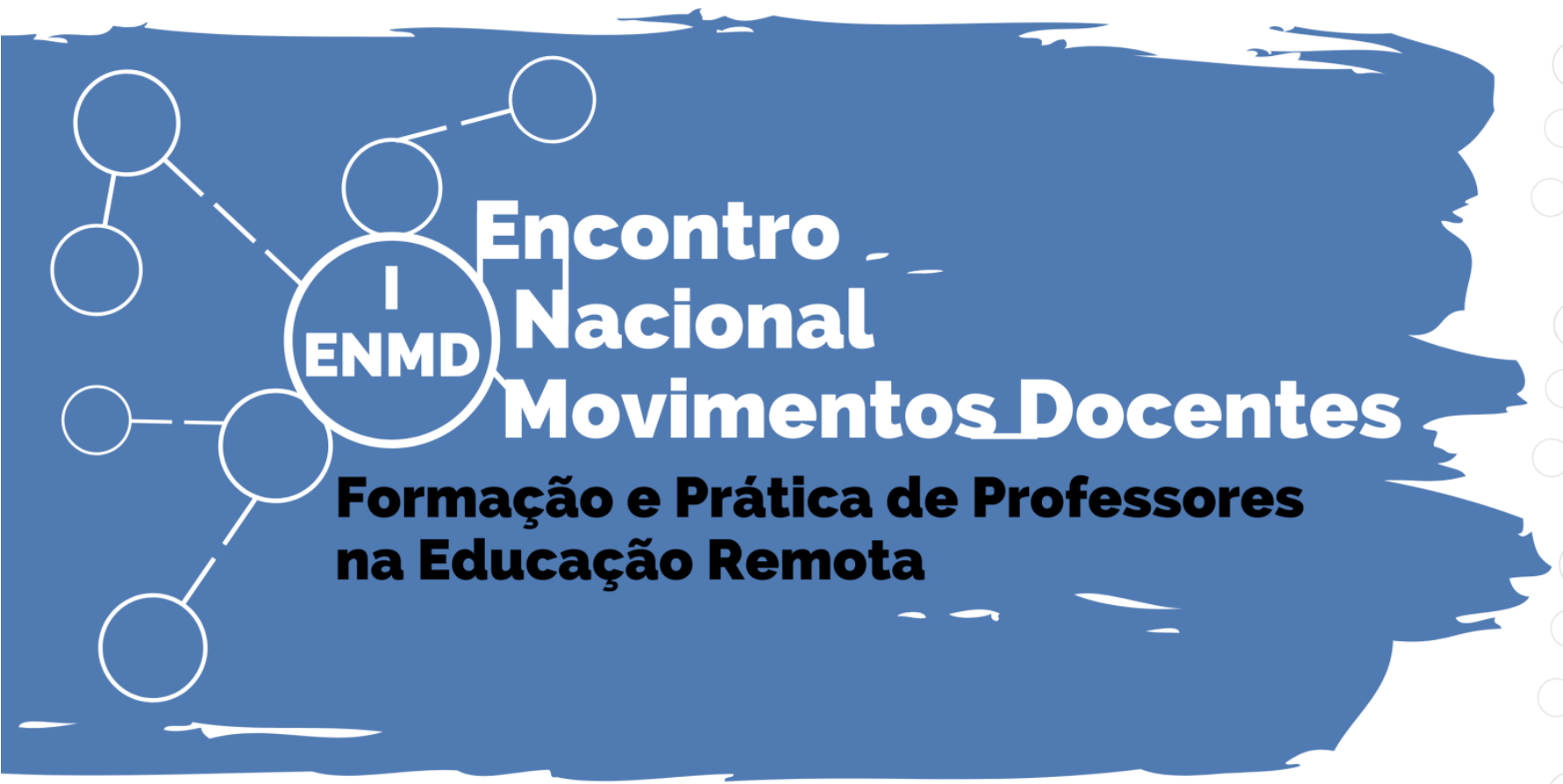

Docentes Comunidade Movimentos Docentes Comunidade Movimentos Docentes Comunidade Movimentos Docentes Comunidade Movimentos Docentes Comunidade Movimentos Docentes Comunidade Movimentos Docentes Comunidade Movimentos Docentes Comunidade Movimentos Docentes Comunidade Movimentos Docentes Comunidade Movimentos Docentes Comunidade Movimentos Docentes Comunidade Movimentos Docentes Comunidade Movimentos Docentes Comunidade Movimentos Docentes Comunidade Movimentos Docentes Comunidade Movimentos Docentes Comunidade Movimentos Docentes Comunidade Movimentos Docentes Comunidade Movimentos Docentes Comunidade Movimentos Docentes Comunidade Movimentos Docentes Comunidade Movimentos Docentes Comunidade Movimentos Docentes Comunidade Movimentos Docentes Comunidade Movimentos Docentes Comunidade
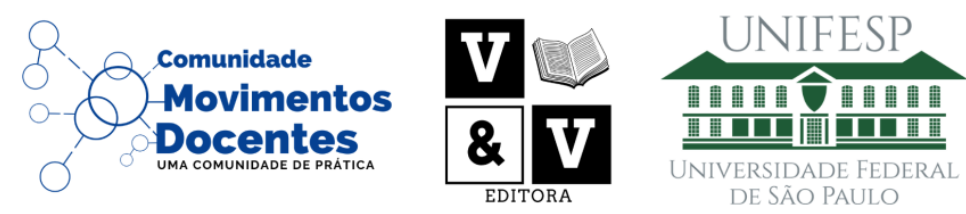
MOVIMENTOS DOCENTES

Universidade Federal de São Paulo

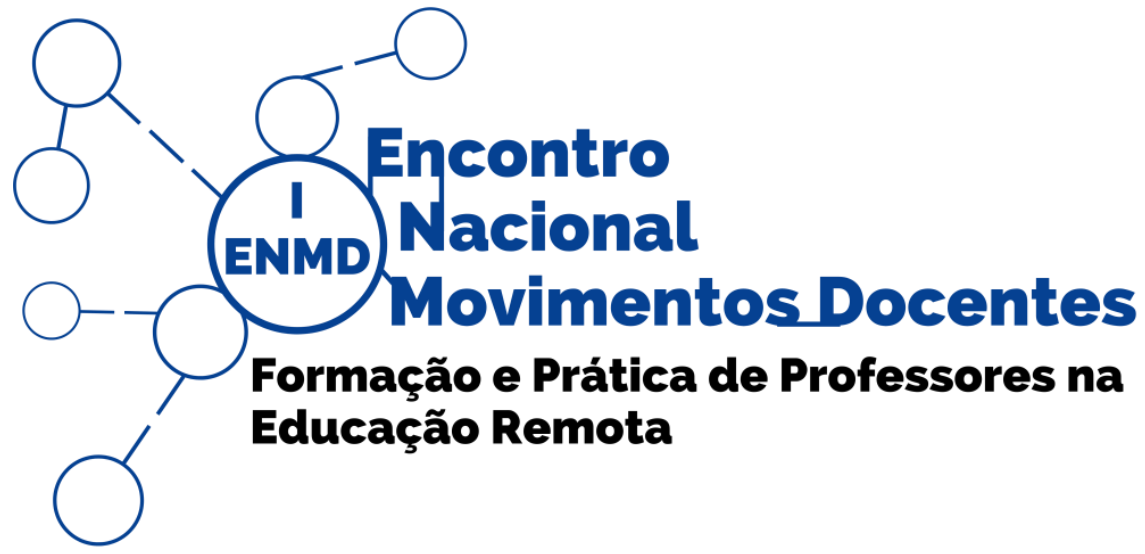

CADERNO DE RESUMOS DO

I ENCONTRO NACIONAL MOVIMENTOS DOCENTES

$1^{a}$ Edição

V\&V Editora

Diadema - SP

2020 


\section{Evento}

I Encontro Nacional Movimentos Docentes

Data

15 e 16 de Outubro de 2020

\section{Local}

On-line, transmitido em youtube.com/movimentosdocentes

\section{Realização}

Grupo de Pesquisa e Comunidade "Movimentos Docentes"

Universidade Federal de São Paulo - Campus Diadema

\section{Instituições coorganizadoras}

UniFOA - Centro Universitário de Volta Redonda

UECE - Universidade Estadual do Ceará

Centro Universitário Internacional UNINTER

FORPIBID-RP - Fórum Nacional dos Coordenadores Institucionais do Programa Institucional de Bolsas de Iniciação à Docência e Residência Pedagógica

PECMA - Programa de Pós-Graduação em Ensino de Ciências e Matemática da UNIFESP

ANPI - Associação Nacional de Procuradores e Pesquisadores Institucionais das IES Privadas

V\&V Editora

\section{Apoio institucional}

PROEC - Pró-Reitoria de Extensão e Cultura da UNIFESP, SIEX 18680

\section{Organização do Caderno de Resumos}

Marilena Rosalen, Ligia Ajaime Azzalis, Letícia Moreira Viesba e Everton ViesbaGarcia

\section{ISBN}

978-65-88471-05-0

\section{DOI}

https:/ / doi.org/ 10.47247/VV/ENMD/88471.05.0 
UNIVERSIDADE FEDERAL DE SÃO PAULO

\section{REITORIA}

\section{Reitora}

Profa. Dra. Soraya Soubhi Smaili

\section{Vice-Reitora}

Profa. Dra. Andréa Rabinovici

Chefe de Gabinete

Profa. Dra. Ieda Longo Maugeri

Pró-Reitora de Extensão e Cultura

Profa. Dra. Raiane Patrícia Severino Assumpção

Pró-Reitora de Administração

Profa. Dra. Tânia Mara Francisco

Pró-Reitor de Assuntos Estudantis

Prof. Dr. Anderson da Silva Rosa

Pró-Reitora de Graduação

Profa. Dra. Isabel Marian Hartmann de Quadros

Pró-Reitora de Gestão Com Pessoas

Profa. Dra. Elaine Damasceno

Pró-Reitor de Planejamento

Prof. Dr. Pedro Fiori Arantes

Pró-Reitora de Pós-Graduação e Pesquisa

Profa. Dra. Lia Rita Azeredo Bittencourt

Diretor Acadêmico do Campus Diadema

Prof. Dr. Dário Santos Júnior 


\section{Pró Reitora}

Raiane Patrícia Severino Assumpção

Pró Reitor Adjunto

Magnus R. Dias da Silva

Gabinete ProEC

Yara Ferreira Marques / Enio Shigueo Maeda

Comunicação e Site

Jose Lincoln M. Casselin / Lidia Arruda

Coordenadoria de Eventos Institucionais

Ana Carolina Costa da Silva

Coordenadoria de Pós-Graduação Lato Sensu

Wallace Chamon Alves de Siqueira

Coordenadoria de Cursos de Extensão

Manuel Camilo de Medeiros

Assessoria de Ações Estratégicas

Anthony Andrey Ramalho Diniz / Ivo Sousa Ferreira

Assessoria Administrativa e Financeira

Daina Goncalves Silva

Coordenadoria de Programas e Projetos

Ana Maria Santos Gouw

Coordenadoria de Direitos Humanos

Carina da Silva Lima Biancolin

Coordenadoria de Cultura

Debora Galvani / Andreia dos Santos Menezes

Monica Angelica Ferreira / Gildean Silva Pereira 
Coordenação do evento

Profa. Dra. Marilena Rosalen

Prof. Everton Viesba-Garcia

Comissão cientifica

Profa. Dra. Lígia Azzalis

Profa. Ma. Letícia Moreira Viesba

Comunicação oficial

Prof. Dr. Flamínio de Oliveira Rangel

\section{Comissão organizadora}

Prof. Dr. Bruno Chaboli Gambarato (UniFOA)

Profa. Dra. Desiré Luciane Dominschek (UNINTER)

Profa. Dra. Ilda Cecília Moreira da Silva (UniFOA)

Profa. Dra. Ivanete da Rosa Silva de Oliveira (UniFOA)

Profa. Dra. Jaqueline Rabelo de Lima (UECE)

Prof. Dr. Julio Cesar Soares Aragão (UniFOA)

Profa. Dra. Lígia Lobo de Assis (UNINTER)

Prof. Dr. Nilson de Souza Cardoso (FORPIBID-RP / UECE)

Comissão de apoio à coordenação

Giovanna Tonzar

Isabella Cavalcante

Jailson Alves

Lara Santana

Pedro Macedo

Thays Soares

Thayná Garcia

Thiago Araújo 
Adelcio Machado dos Santos

Adriana Aparecida Molina Gomes

Alaide Pereira Japecanga Aredes

Alice Dantas de Medeiros

Aliceana R. R. de Menezes Araújo

Aline Rodrigues Gomes

Allan Gomes dos Santos

Ana Karine Furtado de Carvalho

Ana Valéria de Figueiredo

Ana Valéria Santos de Lourenço

Anderson Lopes Nascimento

Anderson Oramisio Santos

André Barbosa Vargas

Andreia de Bem Machado

Ankilma do Nascimento Andrade

Antonia Márcia Rodrigues Sousa

Antonio José A. de Araújo Filho

Antonio José Gomes

Arnaldo Antonio da Silva Junior

Beatriz Consuelo K. Mello Santos

Beatriz L. Rennó Ribeiro Chaves

Beatriz Lucia Salvador Bizotto

Camilo de Lellis Santos

Carlos Adriano Martins

Carlos Eduardo Teobaldo Alves

Carolina Estéfano

Cicero Emanoel Alves Leite

Clarissa Lopes Drumond

Cláudia Bandeira Ribeiro
Claudio de Souza Miranda

Clemil Camelo

Daniele do Amaral Souza Cavaliere

Denilson Cordeiro

Dimitri Ramos Alves

Elisabete Cerutti

Elizania Caldas Faria

Emanuely Rolim nogueira

Érica Paula Borri Bezerra

Érica Regina Silva

Erika dos Santos Brunelli

Fernanda de Oliveira Silva

Fernanda Jardim Maia

Fernanda Lúcia Pereira Costa

Fernanda Silva Veloso

Fernando Ferreira Pires

Flaminio de Oliveira Rangel

Flávia Fernanda Costa

Flávio José Moreira Gonçalves

Francisca Maria da Cunha de Sousa

Gabriela Maria Cabral Nascimento

Giovanna Tonzar dos Santos

Giuliana Rapp Cinezi

Gustavo Rodrigues Barbosa

Hansley Rampineli Pereira

Harerton Oliveira Dourado

Heitor Buzetti Simões Bento

Heloisa Lúcia Castellar Pinheiro

Ilda Cecília Moreira da Silva 
Inês Cristina de Castilhos Pauli

Irani Ferreira da Silva Gerab

Jalles Dantas de Lucena

Jean Carlos Miranda

José Antônio Colvara de Oliveira

José Guilherme Franchi

Joseane Balan da Silva

Júlio Aragão

Júlio Cesar de Almeida Nobre

Jurama Maia

Karina Soledad Maldonado Molina

Leonardo Testoni

Leonice Vieira de Jesus Paixão

Leonides Silva Gomes de Mello

Leticia Moreira Viesba

Lívia da Silva dos Santos

Livia Maria Figueiredo Lacerda

Luana Ribeiro Lima

Luciana Facchini

Luciana Facchini

Luciana H. B. Consentino

Luciano de Figueiredo Borges

Luiz Claudio Gonçalves Junior

Marçal G. do Amaral Campos Filho

Marcela de Oliveira Feitosa

Márcia Marlene Stentzler

Marcos Guimarães de Souza Cunha

Marcos Kazuiti Mitsuyasu

Marcos Roberto Teixeira Halasz

Maria Aparecida da Silva Andrade

Maria das G. Gonçalves Vieira Guerra
Maria Delcina Feitosa

Maria do S. Lima Marques França

Maria Rejane Lima Brandim

Maria Stella Peccin

Marian Dias

Marilurdes Cruz Borges

Marina Goldfarb de Oliveira

Marisa Pascarelli Agrello

Marisa Pascarelli Agrello

Marta de Medeiros Correia

Mônica Celestino Santos

Monique Valéria de Lima Carvalhal

Neusa Lygia Vilarim Pereira

Ocilma Barros de Quental

Olga Aparecida Coelho

Patrícia Lopes Oliveira

Patricia R Linardi

Pedro Braga Gomes

Priscila Bernardo Martins

Queli Cristina Alves Baptista Silva

Rafael Simão da Silva

Rafaela Rodrigues Lins

Raquel Pereira Soares

Raulison Vieira de Sousa

Reginaldo Alberto Meloni

Rejane Steidel

Renata Livia Silva Fonseca

Renato de Almeida

Richard Medeiros de Araújo

Rita de C. Borges de M. Amaral

Rodolfo Magliari de Paiva 
Ronaldo Figueiró Portella Pereira

Roseli Martinez

Roziane Marinho Ribeiro

Sandra Cristiane Rigatto

Sarah Arruda

Silvana Zajac

Silvia H. C. R. Valladão de Camargo

Silvia Messias Bueno

Silvio Henrique Vilela

Solange Cristina Corregio

Suzana Medeiros Batista Amorim

Tainã Brasil Pantarotto Pelat

Taís de Souza Barbosa

Taiza Stumpp
Vagner Camarini Alves

Valéria Scomparim

Vanessa Juvino de Sousa

Verilda Speridião Kluth

Verônica de Souza Fragoso

Vilma de Souza Bonfim

Vinicius Sato

William Júnio do Carmo

Wilson José Gonçalves

Wilson Robson Griebeler

Yara Araujo Ferreira

Zilda Tizziana Santos Araújo

Zulmira Rangel Benfica

Instituições e organizações parceiras

AMPESC - Associação de Mantenedoras Particulares de Educação Superior de Santa Catarina

CAPAC - Centro Acadêmico Professora Anna Canavarro

CEFE - Centro de Formação de Educadores da Escola Básica

Humana Educação

IFSP - Instituto Federal de São Paulo, Campus Capivari

Núcleo de Estudos em Educação Científica, Conhecimento e Sociedade

Observatório de Educação e Sustentabilidade

Podcast ECOnversa

PPGCB - Programa de Pós-graduação em Ciências Biológicas da UNIFAL

Programa de Extensão Universitária Escolas Sustentáveis

Projeto Zero - UNIFESP

UFTM - Universidade Federal do Triângulo Mineiro

Unifesp Recicla - UNIFESP

UNIMEP - Universidade Metodista de Piracicapa

Viesba \& Viesba Consultoria e Projetos 
UMA PRÁTICA VIRTUAL: REALIDADE INOVADORA NA EDUCAÇÃO DE JOVENS E ADULTOS

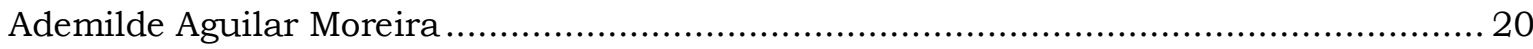

MÉTODOS ATIVOS NO ENSINO DA DOENÇA DE CHAGAS: RELATO DE EXPERIÊNCIA NO ENSINO REMOTO

Adriana Vasconcelos Gomes, Letícia Vasconcelos Gomes

LITERATURA INFANTIL EM VÍDEO: UMA EXPERIÊNCIA NA PRODUÇÃO VISUAL NA DISCIPLINA DE LIBRAS

Adriano Franzoni Wagner, Camila Cardoso Fernandes, Damaris Paula Castilho, Fabíola

Franzoni Wagner, Juliana Tasca Lohn …............................................................. 22

O USO DAS TECNOLOGIAS DE INFORMAÇÃO E COMUNICAÇÃO (TIC's) NO ENSINO DA LEITURA E ESCRITA

Alessandra dos Santos Ribeiro, Adriana Recla Sarcinelli, Harerton Oliveira Dourado,

Marcos Roberto Teixeira Halasz

A IMPORTÂNCIA DA EDUCAÇÃO AMBIENTAL PARA FORMAÇÃO DOCENTE SOBRE A CONCEPÇÃO DOS ALUNOS DE UM CURSO DE BIOLOGIA

Alexsandro Ferreira de Souza Silva, Adson dos Santos Bastos 25

O PROJETO POLÍTICO PEDAGÓGICO E A CONSTITUIÇÃO DE UM CALENDÁRIO ALTERNATIVO DE DATAS COMEMORATIVAS NA ESCOLA: ARTE, DIVERSIDADE, CULTURA, COLETIVIDADE E TRANSFORMAÇÃO

Amanda da Silva Lopes, Cristina da Silva Ferreira Freire, Doralice Aparecida de Andrade, Elaine Cristina Nunes da Luz, Sandra Francisca de Oliveira Silva, Valéria Marques Mendes

NARRATIVAS DE SABERES E FAZERES DOCENTES: COSTURANDO MEMÓRIAS

Suzana Medeiros Batista Amorim, Maria Fernanda Caravana de Castro Moraes Ricci, Maria Luiza Delgado de Medeiros, Suely Cristina de Souza Fernandes Crahim,

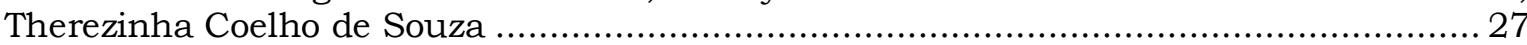

ANIMAIS MAMÍFEROS: UMA PROPOSTA BILÍNGUE PARA ESTUDANTES SURDOS: ENSINO DE CLASSIFICAÇÃO BIOLÓGICA

Caroliny Capetta Martins, Ana Carla Alves Cardoso de Mattos 28 AVALIAÇÃO DE ACADÊMICOS DE ENFERMAGEM SOBRE METODOLOGIAS ATIVAS DE ENSINO-APRENDIZAGEM EM UMA IES NO ESTADO DO MARANHÃO

Ariane Luz Carvalho, José Wáttylla Alves dos Santos Paiva, Eva Mara Uchôa Amorim, Marcus Winicius Mesquita de Brito.

EXPERIÊNCIA DE APLICAÇÃO E FORMULAÇÃO DE UNIDADE DIDÁTICA PELO PIBID: A SENSIBILIZAÇÃO E INCLUSÃO DO ALUNO NO TEMA FAMÍLIA.

Giselle Ruy Bueno, Beatriz Mariano Cyrino

PERCEPÇÕES DE CRIANÇAS DO ENSINO FUNDAMENTAL SOBRE AS RELAÇÕES DE GÊNERO A PARTIR DE NARRATIVAS ORAIS EM RODAS DE CONVERSAS

John Jamerson da Silva Brito, Jónata Ferreira de Moura

EDUCAÇÃO AMBIENTAL E SUSTENTABILIDADE NOS PROJETOS POLÍTICO-PEDAGÓGICOS

Bruna Gimenez da Silva, Sara Maria Blasques, Everton Viesba.

O PAPEL DAS METODOLOGIAS ATIVAS PARA A PROMOÇÃO DE UMA EDUCAÇÃO DE QUALIDADE: METODOLOGIAS ATIVAS NO INSTITUTO DE EDUCAÇÃO E CULTURA RAİZES 
NARRATIVAS DE UMA PROFESSORA EM FINAL DE CARREIRA: A EDUCAÇÃO FRENTE À PANDEMIA

Juliana Pedroso Bruns, Rita Buzzi Rausch 34

DANÇA SINALIZADA: UMA PRÁTICA PEDAGÓGICA PARA INTERAÇÃO ENTRE ALUNOS SURDOS E OUVINTES

Camila Cardoso Fernandes, Adriano Franzoni Wagner, Damaris Paula Castilho, Fabíola

Franzoni Wagner, Juliana Tasca Lohn .... 35

O REINVENTAR PEDAGÓGICO DIANTE DO DESAFIO DA PANDEMIA DO COVID 19

Carla Juliane dos Santos Vilar, Carine de Campos Moraes Barros 36

A INFLUÊNCIA DA TECNOLOGIA NA APRENDIZAGEM DA CRIANÇA: UM ESTUDO A PARTIR DA TEORIA PIAGETIANA

Caroline Ap. Marturano Aranha, Ione Arsênio da Silva, Sabrina Espino Prata RECURSO HÍDRICOS

Cibele Santos Oliveira Martins, Cleyton Alves de Oliveira 38

RECUPERAÇÃO E REFORÇO ESCOLAR EM MATEMÁTICA: APONTAMENTOS E REFLEXÕES FRENTE À PANDEMIA DA COVID-19

Cilene Maria Fontes 39

ENSINO DE CIÊNCIAS EM TEMPOS DE PANDEMIA: DESAFIOS E POSSIBILIDADES DO ENSINO REMOTO

Giovana Della Crocce, Rodolfo Magliari de Paiva, Clemil Camelo, Isabela Nogueira, Vitor

Amorim, Giuliana Rapp Cinezi, Renan Marques .................................................... 40

SÉRIES TELEVISIVAS COMO RECURSO DIDÁTICO PARA A MELHORIA DO ENSINO DE CIÊNCIAS NATURAIS

Giuliana Rapp Cinezi, Roberto Rodrigues de Freitas Maciel, Luiz Afonso V. Figueiredo .. 41 "AVALIAR COM TODOS PARA MUDAR A ESCOLA": A AVALIAÇÃO INSTITUCIONAL EM DOCUMENTÁRIO

Cleberson Henrique de Moura, Fabíola Alice dos Anjos Durães ..... 42

PARCERIA UNIVERSIDADE-ESCOLA: PESQUISA DE RECEPÇÃO DE MATERIAIS EDUCATIVOS EM ARQUEOLOGIA DO MEDITERRÂNEO ANTIGO

Maria Cristina Nicolau Kormikiari, Cleberson Henrique de Moura, Fabíola Alice dos Anjos Durães .43

ENSINO A DISTÂNCIA: OS DESAFIOS DE VESTIBULANDO DE BAIXA RENDA EM MEIO A PANDEMIA DA COVID-19

Aline Teixeira, Gabriela Santiago, Giovanna Silva, Naira de Camargo, Nathália Figueiredo, Clemil Camelo ..... 44 CONTAÇÃO DE HISTÓRIAS EM LIBRAS: RELATO DE EXPERIÊNCIA PRÁTICA NA PRODUÇÃO DE VÍDEO

Damaris Paula Castilho, Adriano Franzoni Wagner, Camila Cardoso Fernandes, Fabíola Franzoni Wagner, Juliana Tasca Lohn 45

FUTEBOL PAIXÃO NACIONAL: A MAGIA DO PENSAR, COMPETINDO COM OS PAIS DA MAGIA

Daniela de Oliveira Eufrázio Rosa 46

PRÁTICAS RESTAURATIVAS NA ESCOLA: NARRATIVAS DE UM COTIDIANO REMOTO

Débora de Lima Marreiro; Thiago Soares Valentim Grass; Gabriela de Proença dos Santos47 LEVANTAMENTO DE BORBOLETAS FRUGIVORAS (INSECTA: LEPIDOPTERA) EM TRÊS FRAGMENTOS FLORESTAIS NO NOROESTE PAULISTA

Denise Bonfim da Silva; Oscar Farina Junior; André Victor Lucci Freitas; Jessie Pereira dos Santos. 
A PRODUÇÃO E O USO DE UM APLICATIVO COMO RECURSO TECNOLÓGICO EDUCACIONAL NO ENSINO DE QUÍMICA

Edmar Marinho de Azevedo. 49

OFICINA PEDAGÓGICA E RESÍDUOS SÓlIDOS: A SENSIBILIZAÇÃO COLETIVA NA CONSTRUÇÃO DE COLETORES PARA A SALA DE AULA

Everton Viesba-Garcia, Pedro Luis Castrillo Yagüe 50

APRENDER E ENSINAR COM DIVERSIDADE NA DIVERSIDADE DO MUNDO: UMA PROPOSTA PEDAGÓGICA PARA UMA (RE)CONSTRUÇÃO IDENTITÁRIA HUMANA

Edmária Conceição Franco Santos, Telma M. Neves Batista, Esiel Pereira Santos 51 ALTAS HABILIDADES/SUPERDOTAÇÃO: PROCEDIMENTOS INCLUSIVOS E ESCOLARES

Elaine Cristina Batista Borges de Oliveira, Prof. Dr. Cláudio Fernando André 52 EDUCAÇÃO INCLUSIVA: RELAÇÃO ENTRE CAPACITISMO, EDUCAÇÃO INCLUSIVA E AUTONOMIA

Aquila Denfha Lima Santos, Elisa dos Santos Freitas 53 REDES SOCIAIS E MEDIAÇÃO DE CONFLITOS

Erika Ap. Piazza Colnaghi, Valéria Scomparim 54 ENSINO REMOTO FORMAL NA PANDEMIA?

Caroline Araujo Santos, Evelin Gabrielle Fernandes Souza. 55 OBSERVATÓRIO DE EDUCAÇÃO E SUSTENTABILIDADE: BREVE RELATO DA IMPLEMENTAÇÃO NA CIDADE DE DIADEMA, SÃO PAULO

Everton Viesba, Letícia Viesba, Marilena Rosalen 56 FORMAÇÃO DOCENTE - E A UTILIZAÇÃO DA TECNOLOGIA NO ENSINO BÁSICO EM MATEMÁTICA

Fátima Aparecida Kian, Ailton Paulo de Oliveira Junior Thiago Rodrigues Oliveira 57 COLETIVOS COLABORATIVOS: EXPERIÊNCIAS DE DOCÊNCIA PARTILHADA NO TRABALHO REMOTO NA EDUCAÇÃO INFANTIL

Fernanda Miranda Cardoso, Nara de Oliveira Vieira 58 REFLEXÃO SOBRE ATUAÇÃO DO PROFESSOR NA PANDEMIA: EDUCAÇÃO REMOTA E SEUS LIMITES

Iris Cristina Gomes do Nascimento Ferreira. 59 VIOLENNCIA NO CONTEXTO DO ESPAÇO ESCOLAR E BULLYING: UM OLHAR ATENTO PARA UM PROBLEMA CONSTANTE

Jonas Lopes dos Santos Filho 61

COMUNIDADE MOVIMENTOS DOCENTES: UMA COMUNIDADE DE PRÁTICA

Everton Viesba, Letícia Viesba, Marilena Rosalen 62

PERCEPÇÕES DOS ESTUDANTES ACERCA DO DESENHO INSTITUCIONAL DO CURSO DE PEDAGOGIA A DISTÂNCIA, DA UNIVERSIDADE DO ESTADO DE MINAS GERAIS

Priscila Rondas Ramos Cordeiro Torres Fontes, Andréia de Assis Ferreira 63 POSSIBILIDADES DE USO DA LOUSA DIGITAL INTERATIVA POR PROFESSORES NA EDUCAÇÃO INFANTIL

Juliana de Almeida Fortunato, Antônio José Lopes Alves, Amanda Tolomelli Brescia..... 64 A EDUCAÇÃO FÍSICA NO ENSINO MÉDIO: UMA REFLEXÃO SOBRE O CAMPO PROFISSIONAL E A PRÁTICA PROFISSIONAL DOCENTE

Francielen I. Ferreira, Samuel de Souza Neto. 65 
DESIGUALDADE SOCIAL EM ESPAÇOS EDUCACIONAIS NO CONTEXTO DA PANDEMIA DO COVID-19

Francielle Gonçalves Teixeira, Lorrany Leal Siqueira, Giuliana Rapp Cinezi 66 IDENTIDADE RENOVADA: GRANDES ALUNOS

Francisco Edivan da SILVA

APRENDIZAGEM BASEADA EM PROJETOS NO ENSINO DE FÍSICA: ESTUDO BIBLIOGRÁFICO SOBRE O TEMA

Gabriel Castiglioni Alves 68

CIÊNCIAS NO ENSINO PÚBLICO: O ENSINO MÉDIO TE PREPAROU?

Franciele Santos, Gabriel Magalhães, Emanoelle Simeão.....

EXPERIÊNCIA DOS RELATOS DE APRENDIZAGEM DURANTE O ENSINO REMOTO EM TEMPOS DE ISOLAMENTO FÍSICO

Gabriela Angelica Villarroel Costa, Tainã Brasil Pantarotto Pelat, Marilena Rosalen....... 70 CONCEPÇÕES E ARQUITETURAS DA EDUCAÇÃO REMOTA: OS PROCESSOS PRODUTIVOS PARA A FORMAÇÃO DO CAPITAL INTELECTUAL EM PERÍODOS DE TRANSFORMAÇÃO

Gabriela de Proença dos Santos, Débora de Lima Marreiro, Thiago S. Valentim Grass ... 71 OS SENTIDOS ATRIBUİDOS POR UM LICENCIANDO DE MATEMÁTICA À ATIVIDADE DE ESTÁGIO

Giane Rodrigues, Patricia R. Linardi

EDUCAÇÃO AMBIENTAL E O ENSINO DE CIÊNCIAS: UMA PROPOSTA DIDÁTICA SOBRE AMBIENTES MARINHOS E COSTEIROS

Grace Victory Bueno da Costa Lima Alves, Simone Aves de Assis Martorano 73

PROJETOS DE VIDA NA JUVENTUDE: UM QUIZ PARA A ESCOLHA PROFISSIONAL COM UM NOVO OLHAR

Hadassa Harumi Castelo Onisaki, Livia Delgado Leandro da Cruz, Gláuci H Mora, Elisabeth Fernandes de Sousa

USO DE MULTIMÍDIA E TECNOLOGIAS DE INFORMAÇÃO E COMUNICAÇÃO EM DISCIPLINAS OFERTADAS NA MODALIDADE A DISTÂNCIA EM CURSOS DE ENGENHARIA

Ludmila Rosalem Borges, Harerton Oliveira Dourado, Adriana Recla Sarcinelli, Marcos Roberto Teixeira Halasz

A ANÁLISE DE PRÁTICA NO CAMPO DA EDUCACA̧ÕO FÍSICA ESCOLAR

Heitor Perrud Tardin

O IMPACTO DA MUDANÇA: DO ENSINO PRESENCIAL PARA O ENSINO A DISTÂNCIA

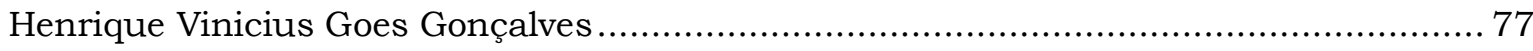

LEVANTAMENTO INICIAL SOBRE A RELAÇÃO ENTRE CIÊNCIAS DA NATUREZA E OS ALUNOS DE UMA ESCOLA DA REGIÃO NORTE DA AMAZÔNIA

Isabela Nogueira, Breno Carvalho, Eduardo Souza, Luiz Eduardo, Maria Monteiro, Maria

Aparecida 78

RELATO DE EXPERIÊNCIA DO USO DE ATIVIDADES PRÁTICAS NO ENSINO DE CIÊNCIAS: PIBID EM AÇÃO

Isabela Nogueira, Breno Carvalho, Eduardo Souza, Luiz Eduardo, Maria Monteiro, Maria Aparecida

A PALEONTOLOGIA BRASILEIRA: DIVULGADA PELA UNIFESP EM DIADEMA

Fernanda Quaglio, Isadora Pizzi, Danilo Rosa 80

REFLEXÃO SOBRE AVALIAÇÃO NA EDUCAÇÃO DE JOVENS E ADULTOS

Izaura Naomi Yoshioka Martins 
LUGAR DE FEMINISMO É NA ESCOLA: O DESAFIO DE ROMPER A AUSENAIA DO DEBATE SOBRE A VIOLÊNCIA À MULHER

Jacimar Rocha de Oliveira.

O ENSINO DA CARTOGRAFIA NA RESIDÊNCIA PEDAGÓGICA: RELATO DE ATIVIDADES DESENVOLVIDAS NA E.E. M PROFESSOR LUÍS FELIPE EM SOBRAL-CE

Janaiára Maria de Paiva Ferreira, Analine Maria Martins Parente.

O DESAFIO DA VIOLÊNCIA ESCOLAR NA PRÁTICA DOCENTE

Jenifer Viana Machado, Marilena Rosalen, 84

UTILIZAÇÃO DE SITES E JOGOS PARA A ANÁLISE DA PREVISÃO DO TEMPO

Jennifer Rafaela Serafim Ferezin. 85

CLUBE DE OBSERVADORES DA NATUREZA: UMA INTRODUÇÃO AO MÉTODO CIENTÍFICO ATRAVÉS DA PRÁTICA DA OBSERVAÇÃO DE NATUREZA

João Pedro Z. de Andrade, Camila Reis dos Santos, Leonardo Prest Merçon, Cristina

Zampa Sanchêz, Viviana Borges Corte. 86 ATENDIMENTOS INDIVIDUAIS: FORTALECIMENTO DE VÍNCULOS E AVANÇOS PEDAGÓGICOS

Lorena Mello, Juliana Silveira Ribeiro 87

EDUCAÇÃO FÍSICA DURANTE A PANDEMIA: APLICANDO AULAS PRÁTICAS, NO AMBIENTE VIRTUAL, PARA ALUNOS DA EDUCAÇÃO BÁSICA NA REDE PÚBLICA

Juvenal dos Santos Borges 88

PLANO DE ENSINO DA DISCIPLINA OPTATIVA “SUSTENTABILIDADE, SAÚDE E SOCIEDADE”

Kaio Felix de Macedo, Filipe Massao de Farias Hara e Leticia Moreira Viesba 89

A DISSECAÇÃO DE MEMBROS INFERIORES COMO FERRAMENTA PEDAGÓGICA: UM RELATO DE EXPERIÊNCIA

Kênia Teixeira.

A PERMANENCIA DO CADÁVER NO ENSINO DA ANATOMIA HUMANA: UM EMBATE TECNOLÓGICO

Lara Silva; LOPES, C. G. S; TEIXEIRA, K. O ; CUNHA, M. G. S .................................. 92

EXPERIÊNCIA DISCENTE EM TEMPOS DE PANDEMIA: UM RELATO DE EXPERIÊNCIA.............93

Leila de Almicê dos Anjos, William Santos Silva, Thalane Souza Santos Silva, Anne

Karoline Pereira Brito, Taiane Gonçalves Novaes ........................................................ 93

ATIVIDADE EDUCATIVA: SAÚDE SEXUAL E REPRODUTIVA NA UNIVERSIDADE

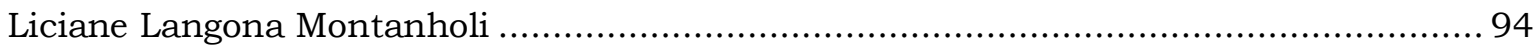

UMA ANÁLISE REFERENTE AO CAMPO DA EDUCAÇÃO MATEMÁTICA INCLUSIVA, NO PERÍODO ENTRE 2010 A 2020 E O DESENVOLVIMENTO DE PESQUISAS NA COMUNIDADE UNIVERSITARIA

Maria Clara Montel Gomes, Reinaldo Feio Lima. 95

HISTÓRIA DA EDUCAÇÃO NO BRASIL: UM BREVE RESUMO SOBRE OS TEMPOS E OS ESPAÇOS ESCOLARES

Antonio Gilbran de Lima, Luana Lima 96

POLİTICAS PÜBLICAS E A EDUCAÇÃO A DISTÂNCIA: EDUCAÇÃO A DISTÂNCIA EM TEMPOS DE PANDEMIA

Thyago Lins..... 97

QUESTÕES DE GÊNERO: DISCUSSÕES EMERGENTES NA FORMAÇÃO INICIAL DO PROFESSOR DE MATEMÁTICA

Livia Godinho Simião, Patrícia Barbosa Melo Maneo. 98 
O ENSINO À DISTÂNCIA E CURSOS DE DIREITO: O QUE APRENDEMOS EM TEMPOS DE COVID-19?

Carina Deolinda da Silva Lopes, Franceli Bianquin Grigoletto Papalia, Nelci Lurdes

Gayeski Meneguzzi.....

LIBERDADE ESCOLAR: EXPERIÊNCIAS NA ESCOLA PÚBLICA

Lorraine Christine De Oliveira.

PENSAR DIDÁTICO: REFLEXÕES SOBRE UM PLANEJAMENTO DE AULA EM TEMPOS DE PANDEMIA

Luana de Lima Maciel, Giovanna Araujo, Luana Lima

ANÁLISE DA PRÁTICA COMO UM DISPOSITUVO PARA A (DES)PRIVATIZAÇÃO DA PRÁTICA DOCENTE: UM RELATO DE EXPERIENNCIA

Luana Monteiro, Márcia Regina Onofre, Samuel de Souza Neto

O PSICODRAMA PEDAGÓGICO NA EDUCAÇÃO ON-LINE

Luciano Gamez, Viviane Cristina Marques

SUAS LÁGRIMAS NÃO TEM SEXO

Angelise Maciel; Jacira Helena Bridi

RESÍDUOS SÓLIDOS E A EDUCAÇÃO PARA A SUSTENTABILIDADE

Marcel Pereira Pordeus

CONTEXTO DA PANDEMIA COMO IMPULSIONADOR DE NOVOS PARADIGMAS METODOLÓGICOS

Márcia Azevedo Coelho 106

ÁFRICA E EDUCAÇÃO: EPISTEMICÍDIO HISTÓRICO

Márcio Wilson Santos Cruz

SOCIEDADE, DESIGUALDADE E EDUCAÇÃO: AS DESIGUALDADES SOCIAIS E SEUS REFLEXOS NO PROCESSO EDUCACIONAL

Maria Eduarda Yamashita, José Victor Rodrigues Barbosa, Taisa Veloso Barretto, Aleck

Soares Alcantara, Marcelo Silva 108

PERCEPÇÃO DE PROFESSORES DOS ANOS FINAIS DO ENSINO FUNDAMENTAL SOBRE A INDISCIPLINA NO PROCESSO EDUCATIVO

Maria Jakeline Vieira Milhomem, Jónata Ferreira de Moura 109

PROJETOS DE EDUCAÇÃO AMBIENTAL NA ESCOLA: PRESENCIAL E À DISTÂNCIA, SEGUIMOS!

Carolina Estéfano.

O PACTO NACIONAL PELA ALFABETIZAÇÃO NA IDADE CERTA (PNAIC): IMPACTOS NA FORMAÇÃO E NAS PRÁTICAS DE ENSINO DOS PROFESSORES ALFABETIZADORES DA REDE MUNICIPAL DE ENSINO DE SÍTIO NOVO DO MARANHÃO/MA

Maria Rita de Sousa Silva Marinho, Jónata Ferreira de Moura

O EDUCADOR DE ONG COMO PROFISSIONAL REFLEXIVO: ANALISANDO UMA AÇÃO DESENVOLVIDA COM OS ADOLESCENTES DO GRUPO TUMM

Maria Antonieta Ribeiro Ciancio Pinto

A MONITORIA E O USO DAS TICS NOS PROCESSOS DE ENSINO E APRENDIZAGEM NO ENSINO REMOTO NAS UNIVERSIDADES: A REALIDADE EM UM CURSO LICENCIATURA EM CIÊNCIAS BIOLÓGICAS

Antonia Maria Alves, Maria Rejane Lima Brandim

A PROFISSIONALIZAÇÃO DA DOCÊNCIA NA EDUCAÇÃO INFANTIL: A ANÁLISE DE PRÁTICAS DE UMA PROFESSORA EM INÍCIO DE CARREIRA

Mariana Fiorioe Márcia Regina Onofre 
DESIGUALDADE NO INGRESSO À UNIVERSIDADE: PERCEPÇÕES, PROBLEMAS E ANÁLISE

Mariana Gonçalves Ribeiro da Costa, Mariana Vasconcelos, Yasmin de Macedo Silva,

Yasmin Parus 115

UMA METODOLOGIA ATIVA EM ATIVIDADES DE CIÊNCIAS PARA AULAS A DISTÂNCIA - BALDE BIOFILTRO

Andrey Patrick Carvalho da Silva, Bruna de Oliveira Menezes, Érica Ferreira de Oliveira, Mariele Leão Alves.... 116

DISCIPLINA DE ÉTICA NA MODALIDADE REMOTA DURANTE PANDEMIA: RELATO DE EXPERIÊNCIA

Marli Aparecida reis Coimbra, Lucas Carvalho Santana, Lúcia Aparecida Ferreira ,

Leiner Resende Rodrigues, Maria Helena Barbosa 117

A REFORMA DO ENSINO MÉDIO E A DESIGUALDADE EDUCACIONAL: IMPACTOS E CONTROVÉRSIAS DA NOVA ESTRUTURA

Gustavo Huang Tai, Julia Beatriz Neves Torres, Matheus Guazzelli Silva, Luana Lima 118 A FORMAÇÃO DOCENTE E O USO DAS METODOLOGIAS ATIVAS E FERRAMENTAS DIGITAIS, COMO PENSAMENTO INOVADOR NO PROCESSO DA METACOGNIÇÃO

Andréa de Sousa Galliza Mitchell de Morais.

GÊNERO, SEXUALIDADES E MASCULINIDADES EM INSTITUIÇÕES SOCIOEDUCATIVAS

Jónata Ferreira de Moura

A PERCEPÇÃO DO ESPAÇO COMO MEDIADOR DE LEITURA

Paula Redigolo Alves de Aguiar.

OS IMPACTOS DA DESIGUALDADE RACIAL E A ESCOLARIZAÇÃO: REFLEXÃO SOBRE O RACISMO E A PERMANÊNCIA ESCOLAR

Ana Laura Sabino dos Santos, Fernando Daros Carvalho Amancio, Julia Azevedo de Sá

Nunes, Paulo Victor Santos Sousa ,Luana Lima.....

EDUCAÇÃO EM TEMPOS DE SURTO DE GRIPE SUÍNA (INFLUENZA A, H1N1): RELATO DE EXPERIÊNCIA NA ESCOLA E O PAPEL DA IMPRENSA E DA CIÊNCIA

Paulo Yuuji Arai, Bruno Silva Ribeiro, Gabriel R. Felipe, Luiz Afonso V. Figueiredo ..... 125 A IMPLEMENTAÇÃO DO ESPAÇO MAKER NO PARQUE CIENTEC

Rafael Gonçalves Dias, Eric Kenji Ikeda, Alexandre Borsalin Junior 126 GOOGLE CLASSROOM: FERRAMENTA TECNOLÓGICA DIGITAL UTILIZADA NA MEDIAÇÃO DE APRENDIZAGENS NO CONTEXTO DO ENSINO MÉDIO EM TEMPOS DE DISTANCIAMENTO SOCIAL

Luciana Rebelo.

A FORMAÇÃO CONTINUADA NA REDE MUNICIPAL PAULISTANA: OS DESAFIOS TRAZIDOS PELA SUSPENSÃO DAS ATIVIDADES PRESENCIAIS

Renata Livia Soares Perini. 128

TURMA DA MÔNICA EM: A REPRESENTAÇÃO DAS CRIANÇAS COM DEFICIÊNCIA

Renata Machado da Silva, Sayonara Amaral de Oliveira.

PROGRAMA RESIDÊNCIA PEDAGÓGICA: UM GRANDE DIFERENCIAL NA FORMAÇÃO DO PROFESSOR PEDAGOGO

Rita de Cássia Borges de Magalhães Amaral....

O PODCAST ECONVERSA COMO FERRAMENTA DE DIVULGAÇÃO CIENTÍFICA: CONTRIBUIÇÕES À FORMAÇÃO DOCENTE

Sabriny Almeida Rodrigues Souza, Kenia Silva Severino, Larissa Correia da Silva, Luan da Silva Lima, Arnaldo Antonio da Silva Junior 
CINEMA, BULLYNG ESCOLAR E A PRODUÇÃO DE MATERIAIS DIDÁTICO-PEDAGÓGICOS

Samira Krupek Donaire, Wanessa Gorri de Oliveira, Divania Luiza Rodrigues 132

RESIDENCIA PEDAGÓGICA: A PRÁTICA COMO LUGAR DA FORMAÇÃO INICIAL E CONTINUADA PARA A DOCÊNCIA EM EDUCAÇÃO FÍSICA - UM RELATO DE EXPERIÊNCIA

Samuel de Souza Neto; Amanda Milani; Maria Carina Fragelli; Rogerio Hatore 133 CURSO DE LICENCIATURA EM EDUCAÇÃO ESPECIAL INCLUSIVA: AVALIAÇÃO DA DEMANDA DAS PROFESSORAS DAS SRMS DA COMCAM/PR

Sandra Garcia Neves, Andrea Geraldi Sasso, Gabriele Garcia Neves da Cunha 134 FORMAÇÃO DE PROFESSORES PARA AEE NAS SRMS: DEMANDA PELA FORMAÇÃO CONTINUADA EM ALFABETIZAÇÃO

Andrea Geraldi Sasso, Gabriele Garcia Neves da Cunha, Sandra Garcia Neves 135 UMA EXPERIÊNCIA DE FORMAÇÃO DE PROFESSORES NA EMEI - CEU BUTANTÃ DE FORMA REMOTA NO PERÍODO DE QUARENTENA

Sandra Cristina Andrade Loiola 136

ANÁLISE COMPARATIVA DE DUAS ADAPTAÇÕES PARA HQS DA OBRA DOM CASMURRO DE MACHADO DE ASSIS

Alcione Sacramento dos Santos 138

A EVIDÊNCIA DAS DESIGUALDADES SOCIAIS TRAZIDAS PELA PANDEMIA: UM OLHAR SOBRE AS DIFICULDADES NO ENSINO DA REDE PÚBLICA DURANTE O LOCKDOWN

Camila Barbosa dos Santos, Helmer Aguiar Pinto

SEPARAÇÃO DE MISTURAS: RECICLAGEM

Vinicius José da Silva

REVISÃO TEXTUAL NO ENSINO FUNDAMENTAL: UMA ALTERNATIVA COM USO DE TECNOLOGIA

Fernanda Sturion da Silva

O USO DE (MULTI) MODALIDADES TECNOLÓGICAS EDUCACIONAIS PARA O ENSINO DE PARASITOLOGIA

Shamaya Thilara Leite Lago, Vitoria Pedrozo Rodrigues, Ronaldo Adriano Ribeiro da Silva 143

(M)EU TERRITÓRIO DE IDENTIDADE: RELATO DE PRÁTICA PEDAGÓGICA COM CRIANÇAS PEQUENAS EM UMA ESCOLA PÚBLICA DE LAURO DE FREITAS/BAHIA

Carla Pinheiro, Silvanne Ribeiro. 144

PERFIL DOS PROFESSORES QUE EXERCEM A DOCÊNCIA NA EDUCAÇÃO INFANTIL NA REDE MUNICIPAL DE ENSINO DE SALVADOR

Marlene Oliveira dos Santos, Silvanne Ribeiro 145

FORMAÇÃO DOCENTE DURANTE A COVID-19: EDUCAÇÃO EM VALORES NA ABORDAGEM DA TEORIA DOS CONTEÚDOS

Emily Bomfim Souza, Paulo Fraga da Silva 146

O PEQUENO PRÍNCIPE E AS CRIANÇAS NA ERA DA ANSIEDADE

Emily Bomfim Souza

A DOCÊNCIA NEGADA DAS AUXILIARES DO MUNICÍPIO DE CARAPICUÍBA -SP

Emily Bomfim Souza

MODALIDADE DE APRENDIZADO EM ESTUDANTES DO CURSO DE ODONTOLOGIA DA UNIVERSIDADE PÚBLICA E PRIVADA

Taís de Souza Barbosa 
VESTIBULÊS: VIDEOAULAS DE LITERATURA

Marianna Schneider, Priscila Rabanea, Taisa Robuste. 150

LINK GAME: DOENÇAS E SISTEMAS DO CORPO HUMANO: PLANO DE AULA PARA ENSINO REMOTO

Taluan Nogueira, Marilena Rosalen

O BRINCAR EM TEMPOS DE ISOLAMENTO SOCIAL

Tatiane Resende Bitencourt

PRÁTICA DOCENTE NO ENSINO SUPERIOR EM TEMPOS DE PANDEMIA: UM RELATO DE EXPERIÊNCIA

Thalane Souza Santos Silva, Taiane Gonçalves Novaes, Anne Karoline Pereira Brito, William Santos Silva. 154

NEUROFIBROMATOSE TIPO 1 E ESCOLARIZAÇÃO: ENTRE A INVISIBILIDADE E POSSIBILIDADES EDUCACIONAIS

Thomas Pontes P. Chequetto, Amália Neide Covic 155 ESCRITA CURSIVA: CÓDIGO SECRETO DA ESCOLA

Tírza Porto Azambuja Verri 156

O USO DOS VÍDEOS EM UM CURSO NA MODALIDADE EDUCAÇÃO A DISTÂNCIA (EAD) ONLINE: ANÁLISE DO POTENCIAL PEDAGÓGICO E TECNOLÓGICO

Ubiratan Pereira dos Santos 157

DIMENSÕES PEDAGÓGICAS E ADMINISTRATIVAS DA SUPERVISÃO ESCOLAR: UM ESTUDO NA PERSPECTIVA DAS REPRESENTAÇÕES SOCIAIS

Valdete Pereira da Silva Nascimento 158

A PRÁTICA PEDAGÓGICA E SUAS INTENCIONALIDADES NA FORMAÇÃO DOCENTE

Veronica Ester Tapia, Luciano Pereira Marotto, Bruna Gabriela Marques 159 CONSCIÊNCIA POLÍTICA: A INFLUÊNCIA DA TECNOLOGIA DA INFORMAÇÃO NA FORMAÇÃO DOS CONCEITOS DE POLITIZAÇÃO E DEMOCRACIA

Vinicius Camargo Chiquito, Valéria Scomparim. 160 BANDA ESCOLAR

Vitória Regina Ramos Bitiano 161 ATIVIDADE DE ENSINO DE CIÊNCIAS NOS ANOS FINAIS

Lucas Marino Vivot 162

RELATOS DO PIBID-UFPR: O TEXTO DRAMÁTICO EM SALA DE AULA

Carolyne Dornelles Melo, Wagner José Negrelo Biscaia. 163

COMO O ISOLAMENTO NOS UNIU: A CONSTRUÇÃO DE UMA COLETIVIDADE REFLEXIVA

Willian Vinicius Silva. 164

COMO NASCEM AS PLANTAS? O DESAFIO DE ENSINAR CIENNCIAS PARA CRIANÇAS EM CARÁTER REMOTO

Angélica Nunes Rocha, Aparecida Adriana Galdino, Márcia César, Margarida Antunes 165 EDUCAÇÃO, CULTURA E DEMOCRACIA: UMA RELAÇÃO DE INTERDEPENDÊNCIA

Evelyn Elen Alves de Brito Cabral, Idelma Izabel de Camargo Silva 166 MATERIAL BIOLÓGICO DA COLEÇÃO DIDÁTICA COMO FERRAMENTA PARA O ENSINO DA ICTIOLOGIA NA EDUCAÇÃO BÁSICA

Josiney Farias de Araújo, Erival Gonçalves Prata, Renan Ferreira de Sousa, Leandro Marques Correia, Adriana de Almeida Sanches 
METODOLOGIAS MISTAS DE ENSINO EM UM PROCESSO DE COMPETIÇÃO EM ESCOLA TÉCNICA DE MINAS GERAIS

Fabiano Henrique Oliveira Sabino, Elisângela Aparecida de Almeida Alves, Luciana Jerônimo de Almeida Silva, Pedro Henrique da Silva Santos...................................... 169

DESAFIOS E POSSIBILIDADES DO ENSINO EM SAÚDE EM AULAS REMOTAS: UM RELATO DE EXPERIÊNCIA

Fabiano Henrique Oliveira Sabino룬 Lucas Fernando Antunes Gomes ${ }^{2}$, Silmara Elaine

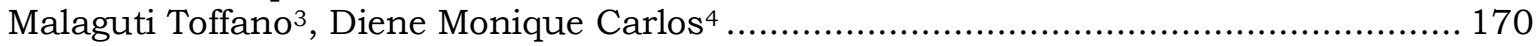

PROFESSORES NO CONTEXTO DA PANDEMIA: UM ESTUDO DAS EMOÇÕES À LUZ DOS PRESSUPOSTOS TEÓRICOS DE MATURANA

Marise Rodrigues Guedes 171

(RE) INVENÇÃO DA PRÁTICA DOCENTE DE NÍVEL SUPERIOR NO PERÍODO DE PANDEMIA

Rose Manuela Marta Santos, Rosana Daily Marta Santos. 172 PAPÉIS DE GÊNERO

Cibele Santos Oliveira Martins, Giovanna Marrochelli Guimarães 173 
UMA PRÁTICA VIRTUAL:

REALIDADE INOVADORA NA EDUCAÇÃO DE JOVENS E ADULTOS

Ademilde Aguilar Moreira ${ }^{1}$

Acesse a apresentação deste trabalho

Este presente resumo aborda uma reinvenção de uma prática pedagógica que antes era realizada na escola, pelos próprios alunos na Educação de Jovens e Adultos II de uma escola da rede municipal de Campinas, estado de São Paulo, mas que no atual contexto, para que acontecesse, passou para prática virtual, denominada "Aproveitamento de alimentos", cuja temática está inserida no contexto de pandemia do novo coronavirus. Tem como objetivos, manter o vínculo com os alunos; conhecer as propriedades nutritivas e terapêuticas de certos alimentos; explorar geograficamente, o local de concentração do alimento. Embora com grande preocupação, muitas incertezas, ainda que estamos vivendo um momento atípico e inesperado, que nos coloca numa realidade totalmente nova, junto aos nossos alunos, é um desafio propor aos alunos, cozinhar, cada um em sua casa, socializar por google meet com todos os professores e os gestores. A proposta é aproveitar ao máximo dos alimentos, como folhas, talos, sementes, cascas, além daquilo que normalmente utilizamos nas nossas culinárias. Como metodologia, primeiramente, discutimos sobre qual culinária fazer e, a decisão, é sempre dos alunos. Todos os termos realizam a culinária, cada aluno desempenha um papel no dia, os que gostam mais de cozinhar, assumem a tarefa, outros socializam as informações obtidas a respeito de localização de maior produção, propriedades dos alimentos e de todas as suas partes. Acreditamos ter possibilitado melhorias na alimentação das pessoas, aumento de alimentos nas mesas de muitos alunos e que as experiências tenham ficado para sempre, como aprendizado construido por eles.

Palavras-chave: Prática virtual. Educação de Jovens e Adultos e reinvenção. Inovação na pandemia.

\footnotetext{
1 Ademilde Aguilar Moreira é mestranda em Educação pela Unilogos; é pós-graduada Lato Sensu em Ensino de Ciências pela Universidade de São Paulo (USP); é pós-graduada Lato Sensu em Psicopedagogia pelas Faculdades Integradas Metropolitanas de Campinas (Metrocamp). É graduada em Ciências Exatas e Bacharel em Química pela Universidade Federal de Viçosa (UFV); é licenciada em Pedagogia pelas Faculdades Integradas de Amparo (FIA). É docente aposentada da rede estadual do Estado de São Paulo; é docente de Ciências na Educação de Jovens e Adultos II, na rede municipal de Educação de Campinas-SP. E-mail:davidvb@uol.com.br
} 


\section{MÉTODOS ATIVOS NO ENSINO DA DOENÇA DE CHAGAS: \\ RELATO DE EXPERIÊNCIA NO ENSINO REMOTO}

Adriana Vasconcelos Gomes ${ }^{1}$, Letícia Vasconcelos Gomes ${ }^{2}$

$\underline{\text { Acesse a apresentação deste trabalho }}$

Doença de Chagas é uma doença parasitária, causada pelo Trypanosoma cruzi, de importância na saúde pública brasileira tanto que está na grade curricular de alguns cursos da saúde. As práticas pedagógicas devem estar alinhadas a consolidação do aprendizado do tema, nesse sentido, relata-se uma experiência sobre métodos ativos no ensino remoto com foco na abordagem da Doença de Chagas. A prática foi desenvolvida durante três aulas virtuais da disciplina de parasitologia humana, em agosto de 2020, com 14 acadêmicos de enfermagem de uma instituição de ensino superior no Estado do Ceará. O tema foi trabalhado em tópicos ao longo dos três encontros, a saber: a) DC no Brasil: uma questão de saúde pública; b) Qualidade de vida do paciente chagásico; c) Cuidados de enfermagem na perspectiva da integralidade. Ao longo dos encontros utilizou-se da colaboração coletiva na construção de nuvens de palavras (conhecimentos prévios), e da gamificação em dois momentos: na fixação dos aspectos histórico-conceituais e características morfológicas, biológicas e fisiopatológicas, neste objetivou-se mediar a autoaprendizagem e a participação do aluno concretizou-se de maneira individual e assincrona (http://gg.gg/dchagas); posteriormente, na revisão realizada no terceiro encontro com o uso de um "jogo de memória" com participação coletiva síncrona (http://gg.gg/mem-dc). Percebeu-se envolvimento no desenvolvimento das atividades mediando o processo de diálogo e exposição de dúvidas na construção da aprendizagem de maneira ativa. A inovação e a demanda do uso de metodologias ativas no ensino não surgiram do atual cenário, entretanto, ganha maior destaque pela necessidade de reinvenção docente, bem como, pela eficiência na promoção de engajamento, satisfação dos alunos e facilitação do processo de ensino-aprendizagem no ensino remoto.

Palavras-chave: Metodologias ativas. Ensino. Educação Superior. Enfermagem. Educação em Enfermagem.

1 Mestranda no Programa de Pós-graduação em Saúde da Família pela Universidade Federal do Ceará (UFC). Docente do curso de graduação e técnico em enfermagem na Faculdade ViaSapiens (FVS). E-mail: adriannavgomes@gmail.com

2 Discente do curso de psicologia e integrante do Programa Iniciação Científica e Tecnológica (PICT) pelo Centro Universitário UniFacid Wyden. E-mail: lethyciavg@hotmail.com 


\title{
LITERATURA INFANTIL EM VÍDEO: UMA EXPERIÊNCIA NA PRODUÇÃO
}

\author{
VISUAL NA DISCIPLINA DE LIBRAS
}

\author{
Adriano Franzoni Wagner ${ }^{1}$, Camila Cardoso Fernandes², \\ Damaris Paula Castilho3 ${ }^{\text {, Fabíola Franzoni Wagner }}{ }^{4}$ Juliana Tasca Lohn ${ }^{5}$
}

Acesse a apresentação deste trabalho

A produção de vídeo é uma atividade de rotina na disciplina de Libras, na vida profissional do intérprete e do professor de Lingua de sinais. A disciplina de Libras pré-intermediário é oferecida aos acadêmicos de Letras Libras, licenciatura e bacharelado, durante o segundo semestre do curso. A narrativa de histórias é um importante recurso para identidade cultural e aquisição linguística, despertando os sentidos no repertório infantil. Como critério final de aprovação os alunos desenvolvem uma adaptação de um livro infantil, registrado em vídeo, na língua de sinais. O objetivo do trabalho é apresentar um relato de experiência descritivo da produção em vídeo de uma história infantil. As obras literárias foram selecionadas individualmente conforme interesse de cada aluno. O período do desenvolvimento do vídeo foi de agosto a novembro de 2019, 36 horas-aulas, prevista dentro da disciplina, prática como componente curricular (PCC). A metodologia constituiu-se em cinco fases: na primeira, elaboração do roteiro; na segunda, a tradução do texto para libras observando todos os aspectos da língua; na terceira transcrição do português para língua de sinais, sistema de glosas; na quarta, gravação do material, interpretação da história; na quinta, a pósprodução (edição) do material visual. O livro selecionado foi "A menina do leite". O projeto final apresentou duração de 6,33 minutos, disponivel em: https://youtu.be/Sy8n9TCH3tg Considerando o plano de ensino, conseguiu-se explorar a proposta acadêmica através da criação do vídeo, respeitando os discursos em Libras. A contação de histórias são importantes auxiliares para a educação infantil, no seu desenvolvimento cognitivo e emocional além de auxiliar no processo ensino-aprendizagem (ZILBERMAN, 1998 e GIRARDELLO, 2008). Além de contribuir para o desenvolvimento acadêmico o uso de recursos tecnológicos como ferramenta de ensino, conseguiu incentivar a produção de vídeos de literatura infantil com grande potencial educacional.

Palavras-chave: Literatura infantil, Libras, material didático.

1 Discente Letras Libras. UFSC. adrianofranzoni@yahoo.com.br

2 Discente Letras Libras. UFSC. camilacf.adv@gmail.com

3 Discente Letras Libras. UFSC. damaris.paula@gmail.com

4 Pedagoga. EEB Edite Gama Ramos. ffwp@hotmail.com

5 Docente Letras Libras. UFSC.julianasurda@hotmail.com

ISBN 978-65-88471-05-0 | https://doi.org/10.47247/VV/ENMD/88471.05.0 


\title{
O USO DAS TECNOLOGIAS DE INFORMAÇÃO E COMUNICAÇÃO (TIC'S) NO
}

\section{ENSINO DA LEITURA E ESCRITA}

\author{
Alessandra dos Santos Ribeiro ${ }^{1}$, Adriana Recla Sarcinelli², \\ Harerton Oliveira Dourado ${ }^{3}$, Marcos Roberto Teixeira Halasz ${ }^{4}$
}

Acesse a apresentação deste trabalho

Tão questionada nos tempos modernos, a tecnologia exige um sujeito atento e altamente inserido no universo do ler e escrever. Do mesmo modo, a escola precisa articular este tema e contribuir com a reflexão em torno do tema. É por esta razão que a ampliação do repertório dos alunos se torna de extrema relevância, pois no processo educativo o aluno pode desenvolver a leitura e a escrita no mundo da cultura digital.Você já parou para pensar como eram as práticas de leitura e escrita há 20 ou 30 anos? Contudo, um tipo de tecnologia tem tido mais impacto na vida contemporânea: as TIC's. Por que será? O que ela tem de diferente de outras "tecnologias" que vêm alterando tanto o nosso modo de viver, de pensar e ensinar também?A escola poderia/deveria fazer alguma coisa que contribua para uma aprendizagem da leitura e escrita em tempos digitais? Mas, o que poderia ser feito? É por estas questões e tantas outras que vamos tematizar sobre a cultura escrita na era digital. Nossa temática desperta um amplo debate, em especial quanto à cultura digital nos modifica como sujeitos leitores e escritores. Por esta razão, a criatividade se torna tão necessária e ao mesmo tempo complexa, tendo em vista que em um mundo tão dinâmico estamos o tempo todo sendo estimulados a criar, a sermos autores, num processo intenso de autoria. Para tanto, o presente resumo aborda uma reflexão importante sobre o uso das Tecnologias da Informação e Comunicação (TIC's) para o ensino da leitura e escrita. Tomamos como objetivo geral: verificar como se dá o uso deste recurso digital no ensino da leitura e da escrita por professores e identificar de que forma as TIC's possibilitam a integração de maneira eficaz ao mundo digital. Nesse sentido, o uso das potencialidades das tecnologias no ensino e aprendizagem da leitura e escrita inserindo o aluno em contextos inovadores acerca das tecnologias digitais, além de analisar a visão dos professores sobre o uso das TIC's no processo de leitura e escrita é um dos desafios no currículo atual. Muitos são os recursos digitais disponiveis para ampliar a perspectiva de ensino e a utilização destas ferramentas para a estratégia pedagógica de estimular a leitura e a escrita, de forma que os alunos se tornem motivados a ler e produzir bons textos, compreendendo que as tecnologias podem colaborar para a aquisição da competência leitora e escritora, tão presentes em nosso cotidiano digital. $\mathrm{O}$ avanço tecnológico vem moldando o mundo há alguns anos e com isso a internet tem sido parte deste avanço, inclusive no ensino. O uso das TIC'sno ensino tem sido bem presente, e, aplicar essa tendência na educação requer uma exigência para os profissionais dentro das instituições de ensino, revendo pontos

1 Aluna em Graduação do curso de Pedagogia da FAACZ. alerib3@hotmail.com

2 Professora e diretora acadêmica da FAACZ, arecla@fsjb.edu.br

3 Professor e coordenador dos cursos de engenharia da FAACZ, harerton@fsjb.edu.br

4 Professor e coordenador de ensino da FAACZ, halasz@fsjb.edu.br 
importantes como atualização permanente, de modo a acompanhar as tendências e sua evolução. Além disso, o uso da TIC's no ensino da leitura e escrita pode possibilitar ao aluno a habilidade de comunicação, indispensável no século XXI e em todas as etapas de vida. É importante ressaltar que a tecnologia tem ampliado um papel muito extensivo nas habilidades da comunicação dos alunos. Com isso, tornou-se fundamental a participação do professor como mediador deste processo de ensino. O uso deste meio no ensino da leitura e escrita permite a inovação, a transformação no pensar e no agir, na essência do saber que é algo já existente no meio atual. Entretanto, precisamos compreender a importância da tecnologia na educação, hoje vivemos na era da informação e levar a escola o conhecimento destas informações é fundamental, pois a escola precisa acompanhar os avanços dos dias atuais. Atualmente percebemos o envolvimento deles e suas habilidades no manuseio nessa era digital, o que nos faz pensar no uso dessas potencialidades e sua utilidade no ensino da leitura e escrita. Logo surge a seguinte problemática diante desse cenário: De que maneira, a inserção das TIC's auxilia o professor neste trabalho? O professor está preparado para o uso dessa tendência em sua realidade mediante aos desafios, dificuldades e a aplicabilidade do recurso tecnológico na sala de aula? Diante desta problemática e do objetivo proposto, justifica-se a escolha do tema, em razão do reconhecimento e crédito da importância da leitura, escrita e das novas tecnologias, a fim de proporcionar ao aluno reflexão e trocas de experiências na leitura e escrita por meio das tecnologias. Entende-se que a inserção das tecnologias da informação e comunicação nas atividades educacionais pode trazer resultados benéficos. $\mathrm{E}$ hoje, os recursos tecnológicos mudaram nossa forma de ver o mundo e a necessidade da inserção no campo educacional, pois possibilita conhecer ferramentas que potencializam o ensino, assim como o acesso a aprendizagem por meio de ferramentas que se tornaram necessárias nos dias atuais.

Palavras-chave: Leitura e Escrita, Tecnologias de Informação e Comunicação TIC's, Metodologia de Ensino. 


\title{
A IMPORTÂNCIA DA EDUCAÇÃO AMBIENTAL PARA FORMAÇÃO DOCENTE
}

\section{SOBRE A CONCEPÇÃO DOS ALUNOS DE UM CURSO DE BIOLOGIA}

\author{
Alexsandro Ferreira de Souza Silva ${ }^{1}$, Adson dos Santos Bastos ${ }^{2}$
}

Acesse a apresentação deste trabalho

A discussão a respeito da educação ambiental se faz necessário e preciso no nosso senário atual, desde a educação infantil até a universidade. Isso se evidencia diante do constante aumento da degradação do meio ambiente. A educação ambiental é um processo indispensável no processo de formação dos cidadãos, como um agregador de transformação em longo prazo, na qual, possibilita a promoção de práticas que reduzam os impactos ao meio ambiente. Esse trabalho é fruto de uma pesquisa de Iniciação Científica desenvolvida na Universidade do Estado da Bahia, Departamento de Educação/Campus VIISenhor do Bonfim, cujo objetivo foi analisar a percepção dos alunos do curso de Licenciatura em Ciências Biológicas, a respeito da importância do componente curricular, Educação Ambiental para sua formação como futuro professor de ciências e biologia. Essa pesquisa é de caráter descritiva com abordagem qualitativa, na qual, se consistiu em duas fases, à aplicação de um questionário semiestruturado aos discentes e analise de trabalhos de conclusão de curso dos anos de 1997 a 2018. Com isso, foram analisados a concepção discente, em diferentes momentos formativos do curso, sobre a importância do debate de questões ambientais na Universidade. O questionário foi aplicado a 31 discentes, na qual 100\% afirmou achar importante o professor de ciências e biologia ter o dominio da temática. Entretanto, 70\% afirma nunca ter participado de atividade relacionadas a Educação Ambiental na Universidade. Foram analisados 252(duzentos e cinquenta e dois) Trabalhos de Conclusão de Curso (TCC) disponiveis na biblioteca, nos quais, 38(trinta e oito) desses tinham relação direta com educação ambiental e/ou sustentabilidade, contabilizando $15 \%$. Os resultados apontam que é necessária a aquisição de conhecimento e experiências de participação social na formação do professor de Biologia com foco em Educação Ambiental.

Palavras-chave: Educação Ambiental; Concepção Discente; Formação Docente.

1 Mestrando do PPG-ECFP. UESB. aleckissf@gmail.com

2 Doutorando do PPGEduC. UESB. Adson.bastos@hotmail.com

ISBN 978-65-88471-05-0 | https://doi.org/10.47247/VV/ENMD/88471.05.0 
O PROJETO POLÍTICO PEDAGÓGICO E A CONSTITUIÇÃO DE UM CALENDÁRIO

\author{
ALTERNATIVO DE DATAS COMEMORATIVAS NA ESCOLA: ARTE, \\ DIVERSIDADE, CULTURA, COLETIVIDADE E TRANSFORMAÇÃO
}

\author{
Amanda da Silva Lopes ${ }^{1}$, Cristina da Silva Ferreira Freire², \\ Doralice Aparecida de Andrade ${ }^{3}$, Elaine Cristina Nunes da Luz \\ Sandra Francisca de Oliveira Silva ${ }^{5}$, Valéria Marques Mendes ${ }^{6}$
}

Acesse a apresentação deste trabalho

A EMEI Jd. Monte Belo, está localizada na zona oeste da cidade de São Paulo. O bairro Monte Belo foi construído no final da década de 90, com a participação de movimentos sociais em prol de moradia digna para população. Os terrenos para construção das escolas EMEI e EMEF Jd. Monte Belo, foram escolhidos pela comunidade, por ser o local menos ingreme e de mais fácil acesso para população, consolidado os dois equipamentos públicos, que acolheria a infância e a juventude da comunidade. A partir do ano de 2008, começamos o processo formativo apoiadas na Sociologia da Infância (Rosemberg, 1976; Qvortrup, 2010; Corsaro, 2011; Nascimento 2013) e da perspectiva teórica da Psicologia Sócio-Histórica (Bock, 2011; Vigotski, 1996), conhecemos o conceito histórico e social da infância, buscando romper os processos de contenção dos corpos infantis, as rotinas fixas, e as visões adultocêntricas frente a decisões coletivas e democráticas. Desde então realizamos diversas reflexões para construir um projeto político pedagógico que rompesse com a organização do calendário escolar através de datas comemorativas e fomos construindo um calendário coletivo, que corroborava com as necessidades das crianças e da comunidade e em consonância com a Constituição Federal de 1988. Construímos coletivamente o nosso próprio calendário de celebrações, tendo como principais vivencias: Dia de quem cuida de mim; Alegrias de Quintal noturno (família e crianças); Cortejo poético; Festa dos aniversariantes do mês; Semana de arte e infância; Festa da Cultura. Durante esses eventos oportunizamos às crianças, famílias e comunidade autonomia e liberdade para participar, preparar e vivenciar diferentes experiências. A escola é imersa em arte e cultura, recebemos artistas do bairro e de outros lugares, partilhamos comida, danças, músicas, poesias, histórias. Valorizando as pessoas, a história do bairro, convivência comunitária e estabelecendo uma escola democrática, participativa e que valoriza a diversidade.

Palavras-chave: infâncias, arte, cultura e periferia.

Este artigo resulta do trabalho coletivo de todas as educadoras e educadores que compõem a equipe da referida EMEI, a sistematização do relato e a versão final do artigo couberam a:

1 Coordenadora pedagógica. E-mail: amanda_unesp@yahoo.com.br

2 Professora. E-mail: cris.freire2015@outlook.com

3 Professora. E-mail: doraliceandrade19@gmail.com

4 Professora. E-mail: elainecnluz@gmail.com

5 Professora. E-mail: sandracoordenadorapedagogica@gmail.com

6 Diretora. E-mail: valeria@pjsp.org.br

ISBN 978-65-88471-05-0 | https://doi.org/10.47247/VV/ENMD/88471.05.0 


\section{NARRATIVAS DE SABERES E FAZERES DOCENTES: COSTURANDO MEMÓRIAS}

Suzana Medeiros Batista Amorim¹, Maria Fernanda Caravana de Castro Moraes Ricci 2, Maria Luiza Delgado de Medeiros ${ }^{3}$, Suely Cristina de Souza Fernandes Crahim, Therezinha Coelho de Souza ${ }^{5}$

Acesse a apresentação deste trabalho

Vivemos tempos cercados de incertezas e indefinições. Os fazeres docentes precisam ser resignificados a cada instante, frente aos desafios de uma mediação pedagógica por tecnologia. Embora o ato comunicacional seja algo recorrente na práxis docente, repensar e partilhar os saberes construídos e suas aplicações no momento educacional experienciado constrói um campo de fortalecimento, empoderando e impulsionando o realinhamento dos atos no currículo. Nesta perspectiva, desenvolveu-se ação do projeto de pesquisa "Trajetórias sociais, Saberes e Práticas Docentes", propondo rodas de conversas com egressos e graduandos do curso de Pedagogia, da Universidade de Vassouras-RJ. Roda de Conversa é probabilidade metodológica para comunicação dinâmica e produtiva, assim, foi traçado o objetivo geral da ação, que é contribuir com a reflexão sobre educação na pandemia, subsidiariamente, analisar práticas pedagógicas desenvolvidas na educação formal e identificar soluções emergenciais na educação formal na pandemia. As rodas de conversas acontecem virtualmente, por streaming, tendo como palestrantes dois egressos do referido curso que estejam experienciando práticas de educação formal. Egressos e graduandos foram convidados a participar do evento, que acontece quinzenalmente às sextasfeiras. Foram agendados cinco encontros com os temas: Os fazeres pedagógicos ressignificados: efeitos da pandemia; Práticas docentes mediadas por tecnologias digitais: diálogos contemporâneos; O trabalho pedagógico da Alfabetização e Letramento em aulas remotas; Avaliação Educacional: um diálogo necessário em tempos de COVID 19; e Gestão educacional: administrando os desafios. As discussões nas rodas de conversas estão subsidiando reflexões sobre diferentes tipos de indicadores de produtos e processos, de contexto formativo e atuação profissional e de recursos físicos e didáticos, podendo amparar formação dos professores partícipes do encontro, e também dos discentes em formação inicial.

Palavras-chave: Formação Docente. Educação Formal. Pandemia. Prática Docente.

1 Doutoranda da Universidade Estácio de Sá e Professora do Curso de Pedagogia da Universidade de Vassouras-RJ - suzana-amorim@uol.com.br

2 Mestre do Curso de Pedagogia da Universidade de Vassouras-RJ 3 mariafernanda.ricci@gmail.com de Pedagogia da Universidade de Vassouras-RJmarialuiza.medeiros@yahoo.com.br 4 Mestre do Curso de Pedagogia da Universidade de Vassouras-RJ - suelycrahim@yahoo.com.br 5 Mestre do Curso de Pedagogia da Universidade de Vassouras-RJ - thei.souza@yahoo.com.br 


\title{
ANIMAIS MAMÍFEROS: UMA PROPOSTA BILÍNGUE PARA ESTUDANTES
}

\section{SURDOS: ENSINO DE CLASSIFICAÇÃO BIOLÓGICA}

\author{
Caroliny Capetta Martins ${ }^{1}$, Ana Carla Alves Cardoso de Mattos ${ }^{2}$
}

Acesse a apresentação deste trabalho

\begin{abstract}
A pandemia da COVID-19 trouxe uma série de incertezas e desafios na área da Educação. Escolas tiveram que manter o ensino de forma remota e forçaram mudanças na forma de ensinar dos professores. Uma prática que deu certo neste momento de trabalho remoto foi uma atividade com o uso do aplicativo de Código de Resposta Rápida (QR Code), usado como ferramenta nas aulas de classificação biológica, com o objetivo de atender as especificidades dos estudantes surdos, que são indivíduos visuais e têm melhor rendimento através do uso das Tecnologias Digitais da Informação e Comunicação (TDIC) e de imagens que possam ser adaptadas junto à Língua Brasileira de Sinais (Libras), já que o uso dos smartphones é cada vez mais comum no ambiente escolar. O conteúdo aplicado foi sobre as Classes de mamiferos, associando os animais de acordo com suas características específicas a cada Classe. Após pesquisa inicial, fez-se uma discussão via aplicativo Meet, utilizado pelo Governo do Estado do Paraná dento do Google Sala de aula, apresentando as principais características de cada grupo e verificando as diferenças entre as classes de mamiferos. Os estudantes se apropriaram do conteúdo e entenderam como os cientistas montavam os sistemas de classificação dos seres vivos. Partimos então para o exercício lúdico, onde cada educando recebeu na sala de aula virtual, um formulário contendo um texto com as características dos animais de cada classe e espaços em branco, tipo complete, para serem preenchidos após a observação dos QR code, postados embaralhados em outro arquivo na mesma atividade. Com seus smartphones, os estudantes capturavam o código que mostrava a foto e sinal em Libras de um animal que deveria ser identificado por suas características e colocado no espaço correto do formulário, enviando ao professor após finalizar. Os resultados foram satisfatórios, pois a maioria dos estudantes, incluindo o surdo, obteve êxito nas respostas enviadas através do formulário individual.
\end{abstract}

Palavras-chave: Tecnologias Educacionais. Educação de Surdos. Biologia. Mamiferos.

1 Mestranda no Programa de Mestrado Profissional em Educação e Novas Tecnologias - UNINTER, Paranaguá, Paraná, Brasil, e-mail: carolliny93@hotmail.com

2 Mestranda no Programa de Mestrado PROFBIO - UFPR, Paranaguá, Paraná, Brasil, e-mail: anacarla2278@gmail.com

ISBN 978-65-88471-05-0 | https://doi.org/10.47247/VV/ENMD/88471.05.0 


\title{
AVALIAÇÃO DE ACADÊMICOS DE ENFERMAGEM SOBRE METODOLOGIAS
}

\section{ATIVAS DE ENSINO-APRENDIZAGEM EM UMA IES NO ESTADO DO}

\author{
MARANHÃO
}

Ariane Luz Carvalho1, José Wáttylla Alves dos Santos Paiva², Eva Mara Uchôa Amorim³, Marcus Winicius Mesquita de Brito ${ }^{4}$

Acesse a apresentação deste trabalho

As metodologias ativas de ensino-aprendizagem constituem um conjunto de técnicas pedagógicas que proporcionam a construção de conhecimento críticoreflexivo, através de uma dinâmica de aprendizagem, onde o educando, torna-se protagonista no desenvolvimento desse conhecimento. Nesse sentido o objetivo deste projeto é analisar como os acadêmicos de enfermagem avaliam a utilização de metodologias ativas em seu processo educacional em uma Instituição de Ensino Superior no estado do Maranhão. Constituído de uma pesquisa de abordagem quantitativa, com caráter exploratório, através de levantamento survey pela técnica de pesquisa de campo, a pesquisa será desenvolvida em uma IES privada, situada na cidade de Pedreiras-MA. Os sujeitos participantes da pesquisa serão os acadêmicos do curso de Enfermagem, devidamente matriculados no respectivo curso no período letivo 2020.2, maiores de 18 anos, e que atendam a todos os critérios de inclusão, e que aceitem participar mediante assinatura do Termo de Consentimento Livre e Esclarecido, atualmente conta com um total de 183 estudantes, perfazendo assim a população do estudo, com amostragem não probabilística por conveniência. O instrumento de pesquisa será constituído por 1 questionário composto de características socioeducacionais dos sujeitos, e abordagens referentes a prática de metodologias ativas. Os mesmos receberão uma roupagem digital, com perguntas fechadas, abertas, de múltipla escolha e de escala, contendo ao total o número de 14 perguntas, que estará disponivel para coleta dos dados em uma plataforma online e distribuído aos participantes por midias digitais. No que se refere aos aspectos éticos e legais, está pesquisa obedecerá a todos os preceitos estabelecidos através das normas e diretrizes vigentes das Resoluções 466/2012 e 510/2016.

Palavras-chave: Metodologias ativas. Enfermagem. Educação.

\footnotetext{
1 Enfermeira. Especialista em Docência do Ensino Superior. Docente do curso de Enfermagem. Faculdade de Educação São Francisco-FAESF. alc@faesf.com.br

2 Enfermeiro. Hospital de Clínicas da UFPR (CHC-UFPR). Especialista em Vigilância em Saúde. Mestrando do Programa do Cuidado em Saúde da UFPR. Jose.wattylla@hotmail.com 3 Acadêmica do curso de Enfermagem. Faculdade de Educação São Francisco-FAESF. emua@faesf.com.br

4 Acadêmico do curso de Enfermagem. Faculdade de Educação São Francisco-FAESF. mwmb@faesf.com.br
} 


\title{
EXPERIÊNCIA DE APLICAÇÃO E FORMULAÇÃO DE UNIDADE DIDÁTICA PELO PIBID: A SENSIBILIZAÇÃO E INCLUSÃO DO ALUNO NO TEMA FAMÍLIA.
}

\author{
Giselle Ruy Bueno, Beatriz Mariano Cyrino
}

Acesse a apresentação deste trabalho

O trabalho tratado nesta apresentação foi desenvolvido por bolsistas do PIBID, estudantes de Letras Espanhol da Universidade Federal do Paraná, em conjunto com alunos e professora supervisora do Colégio Estadual do Paraná. Durante esse período, desenvolvemos vários projetos, dentre eles a unidade didática "Los míos, los tuyos, los nuestros.. ¿Con quienes vivo?", que foi planejada para turmas de $6^{\circ}$ ano, com o intuito de expandir e dinamizar os conteúdos do material didático de espanhol utilizado pela escola. É importante ressaltar o principal foco de aprendizagem dessa unidade: que os alunos consigam sensibilizar-se e compreender a representatividade familiar a partir da exposição a vários núcleos familiares. Para tal, optou-se pelo livro "O livro da família", de Todd Parr, modificado e traduzido para o espanhol pelas bolsistas. Outro aspecto trabalhado foi a inclusão de emojis e desenhos animados de alta repercussão no material, com a intenção de motivar a participação dos alunos, aproximando-os do tema proposto. Além desses aspectos, o livro didático discutia de modo superficial o tema "sentimentos". Tal assunto foi abordado mais profundamente na unidade por meio do áudio livro "La parte que falta", que relata sentimentos diversos, com um personagem que procura sua parte, mas percebe que também é feliz sem ela. Para finalizar a unidade temática, foi proposta uma atividade coletiva, cujo objetivo era levar os alunos a relatar os sentimentos no âmbito familiar. Assim, foi solicitado que respondessem a pergunta ¿qué te hace feliz cuándo estás en familia? As respostas foram transcritas em pedaços irregulares de papéis coloridos, em seguida os estudantes foram separados em grupos e precisaram unir os papéis. Ao posicionar as frases, observaram que não teriam um círculo perfeito, assim foi realizada uma releitura do personagem do livro utilizado. Vale frisar que a experiência foi enriquecedora e a seleção do material foi assertiva, pois os alunos participaram ativamente.

Palavras-chave: PIBID, Espanhol, ensino de L.E, unidade didática. 


\section{PERCEPÇÕES DE CRIANÇAS DO ENSINO FUNDAMENTAL SOBRE AS RELAÇÕES}

\section{DE GÊNERO A PARTIR DE NARRATIVAS ORAIS EM RODAS DE CONVERSAS}

John Jamerson da Silva Brito ${ }^{1}$, Jónata Ferreira de Moura ${ }^{2}$

Acesse a apresentação deste trabalho

As narrativas orais, usadas nesta pesquisa como dispositivo metodológico, ajudam os pesquisadores a compreenderem as percepções das crianças e o entendimento que elas têm de algo que viveram ou estão vivendo, pois captam realmente os sentimentos, as subjetividades que os sujeitos trazem consigo, permitindo a valorização de suas vozes. As rodas de conversas, também utilizadas como metodologia nesta investigação, possuem a característica do diálogo, buscando a reflexão das crianças, a partir das questões de pesquisa e do referencial dos autores citados. Dessa forma, o presente resumo, fruto de uma investigação conclusão de curso de Pedagogia do primeiro autor, tem como objetivo analisar algumas narrativas de crianças sobre as relações de gênero no ensino fundamental, analisando-as na perspectiva da teoria Queer. Utilizando-se de rodas de conversa, pontuaremos como esse dispositivo pode evidenciar o protagonismo das crianças, explanando brevemente sobre as percepções que elas possuem acerca das relações de gênero. A pesquisa foi realizada com crianças do $5^{\circ}$ ano do ensino fundamental de uma escola pública municipal da zona urbana de Imperatriz/MA, e a utilização das rodas de conversa foi decorrente da regência ao logo do Programa de Residência Pedagógica que o primeiro autor deste resumo fez parte no ano de 2018. A construção teórica que permeia o trabalho é baseada em Tedeschi e Pavan (2017), Laplantine (2007), Lopes (2013), Nóvoa e Finger (2010), Ferrarotti (2010), Butler (2013), Louro (2001, 2008, 2018), Miskolci (2009, 2017) e Moura e Lima (2014). Por meio das análises das narrativas das crianças conseguimos identificar aspectos que elas compreendem como estáticos na construção dos gêneros, pontuando características tidas como essências para cada gênero, tais como o uso de roupas, a escolha de cores, as ações e até mesmo o jeito de falar, inferindo percepções reproducionistas.

Palavras-chave: Narrativas Orais. Rodas de Conversas. Relações de Gênero. Crianças do Ensino Fundamental.

\footnotetext{
1 Professor de $1^{\circ}$ ao $5^{\circ}$ ano. Prefeitura Municipal de Davinópolis. jamersonbritobr@gmail.com
} 2 Professor Adjunto. Universidade Federal do Maranhão.jf.moura@ufma.br 


\title{
EDUCAÇÃO AMBIENTAL E SUSTENTABILIDADE NOS
}

\section{PROJETOS POLÍTICO-PEDAGÓGICOS.}

\author{
Bruna Gimenez da Silva1, Sara Maria Blasques², Everton Viesba ${ }^{3}$
}

Acesse a apresentação deste trabalho

Os projetos político-pedagógicos (PPPs) são documentos elaborados, coletivamente, pela direção, coordenação e corpo docente com a comunidade escolar. Neles, estão presentes as atividades, os projetos e os conteúdos que serão abordados nas respectivas disciplinas ao longo dos anos letivos. São nestas divisões que, idealmente, a Educação Ambiental (EA) deveria ser encontrada, onde a sua inserção deve ser feita de maneira transversal e interdisciplinar. Deste modo, o presente estudo é um recorte de um projeto de pesquisa que visa analisar como a EA é abordada nos PPPs de 5 escolas públicas de Diadema. A pesquisa tem como objetivo identificar se os PPPs das instituições selecionadas preveem a inserção e, nos casos positivos, se orientam para o trabalho da EA no cotidiano da escola. Como metodologia será utilizada uma abordagem qualitativa, para que seja possível ter uma maior proximidade com o que deseja ser estudado, neste caso, por meio da análise dos PPPs, complementada pela realização de entrevistas e aplicações de questionários. Presume-se encontrar a EA inserida em projetos, passeios e afins. Entretanto, possivelmente, ela seja estudada apenas nas disciplinas de Ciências e Biologia, como destaca a literatura na área, sem apresentar, necessariamente, uma ligação com as demais disciplinas. Na elaboração do projeto, estudos preliminares e revisão da literatura, constatou-se a necessidade do conhecimento acerca dos PPPs de cada instituição por parte dos professores formados e sobre a sua constituição por parte dos que estão em formação.

Palavras-chave: Projetos Político-Pedagógicos. Educação Ambiental. Escola Pública.

1 Discente de Ciências, Unifesp. E-mail: gimenezsbruna@gmail.com

2 Discente de Ciências Biológicas, Unifesp. E-mail: sara.blasques@unifesp.br

3 Professor. Coordenador do Observatório de Educação e Sustentabilidade da UNIFESP. Pósgraduando em Ensino de Ciências, Unifesp. E-mail: evertonviesba@uol.com.br 
O PAPEL DAS METODOLOGIAS ATIVAS PARA A PROMOÇÃO DE UMA

EDUCAÇÃO DE QUALIDADE: METODOLOGIAS ATIVAS NO INSTITUTO DE

EDUCAÇÃO E CULTURA RAÍZES

Bruno Lopes de Passos ${ }^{1}$

Acesse a apresentação deste trabalho

Os últimos debates sobre o papel da educação como ferramenta eficaz na busca por uma sociedade mais justa fez crescer a necessidade de proporcionar aos estudante uma educação de qualidade, o que pode ser efetivado com a adoção de metodologias ativas no processo de ensino-aprendizagem, que reconheçam o aluno como protagonista, estimulando diversas habilidades e competências, tais como a autonomia, a criatividade, o pensamento complexo, o protagonismo, a responsabilidade e principalmente a participação. O Instituto de Educação e Cultura Raízes, localizada no município de São Sebastião- SP tem implementado nos últimos cinco anos práticas de metodológicas ativas, com destaque nas disciplinas de Ciências Humanas, para os alunos do Ensino Fundamental anos finais e Ensino Médio. A proposta consiste trabalhar com o desenvolvimento de projetos, aula invertida e no trabalho cooperativo em grupos. No processo de construção do conhecimento o professor tem um papel de mediador, se propondo a auxiliar os alunos e a construir os roteiros de estudos direcionados para produção das atividades com o uso de recursos tecnológicos e a utilização dos espaços e recursos disponíveis na instituição. Nos últimos anos a instituição verificou uma mudança significativas no processo de aprendizagem e na inserção dos alunos na comunidade, reflexo das práticas que foram bem trabalhadas alinhadas ao currículo escolar. O objetivo do trabalho foi empreender um estudo de caso sobre essa metodologia, descrevendo os processos de desenvolvimento das metodologias ativas, os principais desafios e as formas encontradas para avaliar o trabalho que vem sendo desenvolvido. Todos esses dados coletados têm como principal objetivo fornecer instrumentos para um debate enriquecedor sobre as práticas educacionais para uma educação de qualidade.

Palavras-chave: Metodologias Ativas; Sala de aula invertida; Ensino Hibrido; Formação de Professores; Educação.

1 Graduado em História pela Universidade Estadual Paulista "Julho de Mesquita filho", Pedagogo e coordenador do Instituto de Educação e Cultura Raízes. brunolopes@raizesescola.com.br 


\section{NARRATIVAS DE UMA PROFESSORA EM FINAL DE CARREIRA: A EDUCAÇÃO FRENTE À PANDEMIA}

Juliana Pedroso Bruns¹, Rita Buzzi Rausch²

$\underline{\text { Acesse a apresentação deste trabalho }}$

Com vistas a valorizar os saberes docentes de uma professora em final de carreira, buscou-se refletir sobre a formação de professores e a utilização das tecnologias digitais nos processos de ensino e aprendizagem, mediante e-learning, no momento em que o país vivencia uma pandemia mundial provocada pelo coronavirus. Observa-se que a chegada das tecnologias no cenário educativo, colocou em evidência inúmeros desafios, sobretudo aos professores e estudantes, mas também visualizam-se muitas oportunidades, já que como observam Vaillant e Marcelo (2012), a educação mediante e-learning pode propiciar reformas e inovações que tenham como eixo central o direito de aprender que todos os estudantes possuem. Tudo isso, portanto, leva-nos a refletir acerca do papel dos docentes nesse novo cenário educativo. Para tal, foi realizada uma pesquisa qualitativa e para recolha dos dados, utilizou-se uma entrevista narrativa com uma professora em final de carreira que atua na Rede Municipal de Ensino de Brusque, (SC). Para analisá-los, foi empregada a técnica de análise de conteúdo. Utilizou-se principalmente as contribuições de Marcelo (2001), Vaillant e Marcelo (2012), Nóvoa (2009, 2019, 2020) e Pérez Gómez (2015). Os resultados evidenciaram lacunas na formação continuada. Por outro lado, ficou evidente que não basta propiciar aos docentes formação continuada, pois muitos estudantes não possuem sequer acesso à internet. Torna-se urgente repensar a educação, sobretudo para as crianças das classes menos privilegiadas.

Palavras-chave: E-learning. Formação continuada de professores. Tecnologias digitais.

1 Mestranda em Educação no Programa de Pós-Graduação em Educação na Universidade Regional de Blumenau - PPGE-FURB. Bolsista CAPES. Pedagogia e Especialista em Educação pelo Centro Universitário de Brusque- UNIFEBE. E-mail. julianap.bruns@gmail.com

2 Doutora em Educação pela UNICAMP e Pós-Doutora em Educação pela UFSC. Docente e pesquisadora no PPGE da FURB e no PPGE da UNIVILLE. E-mail: ritabuzzirausch@gmail.com 
DANÇA SINALIZADA: UMA PRÁTICA PEDAGÓGICA PARA INTERAÇÃO ENTRE

\section{ALUNOS SURDOS E OUVINTES}

Camila Cardoso Fernandes ${ }^{1}$, Adriano Franzoni Wagner², Damaris Paula Castilho ${ }^{3}$, Fabíola Franzoni Wagner4, Juliana Tasca Lohn ${ }^{5}$

$\underline{\text { Acesse a apresentação deste trabalho }}$

A dança é a arte de se movimentar expressivamente o corpo seguindo movimentos ritmados. É uma prática integrativa comum de socialização entre grupos. Segundo Freitas(1998), desde a antiguidade, a humanidade já tinha na expressão corporal, através da dança, uma forma de comunicação. A disciplina de Libras faz parte do currículo do curso de Letras Libras sendo uma oportunidade de aumentar a interação social entre os alunos surdos e ouvintes. O objetivo deste trabalho foi apresentar um relato de experiência descritivo de uma dança sinalizada, como proposta de recreação e integração. A atividade se desenvolveu entre agosto e novembro de 2019 e os ensaios aconteceram dentro da sala de aula por um periodo de 15 minutos, 2 vezes por semana. A música escolhida foi "Não quero dinheiro" do cantor e compositor Tim Maia, para sua aprovação foi levado em consideração os pequenos refrãos, as frases curtas e o compasso suave de fácil marcação. A professora da disciplina fez a tradução em conjunto com os alunos. Os movimentos coreográficos foram desenvolvidos por uma aluna da disciplina com formação em dança. Foram treinados 20 alunos ouvintes e 5 surdos. Para otimização da didática dos ensaios, dividiu-se em três grupos de alunos fazendo a marcação espacial de três fileiras. Esta estratégia permitiu trabalhar com grupos menores, possibilitando a visualização do corpo no espaço cênico entre todos os integrantes. O projeto finalizado recebeu um convite para uma apresentação de abertura do IV Seminário de Letras Libras 2019. O aprendizado do convivio com a diversidade pôde evidentemente, com a troca de experiências, auxiliar na percepção corporal, desenvolvimento de expressão no contexto da linguagem além de proporcionar o crescimento interacional e afetivo. Quando uma proposta pedagógica diversa do habitual, como a dança, foi trazida para sala de aula, criou-se uma motivação para o aprendizado e para relações interpessoais.

Palavras-chave: Dança sinalizada, Libras, Surdos, Ouvintes, Interação.

1 Discente Letras Libras. UFSC. adrianofranzoni@yahoo.com.br

2 Discente Letras Libras. UFSC. camilacf.adv@gmail.com

3 Discente Letras Libras. UFSC. damaris.paula@gmail.com

4 Pedagoga. EEB Edite Gama Ramos. ffwp@hotmail.com

5 Docente Letras Libras. UFSC.julianasurda@hotmail.com

ISBN 978-65-88471-05-0 | https://doi.org/10.47247/VV/ENMD/88471.05.0 


\title{
O REINVENTAR PEDAGÓGICO DIANTE DO DESAFIO DA PANDEMIA DO \\ COVID 19
}

\author{
Carla Juliane dos Santos Vilar1, Carine de Campos Moraes Barros²
}

Acesse a apresentação deste trabalho

Este é um relato de experiência das estratégias utilizadas pela Secretaria Municipal de Educação (SMED) de Piraquara- Pr para realizar atividades de formação continuada com os profissionais da educação neste período de suspensão das aulas presenciais e a retomada do calendário escolar de forma remota com os estudantes. Para escolher a melhor forma/ferramenta virtual para realizar estas ações, foi aplicado um questionário Google Forms com as seguintes perguntas: Qual seu nivel de conhecimento sobre o uso da internet e outras tecnologias de comunicação? O dispositivo que usa para acessar a internet conta com webcam e microfone? Você estaria disponivel para apoiar colegas de sua escola quanto a organização de atividades online? Qual seu nivel de conhecimento sobre as seguintes ferramentas: uso de tecnologias; uso de email; navegação na internet; uso do Whatsapp; uso do Facebook; uso do Moodle? A partir da análise dos dados obtidos concluiu-se pela utilização do ambiente Google Sala de Aula para a formação continuada. Em seguida se aplicou um questionário Google Forms com os pais e responsáveis, sendo as perguntas: Você possui acesso a internet? Você utiliza alguma rede social? Qual? Com quem a criança tem ficado neste período de suspensão de aulas? Organizaremos atividades para ser realizada em casa, assim, qual a melhor forma para acessar as atividades que serão disponibilizadas para os estudantes? Quem será o responsável para contribuir na realização das atividades com a criança? Assim se definiu, entre outras ações, pela elaboração de cadernos de situações de aprendizagem aos estudantes do Ensino Fundamental e Educação de Jovens e Adultos. Este período tem sido muito desafiador especialmente para os professores que agora precisam se reinventar através de outros recursos, nunca antes tão utilizados, superar seus medos de uso da tecnologia, mergulhando num universo desconhecido o qual tem trazido muitas inseguranças e desafios.

Palavras-Chave: Calendário escolar; Ensino remoto; Formação de professores.

1 Universidade Federal do Paraná. carla.vilar@piraquara.pr.gov.br

2 Universidade Federal do Paraná. carinebarros.ufpr@gmail.com 


\section{A INFLUÊNCIA DA TECNOLOGIA NA APRENDIZAGEM DA CRIANÇA: UM ESTUDO A PARTIR DA TEORIA PIAGETIANA}

Caroline Ap. Marturano Aranha1, Ione Arsênio da Silva², Sabrina Espino Prata ${ }^{3}$

Acesse a apresentação deste trabalho

A pesquisa apresentada é fruto de um trabalho de conclusão de um curso de pós-graduação em Tecnologias na Educação e traz a ideia de desconstrução das práticas pedagógicas tradicionais por meio da implementação de ferramentas tecnológicas em sala de aula. Desta forma, surgiu a ideia de investigar os beneficios e maleficios do uso das tecnologias pelas crianças, considerando que esta está presente no cotidiano de todos e que pode ser utilizada na aquisição e reflexão de novos conhecimentos. O objetivo proposto é conhecer a forma como as tecnologias agem no processo de construção da aprendizagem, baseada na teoria do construtivismo de Jean Piaget, tendo como parâmetro algumas pesquisas feitas por outros especialistas com ferramentas digitais diversas e pela própria autora com o uso de um podcast. Por meio de uma pesquisa-ação e também bibliográfica, observou-se que a construção e desenvolvimento do processo cognitivo nas crianças ocorre de forma gradual, dependendo da sua maturidade para cada estágio e através da interação do sujeito com o meio. Sendo assim, o uso das tecnologias pode contribuir no avanço e desenvolvimento desse processo e trazer beneficios aos estudantes como interação, interesse, atenção, engajamento e motivação. Portanto, conclui-se que o uso das tecnologias, aliado a teoria piagetiana, pode transformar a educação e sociedade atual, propiciando uma prática inovadora e colaborando com os professores na organização, planejamento e diversificação das aulas.

Palavras-chave: Educação; Jean Piaget; Tecnologia; Processo cognitivo.

1 Aluna do Curso de Especialização em Tecnologia da Informação e Comunicação na Educação. IFSP/Capivari. carolinemarturano@gmail.com.

2 Professora/Orientadora do Curso de Especialização em Tecnologia da Informação e Comunicação na Educação. IFSP/Capivari. ione@ifspcapivari.com.br.

3 Professora/Coorientadora do Curso de Especialização em Tecnologia da Informação e Comunicação na Educação. IFSP/Capivari. sabrinap.espino@ifsp.edu.br 


\section{RECURSO HÍDRICOS}

Cibele Santos Oliveira Martins ${ }^{1}$, Cleyton Alves de Oliveira²

$\underline{\text { Acesse a apresentação deste trabalho }}$

Por definição os recursos hídricos são as águas subterrâneas e superficiais disponiveis para uso em qualquer região, sendo um bem de domínio público, limitado e com valor econômico. Segundo a Agência Nacional de Águas e Saneamento Básico (ANA, 2017, p. 1), "dos 2,5\% de água doce, a maior parte (69\%) é de difícil acesso, pois está concentrada nas geleiras, 30\% são águas armazenadas em aquíferos e 1\% encontra-se nos rios" e estima-se que o Brasil tenha "cerca de $12 \%$ da disponibilidade de água doce do planeta". Acredita-se que um bilhão de pessoas no mundo não tem acesso a um abastecimento de água suficiente (ONU, 2020), e cerca de 35 milhões de pessoas não têm acesso ao abastecimento de água tratada no Brasil (Trata Brasil, 2020). Levando estes fatos em consideração, pretende-se neste trabalho discutir um plano de aula que aborda a importância e como o uso inadequado impacta a sociedade, além de ajudá-los a procurarem soluções para os problemas desse tema. Tendo em vista o contexto atual de pandemia, a metodologia utilizada para a aplicação do plano de aula será rodas de conversa em meio virtual, estudos de caso, utilização de vídeos e documentários e leitura de textos e notícias. Espera-se que os alunos compreendam a importância dos recursos hídricos, como o mau uso prejudica não só a vida humana, mas também as comunidades bióticas que dependem deles e principalmente aprenderem a fazer um uso mais consciente e a preserválo. A realização das discussões a distância, o desenvolvimento das atividades e as interações exigirão um grande esforço e concentração dos alunos, que irão ser avaliados continuamente. É importante incentivar os alunos a utilizarem o método científico, onde serão orientados sobre os caminhos e questionamentos para que possam adquirir alguma autonomia neste processo. Além disso o tema traz uma problemática que deve ser de interesse coletivo, por isso, o entendimento e a colaboração entre estes para se pensar soluções será imprescindivel.

Palavras-chave: Água, educação, sustentabilidade.

1 Licenciado em Ciências pela Universidade Federal de São Paulo. cibele.maartins@gmail.com

2 Licenciado em Ciências pela Universidade Federal de São Paulo. cleyton.not@gmail.com

ISBN 978-65-88471-05-0 | https://doi.org/10.47247/VV/ENMD/88471.05.0 


\section{RECUPERAÇÃO E REFORÇO ESCOLAR EM MATEMÁTICA: APONTAMENTOS E REFLEXÕES FRENTE À PANDEMIA DA COVID-19}

Cilene Maria Fontes ${ }^{1}$

Acesse a apresentação deste trabalho

Faremos aqui um breve resumo de questões apontadas em nosso trabalho de mestrado "Projetos de recuperação/reforço em matemática no estado de São Paulo: um estudo sobre o decênio 2007-2016", com a pretensão de suscitar o debate acadêmico a cerca dessa temática frente à pandemia COVID-19. Para o desenvolvimento do trabalho, utilizamos a metodologia de pesquisa da História Oral, que nos possibilitou realizar entrevistas com docentes que participaram das cinco modalidades de projetos existentes no período citado: Recuperação paralela, Professor auxiliar, Professor de apoio à aprendizagem, Aventuras do Currículo + e Recuperação intensiva de ciclo II. Esses projetos surgiram e se modificaram no decorrer do tempo, na tentativa de conseguir adesão discente. $O$ não comparecimento dos estudantes mudou a dinâmica de oferecimento dos estudos de recuperação, colocando, por exemplo, essa aula em concomitância de horário com a aula regular e se estendendo a toda a turma de estudantes, pois o modelo de recuperação que era paralelo ao período regular das aulas se mostrou fracassado no que tange a adesão. Apesar dessas mudanças, o projeto de recuperação nada influenciava na avaliação formativa do aluno, em alguns casos era uma forma de treinar listas de exercícios com a finalidade de atingir uma nota satisfatória nas avaliações internas ou externas da escola. A ausência de oferecimento de cursos de capacitação específicos à recuperação, de inovação metodológica e da clareza de objetivos, frutificou em reprises das aulas regulares, na qual muitos dos professores não eram efetivos, com formação não específica em Matemática, assumindo o projeto tardiamente como uma forma de complementar a sua carga horária semanal. Refletindo sobre algumas das situações aqui evidenciadas e conhecendo a legítima necessidade de estudos de recuperação eficientes na atual situação escolar, nos perguntamos: Como se efetivarão os projetos de recuperação em Matemática frente à pandemia da COVID-19?

Palavras-chave: Educação Matemática. Recuperação. Reforço escolar. Covid-19.

1 Doutoranda do programa de Pós-graduação em Educação para a Ciência. Unesp - Bauru. cimafom@gmail.com. 


\title{
ENSINO DE CIÊNCIAS EM TEMPOS DE PANDEMIA: DESAFIOS E \\ POSSIBILIDADES DO ENSINO REMOTO
}

\author{
Giovana Della Crocce ${ }^{1}$, Rodolfo Magliari de Paiva², Clemil Camelo², \\ Isabela Nogueira ${ }^{4}$, Vitor Amorim5, Giuliana Rapp Cinezi ${ }^{6}$, Renan Marques $^{7}$
}

Acesse a apresentação deste trabalho

$\mathrm{O}$ atual contexto de pandemia e isolamento social tem afetado a sociedade em vários setores inclusive o meio escolar teve que se reinventar para continuar com as práticas formais de ensino. Os docentes abraçaram as didáticas com intercessão tecnológica para melhor abordagem de ensino, realocando da sala de aula presencial para a virtual, tornando-se um desafio para professores e alunos. A comunicação entre educadores e educandos ocorre por aplicativos, como o Google Meet, Zoom, Skype, Google Classroom, que são peças fundamentais no ensino remoto. Nesses meses de ensino remoto, tem-se verificado que uma grande parcela dos educandos não possui um dispositivo eletrônico ou recursos básicos para estudar e por outro lado, quando presentes precisam ser utilizados com cautela, uma vez que nesta modalidade de ensino, os alunos estão predispostos a se distraírem e se dispersarem. A novidade do ensino remoto, de certa forma acaba surpreendendo os alunos que mesmo habituados com diversas tecnologias apresentam dificuldades para se adaptar e acompanhar os conteúdos e as aulas, pois o engajamento dos educandos é diferente, o processo de aula se torna impessoal e automático e o desempenho do aluno é baseado em número de acessos a vídeos e material didático nas plataformas educacionais, fazendo com que o processo de aprendizagem se torne de certa forma mais complexo. Para melhor proveito dos temas propostos na BNCC os roteiros de aula passaram a abraçar redes sociais utilizadas pelos adolescentes com linguagem divertida e simplificada com a utilização de memes, jogos online e plataformas interativas. Essas práticas mantém o contato mais dinâmico com o aluno, onde os conteúdos formais de ciências se fazem presentes no meio cotidiano informal dos jovens. A abordagem não formal e criativa encoraja a participação em aulas remotas, facilita a comunicação, estimula o pensamento científico e ascende o interesse dos educandos nos estudos de ciências.

Palavras-chave: Ensino remoto, engajamento discente, pandemia no contexto educacional.

\footnotetext{
1 Mestranda em Ensino de Ciências e Matemática (UNIFESP). E-mail: dellacroccegi@hotmail.com

2 Mestrando em Ensino de Ciências e Matemática (UNIFESP). E-mail: rodolfomagliari@gmail.com

3 Mestrando em Ensino de Ciências e Matemática (UNIFESP). E-mail: clemil_camelo@hotmail.com

4 Licencianda em Ciências Biológicas (UFRR). E-mail: nbs.isabela@gmail.com.

5 Licenciando em Ciências da Natureza (USP). E-mail: vamorim@usp.br.

6 Mestranda em Ensino de Ciências e Matemática (UNIFESP). E-mail: giucinezi@gmail.com

7 Graduando em Ciências Biológicas (UNIOESTE). E-mail: renancezar-marques@hotmail.com
} 


\section{SÉRIES TELEVISIVAS COMO RECURSO DIDÁTICO PARA A MELHORIA DO \\ ENSINO DE CIÊNCIAS NATURAIS}

Giuliana Rapp Cinezi1 ${ }^{1}$, Roberto Rodrigues de Freitas Maciel2 ${ }^{2}$, Luiz Afonso V. Figueiredo ${ }^{3}$

Acesse a apresentação deste trabalho

A presença da rápida troca de informações com o apoio das Tecnologias de Informação e Comunicação foram ganhando seu espaço inclusive no meio escolar, com ambientes integrados às novas tecnologias. Um desses recursos é o sistema multimídia, questão inclusive ampliada nessa época de pandemia. A linguagem audiovisual ganha maior visibilidade, sendo utilizada como um recurso didático. Entre vários instrumentos audiovisuais usados como meio de ensino-aprendizagem, os seriados televisivos passam a ter sucesso didático devido a sua capacidade de prender a atenção do aluno e relacionar a ciência com algo que não é desconexo com a realidade, propicia também trabalhar a questão da interdisciplinaridade, integrando o real, o ficcional e o imaginário, de modo a fortalecer a possibilidade de um aprendizado significativo. O presente estudo resgata e analisa a produção de alunos de Licenciatura em Química do Centro Universitário Fundação Santo André que elaboraram, entre 2014 e 2018, durante as aulas de metodologia científicas a produção de roteiros de aulas e construções de sequências didáticas para o ensino de química por meio de séries de TV que possuem caráter cientifico (Bones, Dr. House, CSI, entre outras) e sendo assim podem mediar a construção de conhecimento e o ensino de conceitos científicos diversos a partir da sua utilização em salas de aulas. $O$ material para sua aplicação em escolas está diretamente ligado aos conteúdos e competências da BNCC e,portanto, podem ser utilizados como ferramentas alternativas diretas para a melhoria do processo de educação científica. As sequências didáticas e os roteiros de aula produzidos eram diversificados em termos de conteúdos possiveis e do apoio de estratégias pedagógicas alternativas. A aplicação do material permitirá avaliar a potencialidade didática efetiva do uso de séries televisas, estimulando o melhor aprendizado do conhecimento científico, de forma divertida, mas que também permite questionar a sociedade em que vivemos.

Palavras-chave: Ensino de Ciências, Séries Televisivas, Estratégias Alternativas.

1 Licenciada em Química (Centro Universitário Fundação Santo André-FSA). Mestranda do PECMA (UNIFESP-Diadema). Professora de Química do Centro de Estudos Júlio Verne. E-mail: giucinezi@gmail.com.

2 Licenciado em Química (Centro Universitário Fundação Santo André-FSA). E-mail: roberto2.pelao@gmail.com.

3 Licenciado em Química (Centro Universitário Fundação Santo André). Mestre em Educação (UNICAMP). Doutor em Ciências, área de Geografia Física (FFLCH-USP). Professor-pesquisador aposentado do Centro Universitário Fundação Santo André. E-mail: figueiredo.afonso61@gmail.com. 


\title{
"AVALIAR COM TODOS PARA MUDAR A ESCOLA": A AVALIAÇÃO INSTITUCIONAL EM DOCUMENTÁRIO
}

\author{
Cleberson Henrique de Mouraํ, Fabíola Alice dos Anjos Durães²
}

Acesse a apresentação deste trabalho

\begin{abstract}
Reportamos neste trabalho um relato de produção do documentário "Avaliar com Todos Para Mudar a Escola" (youtu.be/Vq15oFWLY0Q) que promove um discurso de crítica às avaliações externas ao mesmo tempo em que articula uma defesa propositiva da avaliação escolar do tipo negociada e participativa: a Avaliação Institucional. Assim o faz por meio de um conteúdo que se presta a documentar e divulgar o trabalho do Núcleo de Avaliação Institucional da Faculdade de Educação da Universidade de São Paulo (NAI-FEUSP). Trata-se de uma produção audiovisual que se enquadra na categoria de produção de baixo orçamento ou cinema de guerrilha. Estruturado em entrevistas realizadas com as professoras doutoras Lisete Regina Gomes Arelaro e Sonia Maria Portella Kruppa (fundadoras e coordenadoras do NAI) permeadas por imagens (insert) que evidenciam, em termos práticos, as ideias que envolvem o tipo de avaliação educacional proposta pelo Núcleo. Indo ao encontro do discurso e postura de resistência, não por acaso a trilha sonora é baseada em músicas do gênero rap e ritmos afro-brasileiros, cujos direitos autorais foram gentilmente cedidos pelos artistas Criolo e Emicida, bem como pelo grupo Art's do Tambor. Consideramos que o documentário traz uma significativa contribuição para a área da Educação, pois através das falas das professoras é veiculado um relato da história do Núcleo com ênfase para explanações ético-epistemológicas a respeito da Avaliação Institucional Negociada/Participativa, consistindo em uma grande aula sobre avaliação educacional que faz do vídeo um útil artefato para formação inicial e continuada de professores/as, coordenadores/as, diretores/as e demais envolvidos/as.
\end{abstract}

Palavras-chave: Avaliação Institucional; Avaliação Participativa; Produção de Documentário.

1 Licenciando em Pedagogia. Faculdade de Educação da Universidade de São Paulo. E-mail: cleberson.moura@usp.br.

2 Mestranda em Educação. Faculdade de Educação da Universidade de São Paulo. E-mail: fabiola.duraes@usp.br. 


\title{
PARCERIA UNIVERSIDADE-ESCOLA: PESQUISA DE RECEPÇÃO DE MATERIAIS
}

\section{EDUCATIVOS EM ARQUEOLOGIA DO MEDITERRÂNEO ANTIGO}

\author{
Maria Cristina Nicolau Kormikiari¹, Cleberson Henrique de Moura²,
}

Fabíola Alice dos Anjos Durães ${ }^{3}$

Acesse a apresentação deste trabalho

Apresentamos aqui uma pesquisa em andamento do tipo parceria universidade-escola desenvolvida pelo Laboratório de Estudos sobre a Cidade Antiga (Labeca) do Museu de Arqueologia e Etnologia da Universidade de São Paulo (MAE-USP) e a Escola Técnica Estadual Dr. Emílio Hernandez Aguilar situada na cidade de Franco da Rocha - SP; em um movimento em que o Museu vai à Escola. Apresentamos aqui alguns resultados desta experiência de pesquisa que tem como objetivo investigar a prática pedagógica do Ensino de História a partir de um recorte limitado ao que tange à utilização, pela citada escola, de alguns recursos didáticos (livro, banco de dados, vídeos e maquetes entre outros) produzidos pelo Labeca na área da Antiguidade Mediterrânica (Grécia Antiga). Após realizarmos diversas visitas à escola, desenvolvermos algumas atividades didáticas colaborativas, aplicarmos alguns questionários que resultaram em centenas de respostas - agora em processo de análise - pudemos observar que o conteúdo de Antiguidade pode subsidiar trabalhos pedagógicos fundamentados na perspectiva do multiculturalismo (pois coloca os alunos em contato com outros povos e outra cultura). Já a respeito da parceria entre universidade e escola notamos que: i) é uma ação que envolve a produção de conhecimentos que implicam em um fortalecimento pedagógico metodológico para ambos os lados (uma vez que fornece suplementos aos materiais didáticos tradicionais à escola, ao mesmo tempo que a Universidade aprende sobre seus recursos didáticos produzidos para repensar suas futuras produções); ii) proporciona uma experiência reconhecidamente impactante aos alunos não se limitando apenas ao conteúdo de História (conforme relatos explícitos dos mesmos); e iii) a parceria universidade-escola consiste também em um importante movimento de valorização e apoio na construção da autoridade docente da escola envolvida, especialmente no atual momento de crise democrática e negacionismo no Brasil.

Palavras-chave: Mediterrâneo Antigo; Ensino de História; Recursos Didáticos; Parceria Universidade-Escola; Pesquisa de Recepção.

1 Professora Doutora. Museu de Arqueologia e Etnologia da Universidade de São Paulo. E-mail: tanit@usp.br.

2 Licenciando em Pedagogia. Faculdade de Educação da Universidade de São Paulo. E-mail: cleberson.moura@usp.br.

3 Mestranda em Educação. Faculdade de Educação da Universidade de São Paulo. E-mail: fabiola.duraes@usp.br. 


\title{
ENSINO A DISTÂNCIA: OS DESAFIOS DE VESTIBULANDO DE BAIXA RENDA
}

\author{
EM MEIO A PANDEMIA DA COVID-19
}

\author{
Aline Teixeiraํ, Gabriela Santiago², Giovanna Silva³, Naira de Camargo ${ }^{4}$, \\ Nathália Figueiredo ${ }^{5}$, Clemil Camelo ${ }^{6}$ \\ Acesse a apresentação deste trabalho
}

A pandemia do Coronavírus no Brasil e no mundo trouxe vários desafios para diversos setores. Na educação, com o fechamento das escolas públicas e privadas, a comunidade escolar teve que se reinventar transferindo suas aulas e outras atividades pedagógicas para o modelo de ensino a distância, trazendo consigo vários desafios nessa transição. Tratando da educação pública de nível básico em específico, o desafio de se utilizar tecnologia extra sala, como a internet emerge a real condição de precariedade no Brasil, visto que grande parte dos estudantes não possuem artefatos digitais e recursos financeiros para estudar por meio da internet. Diante disso, o presente estudo busca fazer um comparativo entre escolas públicas e privadas na preparação dos estudantes para o Exame Nacional do Ensino Médio (Enem) 2020 em plena pandemia da Covid-19. Segundo os dados publicados em 2018 pelo Instituto Nacional de Estudos e Pesquisas Educacionais Anísio Teixeira (Inep) que retrata o perfil de seus candidatos, revela que três em cada dez participantes que concluiram o ensino médio na rede pública naquele referido ano não tinham acesso à internet, se comparado com os candidatos que concluíram na rede privada. Os dados apresentados pelo Inep mostra o abismo entre as classes sociais no Brasil, onde a classe média e alta possuem recursos básicos para continuar com o ensino remoto, enquanto grande parte dos estudantes que frequentam a escola pública não tem acesso à internet ou a tecnologia equivalente. Desse modo, tendo sua aplicação em Janeiro de 2021, o Enem deixará mais evidente como há uma discrepância no preparo dos alunos em diferentes condições sociais, não considerando o fato de que isso aumentará ainda mais a desigualdade que existe no ingresso do ensino superior no país, o que vai contra o propósito inicial desse exame, que deve ser a porta de entrada para as pessoas com condições sociais mais vulneráveis a uma universidade pública ou privada.

Palavras-chave: Ensino remoto; Educação; Covid-19; Enem.

\footnotetext{
1 Graduanda em Ciências - Licenciatura (UNIFESP). E-mail: aline.teixeira@unifesp.br

2 Graduanda em Ciências - Licenciatura (UNIFESP). E-mail: gabriela.santiago@unifesp.br

3 Graduanda em Ciências - Licenciatura (UNIFESP). E-mail: paulo.giovanna27@unifesp.br

4 Graduanda em Ciências - Licenciatura (UNIFESP). E-mail: naira_camargo@hotmail.com

5 Graduanda em Ciências - Licenciatura (UNIFESP). E-mail: nifigueiredo@unifesp.br

6 Professor da rede pública estadual de São Paulo. Graduado em Ciências - Licenciatura (UNIFESP). Mestrando do Programa de Pós-Graduação em Ensino de Ciências e Matemática (PECMA - UNIFESP). Membro do grupo de pesquisa Movimentos Docentes. Membro do Programa de Extensão Universitária "Escolas Sustentáveis". E-mail: clemil_camelo@hotmail.com
} 


\title{
CONTAÇÃO DE HISTÓRIAS EM LIBRAS: RELATO DE EXPERIÊNCIA PRÁTICA
}

\section{NA PRODUÇÃO DE VÍDEO}

\author{
Damaris Paula Castilho¹, Adriano Franzoni Wagner², Camila Cardoso Fernandes ${ }^{3}$, \\ Fabíola Franzoni Wagner ${ }^{4}$, Juliana Tasca Lohn ${ }^{5}$
}

Acesse a apresentação deste trabalho

A Literatura, segundo Candido (1995, p.175), tem papel humanizador agindo na formação da personalidade humana de formas diversas. A contação de histórias é um recurso que desperta no público infantil uma predisposição à aprendizagem. $\mathrm{O}$ vídeo pode ser considerado um excelente recurso didático e instrumento capaz de proporcionar uma aula mais prazerosa e significativa. $\mathrm{O}$ objetivo deste trabalho foi relatar a experiência prática na produção na contação de uma história infantil em língua de sinais na disciplina de libras préintermediário do curso de Letras Libras durante o segundo semestre de 2019. O livro escolhido foi 'A lebre e o leão', pelo seus cenários desafiadores com florestas e animais. Inicialmente o desenvolvimento do vídeo foi feito com as escolhas dos sinais respeitando a gramática, a identidade cultural surda e a faixa etária, a linguagem gesto-visual clara e assertiva para que não gerem dúvidas ou entendimento contrário a mensagem. No segundo momento foram estudados e analisados o uso das expressões faciais para reproduzir os animais bem como o uso do corpo para integralizar no contexto das cenas, tentando ser o mais fiel possivel a narrativa e sentido da história. E por último a inserção do narrador dentro do cenário do livro interagindo diretamente com o público infantil. Assim sendo, o vídeo final foi realizado dentro de $5 \mathrm{~min} 45 \mathrm{seg}$ entre 6 cenas, conforme o número de páginas do livro original disponivel no link https://youtu.br/EsvqAGlevuM. A linguagem artística nos permitiu diversas interpretações, pois fez um apelo à nossa criatividade e sensibilidade. Logo, foi usada uma estratégia de dinâmica para prender a atenção criando-se uma expectativa em cada ato cênico da narrativa, pelo público alvo se tratar de crianças, tornando-a mais atrativa. A literatura infantil tem a capacidade despertar e estimular o desenvolvimento da linguagem e o desenvolvimento da consciência, do sensorial ao racional incluindo e ensinando a criança surda.

Palavras-chave: Contação de histórias, Libras, vídeo, literatura Infantil.

1 Discente Letras Libras. UFSC. damaris.paula@gmail.com

2 Discente Letras Libras. UFSC. adrianofranzoni@yahoo.com.br

3 Discente Letras Libras. UFSC. camilacf.adv@gmail.com

4 Pedagoga. EEB Edite Gama Ramos. ffwp@hotmail.com

5 Docente Letras Libras. UFSC. julianasurda@hotmail.com 


\section{FUTEBOL PAIXÃO NACIONAL: A MAGIA DO PENSAR, COMPETINDO COM OS PAIS DA MAGIA}

Daniela de Oliveira Eufrázio Rosa ${ }^{1}$

$\underline{\text { Acesse a apresentação deste trabalho }}$

Na Prática Pedagógica realizada em nossa Instituição de Ensino "A Magia do Pensar" localizada no Estado de São Paulo, na cidade de São José dos Campos na zona Sul, desenvolvemos um Projeto: Futebol Paixão Nacional, quando foram adquiridos diversos conhecimentos através do evento mundial, Copa do Mundo, que reúne vários países, de diferentes raças, religiões e classes sociais. Nas rodas de conversas, cada criança foi relatando diálogos de casa como: o time que o pai gosta, o jogador mais famoso e o técnico mais esperto. Utilizamos também de varias musicas sobre o futebol para ampliar o conhecimento e promover o controle do corpo e movimento e organizamos uma torcida com diversos acessórios em verde e amarelo em homenagem ao nosso país, Brasil. E no término do projeto tivemos uma partida de futebol entre os meninos e as meninas, onde trabalhamos a pluralidade cultural tendo como objetivo conhecer e valorizar a cultura do Brasil e o da Rússia país sede da copa de 2018. Aproveitamos o clima da copa e enfeitamos nossa sala de aula com as cores da Bandeira. Finalizamos com a $18^{\circ}$ Exposição Semestral, com o tema: Futebol, Paixão Nacional! Foram expostos os trabalhos resultantes do primeiro semestre, juntamente com a comemoração de uma década da nossa Instituição de Ensino “ A Magia do Pensar". Sendo ano de Copa do Mundo, foi promovida uma "Pelada"( uma gíria que conhecemos no mundo dos amadores do futebol para brincarem entre amigos) e como o objetivo da escola é trazer os pais, para serem parceiros e amigos, foi promovida entre: Funcionários \& Pais. Através dessa brincadeira valorizamos a importância do respeito, sendo essa a maneira mais autêntica de trazer o tema “Copa do Mundo" para a Educação Infantil, sem se preocupar com quem ganha ou perde, mas sim valorizar o amor pelo esporte. Nosso intuito foi apresentar à criança possibilidades de se identificar como integrante de uma nação e de uma cultura, além de reconhecer a existência de outras tantas, pois um evento desse porte favorece a interação com a herança cultural e histórica de um evento esportivo.

Palavras-chave: Esporte, Futebol e Nação.

1 Escola "A Magia do Pensar", São José dos Campos-SP.

ISBN 978-65-88471-05-0 | https://doi.org/10.47247/VV/ENMD/88471.05.0 


\section{PRÁTICAS RESTAURATIVAS NA ESCOLA:}

\section{NARRATIVAS DE UM COTIDIANO REMOTO}

Débora de Lima Marreiro푸 Thiago Soares Valentim Grass; Gabriela de Proença dos Santos

$\underline{\text { Acesse a apresentação deste trabalho }}$

Disseminar as práticas restaurativas em meio à pandemia e aos desafios socioeducacionais que vivemos é, no minimo, um ato de rompimento de com algumas certezas cristalizadas. Com o objetivo de apresentar o conceito de justiça restaurativa e propiciar a construção de novas práticas pautadas no resgate de concepções já disseminadas por Paulo Freire, Larrosa, Kay Pranis e outros teóricos que se debruçaram no desenvolvimento integral do ser humano a partir de práticas dialógicas e emancipadoras. Propusemos um mergulho no aporte teórico e na narrativa de uma experiência vivida pela pesquisadora que ilustrou a violência (física e passiva) no ambiente escolar a partir de um diagnóstico situacional das práticas dialógicas realizadas na escola e da necessidade de estabelecer um território conversacional inclusivo e colaborativo que prevê a participação de alunos, professores e familiares. Os desafios da comunicação e a identificação de propostas que validem o processo circular e a comunicação nãoviolenta como práticas restaurativas nas escolas foram contemplados na narrativa da pesquisadora que sustenta a validação do saber vivido e propõe, em encontros semanais com os docentes, a experimentação das práticas restaurativas de forma remota (on-line). As práticas restaurativas propiciaram uma maior compreensão das diferentes nuances de violência na comunidade escolar e despertaram potencialidades adormecidas para a construção de um ambiente dialógico crítico e acolhedor que prevê o desenvolvimento de um olhar sistêmico capaz de entender o processo que gera a violência. O olhar acolhedor, a escuta qualificada isenta de julgamentos e a fala respeitosa formam o tripé que sustenta as práticas restaurativas e vem atender a necessidade de implementação de novas práticas em um ambiente sedento de um caminho, não de um "salvador da Pátria", mas, de uma prática de reparação de danos e reconstrução das relações articulada à responsabilização.

Palavras-chave: Justiça Restaurativa, comunicação, prevenção de conflitos, diálogo, competências socioemocionais.

${ }^{1}$ Mestranda - UNILOGOS University. ISBN 978-65-88471-05-0 | https://doi.org/10.47247/VV/ENMD/88471.05.0 


\title{
LEVANTAMENTO DE BORBOLETAS FRUGÍVORAS (INSECTA: LEPIDOPTERA)
}

\section{EM TRÊS FRAGMENTOS FLORESTAIS NO NOROESTE PAULISTA}

\author{
Denise Bonfim da Silva1; Oscar Farina Junior²; \\ André Victor Lucci Freitas ${ }^{3}$; Jessie Pereira dos Santos ${ }^{4}$ \\ Acesse a apresentação deste trabalho
}

Conhecer a diversidade biológica de um ambiente é fundamental para representar a riqueza de espécies de um hábitat e propor medidas para a conservação ambiental da área. Inventários de fauna tem priorizado o registro e monitoramento de espécies locais e regionais presentes em ecossistemas, notificando espécies bioindicadoras resultantes de informações ambientais. Dentre os insetos, as borboletas são amplamente utilizadas em programas de monitoramento e preservação ambiental como indicadoras biológicas de habitats. Além disso, a estratificação vertical tem sido apontada como importante padrão de distribuição e composição de comunidades de borboletas situadas no tempo e espaço, sendo cada estrato marcado por diferença de fatores abióticos. O presente trabalho teve por objetivo realizar um levantamento da fauna de lepidópteros diurnos (borboletas) em fragmentos de floresta no Noroeste Paulista e responder a seguinte questão: A comunidade de borboletas frugivoras apresenta estratificação vertical. Foram utilizadas 30 armadilhas atrativas distribuídas alternadamente entre subosque e dossel ao longo de três fragmentos florestais. A isca foi confeccionada com uma mistura de banana fermentada e caldo de cana. Foram analisadas as diferenças de riqueza e composição de espécies entre os estratos verticais através de curvas de rarefação de indivíduos e ordenação multivariada, respectivamente. No total foram identificados 5.303 indivíduos, distribuídos em 46 espécies, sendo 3.121 indivíduos capturados no sub-bosque e 2.182 no dossel. Os números de abundância e riqueza obtidos são comparáveis a inventários de borboletas realizados em áreas de matas secas e de transição com o Cerrado. Ainda que o sub-bosque tenha uma maior abundância de borboletas, a riqueza de espécies não diferiu estatisticamente. Entretanto, a composição de espécies foi distinta entre os estratos verticais. Isso indica que as comunidades de borboletas frugivoras exploram de forma diferenciada o habitat, com espécies adaptadas a um determinado estrato florestal. Este inventário é um dos primeiros da região noroeste do estado de São Paulo. Embora apresente uma vegetação distinta das florestas tropicais tipicas, as borboletas frugivoras das matas destas regiões apresentaram estratificação vertical. Isso demonstra a importância dos remanescentes florestais para a estruturação das comunidades de borboletas frugivoras.

Palavras-chave: Borboletas, Ecologia, Floresta e Inventário.

\footnotetext{
1 Graduação em Ciências Biológicas pela Faculdades Integradas de Fernandópolis - FIFE/FEF

2 Docente no Centro Universitário de Jales e na Faculdades Integradas de Fernandópolis FIFE/FEF

3 Docente da UNICAMP e Presidente do Instituto de Biologia da UNICAMP (Laboratório de Lepidópteras)

4 Pesquisador da Unicamp
}

ISBN 978-65-88471-05-0 | https://doi.org/10.47247/VV/ENMD/88471.05.0 


\section{A PRODUÇÃO E O USO DE UM APLICATIVO COMO RECURSO TECNOLÓGICO EDUCACIONAL NO ENSINO DE QUÍMICA}

Edmar Marinho de Azevedo ${ }^{1}$

Acesse a apresentação deste trabalho

Fruto de uma pesquisa desenvolvida no Programa de Mestrado em Rede Nacional PROFQUI/UFAL e buscando aliar a prática docente ao uso de ferramentas como recursos tecnológicos educacionais, este trabalho objetivou contribuir no processo de ensino-aprendizagem de alunos da $1^{\mathrm{a}}$ série do Ensino Médio de duas escolas, uma da Rede Federal e outra da Rede Estadual do Município de Maceió, com a produção e uso de um aplicativo de Química, denominado Quimilol. A metodologia consistiu na delimitação do perfil do público participante, seguida de instruções do uso dos aplicativos Socrative e Plickers para coleta de dados. O aplicativo foi testado e avaliado por discentes e docentes de química convidados. Como resultado, 90\% dos alunos o consideraram de fácil manuseio e potencializador do conhecimento acerca do conteúdo distribuição eletrônica, promovendo maior estímulo à participação em sala de aula como facilitador do processo de aprendizagem de química. $O$ aplicativo teve boa aceitação pelos docentes, sendo considerado eficiente como recurso educacional ao qual se propôs.

Palavras-chave: Aplicativo; Recurso Tecnológico; Ensino de química.

1 Ufal - Universidade Federal de Alagoas/IQB - Instituto de Química e Biotecnologia. quiedmar@gmail.com. 


\title{
OFICINA PEDAGÓGICA E RESÍDUOS SÓLIDOS: A SENSIBILIZAÇÃO COLETIVA
}

\author{
NA CONSTRUÇÃO DE COLETORES PARA A SALA DE AULA
}

\author{
Everton Viesba-Garcia1, Pedro Luis Castrillo Yagüe² \\ Acesse a apresentação deste trabalho
}

Este trabalho consiste em relatar o desenvolvimento de uma oficina pedagógica cujo foco foi a sensibilização educativa para a construção de coletores para a gestão de resíduos da UNIFESP Campus Diadema. O descarte incorreto dos resíduos gera uma sobrecarga de rejeitos nos lixões e aterros. Grande parte dos resíduos sólidos gerados podem ser reaproveitados de forma a economizar os bens e serviços naturais, bem como podem contribuir na geração de renda. No Campus Diadema, há um projeto em desenvolvimento que visa à separação e destinação correta dos resíduos inorgânicos sólidos passiveis de reciclagem, gerados pela comunidade acadêmica, por meio de coletores sinalizados e distribuídos por todas as unidades do Campus. A oficina objetivou a mitigação da problemática de separação dos resíduos na universidade, por meio de sensibilização colaborativa dos discentes, ao propor a construção de coletores com a reciclagem de revistas, utilizadas na própria universidade. O trabalho foi iniciado com a coleta de revistas, posteriormente distribuidas entre os participantes da oficina para a confecção de canudos de revistas, utilizados como decoração para os recipientes de descarte de papel como forma de chamar a atenção para o depósito correto naquelas caixas. Os canudos foram dispostos e fixados verticalmente, em volta de todas as quatro caixas de papelão, que foram deixadas pelos Campus, juntamente de uma identificação para o descarte de papel naquele recipiente. Os participantes demonstraram ter uma familiarização com o tema abordado, correspondendo ao objetivo da oficina de forma positiva. A oficina contou com a participação de 38 estudantes com um resultado final de aproximadamente 800 canudos de papel produzidos (uma média de 20 revistas recicladas, das mais de 60 arrecadadas) e quatro coletores produzidos, com material de sobra para produzir mais coletores.

Palavras-chave: Oficina Pedagógica. Coletores. Resíduos Sólidos.

1 Professor de Biologia, Mestrando em Ensino de Ciências e Biologia pela Universidade Federal de São Paulo. E-mail: evertonviesba@uol.com.br

2 Licenciado em Ciências Biológicas, Biólogo Colegiado $\mathrm{N}^{\circ}$ 18073-CL. Doutorando no Departamento de Teoria da Educação e Pedagogia da Universidad Nacional de Educación a Distancia. E-mail: pedroluiscastrillo@gmail.com 


\title{
APRENDER E ENSINAR COM DIVERSIDADE NA DIVERSIDADE DO MUNDO:
}

\section{UMA PROPOSTA PEDAGÓGICA PARA UMA (RE)CONSTRUÇÃO IDENTITÁRIA}

\author{
HUMANA
}

\author{
Edmária Conceição Franco Santos 1, Telma Maria das Neves Batista 2, Esiel Pereira Santos ${ }^{3}$
}

Acesse a apresentação deste trabalho

O mundo contemporâneo revela profunda diversidade humana a respeito das diversas formas de ser e estar, das múltiplas culturas locais e global, além da pluralidade das maneiras e meios de produção e difusão de conhecimentos e saberes pertinentes para a manutenção da vida. A partir desse olhar, a escola assume a importante tarefa de apresentar a Diversidade do Mundo, com ênfase na diversidade das Culturas, Conhecimentos, Saberes e da Ciência para a construção da identidade e cidadania dos sujeitos enquanto cidadãos construtores do mundo. Partindo desse contexto, no ano de 2019 todo o corpo gestor e pedagógico da Escola Municipal Maria Lúcia Alves do município de São Francisco do Conde (BA), junto a toda comunidade escolar de pais, estudantes, funcionários etc., construiu uma proposta anual intitulada "Aprender e Ensinar com Diversidade na Diversidade do Mundo" com o objetivo de conduzir o trabalho pedagógico a partir do reconhecimento da Diversidade do Mundo e das diversas formas de ser e estar com ênfase nas pluralidades identitárias, na diversidade cultural e do entendimento da construção histórica de Saberes e Conhecimentos Científicos realizada pela humanidade. Com resultado tivemos o desenvolvimento de três propostas executadas por unidades letivas que visou abordar um aspecto da diversidade humana, de conhecimentos e saberes, e de culturas distintas, mas que convergem em nosso dia a dia. Assim tratamos dos sub temas: Identidade na Diversidade (I Unidade); Partilhando a Conhecimentos e Saberes na Diversidade e a Diversidade do Mundo (II Unidade); e Como nós transformamos as Comunidades e como as Comunidades nos Transformam (III Unidade).

Palavras-chave: Diversidade. Ensino e Aprendizagem. Identidade. Conhecimentos e Saberes.

\footnotetext{
1 Especialista em Políticas Públicas da Educação pela Faculdade Einstein (FACEI). Licenciada em Pedagogia pela Universidade Católica de Salvador (UCSal). Coordenadora Pedagógica na Educação Básica (Secretaria de Educação de São Francisco do Conde/BA). e-mail: coordfundmarialucia.sfc@gmail.com

2 Especialista em Psicopedagogia pela Faculdade Visconde de Cairu. Especialista em Gestão Educacional pela Faculdade Helio Rocha. Licenciada em Pedagogia pel Universidade Estadual de Feira de Santana (UEFS). Professora da Educação Básica (Secretaria de Educação de São Francisco do Conde/BA). e-mail: neves.tellma@gmail.com

3 Mestre em Educação e Contemporaneidade (PPGEDUC - UNEB). Especialista em Educação Científica e Popularização da Ciência (IFBaiano - Campus Catu). Licenciado em Pedagogia (UFBA). Pesquisador do grupo Geotecnologias, Educação e Contemporaneidade (GEOTEC/UNEB). Pesquisador membro do Núcleo de Estudos em Educação Científica, Conhecimento e Sociedade (NEECCS). Professor da Educação Básica (Secretaria de Educação de São Francisco do Conde/BA) e-mail: esiel3@bol.com.br
} 


\section{ALTAS HABILIDADES/SUPERDOTAÇÃO: PROCEDIMENTOS INCLUSIVOS E \\ ESCOLARES}

Elaine Cristina Batista Borges de Oliveira, Prof. Dr. Cláudio Fernando André

Acesse a apresentação deste trabalho

O movimento de luta pela inclusão é um tema recorrente nas discussões que envolvem a educação no Brasil, já as discussões sobre a educação de pessoas com altas habilidades/ superdotação no Brasil foi acompanhada pela insignificância por um bom período no país. As mudanças começaram em 1961, com a Lei N. 4.024 que dedicou os Artigos $8^{\circ}$ e $9^{\circ}$ à educação dos excepcionais, termo cunhado por Helena Antipoff. (CUPERTINO, 2008). Em 2005, com a ampliação das discussões e alguns avanços legais nacionais e internacionais o sistema educacional brasileiro, que até então, vinha timidamente dando pouca atenção às pessoas com superdotação, por meio da extinta SEESP/MEC (Secretaria de Educação Especial do Ministério da Educação) implanta os Núcleos de Atividades de Altas habilidades/Superdotação (NAAH/S) para o atendimento desse público. (PÉREZ, 2018). Atualmente, temos a regulamentação/normatização do Atendimento Educacional Especializado - AEE por meio do Decreto $7.611 / 11$, que revogou e substituiu o decreto 6571/08, e normatiza que o Estado deverá prover condições de acesso, participação e aprendizagem no ensino regular e garantir serviços de apoio especializado, trazendo orientação às famílias, formação de professores, em conformidade com a política de educação inclusiva na rede pública de ensino. Para isso, todas as escolas públicas precisam ter uma sala de recursos multifuncional. (BRASIL, 2011).

Palavras-chave: Altas habilidades/Superdotação. Atendimento educacional especializado. Inclusão. 


\section{EDUCAÇÃO INCLUSIVA: RELAÇÃO ENTRE CAPACITISMO, EDUCAÇÃO}

\section{INCLUSIVA E AUTONOMIA}

Aquila Denfha Lima Santos, Elisa dos Santos Freitas

Acesse a apresentação deste trabalho

O capacitismo surge do fato de que as habilidades e competências da pessoa com deficiência são constantemente subestimadas. Palavra nova para uma realidade antiga. Além disso, está incluído o preconceito e discriminações, dando a entender a não capacidade necessária para se desenvolver e crescer em diferentes esferas. O surdo está inserido nesta infeliz realidade, sofrendo constantes questionamentos. A Lei Federal $n^{\circ} 13.146$, de 06 de julho de 2015 instituiu o Estatuto da Pessoa com Deficiência. Seu artigo $1^{\circ}$ assegura à pessoa com deficiência condições de igualdade a fim de promover a inclusão social e garantir o exercício da cidadania. A finalidade teórica da Lei é relevante, porém, colocar em ação seus fundamentos encontra-se fora da realidade almejada. Atualmente, com a Pandemia do Coronavirus, vimos a importância do atendimento do Decreto Federal $n^{\circ}$ 5.626, de 22 de dezembro de 2005. Ela recomenda a inserção do Intérprete de Libras em diferentes contextos para que o surdo tenha seu potencial e autonomia reconhecidas, podendo atuar em diferentes contextos, nas atividades culturais, entretenimentos diversos incluindo saraus, shows e em especial as lives. Todos os profissionais precisaram se reinventar para adaptação à nova realidade, precisaram utilizar os recursos tecnológicos disponíveis a seu favor, inclusive plataformas digitais, que facilitaram o ensino remoto de qualidade. Considerando que os surdos têm diferentes características, o professor estando a par dessas nuances, atua respeitando a diversidade surda favorecendo-os sejam eles surdos sinalizados, surdos oralizados, surdos implantados e os surdos bilingues, gerando um ensino equivalente à realidade e que atenda a necessidade com eficácia. Os surdos vêm adquirindo sua tão merecida autonomia, porém, a contribuição dos professores e de interpretes em libras colaborará para o fortalecimento desse processo. Esses profissionais conhecem a singularidade de seus alunos, agindo sem segregação e praticando a educação inclusiva. Concluímos que a ideia equivocada da dependência das pessoas com deficiência, inclusive os surdos, deve ser extinta.

Palavras-chave: capacitismo, surdos, educação inclusiva, autonomia. 


\section{REDES SOCIAIS E MEDIAÇÃO DE CONFLITOS}

\section{Erika Ap. Piazza Colnaghi ${ }^{1}$, Valéria Scomparim²}

\section{Acesse a apresentação deste trabalho}

As Redes Sociais se fazem presentes no cotidiano das pessoas e, principalmente, dos adolescentes e jovens. Observa-se o uso demasiado e desenfreado das redes sociais, acarretando graves conflitos no ambiente escolar. Este trabalho tem como tema Redes Sociais e Mediação de Conflitos e o objetivo é investigar como é feito o uso das redes sociais e das ferramentas tecnológicas usadas pelos adolescentes, (res)significando o uso das tecnologias na escola pública Padre José Bonifácio Carretta na cidade de Capivari/SP. Para coleta de dados primeiramente foi aplicado um questionário no Google Forms para os alunos. Com os resultados da coleta de dados foi realizado uma reunião apresentando aos pais os resultados que estávamos tendo na escola com o mal uso das redes sociais. Na reunião alguns pais participaram de uma entrevista semiestruturada que tinha como objetivo entender como era feito a orientação e acompanhamento do uso da redes sociais e acessos em geral. Com dados coletados e entrevistas realizadas, partimos para as rodas de conversas com os alunos, assim pudemos orientá-los como agir diante de conflitos e outros problemas ocorridos nas redes sociais. A escola está passando por uma nova fase de reestruturação, mas o cuidado que ainda deve-se ter é com os pais, pois conforme resultados obtidos na coleta de dados e rodas de conversas com alunos, entrevistas com pais, nem sempre eles tem controle e tempo para acompanhar os conteúdos acessados pelos filhos.

Palavras-chave: Tecnologias Digitais de Informação e Comunicação, Redes Sociais, Mediação; Conflitos.

1 Aluna do Curso de Especialização em Tecnologia da Informação e Comunicação na Educação. IFSP/Capivari. erikapiazza@ifspcapivari.com.br

2 Professora/Orientadora do Curso de Especialização em Tecnologia da Informação e Comunicação na Educação. IFSP/Capivari. vslima67@gmail.com 


\section{ENSINO REMOTO FORMAL NA PANDEMIA?}

Caroline Araujo Santos ${ }^{1}$, Evelin Gabrielle Fernandes Souza ${ }^{2}$

$\underline{\text { Acesse a apresentação deste trabalho }}$

No ano de 2020 com a pandemia do novo Coronavirus, houve a necessidade do distanciamento social e como consequência, escolas ficaram fechadas por mais de seis meses. Há quem diga que o ensino remoto, no ano de 2020 não pode ser caracterizado como uma educação formal. Por um outro lado, sobre educação não formal, Gadotti (2005) afirma que: ela é mais difusa, menos hierárquica e menos burocrática. Para ele, qualquer educação pode ser formal, pois é uma questão de sentido, não cenário, ou seja, a intenção educar seria a fração formal enquanto o espaço, diferente do ambiente escolar, seria a fração informal. Ele ainda diz que a educação não-formal também pode ser uma atividade organizada e sistemática como no cenário escolar. Sobre isso, Jacobicci (2008), em seu trabalho "Contribuições dos espaços não-formais de educação para a formação da cultura científica, afirma que embora o espaço escolar seja considerado um ambiente formal de aprendizagem, não é em si o espaço escolar que define essa modalidade de educação, e sim ao local em que a educação realizada seja formalizada, garantida por lei e organizada de uma maneira nacional. Em vista dos argumentos mencionados nota-se que a concepção de educação formal e nãoformal, não torna uma melhor que a outra, pois percebe-se que, embora seja valorizado o sistema de educação estruturado, de lugar fixo, que encontramos na escola, não podemos esquecer que a intencionalidade é o fator de grande relevância quando se trata do ensino, independente do espaço em que está inserido e daquilo que denominamos atualmente como não-formal, pois pode se tornar tão estruturado, sistematizado quanto o até então método formal, não para substituir o modelo atualmente adotado mas, complementar e garantir estratégias profiláticas em casos extremos como os vividos no ano de 2020.

Palavras-chave: Educação formal. Educação não formal. Ensino remoto.

1 Licencianda de Ciências da Universidade Federal de São Paulo (UNIFESP). E-mail: caroline.araujo@unifesp.br

2 Licencianda de Ciências da Universidade Federal de São Paulo (UNIFESP). E-mail: evelin.gabrielle@unifesp.br 
OBSERVATÓRIO DE EDUCAÇÃO E SUSTENTABILIDADE: BREVE RELATO DA IMPLEMENTAÇÃO NA CIDADE DE DIADEMA, SÃO PAULO

Everton Viesbaํ, Letícia Viesba², Marilena Rosalen ${ }^{3}$

Acesse a apresentação deste trabalho

Os Observatórios Institucionais e Temáticos da Universidade Federal de São Paulo (UNIFESP) são espaços para articulação participativa e fortalecimento da relação entre Escola-Comunidade-Sociedade-Universidade. O Observatório de Educação e Sustentabilidade - ObES teve sua implementação em 2019 e apresenta como objetivo a atuação como um instrumento sistemático na coleta, pesquisa, organização, tratamento e difusão de temas pertinentes à Educação e Sustentabilidade em Diadema/SP. No municipio de Diadema cerca de 30\% da população está em idade escolar, correspondendo a aproximadamente 120 mil habitantes da segunda cidade mais populosa do país. As instituições de ensino estão distribuídas em todos os 11 bairros da cidade, que também abriga remanescentes importantes da Mata Atlântica, como o Jardim Botânico e a APA Represa Billings, principalmente por ser uma cidade com extrema densidade demográfica. Foi neste contexto que surgiu o ObES, visando contribuir para o desenvolvimento da educação seja ela de nivel básico ou nível superior, e da Sustentabilidade local, fornecendo subsídio para elaboração de políticas públicas que atendam as necessidades da comunidade. Os dados coletados pela equipe são tratados e disponibilizados em diferentes formatos, por exemplo, observa-se a necessidade de que algumas informações como localidade das instituições de ensino possam ser georreferenciadas, de forma que uma vez tratado o dado, possa gerar contribuições quanto à identificação de potencialidades e problemáticas no entorno da instituição, como implementação de pontos de ônibus, áreas de descarte irregular de resíduos, proximidade a parques, entre outras informações. O ObES vislumbra incluir a comunidade na tomada de decisão, fornecendo informações técnicas de forma acessivel. Dessa forma, a publicização de informações e as capacitações realizadas são fundamentais para a comunidade, tendo potencial de rearticular movimentos e ações relacionadas à educação e a sustentabilidade.

Palavras-chave: Observatórios. Educação. Educação para Sustentabilidade. Sustentabilidade.

1 Professor. Pós-graduado em EaD e Formação Docente. UNIFESP. E-mail: evertonviesba@uol.com.br

2 Professora. Mestra em Ciências. UNIFESP. E-mail: leticia.viesba@gmail.com

3 Professora adjunto. Doutora em Educação. UNIFESP. E-mail: marilena.rosalen@gmail.com 


\section{FORMAÇÃO DOCENTE - E A UTILIZAÇÃO DA TECNOLOGIA NO ENSINO BÁSICO EM MATEMÁTICA}

Fátima Aparecida Kian¹, Ailton Paulo de Oliveira Junior² Thiago Rodrigues Oliveira ${ }^{3}$ Acesse a apresentação deste trabalho

Focamos esta pesquisa no campo das tecnologias, como apoio de material didático no ensino básico em escolas públicas, para entender como estão sendo implementadas as tecnologias no ensino inicial, as ocorrências, além da inclusão digital, a investigação apresentada está assentada no pressuposto de que os anos iniciais do ensino básico pode haver TIC para auxiliar o professor no seu papel pedagógico, e como está sendo esta introdução, as dificuldades, os caminhos a seguir, o cumprimento da grade curricular juntamente com estudos da BNCC, a formação do professor está apta a utilizar, saber escolher, saber avaliar uso da TIC pelo aluno, verificar o aprendizado se está acontecendo com as TIC ou não, teoricamente fundamentamos nossa pesquisa em D’Ambrósio (1989), Tedesco (2004), busca-se responder à seguinte questão: há utilização de software educacional no ensino básico, em matemática, como se usa as TDIC nas escolas da Educação Básica, quais são estes softwares, e a formação do professor? Pesquisa empírica, qualitativa, baseado em estudo de caso com analises de dados, apontados a partir da averiguação de 02 escolas do ensino básicos do Município de São Bernardo do Campo. O percurso metodológico da pesquisa compreendeu um levantamento preliminar sobre o total de softwares utilizado nestas duas escolas, parcialmente temos como considerações, em razão de ter averiguado a base teórica/documental, a adoção destes recursos faz necessários politicas públicas de implementação e avaliação, o governo esbarra em atender esta demanda, tanto de pessoal, ações para executar programas de melhorias educacionais, além de falta de recursos materiais, durante a pesquisa dados foram encontrados da investigação feita pelo "Todos Pela Educação", carga de trabalho é o grande desafio para o desenvolvimento da capacitação de professores do ensino fundamental, faixa etária estar acima de 47 anos, Formação continuada em EAD, pode ser um problema, o futuro professor precisa exercer e praticar no seu dia a dia programas tecnológicos ou softwares educacionais no auxilio pedagógico no ensino de crianças.

Palavras-chave: Formação docente. Tecnologia. Ensino Fundamental.

Matemática. Software educacional.

1 UFABC - Universidade Federal do Abc. fatima.kian@ufabc.edu.br

2 UFABC - Universidade Federal do Abc. Ailton.junior@ufabc.edu.br

3 UFSJ - Universidade Federal de São João del Rei. thiagool@ufsj.edu.br 


\title{
COLETIVOS COLABORATIVOS: EXPERIÊNCIAS DE DOCÊNCIA PARTILHADA
}

\section{NO TRABALHO REMOTO NA EDUCAÇÃO INFANTIL}

\author{
Fernanda Miranda Cardoso ${ }^{1}$, Nara de Oliveira Vieira ${ }^{2}$ \\ Acesse a apresentação deste trabalho
}

\begin{abstract}
O presente trabalho traz a partilha da experiência na Educação Remota em tempo de Pandemia por duas professoras que adaptaram algumas propostas do Currículo em Educação Infantil para conectividade e permanência de vínculos com as crianças e familiares em tempos de isolamento físico. Foi uma trajetória de adaptações aos recursos midiáticos e novas interações em canais de grupos coletivos, WhatsApp e Facebook. A proposta foi gerenciada em grupos maiores de planejamento coletivo com parceiras de agrupamento, produções partilhadas autorais das educadoras e curadoria de materiais, trazendo proposta de intervenções em algumas práticas "memoráveis" ao tempo presencial como: brincadeiras, músicas, histórias infantis, natureza e cotidiano. Tentamos resgatar conteúdos do currículo, adaptando a outros meios de comunicação como vídeos no YouTube para contemplar esta proposta. Sugerimos encontros virtuais com grupos pequenos de crianças e a experiência foi interessante e significativa, ainda em caráter experimental. O tempo que existia de formação continuada em hora relógio dentro das escolas estão em acessos permanentes, trazendo interações em tempos diferenciados entre os pares da equipe. A visão de um todo dentro da escola ampliou nossa identidade pedagógica permitida pelas partilhas valiosas nestas trocas de saberes. Além destas, usamos grupos de WhatsApp para planejar e reuniões virtuais com Equipe Gestora para trocas e orientações formativas do trabalho. Ainda contamos com a parceria de formação coletiva em outros canais da prefeitura além do grupo de Carlotas (empresa parceira da escola na formação do coletivo), estabelecendo um importante diálogo sobre saúde Emocional e novas maneiras de se relacionar no trabalho virtual. Acreditamos que a Educação Infantil tem uma particularidade de aprendizagens nas experiências vivenciais no tempo presente, mas sentimos a necessidade de apoiar os pequenos nas ações de intervenção com as famílias e estudamos novas ações de intervenções futuras neste processo incerto de 2020.
\end{abstract}

Palavras-chave: Educação Infantil; Ensino Remoto; Coletivo Colaborativo.

1 Professora de Educação Infantil na Rede Municipal de São Paulo no CEI São Jorge Arpoador (DRE BT).

2 Professora de Educação Infantil na Rede Municipal de São Paulo no CEI São Jorge Arpoador (DRE BT). 


\title{
REFLEXÃO SOBRE ATUAÇÃO DO PROFESSOR NA PANDEMIA: EDUCAÇÃO
}

\author{
REMOTA E SEUS LIMITES.
}

Iris Cristina Gomes do Nascimento Ferreira

Acesse a apresentação deste trabalho

Esta pesquisa teve inicio bem no comecinho das aulas remotas em conversa com alguns profissionais surgiu o interesse de saber como eles estavam vivenciando esse momento, a pesquisa teve dois momentos até então, um primeiro momento observando a prática de duas professoras, e um segundo momento para fechar o trabalho um questionário com perguntas, sobre como elas estavam vivendo esse período na prática. Saber como estava se adaptando ao novo momento, sem deixar de mencionar aqui nunca vivido na história antes, mesmo com outros vírus no passado, nada jamais igual o que o mundo está enfrentando, atualmente, os diálogos buscou entender o contexto que estava sendo configurado na prática das aulas remotas, com os alunos. Os professores no inicio sentia muita dificuldade para lidar com a tecnologia que agora seria indispensável, essas eram as maiores queixas no inicio, com passar dos meses, eles já dominavam esse modelo de dar aulas onlines, mas no ultimo encontro o que pode ser visto foi um cansaço mental, alguns relatos que nesse novo modelo eles estavam sendo professores de tempo integral, sem intervalo, sem descanso, estava era visível a exaustão. Entender esse momento, e fazer uma reflexão do momento delicado cabem aos professores que estão envolvidos nesse cenário, político, econômico, cultural, social, religioso etc.. trazer uma pesquisa para que se discuta, sobre os impactos que está sendo gerado, na educação, sendo aqui posto a discussão fundamental quais os impactos na vida do professor, em especial. Contextualizar e relacionar às ações de preparação, das aulas, quanto tempo leva para preparar cada aula, a partir de um estudo de caso, conversando com duas professoras como tem sido essas aulas, qual a visão delas nesse atual cenário. As professora relataram que os conteúdos são passados através de vídeo aulas, e também numa plataforma, algumas professoras vão até a escola e grava ao vivo as aulas, elas estão se desdobrando, para conseguir se adequar ou se enquadrar nesse novo sistema, e assim buscar a construção de um aprendizado que possa ter significado para a criança, embora a criança no ambiente do lar reluta para entrar e participar das aulas. Buscar entender que o mundo passa por uma crise, em todos os setores praticamente, e com as aulas remotas, não é diferente essa configuração que se desenha é algo que requer um olhar atento para os próximos anos na área educacional, embora hoje ainda não da para medir, buscar pensar de uma forma critica, como esta sendo as aulas remotas, como esse ano vai enfrentar, as barreiras que poderão surgir daqui para frente, até porque o mundo não para e chamar atenção de pesquisadores principalmente na área da educação, com as aulas remotas trazer pontos a serem pensados e discutidos, juntamente com outros professores que estão a frente desse trabalho. Esse processo de escrita, e discussão foram muito proveitoso, o objetivo de discutir as possibilidades de mudanças na prática do professor, com as aulas remotas, serve para esse momento atual, que todos precisam fazer sua parte dos cuidados, pensar nesse modelo de aulas para os próximos anos é algo que fica bem exposto mesmo com 
toda articulação das categorias dos profissionais, não é saudável para os professores, nem para as crianças muito menos para os pais, é preciso levar em conta a ação educativa que está vinculada a escola, onde as crianças aprendem a se socializar, a se comunicar com o outro, é um ambiente cultural onde a criança desenvolve de forma ampla. A prática docente que estava posta até então, mesmo com seus fragmentos, mas o desenvolvimento científico, tinha resultado. As possibilidades que se espera daqui para frente é vencer os desafios apresentados, mas ter um balanço dos impactos causados pela pandemia e as aulas remotas só será possível a partir de 2021, podemos deixar registrado o que foi observado através de pesquisas, mas um resultado ainda não será possível. Escrever os relatos, os anseios vividos é plausivel, sem esperar um resultado imediato dos impactos da pandemia na educação, buscar adequar nesse novo contexto, por hora é o suficiente. Os professores tiveram o primeiro impacto com a tecnologia, que até então não era obrigatório saber utilizar as ferramentas tecnológicas, mas nesse "novo" é a única alternativa, e transformá-la em aliada, tem sido o papel dos professores para auxiliar na sua pratica. Muitos profissionais tem enfrentado esse momento com bastante dificuldade, embora outros se saiam bem, afinal em sala de aula cada professor tem jeito. Falar das aulas remotas e pensar no papel do professor na formação da criança, fica vaga, não é segura, mesmo com os professores buscando fazer o melhor, dando seu máximo. As ferramentas tecnológicas ou digitais levam um tempo para que o professor tenha intimidade com ela, e muitas vezes deixam na mão, no meio de uma aula. Não cabe aqui trazer um trabalho com resultado final até porque não temos o final das aulas remotas por enquanto, então que venhamos refletir em nosso trabalho sendo mediadores indispensáveis nesse momento, e aprender a lidar com a tecnologia, é o que temos para hoje. Buscar entender e dialogar sobre as aulas remotas no intuito de contribuir, trazendo algumas considerações; repensar a prática escolar, a valorização do professor, como agente indispensável na formação da criança. A pesquisa foi feita com a observação da prática pedagógica, de professores que estão dando as aulas remotas e a preocupação com esse tipo de ensino, é acentuado nesse contexto atual.

Palavras-chave: Aulas Remotas; Prática Docente; Tecnologia na Pandemia. 


\section{VIOLÊNCIA NO CONTEXTO DO ESPAÇO ESCOLAR E BULLYING: UM OLHAR}

\section{ATENTO PARA UM PROBLEMA CONSTANTE}

Jonas Lopes dos Santos Filho ${ }^{1}$

$\underline{\text { Acesse a apresentação deste trabalho }}$

O objetivo deste escrito é abordar um tema que não é recente no âmbito da sua prática no espaço escolar: trata-se da violência escolar e a intimidação sistemática, também intitulada de bullying (BRASIL, 1996). Tais práticas são extremamente inaceitáveis, sobretudo tratando-se de pessoas deficientes, as quais apresentam necessidades educacionais especiais; negros, impactados desde o preconceito ao racismo; mulheres, enfrentando a questão estrutural do machismo, e outras minorias. A violência está presente em diversas formas no espaço, e nos tempos hodiernos esse tema tem sido cada vez mais disseminado pela sociedade, inclusive na rede de internet (PAVIANI, 2016). Sobre esse último, destaque para a violência que ocorrem neste ciberespaço (LÉVY,1999). Em tempos de trabalhos remotos, em que esta redes de comunicação virtual tem se intensificado, reverberando também na formação de discentes e docentes, a prática do bullying, tende a tornar-se mais frequente. Por esse motivo que esse escrito segue a perspectiva da provocação, no sentido de buscar refletir e compreender as formas que este fenômeno tem se apresentado também nesse contexto acometido pela pandemia do novo coronavírus, no qual o espaço escolar deixa, momentaneamente, de ser palco de manifestação do bullying para redesenhar essa violência através de plataformas de reuniões utilizadas para aulas, redes sociais e outros meios virtuais. Portanto, este texto está embasado, além da Lei de Diretrizes e Bases da Educação Nacional (BRASIL, 1996), na qual a tipificação do bullying como violência e a responsabilidade do seu combate pela escola já está assegurado; Ribeiro (2004a, 2016b), que adverte sobre uma formação com atenção à diversidade de sujeitos e a invisibilidade de pessoas deficientes com necessidades especiais educacionais no espaço escolar; e Pereira (2009), abordando as implicações do bullying na escola. Por fim, espera-se traçar uma reflexão proficua acerca deste tema.

Palavras-chave: Espaço Escolar. Bullying. Formação. Violência.

1 Graduando do curso de Licenciatura em Geografia e Bolsista de Iniciação Científica (CNPq/UEFS). Universidade Estadual de Feira de Santana (UEFS). jonaslopes.fsa@gmail.com 
COMUNIDADE MOVIMENTOS DOCENTES: UMA COMUNIDADE DE PRÁTICA

\section{Everton Viesba1 ${ }^{1}$, Letícia Viesba², Marilena Rosalen ${ }^{3}$}

As comunidades de prática são comunidades, presenciais ou virtuais, que proporcionam a criação, o gerenciamento e o compartilhamento de conhecimentos. Uma comunidade de prática não é considerada científica, pois se baseia na comunicação sobre práticas do cotidiano. Desde a década de 1990, a formação continuada de professores tem sido vista como um processo complexo e gradativamente foi entendida que pode ocorrer, também, em uma comunidade de prática. Em termos de formação continuada de professores, uma comunidade de prática funciona como um grupo que possibilita a aprendizagem, a troca e a reflexão entre os professores, tendo como matéria prima suas práticas, seus cotidianos escolares e a realidade educacional do país. Foi nesta perspectiva que surgiu a Comunidade Movimentos Docentes (CMD), comunidade de prática que tem como objetivo disponibilizar e difundir, amplamente, diversos recursos, estratégias, metodologias e materiais para a formação continuada de professores, entre eles: artigos; livros; filmes; aplicativos; infográficos; eventos; e sites educacionais. Como orientação metodológica, a comunidade é gerida a partir de um sistema de curadoria, tendo como intermediadores licenciandos, professores da educação básica, técnica e superior, pesquisadores e também professoresformadores. Permitindo uma gestão democrática e representativa, impedindo que os materiais curados sigam esta ou aquela disciplina, modalidade ou nivel de ensino. Com quase 6 meses de criação, a CMD conta com 1400 integrantes, distribuídos por todo o Brasil e exterior. Ao todo são mais de 500 postagens, socializadas por e entre os integrantes. Deste modo, reconhecendo a finalidade de uma comunidade de prática e o alcance, interatividade e engajamento dos integrantes da CMD, cabe enfatizar como resultado em andamento a valorização das boas práticas na Educação e formação docente, sobretudo na ressignificação e no resgate da paixão do ato de ensinar, tão necessários nos dias atuais.

Palavras-chave: Comunidade de Prática. Movimentos Docentes. Comunidade Movimentos Docentes.

1 Professor. Pós-graduado em EaD e Formação Docente. UNIFESP. E-mail: evertonviesba@uol.com.br

2 Professora. Mestra em Ciências. UNIFESP. E-mail: leticia.viesba@gmail.com

3 Professora adjunto. Doutora em Educação. UNIFESP. E-mail: marilena.rosalen@gmail.com 


\section{PERCEPÇÕES DOS ESTUDANTES ACERCA DO DESENHO INSTITUCIONAL DO CURSO DE PEDAGOGIA A DISTÂNCIA, DA UNIVERSIDADE DO ESTADO DE MINAS GERAIS}

Priscila Rondas Ramos Cordeiro Torres Fontes ${ }^{1}$, Andréia de Assis Ferreira²

Acesse a apresentação deste trabalho

Esta pesquisa propõe compreender a percepção dos estudantes acerca do desenho institucional do Curso de Pedagogia na modalidade a distância ofertado pela Universidade do Estado de Minas Gerais (UEMG) em parceria com a Universidade Aberta do Brasil (UAB). Serão analisados os dados obtidos da aplicação de um instrumento de avaliação da disciplina no Ambiente Virtual de Aprendizagem, respondidos pelos estudantes do curso pesquisado, turma 2014. Quatro dimensões nortearão o desenvolvimento desta análise: (1) relação dos estudantes com a equipe multidisciplinar (tutor virtual e presencial, professor conteudista, coordenação do curso); (2) perspectiva da relação dos estudantes com seu próprio aprendizado; (3) relação dos estudantes com seus colegas durante o curso; (4) infraestrutura física e recursos de apoio. A análise será realizada através do software SPSS (Pacote Estatístico para as Ciências Sociais). A partir do resultado, será elaborado e aplicado um novo instrumento de avaliação no formato de Survey aos estudantes, via Google Forms, do Curso de Licenciatura em Pedagogia EaD/UEMG/PBH, turma de 2019, objetivando diagnosticar de forma mais ampla a percepção dos alunos sobre as dimensões acima descritas. A partir dos resultados obtidos e análise, será retornado (como contribuição à instituição) à equipe formativa da UEMG, e um relatório contendo uma proposta de um instrumento avaliativo e de um relatório para a equipe multidisciplinar, com o objetivo de contribuir para a criação de uma cultura permanente de avaliação e planejamento institucional, no âmbito da modalidade de ensino a distância da instituição pesquisada. Espera-se contribuir com a melhoria do desenho institucional do curso, superação dos limites e ampliação das possibilidades focado em ferramentas e diretrizes para a implementação desta avaliação em todas as unidades da UEMG e, contribuir para a institucionalização, fortalecimento e promoção da expansão desta modalidade de ensino na Universidade.

Palavras-chave: Educação a Distância, Pedagogia, Desenho Institucional.

1 Mestranda do PROMESTRE/Faculdade de Educação/UFMG. E-mail: priscilarondas34@gmail.com

2 Orientadora. Professora convidada do PROMESTRE/Faculdade de Educação/UFMG e Profa do Centro Pedagógico da UFMG. E-mail: andreia.assis.ferreira@gmail.com 


\section{POSSIBILIDADES DE USO DA LOUSA DIGITAL INTERATIVA POR}

\section{PROFESSORES NA EDUCAÇÃO INFANTIL.}

Juliana de Almeida Fortunato, Antônio José Lopes Alves, Amanda Tolomelli Brescia

Acesse a apresentação deste trabalho

Estamos diante de uma infinidade de recursos tecnológicos que, além de ser fator modificante e estruturante na sociedade, redefinindo a forma de interação, comunicação e acesso às informações, trouxe desafios e benefícios alterando o dia a dia. A escola, parte integrante e importante para a sociedade, se vê impactada, pois, as mudanças afetaram diretamente nos processos de ensino e de aprendizagem escolar, reforçando a necessidade em lidar com as tecnologias na educação. Conseqüência disto, professores tem se deparado com a inserção de aparatos tecnológicos em sala de aula, estes vão desde televisão, computadores, projetores, tablets, Lousa Digital Interativa (LDI), etc. Sendo assim, esta pesquisa tem como objetivo, analisar como os recursos e as possibilidades de uso da LDI podem contribuir com a prática docente na educação infantil e agregar ao processo de ensino e aprendizagem do aluno; refletir sobre a formação continuada dos professores e a utilização das tecnologias digitais como instrumentos didáticos pedagógicos de apoio à educação; elaborar e executar um curso no ambiente virtual de aprendizagem (Moodle) proporcionando um momento de conhecimento teórico e prático e de compartilhamento de atividades; analisar o conteúdo gerado pelo curso identificando aspectos impulsores e restritivos quanto à utilização da LDI, na educação infantil e; organizar a partir do conteúdo do curso um e-book com sugestões de atividades para professores. A pesquisa será desenvolvida nas Unidades Municipais de Educação Infantil UMEIs, da região metropolitana de Belo Horizonte. A metodologia a ser operada será de uma pesquisa-ação com abordagem de cunho preponderantemente qualitativa, de caráter exploratório, contando com subsídios de natureza quantitativa. A coleta e a análise dos dados serão realizadas por meio de observações diretas, conteúdo do curso e aplicação de questionários.

Palavras-chave: Lousa Digital Interativa; Educação Infantil; Formação de Professores; Tecnologias Digitais. 


\section{A EDUCAÇÃO FÍSICA NO ENSINO MÉDIO: UMA REFLEXÃO SOBRE O CAMPO} PROFISSIONAL E A PRÁTICA PROFISSIONAL DOCENTE.

Francielen I. Ferreira1 ${ }^{1}$ Samuel de Souza Neto ${ }^{2}$

Acesse a apresentação deste trabalho

Este trabalho apresenta um relato de experiência como narrativa, tendo como proposta desenvolver uma reflexão crítica sobre um plano de aula (PA) de Educação Física (EF) - PAEF ministrado para o ensino médio (EM). Assim sendo levou-se em consideração: (a) o campo profissional da educação física; (b) a profissionalização do ensino; (c) os saberes docentes mobilizados na prática pedagógica; e, (d) a análise da prática profissional. Dessa forma, este trabalho teve como objetivos identificar e analisar os saberes mobilizados em um plano de aula. Para atingir esta finalidade se reconstrói a trajetória de construção desse plano de aula a partir dos valores, conhecimentos, crenças e processos de socialização que estão subjacentes a ele. Como metodologia escolheu-se o estudo auto etnográfico, a análise de prática e a análise de conteúdo. $\mathrm{Na}$ análise de prática, trabalhou-se com um plano de aula de EF para o $1^{\circ}$ ano do ensino médio do pesquisador, recorrendo para a análise as quatro ações de Smyth (1992): 1) Descrever - "o que eu faço?" (plano de aula); 2) Informar - "o que -significa isso? qual o significado das minhas ações?"; 3) Confrontar - "como me tornei assim? como cheguei a agir desta forma?"; e 4) Reconstruir - "como posso fazer diferente? como posso me transformar?". Resultados: a) o PAEF foi ministrado para o $1^{\circ}$ ano do EM, tendo como tema: modalidades esportivas - voleibol, organizando a aula em parte inicial - histórico, principal - fundamentos, e, final - relaxamento; b) na organização da aula a professora mobilizou "macetes", "esquemas" e base de conhecimentos da EF, provenientes dos saberes experiencias, mas também dos conhecimentos universitários; c) na reconstrução da aula, ela pode ser mais pedagógica e menos esportivista. Concluiu-se que trabalho permitiu uma reflexão crítica no processo de desconstrução e reconstrução da aula, contribuindo para ressignificar a sua prática já realizada.

Palavras-chave: Educação Física; Ensino Médio; Campo Profissional; Prática Profissional Docente.

1 Universidade Estadual Júlio de Mesquita Filho - campus Rio Claro/SP - Programa de PósGraduação em Ciências da Motricidade; francielen.ferreira01@etec.sp.gov.br.

2 Universidade Estadual Júlio de Mesquita Filho- campus Rio Claro/SP (Prof. Dr.); samuel.souzaneto@unesp.br. 


\title{
DESIGUALDADE SOCIAL EM ESPAÇOS EDUCACIONAIS NO CONTEXTO DA
}

\section{PANDEMIA DO COVID-19}

\author{
Francielle Gonçalves Teixeira¹, Lorrany Leal Siqueira², Giuliana Rapp Cinezi ${ }^{3}$
}

Acesse a apresentação deste trabalho

Devido ao contexto atual com o vírus Covid-19, mudanças tiveram que ser feitas, seja econômicas, comportamentais ou educacionais, a fim de garantir a segurança e saúde. Não há de se negar a desigualdade na educação está sendo bem evidente. Analisaram-se as notícias apresentadas na imprensa e a realidade de adaptação dos alunos, por meio de revisão bibliográfica. O período de adaptação a esse novo estilo escolar está sendo um caminho denso. A situação que preocupa instituições e os pais é a evasão escolar. Segundo a secretaria de educação do estado de São Paulo, aproximadamente metade dos alunos não estão acompanhando as aulas. As midia diz que as escolas passaram a adotar uma série de medidas para atender os alunos, tais como: plataformas online, videoaulas gravadas, materiais digitais, aulas multisseriadas, aulas via TV e tutoria pelas redes sociais, o que não é a realidade de todas, algumas estaduais enfrentam problemas para disponibilizar conteúdos aos alunos, ofertando orientações genéricas via redes sociais. Observa-se uma contradição do governo federal, pois foi decretado um protocolo de 200 dias letivos, segundo a comissão externa da câmera, cita que orçamentos para os meios de educação foram de baixa execução. O acesso à internet é um dos problemas que a mídia destaca, afirmando que muitos alunos não tem acesso nem ao saneamento básico, quanto mais acesso à internet, criando lacunas de diversas naturezas no processo de aprendizado. A imprensa divulga relato de pais solicitando a reabertura das escolas, estes que não observam o perigo que esta ação traz. Por mais promissoras que as novas tecnologias educacionais são, é necessário que se haja com cautela, com uma reposta e um planejamento pós-pandemia baseando-se naqueles que sofreram maior defasagem no processo de ensino-aprendizado, a fim de minimizar, ou reduzir ao máximo os desafios a eles impostos sem comprometer sua saúde e bem-estar.

Palavras-chave: desigualdade educacional, pandemia, dificuldades de alunos e professores.

\footnotetext{
1 Graduanda em Licenciatura em Ciências (Universidade Federal de São Paulo - UNIFESP). Email: franciellegdh@gmail.com

2 Graduanda em Licenciatura em Ciências (Universidade Federal de São Paulo - UNIFESP). Email: lorrany.siqueira@unifesp.br

3 Licenciada em Química (Centro Universitário Fundação Santo André-FSA). Mestranda do PECMA (UNIFESP-Diadema). Professora de Química do Centro de Estudos Júlio Verne. E-mail: giucinezi@gmail.com.
} 


\section{IDENTIDADE RENOVADA: GRANDES ALUNOS}

Francisco Edivan da SILVA ${ }^{1}$

Acesse a apresentação deste trabalho

A pedagogia e/ou andragogia é um dom humano com traços divinos, pois podem tornar qualquer individuo uma nova pessoa. Em minhas práticas docentes, já no primeiro encontro procuro decorar os nomes de todos os discentes. Todo aluno dentro da sala é chamado de Grande; fora dela, procuro incentivá-lo a usar uma identidade forte, capaz e autoconfiante. Meu método de ensino particular, versa sobre a autenticidade de criar uma marca exclusiva, sem jamais esquecer o conteúdo e o alvo, não se perde nada, tudo pode ser aplicado à jornada. Capaz de trazer cor ao mundo cinza da gestão e negócios, fomentador de perspectivas inovadoras, deixando marcas de excelência e paixão. Todos e quaisquer temas em quaisquer disciplinas, eu ministro sempre aliando teoria à prática, procuro conhecer o perfil, situação financeira, familiar, origem e outras informações do aluno; com essa extração, eu aplico e adapto as aulas à realidade do aluno. Assim reúno condições onde que eu possa tratar cada aluno como único, logo não ministro os temas ou conteúdo como algo em série e sim, de forma personificada, pois parto do pressuposto que cada aluno é único e tem sua própria identidade. Em matemática, planejamento estratégico, mercado financeiro e de capitais, controladoria e auditoria, contabilidade, dentre outras várias disciplinas, impreterivelmente eu aplico metodologias ativas com aulas invertidas e transmito ao aluno o poder de decisão e a forma que ele aplicará os conhecimentos, quer sejam através de mapa conceituais, seminários, encenação teatral, musical ou até mesmo professoral. Tudo isso em cumprimento fiel ao que preconiza o plano de ensino. Assim eu faço parceria com empresas locais para abrirem as portas, para que os alunos possam adentrar e fazerem pesquisas em tempo real a situação prática, apontando pontos de melhoria, onde o melhor retorno, é que, um percentual enorme desses alunos acaba sendo contratado pelas empresas onde o objeto de pesquisa melhorou os resultados das mesmas.

Palavras-chave: Identidade, grandes, personificada, autoconfiante, capaz.

1 Cornélio Rodrigues da Silva, UPIS Faculdades Integradas. Edivan.silva@gmail.com ISBN 978-65-88471-05-0 | https://doi.org/10.47247/VV/ENMD/88471.05.0 


\section{APRENDIZAGEM BASEADA EM PROJETOS NO ENSINO DE FÍSICA: ESTUDO BIBLIOGRÁFICO SOBRE O TEMA}

Gabriel Castiglioni Alves ${ }^{1}$

Acesse a apresentação deste trabalho

A discussão sobre metodologias ativas e sua aplicação é uma crescente no Brasil contemporâneo, principalmente na área do ensino de física, mais especificamente pela aprendizagem baseada em projetos. Verificando o recorte do ensino de física, foi realizado um estudo composto de uma revisão de literatura constituída pela pesquisa de artigos, coletados na base de dados Google Scholar, durante o período de 2008 a 2020. O objetivo concentrou-se em reunir informações, que conseguissem servir como um mapeamento das produções acadêmicas publicadas, facilitando os futuros estudos sobre o assunto. A metodologia utilizada foi a revisão bibliográfica de artigos que se basearam em metodologias ativas, visando verificar as abordagens mais utilizadas, além de uma análise quantitativa de artigos com o mesmo tema nessa base de dados. A quantidade total de artigos encontrados neste recorte foram 159 resultados nos 12 anos pesquisados. Também é possivel afirmar que a maioria dos artigos analisados obtiveram conclusões muito semelhantes, apontando que a aprendizagem baseada em projetos traz o aluno como protagonista, demonstrando que o uso das metodologias ativas para o ensino de física, é muito importante para a aprendizagem e que, a despeito do que o senso comum costuma apregoar, os estudantes não são tábuas em branco e os docentes não são os únicos detentores do conhecimento, e que devem ser os mediadores do processo de ensino e aprendizagem dos alunos. Os artigos analisados também revelam que a aprendizagem baseada em projetos, colabora para que os estudantes compreendam assuntos mais complexos de uma maneira mais fácil, e despertam a criatividade e o gosto pela ciência, respeitando a individualidade.

Palavras-chave: Metodologias ativas, Aprendizagem baseada em projetos, ensino de fisica 


\section{CIÊNCIAS NO ENSINO PÚBLICO: O ENSINO MÉDIO TE PREPAROU?}

Franciele Santos ${ }^{1}$, Gabriel Magalhães², Emanoelle Simeão ${ }^{3}$

Acesse a apresentação deste trabalho

Este relato tem como finalidade, demonstrar por meio da análise de uma pesquisa, feito pelos integrantes do grupo, a respeito de como ficaram os estudantes após o ensino médio em relação a falta dos professores de ciências (biologia, química, física e matemática) na rede pública, e se após o final do ensino médio, o aluno se sentiu preparado para prestar vestibulares. Nós como alunos do ensino público, vivenciamos muitas dificuldades no aprendizado, principalmente no ensino médio, pela falta de professores nas área de ciências e pela falta de recursos, dessa forma não atingindo o desempenho necessário para prestar os vestibulares, e consequentemente chegando despreparado nas universidades ou nem ao menos tendo acesso a ela. Sendo assim, a pesquisa feita a partir de um formulário no Google que teve respostas de 200 estudantes colocou em evidencia a problemática que acontece em muitas escolas públicas, o fato de muitos professores largarem suas matérias por meses e não serem substituídos, deixando assim alunos sem aulas, na pesquisa feita $22 \%$ dos alunos já ficaram um ano letivo inteiro sem aulas de ciências, e 24\% responderam que já ficaram mais de 3 meses sem aulas de ciências, mas não chegou ser todo o ano letivo. Esses dados são alarmantes, pois é muito conteúdo perdido onde os alunos acabam não possuindo acesso, o que resulta no seguinte dado: $84 \%$ dos alunos responderam que não se sentiram preparados no final do ensino médio para prestar vestibulares.

Palavras-chave: Professores, Ciência, Ensino Público

1 francielesantos12356887@gmail.com

2 manu.silverio122@gmail.com

3 gabrielmds2120@gmail.com

ISBN 978-65-88471-05-0 | https://doi.org/10.47247/VV/ENMD/88471.05.0 


\title{
EXPERIÊNCIA DOS RELATOS DE APRENDIZAGEM DURANTE O ENSINO REMOTO EM TEMPOS DE ISOLAMENTO FÍSICO
}

\author{
Gabriela Angelica Villarroel Costaํ, Tainã Brasil Pantarotto Pelat², Marilena Rosalen³
}

Acesse a apresentação deste trabalho

O ensino remoto foi adotado em grande escala em todo o mundo, sobretudo por instituições de ensino, devido à pandemia de COVID-19. Nesse contexto, as contradições da sociedade pós-moderna se acirraram evidenciando ainda mais as suas características, que colocam o educando e o educador frente a uma dificuldade: o espaço-tempo para fins de aprendizagem teve que ser ressignificado, trazendo a necessidade de refletir sobre concepções e práticas pedagógicas que se adequem ao ensino remoto. Os relatos de aprendizagem tornaram-se as estratégias avaliativas da Unidade Curricular "Didática", oferecida no curso de licenciatura em Ciências, da Universidade Federal de São Paulo UNIFESP. Para a construção deste estudo foram analisados relatos de aprendizagem da disciplina em tela, os quais foram produzidos a partir de uma bibliografia recomendada pela professora responsável pela U.C., que era o suporte teórico para os encontros síncronos entre estudantes, monitores e professora, com um diferencial: os encontros eram abertos, denominados "Jornada Pedagógica" - que abordou um tema de educação/didática por semana, com a participação de professores, mestres e doutores externos para contribuir com a discussão de cada tema. Assim, a estratégia dos encontros abertos, com leitura prévia, favoreceu a participação ativa dos estudantes nesses, bem como facilitou o desenvolvimento dos relatos semanais de aprendizagem. Tal ferramenta de avaliação visou o estímulo da postura ativa do educando para com a sua aprendizagem, para que assim ele protagonizasse a construção de seus saberes, fazendo uso de sua autonomia (FREIRE, 1996). Concluindo, foi possivel comprovar que os relatos de aprendizagem se constituíram uma alternativa satisfatória quando comparados com formas avaliativas meramente transmissivas, imbuindo criatividade aos educandos na ressignificação de seu espaço-tempo de aprendizagem.

Palavras-chave: Ensino remoto; Relatos de aprendizagem; Ensino-aprendizagem.

1 Licencianda de Ciências da Universidade Federal de São Paulo - UNIFESP. E-mail: angelica.costa@unifesp.br

2 Pedagoga pela Faculdade Diadema (2016), Mestranda na Universidade Federal de São Paulo UNIFESP. Professora de Educação Infantil na Prefeitura Municipal de São Paulo. E-mail: tai.bppelat@gmail.com

3 Profa. Dra. do Curso de Ciências - Licenciatura e do Mestrado de Ensino de Ciências e Matemática da UNIFESP. E-mail: marilena.rosalen@unifesp.br 


\section{CONCEPÇÕES E ARQUITETURAS DA EDUCAÇÃO REMOTA: OS PROCESSOS}

\section{PRODUTIVOS PARA A FORMAÇÃO DO CAPITAL INTELECTUAL EM PERÍODOS DE TRANSFORMAÇÃO}

Gabriela de Proença dos Santos, Débora de Lima Marreiro, Thiago Soares Valentim Grass Acesse a apresentação deste trabalho

O desenvolvimento da humanidade, através do seu conhecimento, habilidade e competência, em conjunto com outros fatores, vem contribuindo para a formação do capital intelectual, e esse processo, mais o período de transformações em que se vive, estão diretamente influenciando a Educação, impactando suas estruturas, seus processos e indubitavelmente, a sala de aula virtual. O conhecimento, incorporado através da autonomia discente, deve ser utilizado em beneficio dos processos produtivos, agregando e incorporando valor, porém, não como componente único, pois entende que o capital intelectual é a soma de diversos fatores. Objetivando explorar a valorização tangivel da modernização educacional, e seu recurso mais valioso, o capital intelectual humano, no contexto educacional, este trabalho abordou o currículo e o desenvolvimento das multimidias através da pesquisa de narrativa etnográfica, com a narração de docentes de ensino fundamental frente ao seu processo formativo e a inserção das metodologias tecnológicas em sua prática pedagógica

Palavras-chave: Capital Intelectual, Educação, Modernização, Multimídias. 


\section{OS SENTIDOS ATRIBUÍDOS POR UM LICENCIANDO DE MATEMÁTICA À}

\section{ATIVIDADE DE ESTÁGIO}

Giane Rodrigues ${ }^{1}$, Patricia R. Linardi ${ }^{2}$

Acesse a apresentação deste trabalho

Este trabalho teve como objetivo, discutir os sentidos atribuídos à atividade de Estágio por um licenciando de Matemática no decorrer da disciplina de Estágio Supervisionado II em Ciências e Matemática da UNIFESP. A análise da atividade de estágio do futuro professor foi alicerçada na perspectiva Histórico-Cultural, com ênfase na Teoria da Atividade, em que sentido é entendido como o modo como o sujeito se apropria de determinada significação (LEONTIEV, 1978). Significação, por sua vez, é entendida como a generalização do conceito. O estágio é a ação educativa escolar, desenvolvida no ambiente de trabalho, que visa a preparação do futuro professor para a sua atividade profissional. Os dados desta pesquisa de âmbito qualitativo foram produzidos pelo acompanhamento de um estudante de Matemática nas aulas da disciplina supramencionada, e principalmente aquelas realizadas na escola-campo. A análise dos dados nos permitiu observar indícios de sentidos e suas mudanças, pois são os motivos que geram sentidos. Assim, quando os motivos para a execução de determinada tarefa sofrem alterações, os sentidos mudam consequentemente. Os resultados mostraram que as experiências vivenciadas na atividade de estágio provocaram reflexão e mudanças dos motivos e sentidos pelo estagiário, isto é, os motivos iniciais - concebidos inicialmente como um processo burocrático obrigatório sofreram mudanças no decorrer da atividade - o estágio tornou-se uma atividade promotora de mediações e vivências que contribuíram para a sua formação docente - e, consequentemente houve a mutabilidade dos sentidos. Assim, interpretamos que as ações propostas e desenvolvidas por essa disciplina promoveram mudanças de motivos e sentidos e uma aproximação com os objetivos e significados relacionados ao estágio.

Palavras-chave: estágio na licenciatura, formação inicial de professores de matemática, sentido e significado.

1 Mestra em Ensino em Ciências e Matemática. UNIFESP. giane.rviana@gmail.com

2 Doutora em Educação Matemática. UNIFESP. patriciallinardi@gmail.com 


\section{EDUCAÇÃO AMBIENTAL E O ENSINO DE CIÊNCIAS: UMA PROPOSTA}

\section{DIDÁTICA SOBRE AMBIENTES MARINHOS E COSTEIROS}

Grace Victory Bueno da Costa Lima Alves; Simone Aves de Assis Martorano

$\underline{\text { Acesse a apresentação deste trabalho }}$

O ambiente marinho tem sofrido transformações e degradações que se mostram, em muitos casos, irreversivel. A maioria das ameaças à biodiversidade da zona costeira é um resultado direto da ocupação humana e expansão demográfica. Assim, conhecer e valorizar esse ambiente representa o inicio do processo de conservação, por isso, é necessária a criação de atividades que relacionam a educação ambiental com esses ecossistemas. Estas atividades não devem englobar apenas a população das cidades litorâneas, mas sim a população em geral, uma vez que, um conjunto de atitudes tomadas em escala local, pode ter uma influência em escala global. O presente trabalho visa contribuir na ampliação do conhecimento com enfoque na conservação do ambiente marinho e de sua biodiversidade. Para isso, será feito um embasamento teórico dos artigos do projeto Biota Araçá, executado por diversas instituições que realiza um amplo levantamento de informações sobre a importância e o funcionamento da Baía do Araçá. Também, ocorrerá a elaboração de uma sequência didática voltada aos alunos do ensino fundamental II, empregando a abordagem de ensino por investigação dentro do contexto de alfabetização científica, desviando assim, o foco do ensino de ciências na memorização de conceitos, privilegiando estratégias de como relacionar os conceitos científicos aprendidos de forma a contribuírem para a construção de uma visão consciente e crítica sobre o conhecimento cientifico.

Palavras-Chave: educação ambiental, sequência didática, alfabetização cientifica. 


\title{
PROJETOS DE VIDA NA JUVENTUDE: UM QUIZ PARA A ESCOLHA
}

\section{PROFISSIONAL COM UM NOVO OLHAR}

\author{
Hadassa Harumi Castelo Onisaki¹, Livia Delgado Leandro da Cruz², \\ Gláuci H Mora ${ }^{3}$, Elisabeth Fernandes de Sousa ${ }^{4}$
}

Acesse a apresentação deste trabalho

Apresentamos uma proposta para auxiliar alunos do ensino médio a refletirem sobre suas escolhas profissionais. A proposta caracteriza-se pela criação de um Quiz online ${ }^{5}$ que busca auxiliar os estudantes a pensarem de uma forma diferenciada sobre o universo de profissões, indo além das tradicionais, como medicina e engenharia, além de trazer uma nova maneira para desmistificar estereótipos sociais que se vinculam às profissões, tais como relacionados ao gênero, raça e classe. Para o desenvolvimento da proposta pautamo-nos em discussões relacionadas ao conceito de projeto de vida, tomando como principais referenciais teóricos os autores Damon (2009) e Bundick (2009). Para Damon, o conceito de projetos vitais pode ser compreendido como algo no sujeito que vai além de sua individualidade. $O$ autor defende que uma das funções mais importantes dos projetos vitais consiste no senso de direcionamento que promove na vida de uma pessoa. Nesse contexto, consideramos que a escolha profissional implica na consolidação e validação de um projeto de vida compreendidos a partir de uma construção, fruto de escolhas pautadas em valores e que representam uma orientação ao sujeito. Uma série de dificuldades são enfrentadas pelos jovens no momento da escolha profissional, como a pressão psicológica dos familiares. Essas escolhas levam em consideração apenas aspectos cognitivos, porém há outros que podem ser explorados. Assim, elaboramos um quiz para que os jovens explorem suas escolhas pautado nos cinco sentidos do corpo humano. A partir da relação dos sentidos há uma série de profissões, como audição/música, tato/acupuntura, visão/fotografia, olfato/biologia e paladar/gastronomia. O Quiz foi proposto com o intuito de criar uma ferramenta que pudesse despertar o interesse dos jovens de uma forma lúdica, reflexiva e pautada em habilidades corporais, ou seja, para além da cognição e pressões dos valores sociais hegemônicos.

Palavras-chave: Projetos de vida. Juventude. Escolha profissional. Educação. Equidade.

\footnotetext{
1 Mestranda pelo Programa de Pós-graduação da Faculdade de Educação da Universidade de São Paulo (FE-USP). hadassaonisaki@usp.br

2 Mestra em Filosofia pelo Programa de Pós-graduação em Estudos Culturais da Escola de Artes, Ciências e Humanidades da Universidade de São Paulo (EACH-USP). livia.delgado.cruz@usp.br 3 Mestre em Psicologia e Educação - Universidade de São Paulo, Orientadora Educacional e Professora Universitária. glamora@terra.com.br

4 Mestranda pelo Programa de Pós-graduação da Faculdade de Educação da Universidade de São Paulo (FE-USP). elisabethfernandesdesousa@gmail.com

5 Link de acesso ao Quiz: https://qz.app.do/projeto-de-vida
}

ISBN 978-65-88471-05-0 | https://doi.org/10.47247/VV/ENMD/88471.05.0 


\title{
USO DE MULTIMÍDIA E TECNOLOGIAS DE INFORMAÇÃO E COMUNICAÇÃO
}

\section{EM DISCIPLINAS OFERTADAS NA MODALIDADE A DISTÂNCIA EM CURSOS}

\section{DE ENGENHARIA}

\author{
Ludmila Rosalem Borges ${ }^{1}$, Harerton Oliveira Dourado ${ }^{2}$, \\ Adriana Recla Sarcinelli ${ }^{3}$, Marcos Roberto Teixeira Halasz ${ }^{4}$ \\ Acesse a apresentação deste trabalho
}

As Faculdades Integradas de Aracruz (FAACZ) passaram a oferecer disciplinas na modalidade a distância em seus cursos presenciais em 2017, inclusive para os cursos de engenharia. Em 2018, a FAACZ investiu em infraestrutura para a produção de conteúdo em vídeo. Sabe-se que o uso das tecnologias de informação e comunicação (TICs) podem ser facilitadoras do processo de ensino e aprendizagem. Dessa forma, o presente trabalho investigou como o uso de material multimídia (áudio e vídeo) em disciplinas ofertadas em cursos de engenharia na FAACZ contribuiu para o resultado das turmas, através de dois experimentos. No experimento 1, foi avaliado o desempenho de dois grupos de alunos do curso de engenharia civil que assistiram à mesma aula, sendo um grupo presencialmente e outro através de um vídeo gravado pela professora. Após à aula os alunos foram submetidos à mesma atividade e os resultados foram comparados. $\mathrm{O}$ experimento 2 consistiu na análise $e$ comparação dos de duas turmas distintas que cursaram a disciplina estatística no semestre 2019/1, uma turma na modalidade presencial e a outra turma na modalidade a distância (EAD). A disciplina EAD utilizou recursos de TIC como vídeos e textos através do ambiente virtual de aprendizagem. A análise estatística dos resultados do experimento 1 apontou que não houve diferença significativa entre as médias de cada grupo $(p=0,08)$, o que permite afirmar que as ambas as modalidades empregadas possibilitam alcançar os mesmos resultados. Para o experimento 2 , as médias das turmas foram estatisticamente semelhantes $(p=$ $0,587)$. Os resultados permitem afirmar que o uso de material multimídia em disciplinas ofertadas na modalidade a distância para alunos de cursos de engenharia da FAACZ não afeta de maneira prejudicial o resultado turmas, sendo o padrão de qualidade dos cursos.

Palavras-chave: multimídia, EAD, engenharias.

1 Engenheira mecânica, ex-aluna do curso de engenharia mecânica da FAACZ, ludmila_rosalem@hotmail.com

2 Professor e coordenador dos cursos de engenharia da FAACZ, harerton@fsjb.edu.br

3 Professora e diretora acadêmica da FAACZ, arecla@fsjb.edu.br

4 Professor e coordenador de ensino da FAACZ, halasz@fsjb.edu.br 


\section{A ANÁLISE DE PRÁTICA NO CAMPO DA EDUCAÇ̧̃̃O FÍSICA ESCOLAR}

\section{Heitor Perrud Tardin ${ }^{1}$}

\section{Acesse a apresentação deste trabalho}

Tornar-se professor é um processo contínuo que perpassa ciclos de vida na incorporação de uma cultura e identidade profissional. Ele envolve processos de socialização e de desenvolvimento pessoal e desenvolvimento profissional. Assim sendo, este estudo teve como objetivo compreender a prática de um professor iniciante, tomando como objeto o seu plano de aula. Especificamente buscou-se identificar e analisar no plano de aula, a trajetória pedagógica de construção dessa aula, a sua fundamentação epistemológica e seus desafios. Opta-se por um estudo exploratório de perspectiva auto etnográfica em que as representações (crenças) são postas em discussão a partir de um exercício simples de análise de um plano de aula. Esse plano de aula passa a ser dissecado, tomando como referência as quatro ações reflexivas de Smyth (1994): descrever, informar, confrontar e reconstruir. Enfim, o que se faz é um exercício de autorreflexão de práticas e de reconstituição dos fundamentos (saberes) que movem as nossas ações em cada etapa de uma aula que mapeiam um plano de aula. Dessa forma, o plano de aula torna-se um documento cuja análise curricular envolve também uma análise de conteúdo. Como resultados do descrever foi apresentado um plano de aula relacionado a aprendizagem de um esporte tipificado em três momentos: introdução, desenvolvimento e conclusão. No informar observou-se a apropriação de um esporte não convencional no Brasil e o desejo de sair do tradicionalismo do ensino de esportes. Porém, no confrontar-se chegou-se no âmbito da fundamentação que perpassa o ensino daquele esporte, estando ancorada numa visão esportivista e comportamental. No reconstruir, como posso fazer diferente, foi apresentado a compreensão de que a análise da prática permitiu identificar concepções que foram sendo incorporadas em processos de socialização. Assim sendo, uma saida passou a ser dar mais autonomia para o estudante, elaborando planos de aula em que ele possa ter tomadas de decisões.

Palavras-chave: Análise de Práticas. Formação Profissional. Educação Física Escolar

1 Universidade Estadual Júlio de Mesquita Filho - campus Presidente Prudente; heitor21perrud@gmail.com 


\section{O IMPACTO DA MUDANÇA: DO ENSINO PRESENCIAL PARA O ENSINO A}

\section{DISTÂNCIA}

Henrique Vinicius Goes Gonçalves

Acesse a apresentação deste trabalho

No mundo contemporâneo todos são colocados frente a adversidades constantemente, essas são importantes no desenvolvimento do indivíduo, o forçando a amadurecer e lidar com esses obstáculos que a realidade o propõe de forma frequente. É comum que essas questões sejam enfrentadas e resolvidas, entretanto, por muitas vezes o processo pode ser mais doloroso e exigir mais esforços do que aparenta. Um bom exemplo é a questão do ensino a distância. Em teoria as únicas diferenças são o ambiente e o meio pelos quais o conteúdo será consumido, mas a realidade não é tão simplista assim. Ao refletir e analisar o meu caso, enxergo que: mesmo sendo de família de classe média baixa, tendo um notebook razoável e uma internet boa, existem diversos obstáculos que surgem nesse processo. Transiciono diariamente do meu ambiente de trabalho para o de estudo, a faculdade - por ora em casa -, e o que costumava ser um hábito rotineiro tornou-se uma prática difícil de se exercer. Não possuo um ambiente apto aos estudos em casa, então me coloco a estudar na mesa da cozinha, onde, por mais que eu peça colaboração de meus familiares, todos passam por ali, ainda mais no horário de jantar, seja para comer ou para preparar a comida, fazendo barulhos que desconcentram e atrapalham o andamento da aula. As possibilidades que o computador oferece também vêm para testar a minha concentração, redes sociais, notificações de e-mail, jogos e tudo mais que a máquina costumava me oferecer em meu tempo vago, e que continuam lá. O cansaço somado ao conforto do lar não são combinações produtivas, o ambiente apto a descanso, ainda mais para os usuários de aparelhos que não sejam de desktop, pois podem usar deles sem que estejam em uma mesa, seja num sofá ou na própria cama, tornando dificil diferenciar o momento de estudo ou folga. As barreiras vão muito além de possuir ou não acesso à internet, a mais dificil de se vencer é a da mente e, nos tempos de quarentena, todos a enfrentamos e cada vez mais sozinhos.

Palavras-chave: EAD, faculdade, internet, barreiras, mente. 


\title{
LEVANTAMENTO INICIAL SOBRE A RELAÇÃO ENTRE CIÊNCIAS DA
}

\author{
NATUREZA E OS ALUNOS DE UMA ESCOLA DA REGIÃO NORTE DA
}

AMAZÔNIA

Isabela Nogueira1 ${ }^{1}$ Breno Carvalho², Eduardo Souza ${ }^{3}$,

Luiz Eduardo ${ }^{4}$, Maria Monteiro ${ }^{5}$, Maria Aparecida ${ }^{6}$

Acesse a apresentação deste trabalho

Acreditando que para ocorrer uma aprendizagem significativa é essencial a participação ativa dos alunos no processo de ensino-aprendizagem, aplicamos um questionário diagnóstico para sondar como estes se relacionam com as disciplinas da área de Ciências da Natureza. Para responder o questionário, por sorteio, foram selecionados quinze discentes de três diferentes turmas $(n=45)$ do terceiro ano do ensino médio de uma escola estadual do município de Boa Vista, RR. Este era composto por doze questões, sendo três questões de múltipla escolha e nove questões de associação onde deveriam concordar ou discordar com as afirmativas propostas. As respostas anônimas foram analisadas pelos bolsistas do PIBID da UFRR. No total, 45 questionários foram analisados neste estudo. Perguntados sobre o interesse em seguir carreira na área de ciências da natureza, 26 alunos demonstraram interesse, mas apenas 4 manifestaram interesse na docência. Sobre a dificuldade em aprender os conteúdos de biologia, 23 alunos atribuíram isto ao excesso de conteúdos. Contudo o excesso de termos científicos não foi frequentemente citado como motivo para atrapalhar o aprendizado. A importância em aprender biologia foi associada ao despertar de uma consciência ambiental. Porém ao relacionar a aplicação prática dos conteúdos de biologia no dia a dia, não foram observados associações com conservação da biodiversidade ou meio ambiente. Os temas mais recorrentes foram tipos sanguíneos, relações de parentesco e saúde pública. Ao fazê-los refletir sobre como contribuir para um melhor aproveitamento dos conteúdos, majoritariamente a resposta dada foi interagir ativamente com o professor. Sendo assim, estes dados corroboram o que é afirmado em literatura sobre a relação da aprendizagem significativa com a participação ativa dos alunos no processo de construção do conhecimento, reforçando ainda a importância de pensar estratégias de ensino que aproximem os conteúdos didáticos e a atuação dos alunos na sociedade.

Palavras-chave: Aprendizagem significativa. Biologia. Ensino médio.

1 Graduação em Ciências Biológicas Licenciatura (UFRR).nbs.isabela@gmail.com

2 Graduação em Ciências Biológicas Licenciatura (UFRR).

3 Graduação em Ciências Biológicas Licenciatura (UFRR).

${ }^{4}$ Mestrado no Programa de Poś-Graduação em Recursos Naturais (UFRR).

5 Graduação em Ciências Biológicas Licenciatura (UFRR).

6 Doutorado no Programa de Pós-Graduação em Educação em Ciências e Matemática (UFPA). 
RELATO DE EXPERIÊNCIA DO USO DE ATIVIDADES PRÁTICAS NO ENSINO DE CIÊNCIAS: PIBID EM AÇÃO

\author{
Isabela Nogueira1 , Breno Carvalho², Eduardo Souza³, \\ Luiz Eduardo, ${ }^{4}$ Maria Monteiro5 ${ }^{5}$, Maria Aparecida ${ }^{6}$
}

Acesse a apresentação deste trabalho

O campo de Ciências da Natureza compreende muitos aspectos ilustrativos sobre seus conteúdos. Porém o método amplamente utilizado para o ensino desta área ainda são aulas expositivas que limitam a participação dos discentes. É importante ressaltar que o uso de atividades práticas não serve apenas para ilustrar, motivar e tirar o aluno de uma "aula monótona": as atividades práticas também propiciam ao aluno a oportunidade de investigar situações, aplicar e expandir seu conhecimento. A partir das atividades práticas desenvolvidas pelos bolsistas do Programa de Iniciação à Docência da Universidade Federal de Roraima em uma escola estadual da rede pública do município de Boa Vista, RR foram observadas mudanças no comportamento dos alunos. Estes se mostravam cada vez mais interessados pela disciplina de biologia e nos conteúdos em que a prática era utilizada como recurso didático. E mesmo em atividades paralelas onde o foco não eram atividades práticas, à exemplo respostas obtidas no questionário diagnóstico que buscava analisar a relação dos discentes com a disciplina de biologia, os alunos manifestaram interesse em ter mais aulas práticas com experimentos e recursos que permitissem a visualização de estruturas biológicas. A vivência com atividades práticas se tornou tão parte do cotidiano de estudos destes alunos que nas apresentações elaboradas por eles nas feiras de conhecimento, eles solicitavam que as atividades práticas fossem utilizadas como recurso para apresentação do conteúdo. Com base nos resultados deste estudo de observação fica recomendado a utilização de atividades práticas como importante recurso para fomentar a participação dos alunos em sala de aula e o interesse em outras atividades relacionadas a área de biologia visando que o aluno participe de forma ativa de seu aprendizado mediante atividades de experimentação, estímulo à dúvida, capacidade de solucionar problemas e ter desenvolvimento de raciocínio.

Palavras-chave: Atividades práticas. Biologia. Ensino médio.

1 Graduação em Ciências Biológicas Licenciatura (UFRR).nbs.isabela@gmail.com

2 Graduação em Ciências Biológicas Licenciatura (UFRR).

3 Graduação em Ciências Biológicas Licenciatura (UFRR).

4 Mestrado no Programa de Poś-Graduação em Recursos Naturais (UFRR).

5 Graduação em Ciências Biológicas Licenciatura (UFRR).

6 Doutorado no Programa de Pós-Graduação em Educação em Ciências e Matemática (UFPA). 


\section{A PALEONTOLOGIA BRASILEIRA: DIVULGADA PELA UNIFESP EM DIADEMA}

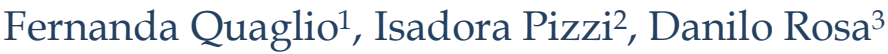

A Paleontologia é um ramo científico que integra Biologia, Geologia, Química, Geografia, e tantas outras áreas que compõem as Ciências da Vida e da Terra, as quais colaboram ara o entendimento de como a configuração das formas de vida no planeta foi alterada pelas dinâmicas ambientais em escala de tempo geológico. É, portanto, uma área interdisciplinar de grande interesse pedagógico para ser tratada como tema transversal no Ensino Básico e como tema geral pela comunidade não-acadêmica. A despeito disso, o público em geral desconhece que o território brasileiro preserva jazigos fossilíferos de grande importância científica mundial. Este projeto buscou desenvolver atividades práticas (aulas em laboratório e de campo) e de extensão (atividades com alunos dos ensinos Fundamental e Médio) e alcançou mais de 300 alunos, tanto estudantes de graduação dos cursos de Ciências Ambientais e Ciências Biológicas da UNIFESP, como estudantes de uma ONG e de escola do Ensino Básico de Diadema. Cada grupo de 4-7 alunos da unidade curricular Paleontologia das turmas de Ciências Ambientais e Ciências Biológicas da UNIFESP, campus Diadema, desenvolveu um tópico da temática de "Fósseis do Brasil" para alunos de 11-13 anos da ONG, e contou com material de apoio da Coleção de Paleontologia ligada ao PET-Biologia e da Coleção de Referências do Laboratório UNIFESP de Paleontologia de Invertebrados - LUPI, tanto fósseis como réplicas. As atividades que mais obtiveram sucesso de atenção e permanência dos alunos da ONG estão sendo selecionadas e re-editadas em português, inglês e espanhol, para resultarem em um repositório virtual de atividades propostas para serem utilizadas por escolas ou outras entidades de interesse no Brasil e no mundo. Também coloca a UNIFESP em um importante papel no desenvolvimento de projetos de extensão para o desenvolvimento de habilidades pedagógicas dos alunos universitários, e também contribui para o acesso à informação pela comunidade de Diadema.

Palavras-chave: Educação Científica; Divulgação Científica; Extensão em Paleontologia; fósseis.

1 Departamento de Ecologia e Biologia Evolutiva. UNIFESP, campus Diadema. quaglio@unifesp.br

2 Curso de Ciências Biológicas. UNIFESP, campus Diadema. isadora.pizzi@unifesp.br

3 Curso de Ciências Ambientais. UNIFESP, campus Diadema. danlopesro@outlook.com 


\title{
REFLEXÃO SOBRE AVALIAÇÃO NA EDUCAÇÃO DE JOVENS E ADULTOS
}

\author{
Izaura Naomi Yoshioka Martins ${ }^{1}$
}

$\underline{\text { Acesse a apresentação deste trabalho }}$

Quando tratamos de Educação de Jovens e Adultos, referimo-nos a um público que sofreu, de alguma forma, negação ao direito à educação. Então quando um jovem, adulto ou idoso procura a escola traz sempre uma esperança na superação dessa situação e Paulo Freire (2011) nos ensina que a transformação é possivel. A partir desse pensamento de Freire, muitos currículos desenharam-se na perspectiva de melhor atender o educando de EJA, com a preocupação do acesso, da permanência e do sucesso escolar desses sujeitos. Porém, há um número considerável de educandos que não conseguem concluir o estudo, sendo avaliado insatisfatoriamente. Nesse sentido, o presente projeto pretende realizar um estudo com foco nesse problema. As hipóteses passam pela forma conteudista de avaliação, que apesar de desenvolvimento de projetos considerando os saberes e a caracterização do sujeito, há justificativa dos professores de que devem preparar os educandos para darem continuidade aos estudos; os educandos desistem porque não aceitam esse novo formato dialógico, diferente das cópias, entre outros. O estudo baseado apenas nessas hipóteses trariam apenas constatações, que pouco contribuiria para superar essa situação referente à avaliação na EJA; dessa forma, a proposta é avançar para o estudo de uma ação realizada em diálogo com os professores, numa perspectiva de pesquisa-ação participante. A expectativa dessa ação é tentar construir caminhos para uma avaliação que, como na própria etimologia da palavra valora, valoriza o educando, o seu saber e considera as suas expectativas, os anseios e as situações limite (FREIRE, 2011), a partir de um projeto de trabalho dialógico entre educador e educando, para a sua transformação, para a sua emancipação. O argumento maior da relevância desse projeto está pautado na defesa do direito ao sucesso escolar dos educandos de EJA, que não poderão nessa segunda passagem pelos bancos escolares (ou primeira), sofrerem novamente outra negação.

Palavras-chave: Educação de Jovens e Adultos; Avaliação; Avaliação emancipatória. 


\section{LUGAR DE FEMINISMO É NA ESCOLA: O DESAFIO DE ROMPER A AUSÊNCIA}

\section{DO DEBATE SOBRE A VIOLÊNCIA À MULHER}

Jacimar Rocha de Oliveira ${ }^{1}$

Acesse a apresentação deste trabalho

Segundo o Mapa da Violência 2015, o Brasil é o $5^{\circ}$ país no mundo a assassinar mulheres, com 13 feminicídios diários. Diante desses números, urge discutir esse tema; e a escola, espaço de poder por construir conhecimento, é um ambiente estratégico, rumo a dados decrescentes. No entanto, a temática segue sendo invisibilizada; rompamos esse silêncio feminicida! No colégio estadual em que leciono, temos o projeto de iniciação científica. Utilizando o protagonismo estudantil, os estudantes partem de pesquisas para fomentarmos discussões e elaboramos ações diversas, inclusive intervenções artísticas, que mobilizem a escola e a comunidade, já que o conhecimento precisa atravessar os muros da escola para modificar a sociedade. Sempre intentei capacitar, minimamente, estudantes para multiplicar as vozes que lutam pela não violência. Em 2017, abordamos questões basilares acerca dessa temática; fiz um documentário, obtivemos relatos entristecedores. Prossegui com o tema em 2018; houve um número maior dessas desoladoras narrativas. Constatei, empiricamente, que o silêncio é uma cruel realidade - protege o agressor e segue violentando as vítimas. Discutimos o quão necessário é o tratamento pós-traumático, e sobre a tecnologia aliada no socorro às mulheres. Mostramos as possibilidades de socorro gratuitas e apresentamos casas de acolhimento às vítimas, aplicativos, ONGs, coletivos etc. Em 2019, as explanações de violências seguiram e discutimos sobre a masculinidade tóxica e as relações abusivas. Resultado surpreendente! Entre os frutos colhidos, fundamos o coletivo feminista Marielles Vivas, que visa levar esse debate a outras escolas. Cada vez mais sou procurada até por estudantes que não são das minhas turmas para conversas, denotando a urgência da abordagem. Seguimos combativas "até que todas sejamos livres" (frase nossa), pois se faz mister construir caminhos que atenuem o futuro, vislumbrado, ainda hoje, com a perpetuação das dores das vítimas, reverberando na sociedade.

Palavras-chave: Violência; violência à mulher; escola. 


\section{O ENSINO DA CARTOGRAFIA NA RESIDÊNCIA PEDAGÓGICA: RELATO DE}

\section{ATIVIDADES DESENVOLVIDAS NA E.E. M PROFESSOR LUÍS FELIPE EM SOBRAL-CE}

Janaiára Maria de Paiva Ferreira1, Analine Maria Martins Parente²

Acesse a apresentação deste trabalho

O presente trabalho tem o objetivo de relatar as experiências das regências desenvolvidas na E.E.M. Professor Luís Felipe no Programa Residência Pedagógica contribuindo com o Projeto ENEM. O projeto supracitado foi elaborado com o intuito de atender a demanda dos conteúdos de Geografia mais presentes no Exame Nacional do Ensino Médio- ENEM. O conteúdo abordado foi Cartografia situado no eixo da Geografia Física e direcionado as turmas de Geografia dos $3^{\circ}$ Anos do Ensino Médio. Ao iniciar as atividades percebeu-se o distanciamento do conteúdo proposto e a grande dificuldade dos alunos em compreender os pontos apresentados, muitos discentes não sabiam o básico dos sistemas de orientação, mapas, escalas, coordenadas geográficas e projeções cartográficas. Após o término da primeira regência, por meio do diálogo com os discentes, ao serem questionados sobre o nivel de conhecimento em relação ao conteúdo, eles relataram suas fragilidades e em virtude disso tornou-se necessário adaptar o conteúdo de acordo a realidade. Desse modo, foi necessário mudar a metodologia utilizada na aula, uma das estratégias foi o uso de cartazes, imagens impressas e vídeos, objetos que representassem a terra, por meio do uso desses recursos percebeu-se uma melhoria nos resultados observados nas atividades propostas, haja vista uma maior participação dos alunos durante as regências. O projeto-ENEM foi uma maneira didática de abordar os conteúdos mais cobrados pelo exame nacional e, possibilitou vivenciar de perto os desafios da docência e que necessidade de repensar as práticas educativas deve ser um exercício constante do trabalho do professor. Contudo a Residência Pedagógica oportunizou grandes momentos de aprendizagem, permitindo a superação de alguns anseios e na desconstrução de uma aula "perfeita". Ademais, que o conhecimento é um ato coletivo que não pode ser pautado na transmissão de saberes.

Palavras-chave: Ensino de cartografia; Projeto ENEM; Residência Pedagógica.

1 Universidade Estadual Vale do Acaraú-UVA. janageo2013@gmail.com

2 Universidade Estadual Vale do Acaraú- UVA. analine.p@hotmail.com 


\title{
O DESAFIO DA VIOLÊNCIA ESCOLAR NA PRÁTICA DOCENTE
}

\author{
Jenifer Viana Machadoํ, Marilena Rosalen²,
}

Acesse a apresentação deste trabalho

A prática docente é cheia de desafios e cada dia representa uma nova experiência, pois cada sala de aula é única e cada estudante é único. Não existe monotonia. Dentre os desafios, nesse trabalho, evidenciamos a violência escolar. Dependendo das condições sócio-econômicas do entorno da escola, o professor pode receber ameaças, ser vítima de violência corporal e verbal e presenciar tráfico de entorpecentes, que podem dificultar o processo de ensino e aprendizagem, ou seja, a situação afeta tanto os estudantes como o professor, que pode se sentir incapaz de ministrar as aulas e pode ter problema com a sua saúde mental (GOMES; PEREIRA, 2009). As escolas, principalmente as públicas, vulneráveis a estas condições, geralmente contam com falta de estruturas adequadas para o ensino, dificultando ainda mais o que já não estava fácil de ser feito. A postura dos estudantes vistos como mais rebeldes, pode ter suas raízes dentro do núcleo familiar. Eles podem vir de uma família onde a violência e o desrespeito sejam a rotina deles, não sendo este um fator justificativo para os atos, mas podendo ser um fator de reflexo do que é vivido dentro de suas casas. Quando o professor se depara com alguém assim, ele não lida apenas com o estudante sendo estudante, mas sim com toda a história que tem por trás dele. De fato, nada justifica todos os problemas enfrentados pelo professor quanto a sua realidade de violência dentro da sala de aula em algumas escolas. A gestão escolar, o núcleo familiar e o próprio professor devem caminhar sempre no mesmo ritmo e entrelaçados, para construir uma politica anti-violência escolar, ajudando os estudantes "rebeldes" a superarem suas dificuldades e não extrapolarem a raiva na escola, ao mesmo tempo que buscam alternativas que viabilizem melhores condições de trabalho aos professores, sem que seja necessário passar por situações as quais podem traumatizar e violar o professor enquanto ser humano e dificultar o seu trabalho enquanto profissional.

Palavras-chave: violência escolar; prática docente; desafio escolar.

1 Licencianda em Ciências na Universidade Federal de São Paulo (UNIFESP). E-mail: viana.machado@unifesp.br

2 Profa. Dra. do Curso de Ciências e do Programa de Mestrado em Ensino de Ciências e Matemática (PECMA) da UNIFESP. E-mail: marilena.rosalen@unifesp.br

ISBN 978-65-88471-05-0 | https://doi.org/10.47247/VV/ENMD/88471.05.0 


\section{UTILIZAÇÃO DE SITES E JOGOS PARA A ANÁLISE DA PREVISÃO DO TEMPO}

Jennifer Rafaela Serafim Ferezin ${ }^{1}$

Acesse a apresentação deste trabalho

Este relato apresenta atividades utilizando a tecnologia através de sites e da alfabetização científica com uma turma de educação infantil de 4 a 5 anos. A relevância desta atividade está pautada nos estudos de (ALMEIDA e FACHÍNTERÁN, 2015; MORAES, 2015) que demonstram as potencialidades da infância e como a alfabetização cientifica proporciona a construção crítica e reflexiva do pensamento e das aprendizagens. A proposta refere-se à observação da previsão do tempo através de sites específicos, além de explorar outros temas, como, a chuva através de jogos grátis. O desenvolvimento ocorreu com a construção das hipóteses de pesquisa em sala de aula, identificação das perguntas norteadoras do projeto e a organização das situações de aprendizagens através de listas, desenhos, pesquisas e rodas de conversas. O grupo demonstrou interesse em acompanhar a previsão do tempo, assim, observações diárias do clima, relatos, registros, desenhos e falas de cada um foram compondo a documentação da pesquisa, logo, é necessário aprofundar os conhecimentos, refletir sobre as observações e utilizar novas estratégias de aprendizagem, como a utilização de sites da previsão do tempo. A atividade ocorreu no "espaço conexão", sendo essa, uma sala composta por computadores com acesso à internet. Contamos com o apoio da orientadora de atividades que atua nesta sala e de seus alunos que participam de cursos direcionados a utilização da tecnologia. Os alunos contribuíram na identificação dos sites, leitura de informações sobre a previsão do tempo, bem como, na utilização dos jogos grátis sobre o mesmo tema. Ao final da proposta, foi possivel observar o interesse e relatos das crianças que demonstraram diariamente mais atenção as mudanças climáticas, buscam informações em outros suportes, compartilham com as famílias e constroem coletivamente um envolvimento com o ensino cientifico. A reflexão envolve o desenvolvimento de cada um e a inserção de bases teóricas desde o ensino infantil.

Palavras-chave: educação infantil; pesquisa; ciências.

1 Professora na Prefeitura Municipal de Foz do Iguaçu - PR, Docente do Curso de Pedagogia no Centro Universitário UNIAMÉRICA e aluna especial do Programa de Pós-Graduação em Ensino Mestrado pela Universidade Estadual do Oeste do Paraná - UNIOESTE. E-mail: jenniferferezin@gmail.com 


\title{
CLUBE DE OBSERVADORES DA NATUREZA: UMA INTRODUÇÃO AO MÉTODO CIENTÍFICO ATRAVÉS DA PRÁTICA DA OBSERVAÇÃO DE NATUREZA
}

\author{
João Pedro Z. de Andrade1, Camila Reis dos Santos², Leonardo Prest Merçon², \\ Cristina Zampa Sanchêz ${ }^{4}$, Viviana Borges Corte ${ }^{5}$
}

Acesse a apresentação deste trabalho

As novas tendências da era digital globalizada trouxeram grandes avanços no acesso a informação e assim tornou o ambiente virtual mais interessante para as crianças do que passeios ao ar livre, mudando a infância para dentro de casa e tendo as crianças cada vez mais desconectadas da natureza. Neste sentido o ensino de ciências e a educação ambiental se torna fundamental para reaproximar os indivíduos do ambiente natural ao mesmo tempo que apresenta uma forma mais prática de aprendizado sobre temas com a biodiversidade, estudo da fauna, ecologia, cadeia alimentar, relações naturais e etc. O estudo foi realizado nas turmas de ensino fundamental 2 de uma escola pública na cidade de Serra, no Espirito Santo onde foi apresentada a pratica da "Observação de Natureza" como estratégia de educação científica, usando como ferramenta as redes sociais, fotografia e trilhas ao ar livre para atrair os alunos a fazerem parte das atividades. Através de uma metodologia separada em momentos pedagógicos os alunos ao longo de 6 meses puderam aprender sobre a biodiversidade regional, participarem de atividades práticas ao ar livre, onde eles se tornaram protagonistas do próprio aprendizado com intermédio dos professores e educadores, e ao final puderam produzir contribuições cientificas para internet e compartilhar seu aprendizado através da plataforma Biofaces. Sendo assim o projeto de educação ambiental se mostrou como uma alternativa interessante no reforço do conteúdo aprendido em sala de aula, na re-conexão do aluno com o meio ambiente e na introdução do método científico gerando assim um incentivo a realização da ciência cidadã pelos alunos em suas comunidades.

Palavras-chave: Observação da Natureza. Intervenção Pedagógica. Momentos pedagógicos. Prática investigativa.

1 Centro Universitário FAESA. Vitória, ES - Email: joaopedrozanardo@gmail.com

2 Universidade Federal do Espírito Santo. Vitória, ES - Email: camiletsreis@yahoo.com.br

3 Instituto Últimos Refúgios. Vitória, ES - Email: leonardomercon@gmail.com

4 Escola Serrana. Serra, ES - Email: cris.zampa38@gmail.com

5 Universidade Federal do Espírito Santo. Vitória, ES - Email: viviana.borges@gmail.com ISBN 978-65-88471-05-0 | https://doi.org/10.47247/VV/ENMD/88471.05.0 


\section{ATENDIMENTOS INDIVIDUAIS: FORTALECIMENTO DE VÍNCULOS E}

AVANÇOS PEDAGÓGICOS

Lorena Mello', Juliana Silveira Ribeiro ${ }^{2}$

Acesse a apresentação deste trabalho

O ensino remoto para alunos e alunas dos anos iniciais do Ensino Fundamental traz uma série de desafios. O acompanhamento próximo das crianças talvez seja um dos maiores. Após analisarmos as primeiras evidências de aprendizagem, percebemos que alguns estudantes precisavam de um olhar mais individualizado e cuidadoso. Levando essa necessidade em consideração, com apoio e orientação da coordenação pedagógica e da coordenação da área de Língua Portuguesa, fizemos uma parceria. Lorena, assistente de classe, teve encontros semanais com duas alunas que demonstravam mais fragilidades pedagógicas. O planejamento das atividades a serem trabalhadas era realizado de forma colaborativa: Lorena, Juliana (professora responsável pela disciplina de Língua Portuguesa) e coordenação. Os encontros eram realizados pelo Zoom. Em alguns encontros as atividades que haviam sido propostas para todo o grupo eram retomadas pela Lorena. Elaboramos estratégias para que as alunas revisitassem os conteúdos e avançassem no percurso. Em outros momentos, Lorena apresentou novas propostas e estratégias para que as crianças atingissem as expectativas de aprendizagem, além de possibilitar novos recursos a serem utilizados em diferentes áreas do conhecimento. Percebemos que as alunas tiveram grandes avanços, não apenas nas questões pedagógicas. Observamos um aumento de autoconfiança, maior envolvimento nas atividades propostas e participação na aula, além de reforçar uma visão positiva das alunas frente ao aprendizado. Lorena conseguiu criar um grande vínculo com as alunas, mesmo remotamente, se tornando uma referência para as duas. Decidimos compartilhar essa prática pois é uma ideia que pode ser replicada em outros contextos e que teve impactos muito positivos. Assim, acreditamos que outros profissionais e estudantes possam se beneficiar de práticas semelhantes a essa. Acolhimento também é possivel e necessário no ambiente virtual.

Palavras-chave: Vínculos afetivos. Planejamento. Acolhimento. 


\section{EDUCAÇÃO FÍSICA DURANTE A PANDEMIA: APLICANDO AULAS PRÁTICAS, NO AMBIENTE VIRTUAL, PARA ALUNOS DA EDUCAÇÃO BÁSICA NA REDE PÚBLICA.}

O ano de 2020 se tornou um período atípico, pios, em meio à pandemia (COVID 19), todos os setores tiveram que migrar os seus negócios para o ambiente digital, tornando o home office a atividade alternativa mais comum a ser adotada. Fernandes (2010) defende a utilização do ambiente virtual para a prática educacional quando afirma que a inserção dos computadores na educação proporcionou novas ferramentas de auxílio à aprendizagem. No entanto, a educação básica pública ainda não estava estruturada para esse tipo de atendimento, enfrentando bastante dificuldade para se adequar ao "novo real". $\mathrm{Na}$ Educação Física, uma vez que as aulas exigem o movimento corporal, ficou ainda mais dificil, pois o contato com o professor para a correção da execução do movimento e da postura é de fundamental importância para o sucesso da execução da tarefa. Como meios para diminuir essa defasagem foram utilizados as seguintes ferramentas virtuais na aplicação das aulas: blog - foram disponibilizadas todos os conteúdos, bem como vídeos explicativos; Youtube utilizou-se esse recurso para expor as aulas práticas; Google Classroom, Whatsapp e E-mail - meios os quais alunos forneciam a devolutiva das tarefas; e Google Meet - possibilitando a interação em tempo real. As dificuldades apresentadas foram: a produção das aulas; a falta de internet ou a baixa qualidade dessa; a falta de preparo dos responsáveis para orientar os alunos em suas tarefas; o acúmulo de atividades; a qualidade do registro feito pelos alunos; a avaliação; e o direito de imagem. Em face de todas as dificuldades, com o tempo, a rotina escolar na rede pública acabou se adequando ao momento. Mesmo na Educação Física, foi possivel se adequar ao ambiente virtual para a aplicação do conteúdo programático em época de pandemia. No entanto, concordando com Yaegashi e outros (2017), num mundo em profunda transformação a educação precisa ser muito mais flexível, híbrida, digital, ativa, diversificada.

Palavras-chave: Educação Física, aula virtual, pandemia. 


\title{
PLANO DE ENSINO DA DISCIPLINA OPTATIVA
}

\author{
"SUSTENTABILIDADE, SAÚDE E SOCIEDADE"
}

Kaio Felix de Macedo 1, Filipe Massao de Farias Hara² e Leticia Moreira Viesba

Acesse a apresentação deste trabalho

Resumo: Esse resumo apresenta um plano de aula, que foi criado e apresentado na disciplina de Didática, no curso de graduação de licenciatura em ciências da Universidade Federal de São Paulo. Dentre os problemas socioambientais enfrentados pela humanidade, existe uma porção que afeta diretamente a saúde, de modo que se torna uma tarefa dificil e complicada analisar tais problemas. Por isso se tornou indispensável o oferecimento de um conteúdo que aborde as problemáticas da relação saúde-sustentabilidade, que se caracteriza pela integração de diversas áreas do conhecimento, para sensibilizar as futuras gerações. Portanto, se tornam metas desse projeto, a geração de competências para os alunos como ampliação da capacidade de análises críticas, composição e estruturação de argumentos e cooperatividade. O plano foi idealizado com o uso de metodologias ativas atreladas a abordagem cognitivista, pois a proposta do projeto é qualificar os estudantes individualmente, respeitando as particularidades de cada um ao mesmo tempo que é imposto a potencialização da superação de desafios. E ainda, o projeto conta com avaliações continuadas, que buscam analisar a superação semanal dos alunos. A proposta se aplica em uma carga horária de $2 \mathrm{~h} 10 \mathrm{~min}$ semanais, sendo metade de conteúdo síncrono e metade assíncrono. O conteúdo proposto segue os tópicos: Apresentação do senso científico; tópicos de ciências ambientais, de ciências da saúde, de sustentabilidade e do SUS; agrotóxicos e seus impactos; poluição e seus impactos; os 17 objetivos de desenvolvimento sustentável; genética básica e suas aplicações; biotecnologia básica e suas aplicações. As aulas se restringem a realização de debates e os alunos devem entregar uma atividade em todas as semanas, podendo variar entre mapas mentais e cartas de autoavaliação. Também contará a participação orgânica no debate, se o aluno não participar por quaisquer razões, o mesmo poderá entregar um texto explicando seu desenvolvimento durante a semana.

Palavras-chave: Interdisciplinaridade, Educação ambiental e Educação em saúde.

1 Graduando em licenciatura em ciências pela Universidade Federal de São Paulo.

2 Graduando em licenciatura em ciências pela Universidade Federal de São Paulo.

3 Cientista Ambiental e Mestre pela Universidade Federal de São Paulo, Professora contratada da Secretaria de Educação do Estado de São Paulo. 


\title{
A DISSECAÇÃO DE MEMBROS INFERIORES COMO FERRAMENTA
}

\author{
PEDAGÓGICA: UM RELATO DE EXPERIÊNCIA.
}

\author{
Kênia Teixeira1, SILVA, L. T. A. O², LOPES, C. G. S3, CUNHA, M. G. S4
}

Acesse a apresentação deste trabalho

A Anatomia Humana durante toda a história, instigou questionamentos daqueles que, incansavelmente, aspiravam por descobrir o que se esconde sob a pele. Em meados do século $\mathrm{V}$ a.C. no sul da Itália, Alcméon de Crotona realizou dissecações em animais, na tentativa de estender suas descobertas à espécie humana. Durante o Renascimento, artistas buscavam, na Anatomia, bases para retratarem de maneira mais precisa a figura humana. Em destaque, Leonardo da Vinci, ainda é reconhecido por seus diversos esboços e obras baseados na arte da dissecação. Atualmente a disciplina de Anatomia Humana é de caráter obrigatório para todos cursos da Área da Saúde, visto que o seu entendimento se faz fundamental para a compreensão da fisiologia e dos processos patológicos que acometem o Ser Humano. O objetivo desse estudo consiste em apresentar um relato de experiência que visa explicar a importância da dissecação como extensão do conhecimento acerca da anatomia humana, e isso, por meio do curso de dissecação de cadáveres humanos proposto pela LAAH (Liga Acadêmica de Anatomia Humana) do curso de Medicina do UniFOA (Centro Universitário de Volta Redonda) através da metodologia ativa. A justificativa situa-se em demonstrar como a dissecação de membros inferiores, preconiza o conhecimento prático do discente e enaltece seus saberes a respeito da fisiologia e consequentes patologias do componente do corpo humano. Para tanto, construiu - se um "caminho" baseado em estudos teóricos e demarcações na "peça", somando - se as explicações do professor orientador a respeito da anatomia e a utilização dos materiais de dissecação tais como; pinças finas para manipulação de estruturas delicadas, pinça dente de rato, tesouras e agulha curva para sutura, além de bisturi de tamanho adequado. Dessa forma, evidencia - se a importância da dissecação na solidificação do conhecimento acerca da anatomia humana através do saber prático. Como resultados tivemos a oportunidade de estudar estruturas presentes na pele, tela subcutânea, assim como veias superficiais da perna (safena magna e safena parva) seus pontos de origem, inserção, trajeto e suas acessórias. Além disso, preparamos o membro para que este possa servir posteriormente como material de estudo para outros alunos. Logo, a oficina de dissecação é um curso de extensão que tem como público alvo alunos de graduação dos cursos de Medicina. Este curso oportuniza aos alunos de graduação a consolidação dos seus conhecimentos de Anatomia Humana e aprendizado de técnicas cirúrgicas, através da dissecação no preparo de peças anatômicas. Estas peças diferenciadas produzidas são utilizadas como material didático para as aulas práticas de anatomia de todos os cursos de graduação. A

\footnotetext{
1 UniFOA, Centro Universitário de Volta Redonda, Volta Redonda, RJ. larathoany@hotmail.com

2 UniFOA, Centro Universitário de Volta Redonda, Volta Redonda, RJ. camillasalmont.lopes@gmail.com

3 UniFOA, Centro Universitário de Volta Redonda, Volta Redonda, RJ. keniateixeir@gmail.com

4 UniFOA, Centro Universitário de Volta Redonda, Volta Redonda, RJ. marcoscunham@hotmail.com
} 
Oficina de Dissecação também possibilita o desenvolvimento de pesquisa a partir dos materiais produzidos e da análise do impacto das atividades na formação dos participantes. Assim, seus beneficios estendem-se não apenas aos alunos participantes, mas também aos estudantes da disciplina de Anatomia Humana de todos os cursos do UniFOA e à comunidade em geral

Palavras-chave: Dissecação. Anatomia Humana. Membro Inferior 


\section{A PERMANENCIA DO CADÁVER NO ENSINO DA ANATOMIA HUMANA: \\ UM EMBATE TECNOLÓGICO}

Lara Silva; LOPES, C. G. S; TEIXEIRA, K. O ; CUNHA, M. G. S

$\underline{\text { Acesse a apresentação deste trabalho }}$

No decorrer da história, a utilização de cadáveres humanos para fins de ensino médico desempenhou papel central na aquisição de conhecimentos e no progresso científico. Atualmente, esta ferramenta ainda se faz presente nos ensinamentos, visto que, dotada de realismo e humanidade possibilita o desenvolvimento da capacidade de observação e destreza manual. O objetivo do estudo é reforçar a utilização de cadáveres humanos como peça fundamental na graduação dos estudantes de medicina, embora novas metodologias de ensino tenham sido acrescentadas com os avanços tecnológicos. Este estudo foi realizado mediante revisão de dois artigos da plataforma Scielo e um da revista da Universidade Federal de Goiás, publicados entre os anos de 2012 a 2014. Essas três obras, em conjunto, reafirmam a indispensabilidade dos cadáveres humanos nos estudos anatômicos. É evidente, portanto, que a presença de cadáveres no ensino da disciplina de anatomia é fundamental e indispensável. Embora haja outros métodos de aprendizagem como, atlas, peças anatômicas de plásticos e recursos eletrônicos, o estudo em peças cadavéricas permite a análise de variações morfológicas e patologias que não seriam observadas nas demais metodologias visto que abordam somente o corpo humano em seu estado normofuncional. Ademais, o emprego de cadáveres contribui tanto para a consolidação do saber anatômico teórico quanto para a construção de valores bioéticos que serão fundamentais nas relações médico-paciente futuras.

Palavras-chave: Anatomia. Cadáver. Tecnologia. 


\section{EXPERIÊNCIA DISCENTE EM TEMPOS DE PANDEMIA:}

\section{UM RELATO DE EXPERIÊNCIA}

Leila de Almicê dos Anjos', William Santos Silva², Thalane Souza Santos Silva ${ }^{3}$, Anne Karoline Pereira Brito ${ }^{4}$, Taiane Gonçalves Novaes ${ }^{5}$

Acesse a apresentação deste trabalho

Diante da pandemia de COVID-19 o Ministério da Educação e Cultura autorizou a substituição das aulas presenciais nas Instituições de Ensino Superior (IES) no Brasil por aulas remotas mediadas pelas tecnologias de informação e comunicação, através da portaria $n^{\circ} 343$ de 17 de março de 2020 . Objetivou-se apresentar o relato de experiência discente do curso de Nutrição em uma IES privada na Bahia em meio à crise de COVID-19. Em março de 2020 as aulas presenciais, as atividades práticas e os estágios curriculares foram suspensos, sendo as aulas teóricas ministradas em plataforma digital. Os discentes experimentaram dificuldades econômicas,pessoais, familiares ede saúde, como a própria COVID-19, óbitos de entes próximos e o distanciamento físico-social. A virtualização da sala de aula e sua inserção no âmbito domiciliar impactou nos estudos pela falta de privacidade, desafio no gerenciamento de atividades, ausência e/ou compartilhamento de internet e de dispositivos de tecnologia, dificuldades na utilização das ferramentas digitais, empecilhos na realização de atividades em grupo, entre outras. Houve um empenho da IES na oferta de tutoriais para viabilizar a utilização das ferramentas digitais, mas para muitos discentes não foi suficiente ou o tempo foi curto para permitir o desenvolvimento de habilidades. A sobrecarga de atividades e as dificuldades dos docentes com a nova modalidade também emergiram como dificuldades percebidas pelos discentes. As vivências no âmbito educacional e seu compartilhamento com colegas, professores e colaboradores passaram a ser vistos sob uma nova perspectiva, afetando as relações interpessoais que se estabeleciam presencialmente nos espaços da instituição e suas extensões. Muitos discentes tiveram a saúde mental afetada nesse período, demandando apoio psicológico e até mesmo afastamento das atividades educacionais. $\mathrm{O}$ ensino remoto reinventou a educação superior, mas não foi capaz de sanar prejuízos na vida educacional dos discentes.

Palavras-chave: Educação Superior; Avaliação Discente; Educação a Distância; Infecções por Coronavirus.

1 Discente do curso de Nutrição da Faculdade de Tecnologia e Ciências, Campus Jequié. E-mail: leilaalmice@hotmail.com

2 Coordenador do curso de Nutrição da Faculdade de Tecnologia e Ciências, Campus Jequié. Email: wsilva.jeq@ftc.edu.br.

3 Docente do curso de Nutrição da Faculdade de Tecnologia e Ciências, Campus Jequié. E-mail: thsouza.jeq@ftc.edu.br

4 Docente do curso de Nutrição da Faculdade de Tecnologia e Ciências, Campus Jequié. E-mail: akpereira.jeq@ftc.edu.br

5 Docente do curso de Nutrição da Faculdade de Tecnologia e Ciências, Campus Jequié. E-mail: tgnovaes.jeq@ftc.edu.br. 


\section{ATIVIDADE EDUCATIVA: SAÚDE SEXUAL E REPRODUTIVA NA \\ UNIVERSIDADE}

Liciane Langona Montanholi ${ }^{1}$

Acesse a apresentação deste trabalho

Apesar da sexualidade e reprodução serem inatos ao ser humano, nem sempre é um tema discutido abertamente, o que pode levar à práticas sexuais e reprodutivas inseguras. Os Serviços de Saúde e as instituições de ensino de Cabo Verde já promovem Educação em Saúde sobre esses temas, no entanto, observase muitos adolescentes e jovens realizando sexo de forma insegura, o que também é percebido entre universitários. Vários alunos tiveram filhos na adolescência ou durante o curso, gerando dificuldades para a criação dos mesmos e continuidade dos estudos. Dessa forma, os alunos do curso de licenciatura em enfermagem da Universidade de Santiago tem realizado uma atividade, sob a coordenação da Profa Liciane Montanholi com o objetivo de promover a saúde sexual e reprodutiva da comunidade que frequenta essa universidade. Desde o início das atividades (Abril/2019) até Abril/2020 foram realizadas 20 sessões de Educação em Saúde. As atividades foram desenvolvidas no hall da universidade, facilitando a interação da comunidade acadêmica, despertarndo o interesse pelos assuntos abordados. As sessões foram realizadas de forma individual ou em pequenos grupos, uma vez por semana, com duração variável. Os temas abordados foram:: namoro seguro, uso de métodos contraceptivos, infecções sexualmente transmissiveis e cuidados com o recém-nascido. Nas primeiras sessões, observouse distanciamento dos alunos por timidez diante dos temas relacionados à sexualidade. Com o passar do tempo, houve maior aproximação e interesse, surgindo as dúvidas. Com essa atividade, ficou evidente que, embora o tema sexualidade seja abordado nas redes sociais, canais de comunição, Serviços de Saúde e Instituições Educacionais, ainda há timidez na sua discussão. Assim, a proposta de realizar atividades de forma mais próxima, informal, mostrou-se adequada para essa população, possibilidando o esclarecimento de diversas dúvidas e maior liberdade de expressão em relação à sexualidade e reprodução.

Palavras-chave: Enfermagem, Atividades Educativas, Saúde Sexual, Saúde Reprodutiva.

1 Enfermeira. Doutora Enfermagem Escola de Enfermagem de Ribeirão Preto. Universidade de Santiago. Cabo Verde. licianelm@gmail.com. 
UMA ANÁLISE REFERENTE AO CAMPO DA EDUCAÇÃO MATEMÁTICA

INCLUSIVA, NO PERÍODO ENTRE 2010 A 2020 E O DESENVOLVIMENTO DE

PESQUISAS NA COMUNIDADE UNIVERSITARIA.

Maria Clara Montel Gomes ${ }^{1}$, Reinaldo Feio Lima²

Acesse a apresentação deste trabalho

Este artigo evidencia um recorte do projeto maior, o qual se refere a um mapeamento do estado da arte acerca de teses e dissertações relacionadas aos processos de ensino e de aprendizagem da Educação Matemática Inclusiva, no período de 2010 a 2020. Aqui, apresentamos nossas primeiras análises sobre as dissertações brasileiras relacionadas ao campo da Educação Matemática Inclusiva. Uma Pesquisa qualitativa por meio do estado da arte foi possivel catalogar 194 dissertações, destacando as características da primeira categoria. Com relação as instituições de ensino que mais desenvolveram pesquisas relacionadas à Educação Matemática Inclusiva foram: Universidade Estadual Paulista "Júlio de Mesquita Filho" (UNESP), com 09 teses; Pontifícia Universidade Católica de São Paulo - PUC-SP, com 05 teses; Universidade Estadual de Maringá (UEM), com 04 teses; Universidade Federal do Rio Grande do Sul (UFRGS), com 02 teses; Universidade Estadual de Londrina (UEL), com 02 teses; Universidade Federal de Goiás (UFG), com 02 teses; Universidade Luterana do Brasil (ULBRA), Universidade de São Paulo (USP), Universidade Federal do Rio Grande do Norte (UFRN), Universidade Federal de Pernambuco (UFPE), cada uma com 01 tese cada. Por fim conclui-se que por mais que área da educação matemática inclusiva seja um campo que proporciona grande potencial, e que nos últimos anos tenha gerado mais interesse na comunidade universitária ainda sim, não é explorada o suficiente. Portanto e importante que haja mais investigações nesse âmbito e a possibilidade da inclusão de alunos deficientes tanto no ensino básico quanto no superior.

Palavras-chave: Educação Matemática inclusiva, Estado da arte, Mapeamento.

1 Aluna do curso de Licenciatura em Matemática e Bolsista de Iniciação Científica. UNIFESSPA. E-mail: mariamaria2017ifpapara@gmail.com

2 Professor Doutor, no Curso de Licenciatura em Matemática. UNIFESSPA. E-mail: reinaldo.lima@unifesspa.edu.br 


\section{HISTÓRIA DA EDUCAÇÃO NO BRASIL: UM BREVE RESUMO SOBRE OS TEMPOS E OS ESPAÇOS ESCOLARES.}

Antonio Gilbran de Lima¹, Luana Lima²

Acesse a apresentação deste trabalho

O cenário escolar é marcado, ao longo dos tempos, por fatores que por si só não demonstram neutralidade, mas unidos possibilitam o acesso ao objetivo central da escola: o aprender. Criando assim um devir dialético, onde é necessário compreender quais são estes elementos e a sua relevância na estruturação do ensino público primário no Brasil, foco do presente trabalho. Escola de improviso (século XIII e XIX): o período colonial é marcado pelo improviso no que tange as escolas régias, funcionando em espaços cedidos outrora organizado pelos pais dos alunos e participantes da sociedade. EscolasMonumento: na segunda década do século XIX, é retomada a proposta dos grupos escolares, que remete ao modelo das escolas seriadas, com ambientes planejados e arquitetonicamente elaborados. Que permitiria uma ruptura ao ideal imperial, visando assim uma reconciliação, pátria ordeira e progressista, com a nação Republicana. Escola Funcional: no início do século XX, a necessidade de homogeneização dos prédios escolares e da mensagem que este deveria transmitir, veio à tona. Inspiradas em ideias escolanovistas, as reformas de ensino ocorrem para ressignificar tempos e espaços escolares. Sendo proposto, uma arquitetura escolar: o neocolonial, centrada nas brasilidades, valores pátrios e signos da nacionalidade. O século XXI tem sido movido pelo repensar a educação, por mais que ainda existam resquícios dos primeiros movimentos educacionais. Como exemplo, temos o grande desafio do ensino à distância (EAD) e a desigualdade social, evidenciados com a pandemia mundial. A necessidade do olhar à Educação, a partir de uma atuação firme do Estado e com atenção à Constituição brasileira: educação pública; de qualidade e a permanência dos estudantes é latente. Pensar educação, não é apenas garantir o acesso à escola, é dar aos docentes e discentes, possibilidade para transformação.

Palavras-chave: História da Educação; Educação no Brasil; Ensino Público.

1 Antonio Gilbran de Lima é graduado em direito pela Universidade Estácio e especialização em direito do trabalho pela Escola Paulista de Direito. Graduação Ensino de Ciências pela Universidade Federal de São Paulo - UNIFESP.

2 Luana Lima é psicopedagoga graduada pela UNIFIEO e pós-graduada pelo Mackenzie. Deu aula na Fundação Casa e em cursinhos populares. Graduação Ensino de Ciências e Aluna Especial do PECMA pela Universidade Federal de SP - UNIFESP. 


\section{POLİTICAS PÙBLICAS E A EDUCAÇÃO A DISTÂNCIA: EDUCAÇÃO A}

\section{DISTÂNCIA EM TEMPOS DE PANDEMIA.}

Thyago Lins ${ }^{1}$

Acesse a apresentação deste trabalho

A Educação a Distância (EAD ou EaD) ganhou um destaque nos meios de comunicação com a pandemia, como uma alternativa para atender a suspensão das aulas presencias da Educação Básica ao Ensino Superior. É fato que a Educação a Distância não é algo novo, a sua discussão quanto a regulamentação teve início em 1972 com a comissão de especialistas estudando o caso da Universidade Aberta da Inglaterra e como isso poderia acontecer no Brasil, com este primeiro passo a caminhada prossegue com a criação de Grupo de Trabalho através de portaria ministerial 418/1988, em meados de 1995 a criação de uma Secretaria no Ministério da Educação voltada para a Educação a Distância (SEED/MEC), e no decorrer dos próximos anos foram criadas e regulamentadas as mais diversas soluções. Chegando no estágio no qual a EAD começa a se posicionar como uma alternativa para que o Ensino Superior supere as distâncias físicas e territoriais, o crescimento das ofertas foi e é evidente. Com a pandemia o tema EAD torna-se nítido e levanta questionamentos quanto a sua qualidade, eficiência e eficácia. Nos revela o quanto ainda é carente de politicas públicas que garantam a sua qualidade, o seu progresso, alcance e manutenção. A pandemia que estamos vivenciando revelou a falta de infraestrutura fisica para que o mínimo necessário esteja disponivel para a sociedade: energia, rede de dados/internet, equipamentos disponibilizados e ainda o quanto as instituições de ensino, sejam elas públicas ou privadas ou sejam elas da Educação Básica ou do Ensino Superior, carecem de investimentos de infra e qualificação do seu quadro administrativo, técnico e pedagógico. Isto é o reflexo da carência de Políticas Públicas de Estado para a garantia de uma modalidade de ensino que é eficiente, eficaz e de qualidade desde que regida da forma adequada e com o comprometimento que é necessário assim como na Educação Presencial.

Palavras-chave: Educação a Distância, EAD, Políticas Públicas.

1 Funcionário PAEPE na Unicamp, graduado em Processos Gerencias, Especialização lato sensu em Gestão Escolar pela FAVENI, MBA em Gestão Empresarial pela UNIP, cursando Pedagogia no Centro Universitário Braz Cubas. thyagoismael@gmail.com 


\section{QUESTÕES DE GÊNERO: DISCUSSÕES EMERGENTES NA FORMAÇÃO INICIAL DO PROFESSOR DE MATEMÁTICA}

Lívia Godinho Simião수 Patrícia Barbosa Melo Maneo²

Acesse a apresentação deste trabalho

A discussão proposta por meio desta pesquisa tem como objetivo investigar se e como questões de gênero estão sendo abordadas no curso de Licenciatura em Matemática de uma instituição pública do estado de São Paulo, e também identificar como alguns professores que ensinam matemática na Educação Básica têm lidado com discussões ou situações, em sua prática docente, quando estas envolvem temáticas acerca das questões de gênero. A literatura vem discutindo que o gênero é inerente ao indivíduo, de forma a acompanhá-lo em todas as instituições sociais que frequenta, ou seja, as questões de gênero não são barradas pelos muros das escolas. Então nos cabe investigar como o docente, em especial aquele que ensina matemática, vem sendo preparado para lidar com situações que envolvam o tema em sala de aula. A hipótese inicial é que as discussões que abordam esta problemática não têm sido fomentadas ao longo da formação inicial do professor de matemática, e entendemos ser relevante que os professores da Educação Básica, inclusive os que ensinam matemática, sejam preparados para lidar, nas escolas, com as questões de gênero. Entretanto, sem discussões acerca desta temática, ao longo da formação inicial do professor, qual será o repertório dele para provocar e lidar com estas discussões desta natureza em sua prática docente? Este questionamento é um eixo norteador para nossa investigação. Esta pesquisa qualitativa se caracteriza, metodologicamente, como um estudo de caso, e para a produção de dados utilizaremos: (i) entrevista com o grupo de professores; (ii) observação de aula; (iii) análise documental do curso de licenciatura em matemática. Para a realização das entrevistas, teremos como participantes professores que atuem em um curso de Licenciatura em Matemática e/ou na educação básica, e realizaremos a observação das aulas na Licenciatura em Matemática da instituição selecionada. Esta investigação nos permitirá conhecer a forma como os professores enxergam a temática, como trabalham essas questões em sua prática e como foram apresentados a tais discussões durante a formação inicial.

Palavras-chave: Formação de professores. Questões de gênero. Licenciatura em matemática. Prática docente.

1 Mestranda no Programa de Pós-Graduação em Ensino de Ciências e Matemática UNIFESP Diadema. E-mail: godinho.livia@gmail.com

2 Licencianda em Matemática no Instituto Federal de Educação, Ciência e Tecnologia de São Paulo - IFSP/Guarulhos. E-mail: patriciammaneo@gmail.com 


\title{
O ENSINO À DISTÂNCIA E CURSOS DE DIREITO: O QUE APRENDEMOS EM
}

TEMPOS DE COVID-19?

\author{
Carina Deolinda da Silva Lopes ${ }^{1}$, Franceli Bianquin Grigoletto Papalia², \\ Nelci Lurdes Gayeski Meneguzzi³. \\ Acesse a apresentação deste trabalho
}

Resumo: Trabalhar com temas que demandam reflexos sobre a atualidade social, especialmente, um assunto tão delicado e incerto quanto a pandemia do COVD 19, a determinação mais evidenciada nestes tempos é "fiquem em casa", e consequentemente a isso, estamos todos confinados em nossas residências, tentando continuar nossas vidas, na rotina que tínhamos, o que afetou não só as atividades laborativas, mas também as atividades escolares e aos estabelecimentos de ensino de forma abrupta e inesperada, obrigando-se a adotar medidas de ensino totalmente diferentes do que as habituais, o modo de ensinar mudou de um dia para o outro. O presente estudo faz inicialmente uma abordagem a respeito do COVI-19, bem como da educação à distância no Brasil, com uma análise da aplicabilidade desta ao ensino jurídico, frente as alterações na rotina mundial causada pela pandemia. A temática da pesquisa irá estudar também o trabalho pedagógico desenvolvido pelos professores dos Cursos de Direito e como a educação à distância poderá ser utilizada junto ao Curso referido, em tempos de isolamento presencial social e seus reflexos na educação superior jurídica. Para tanto, será utilizado o método indutivo e a técnica teórico conceitual, enfatizando alguns conceitos como o científico a respeito do coronavírus, sobre educação à distância, trabalho pedagógico, cursos de direito e o contexto atual da pandemia do COVID 19, realizada por meio de levantamento bibliográfico e documental. Com a consequente discussão da sua viabilidade de implementação da graduação em Direito no modelo EAD para o futuro. A pretensão da pesquisa é dar continuidade a análise a respeito dos reflexos da pandemia e da utilização do ensino à distância nos cursos de Direito, e se com este direcionamento podem ocorrer mudanças significativas no ensino e aprendizagem jurídica, favorecendo a qualidade da educação superior e a formação profissional.

Palavras-chave: COVID 19, Educação à distância, Ensino jurídico.

1 Doutoranda do Programa de Pós-graduação em Direitos Humanos da UNIJUI, Mestre em Direito; Bolsista Capes, vinculada à linha de pesquisa do PPGDH/UNIJUÍ "Democracia, Direitos Humanos e Desenvolvimento"; orientanda da Profa. Dra. Elenise Felzke Schonardie; Advogada. Email: lopesdeo@hotmail.com.

2 Mestranda em Educação pela UFSM, vinculada a Linha de Pesquisa "LP2: Políticas públicas educacionais, práticas educativas e suas interfaces" orientada pela Professora Doutora Liliana Soares Ferreira; Advogada; Juíza leiga da Comarca de Faxinal do Soturno - TJRS; docente e pesquisadora do grupo de pesquisa Káiros. E-mail: franpapalia@gmail.com.

3 Doutoranda do Programa de Pós-graduação em Direitos Humanos da UNIJUI, vinculada à linha de pesquisa do PPGDH/UNIJUÍ "Democracia, Direitos Humanos e desenvolvimento"; orientanda do Prof. Dr. Gilmar Antônio Bedin e co-orientanda da Prof ${ }^{a}$. Dra. Denise Pires Fincato. Mestra em Direito pela Universidade de Caxias do Sul - UCS. E-mail: nelcimeneguzzi@hotmail.com 


\section{LIBERDADE ESCOLAR: EXPERIÊNCIAS NA ESCOLA PÚBLICA}

\section{Lorraine Christine De Oliveira ${ }^{1}$}

Acesse a apresentação deste trabalho

Estudei minha vida toda em escola pública, e quando entrei na faculdade, mesmo em apenas alguns meses, percebi ter formado um senso crítico que me possibilitou fazer algumas reflexões sobre minha experiência escolar. Durante minha formação, estudei em duas escolas bem diferentes, a primeira é considerada uma escola de periferia, já a segunda, é considerada a melhor escola pública da região, entretanto, ambas possuem muitos problemas. A primeira escola carecia muito de professores, e mesmo com toda essa defasagem, passávamos de ano de maneira automática, já que não tinha professor para nos avaliar. Assim que entrei na faculdade, compreendi mais sobre as metodologias de Paulo Freire e ao entender que ele defendia um sistema de ensino mais livre, onde os alunos e os professores dialogassem, percebi que esse era o grande erro da minha segunda escola. Lá, grande parte dos professores mantinham um certo abismo: aluno x professor, não podíamos nos aproximar para tirar dúvidas e muito menos expressar nossas opiniões. Existiam muitas dúvidas as quais precisavam ser sanadas, e na maioria das vezes, os alunos recorriam aos pais e à internet, claro, quem tinha a sorte de tê-los, em alguns casos ou um ou outro em outros nem um nem outro e para o professor, uma certa distância dos alunos parecia protocolar, e pelo número de vezes que olhavam o relógio, era flagrante que o crescimento intelectual dos alunos não fazia parte do seu objetivo. Alguns professores ainda faziam questão de enfatizar que na faculdade, o ambiente seria bem pior! Então, quando entrei na UNIFESP, logo na primeira semana de aula, tive um enorme espanto, porque percebi que diferentemente do que meus professores diziam, no ambiente acadêmico, há muito compromisso por parte dos professores, são atenciosos, estão sempre dispostos a tirar dúvidas, são mais flexiveis e sempre apoiam a interação entre alunos e professores, um ensino por excelência regado pelo espírito freireano.

Palavras-chave: Educação, qualidade, ensino, estado, aluno. 


\section{PENSAR DIDÁTICO: REFLEXÕES SOBRE UM PLANEJAMENTO DE AULA EM}

\section{TEMPOS DE PANDEMIA}

Luana de Lima Maciel${ }^{1}$, Giovanna Araujo², Luana Lima3

Acesse a apresentação deste trabalho

A água é um dos recursos mais importante, se não o mais, para a existência da vida. Os seres vivos, assim como os não vivos, têm a água como a substância que regula e faz manutenção de suas funções ou as altera física ou quimicamente. No meio, a água interage com esses diversos componentes, sejam eles abiótico ou bióticos, passando por diversas "fases" e transformações. Frente a isso, pensar em como construir a temática, junto ao estudante, é um desafio ao docente. Uma vez que é através do plano de aula que se terá um instrumento para ação, e assim a construção de saberes entre professor e o estudante. Aprendizagem é um processo contínuo e bilateral, não há uma forma única, se constrói guiada por sua época histórica, diretrizes e orientações de profissionais e das políticas governamentais. Planejar uma aula é, então, construir a possibilidade de se ter a educação para libertação, como para opressão, sendo a linha tênue do pensar do docente que a equilibrará ao lado que se deseja. O plano de aula planejado, foi apresentado como parte dos requisitos da Unidade Curricular Eletiva: Didática no Curso de Ciências da UNIFESP, ministrada pela Profa. Dra Marilena Rosalen. Sendo proposto que fosse construído a partir de temas relacionados à sustentabilidade e ecologia de modo virtual no ensino remoto. Norteadas por esta premissa, o foco do estudo foi levar aos estudantes, do ensino fundamental II ( $9^{\circ}$ ano), em aulas de 50 minutos, os conceitos sobre a água - suas propriedades químicas, físicas, biológicas - bem como questões socioambientais. Pautas na desigualdade social presente no contexto escolar, buscou-se explorar essas questões de forma simples e com baixo custo financeiro, de modo que os alunos pudessem identificar diferentes fenômenos da água, com materiais utilizados no dia-a-dia, uma vez que aprendemos quando algo nos faz sentido. Este aprender está, também, associado as relações sociais por meio da práxis, em que há elo no que se diz e no que se faz e não distância.

Palavras-chave: Plano de Ensino; Ciências da Natureza; Água; Ensino Fundamental.

\footnotetext{
1 Luana Maciel foi graduanda de Ciências Biológicas - Licenciatura pela UNICAMP. Deu aulas de programação de Lego Mindstorms $2.0 \mathrm{em}$ projeto escolar durante ensino médio, bem como aulas voluntárias. Fez Pré Iniciação Científica pela Escola Politécnica da USP. Graduanda de Ciências Licenciatura pela Universidade Federal de São Paulo - UNIFESP. E-mail: luana.maciel@unifesp.br 2 Giovanna Araújo é Técnica Contábil pela ETEC e Graduanda em Licenciatura em Ciências pela Universidade Federal de São Paulo - UNIFESP, além de integrante do projeto PandeMina, da UNIFESP Diadema. E-mail: giovanna.araujo@unifesp.br

3 Luana Lima é psicopedagoga graduada pela UNIFIEO e pós-graduada pelo Mackenzie. Graduanda na Licenciatura em Ciências e Aluna Especial do PECMA pela Universidade Federal de SP _ UNIFESP. lima.luana@unifesp.br
} 


\title{
ANÁLISE DA PRÁTICA COMO UM DISPOSITUVO PARA A (DES)PRIVATIZAÇÃO DA PRÁTICA DOCENTE: UM RELATO DE EXPERIÊNCIA
}

\author{
Luana Monteiro $^{1}$, Márcia Regina Onofre ${ }^{2}$, Samuel de Souza Neto ${ }^{3}$ \\ $\underline{\text { Acesse a apresentação deste trabalho }}$
}

O presente trabalho propõe apresentar um relato de experiência sobre a Análise da Prática como um dispositivo para a (des)privatização da prática e para o reconhecimento dos saberes que os docentes mobilizam e precisam para o ensino. O exercício de análise e reflexão sobre a prática, processo inerente ao fazer profissional, permite ao professor identificar, verbalizar e registrar suas experiências e saberes. Os dispositivos no campo da formação de docente são ferramentas que possibilitam a transformação dos professores envolvidos, a partir da problematização de suas experiências postas em diálogos com repertórios formativos. Cochran-Smith (2012) chamou a atenção para a importância de tornar públicas as práticas especializadas dos professores, o que nomeou esse movimento como (des)privatização da prática docente. Nessa perspectiva, temos como objetivo apresentar a Análise da Prática como um dispositivo para conhecimento e reflexão crítica sobre a prática e os saberes dos professores. Para embasamento teórico adotamos Cochran-Smith (2012) Gauthier (1998), Nóvoa (2017), Ortiz (2005), Pimenta (1996), Shulman (1987), Tardif (2002, 2013) e Wittorski (2014). Para operacionar o exercício da Análise da Prática, adotamos como base a proposta de Ortiz (2005) com a sistematização de uma análise reflexiva a partir de quatro ações: (I) Descrever; (II) Informar; (III) Confrontar e (IV) Reconstruir. Considerando o roteiro, realizamos o desenvolvimento da Análise da Prática de uma professora de Língua Portuguesa, do Ensino Médio. Conclusivamente, considerando as etapas da Análise da Prática, foi possível reconhecer os saberes que constituiram a prática relatada, confirmando a natureza desses saberes como heterogêneos, temporais e sociais, bem como, as potencialidades desse dispositivo para (des)privatização da prática, para construção da base de conhecimentos docentes e para o reconhecimento dos professores como profissionais do ensino.

Palavras-chave: Análise de práticas; (Des)privatização da prática; Saberes docentes.

1 Universidade Estadual Júlio de Mesquita Filho - campus Rio Claro/SP (Prof. ${ }^{\text {a }}$ Mestra); lm_luana@hotmail.com.

2 Universidade Federal de São Carlos - UFSCar (Prof. $^{a}$ Dr. $^{\text {a }}$ colaboradora); mareonf@yahoo.com.br.

3 Universidade Estadual Júlio de Mesquita Filho- campus Rio Claro/SP (Prof. Dr.); samuel.souzaneto@unesp.br. 


\section{O PSICODRAMA PEDAGÓGICO NA EDUCAÇÃO ON-LINE}

\section{Luciano Gamez¹, Viviane Cristina Marques² \\ $\underline{\text { Acesse a apresentação deste trabalho }}$}

A pandemia da Covid 19 colocou a educação online no centro do processo de ensino e aprendizagem, provocando a necessidade urgente de repensar os modelos tradicionais de ensino e aprendizagem. O ensino remoto emergencial se colocou como alternativa aos estabelecimentos de ensino que decidiram não interromper o ano letivo em plena crise epidemiológica. Porém, essa mudança de paradigma, tão drástica e repentina, trouxe diversas implicações, tanto para professores como para alunos, que forçosamente tiveram que se adaptar a esse formato e experimentar metodologias e recursos pedagógicos que não estavam habituados. A preocupação em manter o caráter ativo do processo educacional, na perspectiva de construir conhecimento de forma pessoal e relacional em um contexto diverso, sem deixar de conter elementos significativos de interação dinâmica, tais como os culturais, sociais, filosóficos, psicológicos entre outros, enfatizando os aspectos que emergem da socialização dos indivíduos em grupo, nos remeteu a experimentações de técnicas do Teatro Espontâneo e do Psicodrama Pedagógico como método na Educação online. Partindo do pressuposto de que utilização desses métodos e técnicas, nesse contexto, contribui efetivamente para a dinamização dos processos de ensinoaprendizagem, e que permitem maior integração, modificação, estabelecimento de novas relações e conexões com os conhecimentos e vivências internalizadas de alunos e professores, nos dedicamos a investigar e sistematizar o Psicodrama Pedagógico como metodologia ativa na Educação Online, fundamentada na Socionomia, que tem como objetivo compreender de forma aprofundada a dinâmica do processo de interação humana, estimulo à aprendizagem de ações adquiridas nas relações interpessoais através de jogos dramáticos que estimulem a espontaneidade e a criatividade. Acreditamos que essas premissas se constituem como um relevante campo de pesquisa e de experiências práticas no atual contexto educacional pandêmico.

Palavras-chave: Ensino Remoto, Pandemia, Teatro Espontâneo, Psicodrama Pedagógico online.

1 Universidade Federal de São Paulo - lucianogamez@unifesp.br

2 Universidade Estadual de Campinas - vivicmarques@gmail.com 


\section{SUAS LÁGRIMAS NÃO TEM SEXO}

Angelise Maciel $^{1}$; Jacira Helena Bridi²

Acesse a apresentação deste trabalho

Este Projeto de Pesquisa está em processo de desenvolvimento junto a Escola Municipal de Educação Básica Oswaldo Aranha, em Esteio no Estado do Rio Grande do Sul no ano de 2020. Orientar o projeto com duas alunas do oitavo ano do ensino fundamental de forma remota, em época de pandemia tem sido um grande desafio para as professoras orientadoras que através de ação interdisciplinar, tem a grandeza de interligar a matemática e a geografia nessa busca pelo conhecimento. Fomentar a importância da pesquisa científica na rede pública, com adolescentes que tem interesse em conhecer e compreender a história da masculinidade tóxica, bem como sua influência na saúde mental e física, tem sido desafiador por estarmos em um momento diferenciado. A temática que envolve grande problemática nos faz buscar novos olhares sociais. Precisa-se inicialmente responder o conflito: Homem não chora? Para isso é necessário criar os objetivos como: pesquisar a história da masculinidade tóxica e suas implicações na sociedade, buscar compreender o sofrimento masculino diante das pressões no papel de ser homem, utilizar mídias sociais, especificamente o instagram com reflexões e posicionamentos de profissionais de áreas (professores de diversas áreas, psicólogos, enfermeiros, médicos, advogados, juízes, entre outros) sobre os diversos temas que implicam a masculinidade tóxica, promover e incentivar produção textual reflexiva das alunas participantes do projeto. Utilizar de recursos tecnológicos para criação de post e legenda para mídias sociais. Encaminhar todo o processo que envolve as etapas para a construção de um trabalho cientifico e sua importância. Utilizar com certeza a pesquisa quantitativa onde a área da matemática através da estatística irá coletar, tabular, mensurar e apresentar os dados através de gráficos com as opiniões dos diversos profissionais e colaboradores. Vale lembrar que a matemática não se faz presente somente com a parte estatística, mas em todas as etapas: orientar, mediar, partilhar e encaminhar em parceria com geografia, o referido assunto e suas discussões. Ainda temos um grande caminho a percorrer. Acolher as dúvidas e demandas das educandas em pesquisa de educação remota, implica sensibilidade e cria novas estratégias em orientar esse trabalho que tem grande relevância social.

Palavras-chaves: Pesquisa, Masculidade Tóxica, Interdisciplinar. 


\section{RESÍDUOS SÓLIDOS E A EDUCAÇÃO PARA A SUSTENTABILIDADE}

Marcel Pereira Pordeus ${ }^{1}$

A temática de resíduos sólidos será sempre algo complexo, por se tratar de algo inerente a produção humana, que cada vez mais tem sido vítima do seu próprio desejo exacerbado de consumir. Deste fato, postulamos a necessidade de ações educativas que trabalhem em prol da conservação do meio ambiente, sobretudo de uma mudança de hábitos, de quebra de paradigmas e inserção de medidas pedagógicas como forma de despertar a consciência para a sustentabilidade. Com efeito, esta pesquisa objetiva discorrer e problematizar a questão da reciclagem dos residuos sólidos no contexto educacional para valorização da sustentabilidade. Por processo metodológico, optamos por permear a conjuntura bibliográfica de autores/pesquisadores que discorrem supracitada temática, tais como Roveriego (2004) e Trigueiro (2014). Acreditamos que quanto mais se investir em ações pedagógicas voltadas para a reciclagem em programas de coleta seletiva, mais estaremos perto de desvendar os nós desta problemática para o mundo, considerado um dos maiores entraves ambientais do Brasil, "o lixo". Como resultados parciais, hodiernamente aufere-se a necessidade de ações didáticas sistematizadas e sustentáveis nas escolas, que visem o incentivo e ampliação de materiais pelas associações responsáveis por resíduos sólidos, como forma de efetuar metas definidas; expandir sua exposição (jornais, banners, internet etc.); adquirir novos equipamentos, elaborar programas que visem a conquista de maiores financiamentos para a ampliação de cooperativas, no intento de agregar valores aos objetos comercializados por meio de seu beneficiamento e educação ambiental no âmbito da sala de aula e além deste espaço.

Palavras-chave: Educação ambiental. Resíduos sólidos. Sustentabilidade. 


\section{CONTEXTO DA PANDEMIA COMO IMPULSIONADOR DE NOVOS}

\section{PARADIGMAS METODOLÓGICOS}

Márcia Azevedo Coelho

Acesse a apresentação deste trabalho

Desde o início do século XXI a educação brasileira ensaiava mudanças metodológicas e curriculares, a fim de atender aos anseios diversas demandas que iam das necessidades e anseios dos estudantes a pressões do mercado internacional. Contudo, em decorrência do cenário imposto pela pandemia do COVID-19, em 2020, programas que vinham sendo timidamente implementados assumiram o protagonismo em diferentes instituições de educação básica. Esse foi o caso de um Colégio, da Zona Leste de São Paulo, que investiu massivamente no desenvolvimento de Projetos Interdisciplinares, antes trabalhados como apêndices de outros instrumentos avaliativos. Isso porquê, em função da nova conjuntura, a qual exigira avaliações processuais em detrimento de somativas e atividades mais metacognitivas do que mnemônicas, os projetos foram a metodologia que melhor respondeu à situação que demandava flexibilidade cognitiva, planejamento, autonomia, reflexão, funcionalização do conhecimento, dentre outras habilidades. Os projetos visaram possibilitar que os estudantes desenvolvessem a capacidade de relacionar conteúdos programáticos a um tema gerador, respondendo a perguntas-problema (de cunho ambiental, social, político e/ou econômico) de maneira transdisciplinar e com caráter reflexivo ou propositivo. O percurso do disciplinar para o inter e deste para o transdisciplinar fomentou uma visão integradora que, por meio de orientação remota, compeliu os estudantes a atuarem de maneira mais protagonista, autônoma e colaborativa, com o intuito não mais de reproduzir informações, mas de funcionalizar os conhecimentos. O cenário impôs formas de promoção de aprendizagem que tivessem aderência às complexidades do contemporaneidade, abrindo espaço a propostas educacionais que permitam a percepção do planeta como um todo indissociável, um universo transdisciplinar e multirreferenciado (Morin, 1991).

Palavras-chave: Transdisciplinaridade; pensamento complexo; metodologia de projetos. 


\section{ÁFRICA E EDUCAÇÃO: EPISTEMICÍDIO HISTÓRICO.}

Márcio Wilson Santos Cruz

Acesse a apresentação deste trabalho

Talvez poucas pessoas já tenham se deparado com literaturas africanas ou pensadores que os referenciam, referenciais negros são ignorados pela academia docente e pela sociedade como um todo. Sendo o descarte histórico sobre África uma realidade estrutural no Brasil, unida a deslegitimação da cultura, ancestralidade e importância histórica as formas mais abrangentes desse genocídio estrutural, ainda esbarramos nos mitos construídos sobre os AfroBrasileiros. Algo que se torna pejorativo ao repasse acadêmico. As aulas régias buscou em modelos Europeus o auxílio no desenvolvimento do processo pedagógico da Educação, o que em regra não foi algo ruim caso o reflexo de sua população correspondesse ao que foi buscado como modelo. É importante lembrar que boa parte da história do povo brasileiro foi escrita sobre influência africana, entretanto um país que é considerado aberto a todos os povos, ignora, permanentemente, a história do povo preto, sobretudo no contexto educacional, onde a luta contra a supremacia deveria, segundo os modelos atuais que regem e direcionam o Estado e sua constituição, ser pétrea. O Brasil tem em sua construção pedagógica uma forte influência de diversos países e culturas, porém ao falar em ensino democraticamente racial um povo em específico fica de fora, transformando então o ensino em uma manutenção da supremacia branca, uma realidade que não deveria ter mais força nas escolas atuais, onde o rito de aprendizagem já faz parte do direito de todas as pessoas. Temos na lei 10.369, de janeiro de 2003, o direito de aprender sobre a história de África nas escolas, o que deveria assegurar a inserção de intelectuais negros de todos os campos de ensino. Optar pelo silêncio contribui para esse processo epistêmico. Aos educadores, utilizar o espaço escolar como palco de protagonismo e resistência também africana é uma responsabilidade, antes mesmo de uma lei. O povo preto deve ser referenciado.

Palavras-chave: África, Educação, Histórico. 
SOCIEDADE, DESIGUALDADE E EDUCAÇÃO: AS DESIGUALDADES SOCIAIS E SEUS REFLEXOS NO PROCESSO EDUCACIONAL

Maria Eduarda Yamashita1, José Victor Rodrigues Barbosa², Taisa Veloso Barretto ${ }^{3}$, Aleck Soares Alcantara ${ }^{4}$, Marcelo Silva ${ }^{5}$

Acesse a apresentação deste trabalho

Dado o presente cenário vivido na educação - causado, especialmente, pela pandemia -, o presente resumo tem como objetivo apresentar uma reflexão sobre as desigualdades sociais na educação, as quais ficaram ainda mais evidentes no quadro atual, principalmente na rede pública (onde se concentra a maior parte da população de baixa renda). O trabalho consiste na análise do trabalho de professores que tem a necessidade de atuar de forma mais criativa em sala de aula - enfatizando duas em especial, que atuam tanto na rede privada, quanto na pública, possibilitando levantar comparações entre o ensino público e privado; uma vez que ainda é muito comum que os docentes se encontrem em situações adversas, nas quais faltem equipamentos e salas adequadas (em especial para o ensino de ciências) e, também, as dificuldades que as diversas desigualdades - enfatizando a social - causam no processo educacional. A partir das informações obtidas no trabalho, foi constatado a grande disparidade não apenas entre o ensino público e privado, como também entre o ensino básico e superior - essa ocorrência tem inúmeras explicações, como a negligência de direitos que antecedem o direito à educação (como alimentação, saneamento básico, saúde, etc.), o preconceito contra LGBTQ+ e o racismo, outrossim, muitas crianças e adolescentes de baixa renda precisam afastar-se da escola para trabalhar (um dos fatores para o elevado índice de evasão nas escolas públicas); conjuntamente a isso e outros desafios que são enfrentados por professores e alunos, têm-se o sucateamento da educação básica, isto é, a falta de investimento na área, contribuindo para a baixa qualidade educacional. Posto isso, conclui-se que é de suma importância que na formação docente, os professores não apenas tenham ciência, mas também tenham um preparo de forma prática dessas dificuldades; dessa forma, apesar de ainda se estar longe do que seria o ideal educacional, a docência estará apta para superar as condições - muitas vezes, caótica- na educação.

Palavras-chave: Desigualdade, Iniquidade Social, Ensino, Problemas Sociais.

\footnotetext{
1 Discente de Ciências - Licenciatura, UNIFESP Campus Diadema.

2 Discente de Ciências - Licenciatura, UNIFESP Campus Diadema.jv.barbosa316@gmail.com

3 Discente de Ciências - Licenciatura, UNIFESP Campus Diadema. taisa.veloso@unifesp.br

4 Discente de Ciências - Licenciatura, UNIFESP Campus Diadema. aleckdealcantara@gmail.com

5 Discente de Ciências - Licenciatura, UNIFESP Campus Diadema. Marcelo.silva25@unifesp.br
} 


\section{PERCEPÇÃO DE PROFESSORES DOS ANOS FINAIS DO ENSINO FUNDAMENTAL SOBRE A INDISCIPLINA NO PROCESSO EDUCATIVO}

Maria Jakeline Vieira Milhomem ${ }^{1}$, Jónata Ferreira de Moura ${ }^{2}$

Acesse a apresentação deste trabalho

Este resumo é fruto de uma pesquisa de conclusão do curso de Pedagogia do Programa de Formação de Professores para a Educação do Plano de Ações Articuladas da Universidade Federal do Maranhão (PARFO/UFMA), em andamento, que tem como temática a indisciplina no processo educativo em turmas dos anos finais do Ensino Fundamental. Este fenômeno é um desafio encarado nas escolas de todo o país, manifestando-se como consequência de uma sociedade em que os valores têm sido secundarizados, mas também como resposta há imposições e desmandos. Elaboramos a seguinte questão de pesquisa: Quais as causas e interferências da indisciplina no processo educativo em turmas dos anos finais do Ensino Fundamental de uma escola da zona urbana de Sítio Novo-MA? Para encontrar respostas para a questão, elencamos os seguintes objetivos: 1. Conceituar os termos disciplina e indisciplina, apresentando suas características; 2. Investigar as causas da indisciplina no processo educativo em turmas dos anos finais do Ensino Fundamental; 3. Discutir os fatores que contribuem para as manifestações de indisciplina, bem como, sua interferência no processo de ensino e aprendizagem em turmas dos anos finais do Ensino Fundamental. A cidade onde está sendo realizada a pesquisa fica no interior do estado do Maranhão, fundada em 15 de dezembro de 1961 e localizada na microrregião de Alto Mearim e Grajaú, ao sul do estado, distante da capital São Luís $679 \mathrm{~km}$. Adentrar no universo de quatro professores dos anos finais do Ensino Fundamental é importante para entender as percepções deles sobre indisciplina de alunos adolescentes, principalmente para que eles possam dizer das manifestações deste sentimento e de como isso interfere em suas atividades docentes. Realizamos uma pesquisa qualitativa e utilizamos a entrevista semiestruturada para produzir dados. Até o momento, as entrevistas revelam o desconhecimento do docente frente às causas sociais da indisciplina e uma percepção psicologizante dos docentes para a indisciplina.

Palavras-Chave: Indisciplina. Anos Finais do Ensino Fundamental. Processo Educativo.

1 Estudante do curso de Pedagogia do Programa de Formação de Professores para a Educação do Plano de Ações Articuladas da Universidade Federal do Maranhão (PARFO/UFMA). E-mail: jakeline1962@hotmail.com

2 Professor Adjunto da Universidade Federal do Maranhão (CCSST/UFMA). E-mail: jf.moura@ufma.br 
PROJETOS DE EDUCAÇÃO AMBIENTAL NA ESCOLA: PRESENCIAL E À

DISTÂNCIA, SEGUIMOS!

Carolina Estéfano ${ }^{1}$

Acesse a apresentação deste trabalho

Trabalhar a Educação Ambiental é também possivel no ensino à distância, nas aulas online, que estão ocorrendo durante a quarentena da pandemia do Covid-19. Trabalho em Escola de Ensino Médio e Técnico, em que projetos são bem-vindos e optei por assim continuar o percurso que utilizo em minhas aulas presenciais, de sempre estimular os debates e expressões verbais e escritas das experiências e vivências de meus alunos, seja de forma individual, seja em grupo, por meio do WhatsApp. A disciplina de Biologia favorece a conectividade com os acontecimentos, sendo muito simples inserir temas da atualidade e estabelecer as conexões complementares, que envolvem a vida dos alunos e possiveis melhorias a serem tomadas, despertando interesse real, pois tudo que nos envolve, tem áreas da Biologia inseridas! Vimos o que é meio ambiente de forma ampla e holística e que os 17 Objetivos de Desenvolvimento Sustentável (ODSs) da Organização das Nações Unidas representam muito bem essa visão; fizemos um exercício de pensar quais ODSs cada um tem colaborado de forma individual e o que podemos fazer de forma coletiva, para ajudar no cumprimento das metas. Realizamos uma sessão cineclube, juntos, com um vídeo de 20 minutos, extraído da Mostra EcoFalante, sobre os biomas Mata Atlântica, Cerrado e Floresta Amazônica, biodiversidade, ações antrópicas, serviços ecossistêmicos e possíveis soluções para os impactos negativos que o homem vem causando aos recursos naturais e à nos mesmos! Fizemos um debate dos principais pontos e posteriormente, os alunos entregaram um relatório sobre o ciclo da água, quais os 17 ODSs que foram relatados e sobre os tipos de serviços ecossistêmicos. Também estamos participando do Desafio Circular, da rede de Escolas, sobre Economia Circular e vamos apresentar ideias de produtos que solucionem vulnerabilidades sociais, ambientais e econômicas da escola e do território, por meio de reuso e customização de materiais que seriam descartados.

Palavras-chave: Educação Ambiental; Projetos Escolares; Ensino à Distância. 
O PACTO NACIONAL PELA ALFABETIZAÇÃO NA IDADE CERTA (PNAIC): IMPACTOS NA FORMAÇÃO E NAS PRÁTICAS DE ENSINO DOS PROFESSORES ALFABETIZADORES DA REDE MUNICIPAL DE ENSINO DE SÍTIO NOVO DO

\author{
MARANHÃO/MA \\ Maria Rita de Sousa Silva Marinho1, Jónata Ferreira de Moura² \\ Acesse a apresentação deste trabalho
}

Este resumo é fruto do Trabalho de Conclusão de Curso de Pedagogia do Programa de Formação de Professores para a Educação do Plano de Ações Articuladas da Universidade Federal do Maranhão, e tem como tema, o Pacto Nacional pela Alfabetização na Idade Certa (PNAIC) na rede municipal de ensino do Município de Sítio Novo do Maranhão/MA. A questão da pesquisa é: quais os indícios de melhorias, a partir do IDEB de 2013 a 2017, que o PNAIC proporcionou a rede municipal de ensino de Sítio Novo do Maranhão/MA, particularmente na formação e na prática das professoras-alfabetizadoras? Elencou-se os seguintes objetivos: 1. Analisar a adesão do PNAIC pelo município de Sítio Novo do Maranhão e seu desenvolvimento; 2. Averiguar as contribuições do PNAIC na formação permanente das professoras-alfabetizadoras; 3. Identificar as potencialidades que o PNAIC ofereceu na prática docente das professorasalfabetizadoras. A pesquisa é de abordagem qualitativa, fez-se uso de entrevistas semiestruturadas com as três formadoras do programa, a coordenadora local, três professoras-alfabetizadoras e a secretária de educação da época que o programa funcionava no município de Sitio Novo/MA. A investigação revelou que há indicios de melhorias nas práticas docentes resultadas pelo PNAIC; as professoras alfabetizadoras reconhecem as contribuições do programa para sua prática, no que concerne na seleção dos conteúdos, na escolha da metodologia para ensinar este ou aquele conteúdo escolar, estratégias para ensinar as crianças a lerem e a escreverem; com os encontros proporcionados pelo PNAIC, ficou entendido que a formação oferecida pelo programa foi uma grande oportunidade de repensar as práticas pedagógicas dos professores alfabetizadores, trazendo resultados positivos no aprendizado das crianças no ciclo de alfabetização no Município de Sítio Novo do Maranhão/MA.

Palavras-chave: PNAIC; Formação Continuada; Sítio Novo do Maranhão.

1 Acadêmica do $9^{\circ}$ período do curso de Pedagogia do Programa de Formação de Professores para a Educação Básica do Plano de Ações Articuladas - PROFEBPAR/UFMA, e-mail: kauaetiago2016@gmail.com

2 Professor Mestre do curso de Pedagogia do Centro de Ciências Sociais, Saúde e Tecnologia da Universidade Federal do Maranhão UFMA/CCSST, E-mail: jf.moura@ufma.br

ISBN 978-65-88471-05-0 | https://doi.org/10.47247/VV/ENMD/88471.05.0 


\title{
O EDUCADOR DE ONG COMO PROFISSIONAL REFLEXIVO: ANALISANDO UMA
}

\section{AÇÃO DESENVOLVIDA COM OS ADOLESCENTES DO GRUPO TUMM}

\author{
Maria Antonieta Ribeiro Ciancio Pinto
}

Acesse a apresentação deste trabalho

Esse trabalho refere-se a um Relato de experiência sobre minha rotina de trabalho desenvolvida como educadora de uma atividade não formal, com as ações do Grupo TUMM, realizadas na Casa do Adolescente situada em um municipio do interior paulista. O estudo visa ressaltar a importância do educador da ONG como profissional reflexivo e o seu papel na formação dos adolescentes. O recorte da pesquisa se assenta na análise de ação realizada em uma oficina de formação de adolescentes multiplicadores em que meu papel foi o de mediadora do processo. Para o desenvolvimento do estudo foi utilizado como metodologia de pesquisa as quatro ações, desenvolvidas por Smyth (1992) (descrever; informar; confrontar e reconstruir). Como referencial teórico para a discussão sobre profissionalização e profissional reflexivo foram utilizados autores tais como: Tardif (2010); Wittorski (1998); Nóvoa (1997); Schön (1992). Também contribuíram com o estudo autores que auxiliaram na discussão sobre a ONG como um espaço educativo (GONÇALVES E SILVA, et al, 2009). A análise dos dados revela que o educador da ONG é um profissional que mobiliza diversos saberes e reflete sobre suas ações num processo contínuo de busca de conhecimento, diálogo, articulação entre os diversos contextos e de intencionalidade politico-pedagógica em seu cotidiano de trabalho. Neste sentido, os dados levantados com esse estudo além de fortalecer e reafirmar a importância desse profissional em espaços não formais, também, revelou para a pesquisadora participante, um novo olhar sobre sua ação, seus referenciais de base e sobre a possibilidade da reflexão na ação e sobre a ação de forma intencional, transformadora e investigativa.

Palavras-chave: ONG, Educador; Profissional Reflexivo. 
A MONITORIA E O USO DAS TICS NOS PROCESSOS DE ENSINO E APRENDIZAGEM NO ENSINO REMOTO NAS UNIVERSIDADES: A REALIDADE EM UM CURSO LICENCIATURA EM CIÊNCIAS BIOLÓGICAS

\author{
Antonia Maria Alves ${ }^{1}$, Maria Rejane Lima Brandim ${ }^{2}$
}

Acesse a apresentação deste trabalho

\begin{abstract}
A monitoria é um atividade que contribui para a formação do aluno universitário, com o estabelecimento de novas práticas e experiências pedagógicas que visem fortalecer a articulação teoria e prática e a integração nas atividades de ensino, pesquisa e extensão dos cursos de graduação conforme Candau (1986) e Friedlander (2003). Contudo, no contexto da Pandemia pelo Covid-19, a monitoria precisou ser revista e rearticulada nas universidades no estabelecimento do ensino remoto mediado pelas Tecnologias da Informação e Comunicação - TICs. No Curso de Licenciatura em Ciências Biológicas da Universidade Federal do Delta do Parnaíba-UFDPar não foi diferente. Algumas disciplinas foram ofertadas pelo curso na modalidade remota nesse período e precisaram do auxílio de monitores para a condução dos trabalhos, considerando situações tais: domínio das plataformas digitais por parte dos professores e alunos, apoio para a realização das atividades sincronas e assíncronas, orientação e apoio aos estudos on line e/ou off line. Esta pesquisa, em andamento, tem por objetivo discutir os processos de adaptação realizados para que os alunos monitores pudessem conduzir suas ações frente a essa realidade e caracterizar o processo de ensino e aprendizagem dos conteúdos mediados pelas TICs. Utilizamos como metodologia a abordagem qualitativa para nos aproximarmos dessa realidade tendo como eixo central a compreensão da complexa dinâmica estabelecida nas ações dos monitores e suas relações com os conteúdos, com os professores, com os alunos, com as novas metodologias digitais. Os sujeitos da pesquisa foram 05 monitores de disciplinas de ciências biológicas, 10 professores e 170 alunos matriculados na modalidade remota. Os primeiros dados nos permitem avaliar que a) a adaptação ao ensino remoto tem sido um processo complexo; b) o domínio das TICs é condição fundamental para trabalho nas disciplinas; c) as ações dos monitores viabilizaram as atividades de ensino e aprendizagem dos conteúdos.
\end{abstract}

Palavras-chave: Monitoria; ensino remoto; mediação tecnológica; ensino aprendizagem

1 Aluna do Curso de Licenciatura em Ciências Biológicas da Universidade Federal do Delta do Parnaíba-UFDPar

2 Professora Doutora do Curso de Licenciatura em Ciências Biológicas da Universidade Federal do Delta do Parnaíba-UFDPar 


\title{
A PROFISSIONALIZAÇÃO DA DOCÊNCIA NA EDUCAÇÃO INFANTIL: A
}

\section{ANÁLISE DE PRÁTICAS DE UMA PROFESSORA EM INÍCIO DE CARREIRA}

\author{
Mariana Fiorio ${ }^{1}$ e Márcia Regina Onofre ${ }^{2}$ \\ Acesse a apresentação deste trabalho
}

Este relato de experiência no campo da docência na educação infantil teve como objetivo averiguar quais são os saberes mobilizados na prática de uma professora iniciante. Justificamos esse exercício pela necessidade de compreender como a prática pedagógica na Educação Infantil tem constituído o fazer, o ser e o saber docente enquanto profissional da área, tendo como eixo o movimento de profissionalização do ensino. Como metodologia foi utilizada a proposta de Smyth (1992), enfocando as etapas de análise: descrição, informação, confrontação e reconstrução da prática investigada. O trabalho de reflexão teve como ponto de partida, a análise de um plano de aula de uma professora da educação infantil, elaborado em uma turma do Pré I, tendo como temática a Identidade. O exercício oportunizou um olhar investigativo sobre a prática proposta, promovendo, assim, uma reflexão pautada em uma releitura sobre a ação docente e os saberes que a constitui, reconhecendo, dessa forma, a identidade profissional da professora iniciante da educação infantil. Os resultados revelam, que por se tratar de uma professora em início de carreira, suas ações foram pautadas: a) pelos saberes experiencias, ou mesmo préprofissionais (educação familiar, escolarização) e pela universitarização; b) a questão dos valores, disciplina (regras) e a relação professor/aluno; e, c) a experiência no Estágio Supervisionado, marcada pela abordagem dialógica e afetiva. Nesta direção, concluímos que este processo implicou mais do que refletir, transformar e ressignificar a prática pedagógica, na medida que se buscou com tal exercício, desenvolver uma cultura profissional como professora na educação infantil, enfatizando a superação das lacunas formativas por meio da profissionalização docente.

Palavras-chave: Educação Infantil; Profissionalização da docência; Análise de práticas.

\footnotetext{
1 Universidade Estadual Júlio de Mesquita Filho - campus Rio Claro/SP; maafiorio12@gmail.com.

2 Universidade Federal de São Carlos - UFSCar (Prof. ${ }^{a}$ Dr. $^{a}$ colaboradora); mareonf@yahoo.com.br.
} 


\title{
DESIGUALDADE NO INGRESSO À UNIVERSIDADE:
}

\author{
PERCEPÇÕES, PROBLEMAS E ANÁLISE
}

\author{
Mariana Gonçalves Ribeiro da Costa ${ }^{1}$, Mariana Vasconcelos' ${ }^{2}$, \\ Yasmin de Macedo Silva ${ }^{3}$, Yasmin Parus ${ }^{4}$
}

Acesse a apresentação deste trabalho

Diferente do que muitos pensam, a Universidade Pública não é um privilégio do cidadão, mas sim um direito. Logo, por esse pensamento e por falta de oportunidade, é frequente se deparar menos com ingressantes negros, de baixa renda e deficientes. Este trabalho surgiu como um relato de aprendizagem da disciplina de Introdução aos Estudos em Educação para a reflexão e uma breve análise sobre a desigualdade no ingresso à Universidade. E as autoras desse resumo, colocam suas percepções baseadas nas seguintes perguntas: Quais dificuldades precedem e sucedem a entrada dos ingressantes na Universidade? Como este lida e por que existe a desigualdade? Em reflexão sobre essas perguntas, foi possivel compreender que estudantes corriqueiramente encontram desigualdade no ingresso à Universidade por conta da entrada à instituição ser natural para a elite e a realidade ser muito diferente para os alunos de escolas públicas. Sendo assim, a defasagem na educação básica e uma menor situação financeira afetam as chances de conseguir o ingresso, como observamos em diferentes estudos. Com isso, num cenário onde estudantes menos favorecidos conseguem uma vaga, após adentrar à Universidade, as desigualdades passam a ser outras, como, por exemplo, deslocamento, conciliação de trabalho e estudos e a alimentação, sendo estes os fatores que dificultam o ingresso e permanência na Universidade, sobrecarregando também a saúde psicológica e fisica dos discentes. Logo, para auxiliar o ingresso e permanência desses estudantes, as Universidades dispõem-se de cotas para estudantes de escolas públicas, baixa renda e raciais e, também, bolsas para auxiliá-los. No entanto, existem furos no sistema diferindo a teoria da prática. Com base no aprendizado adquirido em aulas e na vida das quatro autoras, conclui-se que a desigualdade presente antes do ingresso à Universidade e durante o período de estudos é real, e afeta em maioria estudantes de escola pública, devendo ser combatida de maneira efetiva.

Palavras-chave: Desigualdade social, Universidade Pública, estudantes ingressantes.

\footnotetext{
1 Discente do curso de Ciências - Licenciatura, Universidade Federal de São Paulo (Unifesp). Email: ribeiro06mariana@gmail.com.

2 Discente do curso de Ciências - Licenciatura, Universidade Federal de São Paulo (Unifesp). Email: mvekawamura@unifesp.br.

3 Discente do curso de Ciências - Licenciatura, Universidade Federal de São Paulo (Unifesp). Email: yasmin.m.silva@hotmail.com.

4 Discente do curso de Ciências - Licenciatura, Universidade Federal de São Paulo (Unifesp). Email: yasminparus@hotmail.com
} 
UMA METODOLOGIA ATIVA EM ATIVIDADES DE CIÊNCIAS PARA AULAS A

\title{
DISTÂNCIA - BALDE BIOFILTRO
}

\author{
Andrey Patrick Carvalho da Silva, Bruna de Oliveira Menezes, \\ Érica Ferreira de Oliveira, Mariele Leão Alves
}

$\underline{\text { Acesse a apresentação deste trabalho }}$

Com o fechamento de escolas ocasionadas pela pandemia de Covid-19, diversos setores foram forçados a remodelar padrões de trabalho, dentre eles a educação. Para docentes de ciências, o obstáculo é grandioso: Como ensinar conteúdos que exigem práticas e demonstrações experimentais à distância? Como incitar participação ativa dos discentes na execução de tais atividades? Visando minimizar as dificuldades encontradas no processo de ensino-aprendizagem remoto no Ensino Fundamental II, propõe-se o desenvolvimento de uma atividade de metodologia ativa, que propicia o estudo de temas relacionados a sustentabilidade, baseando-se no trabalho de Francisco Fechine Borges, intitulado Caixa de Ciências Água, com a construção de um balde biofiltro (BBF), cujo objetivo é realizar a filtração e descontaminação da água por camadas porosas, tornando-a potável. Segundo Macedo et al (2018) a Metodologia Ativa (MA) tem uma concepção de educação crítico-reflexiva com base em estímulo no processo ensino-aprendizagem, resultando em envolvimento por parte do educando na busca pelo conhecimento, possibilitando inserir o aluno como responsável pelo seu aprendizado e seu conhecimento. $O$ princípio de funcionamento do BBF é simples e utiliza materiais de baixo custo: um balde com tampa é o reservatório, conexões do tipo $\mathrm{T}$ e pedaços de mangueira realizam a irrigação e interligação, um copo é o reservatório da água filtrada e areia e pedras fazem a filtração. Espera-se que a elaboração do BBF induza reflexões sobre a importância e contextualização de alguns conceitos no atual momento, estimulando o desenvolvimento de práticas metodológicas que tornem o aluno parte ativa de seu aprendizado e que a montagem do BBF seja beneficiada pela interdisciplinaridade científica.

Palavras Chave: Metodologia ativa. Balde biofiltro. Sustentabilidade. 


\title{
DISCIPLINA DE ÉTICA NA MODALIDADE REMOTA DURANTE PANDEMIA: RELATO DE EXPERIÊNCIA
}

\author{
Marli Aparecida reis Coimbraํㅜ, Lucas Carvalho Santana 2, Lúcia Aparecida Ferreira 3 , \\ Leiner Resende Rodrigues ${ }^{4}$, Maria Helena Barbosa ${ }^{5}$
}

Acesse a apresentação deste trabalho

O presente estudo visa descrever a avaliação de pós-graduandos de mestrado quanto ao ensino na modalidade remota da disciplina de ética, em período de pandemia do novo coronavirus SARS-Cov2. Trata-se de um estudo descritivo, do tipo relato de experiência, segundo Resolução 510/2016. Foi realizado no mês de julho de 2020 . A disciplina de ética tem carga horária de 30 horas e contou com a participação de 11 mestrandos matriculados. As aulas remotas foram ministradas pela Plataforma Google Meet e contou com exposição dialogada dos assuntos referentes à temática. Os alunos apresentaram seminários, trouxeram suas vivências, foram aplicados quiz (perguntas e respostas), e os alunos também puderam conhecer ferramentas para o pesquisador como o ORCID (Open Researcher and Contributor ID). A comunicação aluno-professor manteve-se além das aulas remotas, como o uso de WhatsApp para esclarecimentos e informações, e e-mails para troca de material didático elaborado. Ao final da disciplina foi aplicado um formulário de avaliação da disciplina na tentativa de os alunos expressarem suas opiniões acerca da condução da disciplina. Todos os alunos responderam, e destes $90,9 \%$ julgaram a disciplina como muito relevante para a formação acadêmico-científica; 50,4\% acreditaram que a disciplina apresentou grau de dificuldade razoável; $72,7 \%$ consideraram que os professores apresentaram muita disponibilidade fora da sala de aula; e $72,7 \%$ dos alunos consideraram o domínio do tema pelos professores muito alto. Em relação à autoavaliação dos alunos, 63,6\% relataram o máximo de dedicação à disciplina; $81,8 \%$ se autoavaliaram como participativos nas discussões em grupo; e 63,6\% acreditam que atingiram o nível máximo de aproveitamento na disciplina. Todos os alunos consideraram que adquiriram novos conhecimentos. A disciplina de ética, abordada pela primeira vez na modalidade remota não comprometeu o aprendizado dos mestrandos, sendo avaliada de forma positiva.

Palavras-chave: Aula; Acesso à Internet; Docentes.

1 Programa de Pós-Graduação em Atenção à Saúde. Universidade Federal do Triângulo MineiroUFTM. marli.apr.coimbra@gmail.com

2 Programa de Pós-Graduação em Atenção à Saúde. Universidade Federal do Triângulo MineiroUFTM. lucas_enfer@hotmail.com

3 Programa de Pós-Graduação em Atenção à Saúde. Universidade Federal do Triângulo MineiroUFTM. Lap2ferreira@yahoo.com.br

4 Programa de Pós-Graduação em Atenção à Saúde. Universidade Federal do Triângulo MineiroUFTM. leiner.r.rodrigues@gmail.com

5 Programa de Pós-Graduação em Atenção à Saúde. Universidade Federal do Triângulo MineiroUFTM. mhelena331@hotmail.com 


\title{
A REFORMA DO ENSINO MÉDIO E A DESIGUALDADE EDUCACIONAL:
}

\section{IMPACTOS E CONTROVÉRSIAS DA NOVA ESTRUTURA}

\author{
Gustavo Huang Tai ${ }^{1}$, Julia Beatriz Neves Torres ${ }^{2}$, Matheus Guazzelli Silva ${ }^{3}$, Luana Lima ${ }^{4}$
}

Acesse a apresentação deste trabalho

A Reforma do Ensino Médio, proposta pelo governo Michel Temer, em 2016, inicialmente apresentada como Medida Provisória (MP) n. ${ }^{\circ} 746 / 2016$, e instituída pela lei federal 13415 de 2017. Tal proposta é expressa com a homologação da BNCC (Base Nacional Comum Curricular), aprovada pelo Conselho Nacional de Educação (CNE) no dia 4 de dezembro de 2018, onde o seu objetivo principal é sanar as incongruências do sistema educacional, a partir de um ensino médio integral, somadas à implementação de um currículo menos extenso, diversificado e atrativo, possibilitando assim, um diálogo com os estudantes, bem como estímulo para desenvolvimento das suas habilidades e competências. Contudo, as alterações postas como soluções, reforçam um currículo desigual. O presente estudo, tem como foco, refletir sobre as desigualdades possiveis na reforma educacional. A análise nos permite observar que a tentativa de padronização do ensino médio brasileiro, evidência as desigualdades, já que torna, como função exclusiva da escola, a oferta de itinerários formativos, que compõem $40 \%$ do currículo escolar, não inserem como pauta que, a quantidade e variedade dos roteiros disponibilizados, dependerá das condições econômicas e estruturais das escolas. Outro ponto identificado, é a participação do Banco Mundial e a OCDE (Organização para a Cooperação e Desenvolvimento Econômico), com a utilização de testes, como o PISA (Programa Internacional de Avaliação de Estudantes), que apontam nos seus resultados o não cumprindo do "papel" formacional da escola e desconsideram as particularidades socioeconômicas regionais. Há uma linha tênue dos interesses (cultural, econômico e político), ou seja, a reforma não busca sanar as desigualdades entre os setores público e privado, e sim, assegurar e prolongar os privilégios, uma vez que a conduz para favorecimento do capital e distanciando do caráter da premissa educacional que é a formação de um sujeito com pensamento crítico na sociedade.

Palavras-chave: Reforma Educacional; BNNC; Desigualdade na educação.

1 Graduando de Licenciatura em Ciências. UNIFESP. gtai@unifesp.br.

2 Graduando de Licenciatura em Ciências. UNIFESP. julia.beatriz26@unifesp.br

3 Graduando de Licenciatura em Ciências. UNIFESP. matheus.guazzelli@unifesp.br

4 Psicopedagoga graduada pela UNIFIEO e pós-graduada pelo Mackenzie. Graduanda de Licenciatura em Ciências e Aluna Especial do PECMA pela Universidade Federal de SP UNIFESP.lima.luana@unifesp.br 
A FORMAÇÃO DOCENTE E O USO DAS METODOLOGIAS ATIVAS E

\author{
FERRAMENTAS DIGITAIS, COMO PENSAMENTO INOVADOR NO PROCESSO
}

DA METACOGNIÇÃO

Andréa de Sousa Galliza Mitchell de Morais ${ }^{1}$

Acesse a apresentação deste trabalho

Trata e defende a abordagem de empregar o processo de formação com o auxilio da Metodologias Ativas na integração entre teoria e prática que prometem um novo olhar na formação, tornando-a mais sólida, coerente e efetiva, na aprendizagem significativa e na construção da metacognição. Objetiva entender que as Metodologias ativas surgem como alternativa para a educação superior e para um melhor aperfeiçoamento do acadêmico para o mercado de trabalho. Empregando as Ferramentas Digitais no ensino, presencial, virtual e híbrido, que contribui para a formação integrada nas atividades de ensino, pesquisa e extensão, no cenário sociotécnico contemporâneo, de nossa cultura estruturada pelas Ferramentas Digitais em rede, para reconfigurar a educação formal e estar mais em sintonia com o espírito de nosso tempo. Este trabalho tem como intuito o pensar na formação docente com o uso das Metodologias Ativas e Ferramentas Digitais, na utilização de técnicas de ensino como objetivo para melhorar a prática profissional que é baseada em atitudes e valores, tendo-os como pensamento inovador no processo da metacognição. As Ferramentas Digitais e Metodologias Ativas tem como função principal permitir o alcance da autonomia para a autoformação. Então, a metacognição não seria o planejamento de melhoras pedagógicas para um processo cognitivo e afetivo? Tendo como objetivo atuar na formação docente, será investigado neste trabalho quais técnicas para que isso ocorra e analisadas as linhas doutrinárias para o respaldo desta pesquisa. A pretensão deste trabalho é de otimizar o processo de formação com inovação, utilizando recursos tecnológicos, processo híbrido, novos modelos de pensamento e desenvolvimento humano para o saber, habilidades e conhecimentos adquiridos a relação-chave entre tecnologias e competências e a formação baseada em competências. Serão estudadas as diversas metodologias ativas para esse processo de autoformação, sendo apresentadas com suas abordagens para as mais diversas formas de aprendizagem. Metodologias ativas são técnicas, estruturas, recursos, sistemas ou abordagens cujo objetivo é incentivar seus estudantes a aprender de forma mais autônoma. Para isso, esses métodos utilizam atividades que envolvem colaboração, problemas reais, diversão, empatia, pensamento crítico e, em vários casos, tecnologia para buscar uma melhor formação, levando a buscar melhores condições de trabalho, estrutura e organização da atividade profissional. Essas práticas parecem, mas não são novas. Na obra "Emílio" de Jean Jacques Rousseau (1712-1778), a experiência assume destaque em detrimento da teoria. Diversos processos de ensino são pautados na aprendizagem pela interação social, preconizada por Lev Vygotsky (1896-934), na aprendizagem pela experiência (Dewey, 1978), a aprendizagem significativa de David Ausubel (1918-2008) e levando em consideração a perspectiva freiriana da autonomia (Freire, 2015). A metodologia

1 andreagalliza@hotmail.com

ISBN 978-65-88471-05-0 | https://doi.org/10.47247/VV/ENMD/88471.05.0 
utilizada para essa pesquisa é a descritiva analitica. $\mathrm{Na}$ pesquisa descritiva, se descreve os fenômenos a fim de ter informações sobre o problema levantado, a analitica vem ampliar essas conclusões, analisando e explicando o porque dos fatos e como esses estão acontecendo, estabelecendo relações causais, entre as causas e os elementos dos efeitos. As metodologias ativas são modelos de ensino que visam desenvolver a autonomia e a participação dos alunos de forma integral. Com isso, as práticas pedagógicas são beneficiadas e todo o processo educativo é melhorado e aprimorado. Utilizando-as no processo de formação docente estaremos trabalhando e investindo em uma bagagem educacional, e esse conhecimento adquirido se transformará e perpassará para as novas gerações. Juntos com as diversas Metodologias Ativas, ágeis, imersivas e analíticas existentes hoje na educação também existem diversas Ferramentas Digitais, com as mais variadas funções podendo estimular e desenvolver todas as competências a que se desejar. Com a personalização do ensino trazido pelos novos processos de aprendizagem é possivel trabalhar com cada estudante em seu ritmo individual, ajudando a desenvolver as competências e habilidades individuais. Temos fora do ambiente escolar vastas ferramentas de aprendizagem, o celular nos traz acontecimentos diário do mundo todo em tempo real, temos a disposição vários sites e apps que nos levam a vários lugares do mundo em um clique, temos a mão vídeos de qualquer assunto que se queira saber ou aprofundar-se, temos os significados de qualquer palavras em poucos segundos, então fica claro que as instituições de ensino não podem se tomar alheias a essa realidade, pois isso torna os alunos ou docentes em formação sem estímulos, o mundo fora da escola esta cheio desses incentivos, a pandemia não precipitou essas mudanças de enormes proporções, ela apenas trouxe á tona o que já deveria estar no sistema educacional como um todo. Inicialmente tem-se que pensar a avaliação em função do planejamento, quais habilidades e capacidades se pretende desenvolver, escolhendo para isso as metodologias e ferramentas que se adapte as essas intenções. A forma de avaliar deve se adequar ao aluno, por ser um ensino personalizado e individualizado. As formas de avaliar são muitas e as possibilidades são constantes, e a partir desses resultados diários e constantes faz-se ou não necessária uma adequação aos métodos, ritmos, formas no processo, para uma adaptação do melhor caminho a ser seguido por cada docente em formação. Deve-se mesclar nesse processo o virtual e o físico, a avaliação deve verificar o processo de aprendizagem agindo nos resultados obtidos, como um feedback metacognitivo, "o docente conseguiu desenvolver sua aprendizagem autônoma? “. Hoje temos muitos caminhos abertos para avaliação como a internet, computadores, tablets e celulares que passaram a integrar a educação, mesmo que por vias limitadas. Temos fora do ambiente escolar vastas ferramentas de aprendizagem, o celular nos traz acontecimentos diário do mundo todo em tempo real, temos a disposição vários sites e apps que nos levam a vários lugares do mundo em um clique, temos a mão vídeos de qualquer assunto que se queira saber ou aprofundar-se, temos os significados de qualquer palavras em poucos segundos, então fica claro que as instituições de ensino não podem se tomar alheias a essa realidade, pois isso torna os alunos ou docentes em formação sem estímulos, o mundo fora da escola esta cheio desses incentivos, a pandemia não precipitou essas mudanças de enormes proporções, ela apenas trouxe á tona o que já deveria estar no sistema educacional como um todo. Para concluir o tema abordado e sua problemática de que as Ferramentas Digitais e Metodologias Ativas tem como função principal de permitir o alcance da 
autonomia para a autoformação e uma aprendizagem individualizada e personalizada em detrimento das diferentes competências e habilidades de cada um na sua individualidade. Pode-se perceber que quando temos a possibilidade de atingir através das metodologias ativas, ágeis, imersivas e analíticas o desenvolvimento da aprendizagem autônoma, construindo assim a metacognição de cada individuo, teremos os seus objetivos individuais, seus pontos fracos, suas habilidades trabalhadas de forma mais assertiva e eficaz. Sabemos que se um docente em formação tem habilidades com textos escritos, este se destacará em atividades com produções textuais, com criação de histórias, infográficos, cartazes e outros, se outro tem facilidade com a oralidade, se destacará em atividades tipo podcast, vídeos, narrativas, etc, se outro se destaca pela dramatização e uso corporal, terá destaque em dramas, teatros, tik tok etc. Conclui-se que nas Metodologias ativas e com as ferramentas digitais a forma de avaliação é muito vasta e faz com que além de altos estímulos serem testados, torna-se mais justa a avaliação final, fazendo que cada um tenha um arsenal de métodos a seu dispor para ser suporte de meio e fim no processo de aprendizagem e que corresponda com suas competências e habilidades. Dentro de todo contexto, sabemos que nós somos fruto do nosso processo de ensino aprendizagem, e para formarmos docentes ativos e híbridos, devemos fazê-lo assim durante toda sua formação.

Palavras-chave: Metodologias Ativas, Ferramentas Digitais, Formação Docente 


\section{GÊNERO, SEXUALIDADES E MASCULINIDADES EM INSTITUIÇÕES}

\section{SOCIOEDUCATIVAS}

Jónata Ferreira de Moura ${ }^{1}$

Acesse a apresentação deste trabalho

Este resumo é fruto de uma pesquisa em andamento que tem como eixo temático Educação e Direitos Humanos. Presume-se que adolescentes brasileiros, sobretudo aqueles oriundos das classes populares ou de baixa renda, apresentam-se em conjunturas de vulnerabilidades sociais, podendo a arquitetura dessas condições propiciar a implicação com alguma forma de prática infracional. Pode-se mencionar, ainda, a falta de acesso à informação sobre métodos contraceptivos e prevenção às doenças sexualmente transmissiveis, a ausência de assistência médica de qualidade em postos de saúde que concretizem programas de cuidados específicos para a adolescência, o que, de forma direta ou indireta, inibe a superação dos obstáculos impostos socialmente, inclusive de viver sua sexualidade; ainda mais quando encontram-se em cumprimento socioeducativo. Assim, o objetivo é analisar as políticas públicas que proporcionem a reflexão sobre gênero e sexualidades com adolescentes em cumprimento socioeducativo, via agentes socioeducadores/as. Conhecer como se configura o exercício da sexualidade por parte de sujeitos privados de liberdade, coadunando-se a um posicionamento teórico abalizado pelos Estudos de Gênero e Culturais faz-se necessário e urgente, pois nestes espaços muitos são silenciados e seus sentimentos são negligenciados. A investigação é de caráter exploratóriodescritivo, abordagem qualitativa, em uma unidade de internação masculina no Maranhão (CSRT/FUNAC). Os sujeitos são socioeducadores/as das áreas da segurança, psicossocial e pedagógica. Utilizei entrevistas e questionários semiestruturados para produzir os dados, que foram analisados via análise de conteúdo. As primeiras análises revelam a necessidade de refletir sobre as condições construídas que podem estabelecer e manter práticas sexistas e homo/transfóbicas em ambientes onde a proposta pedagógica deveria agenciar uma educação social que aquilatasse os princípios básicos dos Direitos Humanos, conforme as normativas legais estabelecidas.

Palavras-chave: Sexualidades; Gênero; Juventudes; Socioeducação; Privação de liberdade.

1 Professor Adjunto da Universidade Federal do Maranhão (CCSST/UFMA). E-mail: jf.moura@ufma.br 


\section{A PERCEPÇÃO DO ESPAÇO COMO MEDIADOR DE LEITURA}

Paula Redigolo Alves de Aguiar ${ }^{1}$

Acesse a apresentação deste trabalho

Este artigo trata-se de um relato de experiência sobre um trabalho de mediação de leitura literária com instalação mediadora fora do ambiente destinado à leitura, desenvolvido com um grupo de crianças visitantes de espaços culturais de São Paulo e interior. Tem como objetivo relatar a experiência da autora na condução de um grupo infantil diversificado, com permanência na prática literária com tempo variável. Estas atividades foram desenvolvidas com metodologia participativa, na qual procurou-se preservar a identidade social e cultural dos participantes. Ao final das sessões de mediação de leitura literária, tantos os participantes, quanto seus responsáveis presentes, expressaram relatos sobre sua experiência pessoal, advinda da prática e sensações sobre a instalação mediadora. Participaram do grupo, crianças de 3 a 10 anos acompanhadas de seus responsáveis. Foram realizadas vinte mediações de leitura literária com o projeto Telhado de Histórias, entre o periodo de abril a dezembro de 2019. Muito antes de aprender a ler, as crianças já se acostumam com o objeto livro e através de estímulos, se aproximam das palavras escritas e faladas. A leitura é capaz de transformar o indivíduo em um sujeito ativo, responsável pela sua aprendizagem, que sabe compreender o contexto em que vive e modificá-lo de acordo com a sua necessidade. A curadoria dos livros torna-se fundamental para aproximar o leitor da obra literária e o espaço mediador, transforma-se em ponte diante das palavras e dos olhos ávidos da criança. E como fazer a mediação desta leitura, sem o espaço e uma curadoria especializada? Os resultados dessas atividades foram registrados, aprimorando as práticas de curadoria de livros nãoconvencionais e compreensão dos ambientes destinados à leitura, como mediadores na formação do leitor literário na atualidade, de forma a permitir reflexões e adequações a estes espaços.

Palavras-chave: Mediação de leitura, espaço mediador, leitor

1 Artista, educadora e pesquisadora. Pesquisadora pelo selo Raconto de projetos de incentivo à leitura e professora de Arte e Cultura na Fundação Casa. E-mail raconto@outlook.com 
OS IMPACTOS DA DESIGUALDADE RACIAL E A ESCOLARIZAÇÃO: REFLEXÃO SOBRE O RACISMO E A PERMANÊNCIA ESCOLAR

Ana Laura Sabino dos Santos ${ }^{1}$, Fernando Daros Carvalho Amancio², Julia Azevedo de Sá Nunes³, Paulo Victor Santos Sousa ${ }^{4}$,Luana Lima ${ }^{5}$

Acesse a apresentação deste trabalho

Há séculos, compreende-se que a educação deveria ser uma forma de reduzir desigualdades, contudo, nas práticas sociais cotidianas, os atos de discriminação racial reforçam que o sistema educativo, deste sua gênesis, assegura o prolongamento do privilégio educacional, em que há os guiados para a educação e outros guiados para o trabalho, estabelecendo-se, assim, a cor da pele como um patrimônio, que atribuirá vantagens ou desvantagens. Ao compreender as disparidades escolares existentes, o presente estudo tem como objetivo compreender qual relação da evasão escolar e a desigualdade racial. Os participantes $(n=150)$, sobretudo estudantes de escola pública $(n=76 \%)$, responderam a um questionário digital com uma pergunta aberta e 10 do tipo Likert, totalizando 11 questões. Onde foi abordado, temas relacionados as questões raciais. Ao questionar qual sua autoidentificação racial: 42\% se autodeclararam como pardos, enquanto $19 \%$ como pretos. Dentre as questões realizadas, as que norteiam maior relevância neste estudo são: "Já presenciou algum ato de racismo na escola?" onde 79,3\% responderam que SIM; "Como os professores reagiram aos atos de desigualdade racial?" em que apenas 43,3\%, optaram pela alternativa "acionaram as medidas cabiveis", seguido pela opção "não se posicionaram" com 42\%. Os resultados demonstram a urgência numa formação docente com base na Lei $n^{\circ} 11.645$ - obrigatoriedade do estudo da história afro-brasileira e indígena - uma vez que, mesmo passado mais de um século da abolição da escravização do Brasil, ainda há uma ambiguidade na forma em que as questões étnico-raciais são tratadas, sendo o negro, ainda, um cidadão à margem. O incentivo à formação com um olhar mais empático ao que tange as desigualdades raciais no meio escolar, possibilitará que o estudante usufrua plenamente do seu direito de acesso à educação e garantir as condições para permanência na escola, assegurados pela constituição brasileira.

Palavras-chave: Desigualdade Racial; Educação Étnico-racial; Lei n ${ }^{\circ}$ 11.645.

\footnotetext{
1 Graduando de Licenciatura em Ciências. UNIFESP. alssantos@unifesp.br

2 Graduando de Licenciatura em Ciências. UNIFESP. fernando.carvalho18@unifesp.br

3 Graduando de Licenciatura em Ciências. UNIFESP. nunes.azevedo@unifesp.br

4 Graduando de Licenciatura em Ciências. UNIFESP. victor.paulo@unifesp.br

5 Psicopedagoga graduada pela UNIFIEO e pós-graduada pelo Mackenzie. Graduanda de Licenciatura em Ciências e Aluna Especial do PECMA pela Universidade Federal de SP UNIFESP.lima.luana@unifesp.br
} 


\title{
EDUCAÇÃO EM TEMPOS DE SURTO DE GRIPE SUÍNA (INFLUENZA A, H1N1):
}

\author{
RELATO DE EXPERIÊNCIA NA ESCOLA E O PAPEL DA IMPRENSA E DA CIÊNCIA
}

Paulo Yuuji Arai ${ }^{1}$, Bruno Silva Ribeiro², Gabriel Rodrigues Felipe ${ }^{3}$, Luiz Afonso V. Figueiredo ${ }^{4}$

Acesse a apresentação deste trabalho

A existência de surtos pandêmicos permitem reflexões sobre formas de atuação com relação ao papel da imprensa, da ciência e da educação. O inusitado da situação pode comprometer o atendimento à saúde e facilitar a proliferação da doença. O caso trata da pandemia de gripe suína (2009), a partir de um relato escolar na cidade de São Paulo e depoimentos de atores envolvidos, realizados em 2020. Analisou-se o papel da imprensa a partir de um jornal de grande circulação (OESP) e da ciência, por meio de revisão bibliográfica. A experiência direta de um dos autores, contaminado por $\mathrm{H} 1 \mathrm{~N} 1$, foi a base do relato. Os dados coletados nos depoimentos demonstram que há uma contradição nas falas dos depoentes, enquanto um docente afirmou haver um aluno infectado e apenas entrega de folhetos e dispensers de álcool, a dirigente negava haver ocorrências, mas realizavam limpeza mais severa e ventilação. Já os pais disseram que o diagnóstico foi possível devido ao quadro clínico da mãe, com baixa imunidade. Ambos sofreram discriminação dos condôminos, mas sentiram-se satisfeitos com a escola. Quanto ao papel da imprensa, observou-se no jornal analisado o destaque para a disseminação de informações pertinentes à pandemia, auxiliando no esclarecimento à população. A Secretaria de Estado da Saúde e da Educação forneciam os dados para a geração de notícias, alimentando a imprensa. Já no campo científico, realizou-se estudos essenciais para o entendimento da situação e a mitigação dos danos causados pela pandemia, onde essas descobertas possibilitaram um maior controle do surto por meio de inovações em práticas de tratamentos ou de contenção ao vírus (H1N1). O estudo demonstrou o despreparo inicial da escola. Percebeu-se a importância da relação entre ciência e imprensa e atuação da escola nos processos educativos, como os que vemos hoje com relação à Covid-19. Entretanto, observa-se muitas vezes descompasso entre os agentes sociais que deveriam contribuir para a resolução do problema.

Palavras-chave: Pandemia, Gripe Suina (Influenza A, H1N1), Relato de experiência, Papel da Escola.

\footnotetext{
1 Licenciando em Ciências. Universidade Federal de São Paulo-UNIFESP-Diadema. yuuji.paulo@gmail.com

2 Licenciando em Ciências. Universidade Federal de São Paulo-UNIFESP-Diadema. bruno.ribeiro14@unifesp.br

3 Licenciando em Ciências. Universidade Federal de São Paulo-UNIFESP-Diadema. eedneifelipe@hotmail.com

4 Professor doutor aposentado do Centro Universitário Fundação Santo André. figueiredo.afonso61@gmail.com
} 


\title{
A IMPLEMENTAÇÃO DO ESPAÇO MAKER NO PARQUE CIENTEC
}

\author{
Rafael Gonçalves Dias1, Eric Kenji Ikeda2, Alexandre Borsalin Junior3
}

$\underline{\text { Acesse a apresentação deste trabalho }}$

O presente resumo tem o propósito de trazer as bases e objetivos para a implementação do projeto Laboratório Atividades Culturais Educativas Maker dentro do Parque Cientec da Universidade de São Paulo. Trata-se de uma iniciativa que pretende criar um espaço para que alunos, em período de contraturno, da Escola Estadual Álvaro de Souza Lima, possam usufruir. Dessa forma pretendemos usar metodologias norteadoras para a criação de um espaço democrático, acessivel e que prepare os alunos para o futuro, assim utilizando Cordova e Vargas (2016), Brockveld, Teixeira e Silva (2017). Para complementar, será utilizado Rolasen (2015) embasando o ensino prático dos graduandos. Assim com o funcionamento do projeto, espera-se a formação de estudantes com mais interesse na área de ciências, e informações sobre o funcionamento das faculdades devido às conversas que serão realizadas com os monitores, que por sua vez, podem utilizar da experiência para ampliar seu repertório de práticas pedagógicas e processos de aprendizagem. Ademais, o projeto pode servir também como uma maneira de democratizar o acesso à divulgação científica que muitas vezes fica restrita aos ambientes universitários.

Palavras-chave: Educação, Cultura Maker e Ambiente Democrático.

1 Graduado em Bacharel em Gestão Ambiental pela Universidade de São Paulo, e Graduando em Licenciatura em Ciências na Universidade Federal de São Paulo. Email: rgdias@unifesp.br.

2 Graduando em Licenciatura em Ciências na Universidade Federal de São Paulo. . Email: e.ikeda07@unifesp.br.

3 Graduando em Licenciatura em Ciências na Universidade Federal de São Paulo. Email: ab.junior06@unifesp.br. 
GOOGLE CLASSROOM: FERRAMENTA TECNOLÓGICA DIGITAL UTILIZADA NA

MEDIAÇÃO DE APRENDIZAGENS NO CONTEXTO DO ENSINO MÉDIO EM

TEMPOS DE DISTANCIAMENTO SOCIAL.

Luciana Rebelo

Acesse a apresentação deste trabalho

O presente estudo tem como foco verificar as ferramentas tecnológicas digitais, no tocante o Google Classroom, na mediação de aprendizagens no contexto do ensino médio em tempos de distanciamento social. Para tanto foi utilizado como método para a coleta de dados a pesquisa bibliográfica, através de um estudo levantado em livros, sites e artigos científicos sobre a utilização da plataforma, bem como, compreender sua efetividade na assimilação e disposição dos conteúdos propostos pelos professores, considerando a perspectiva de mediadora de aprendizagens no que corresponde a continuidade dos estudos de forma remota. A partir da análise de dados foi possível perceber a importância em dar continuidade nas atividades escolares mesmo em tempos de distanciamento social recomendado pelo Ministério da saúde. Percebe-se que, sua utilização na grande maioria ainda é pouco utilizada por vários fatores. Enfim, através de todo o estudo e pesquisa foi possivel confirmar que a utilização da plataforma Google Classroom, ou mais comumente Google sala de aula, é uma grande aliada da comunidade escolar na busca por continuidade dos estudos e interação entre professores e estudantes de forma remota em tempos de distanciamento social.

Palavras-chave: Google classroom. Ferramentas tecnológicas digitais e Distanciamento social. 


\title{
A FORMAÇÃO CONTINUADA NA REDE MUNICIPAL PAULISTANA: OS
}

\section{DESAFIOS TRAZIDOS PELA SUSPENSÃO DAS ATIVIDADES PRESENCIAIS}

\author{
Renata Lívia Soares Perini ${ }^{1}$
}

Acesse a apresentação deste trabalho

O relato de prática trata dos desafios trazidos à formação continuada docente pela suspensão das atividades presenciais em virtude da pandemia do novo Coronavirus na rede direta de escolas municipais paulistanas. A rede tem o Projeto Especial de Ação (PEA) como instrumento de formação continuada docente que, anteriormente à pandemia, ocorria nas escolas de maneira presencial, sendo calçado nas demandas formativas elencadas pela equipe docente em diálogo com as políticas curriculares da rede, configurando-se como uma formação centrada na escola. Contudo, em maio de 2020, a administração municipal emite o memorando circular $n^{\circ} 19$ que suspende, enquanto perdurar a situação de emergência no município, diversas atividades formativas, como as reuniões e jornadas pedagógicas, reuniões de conselho de classe, momentos de avaliação institucional da Educação Infantil e os PEAs. É proposto que o horário de formação seja utilizado para discussões e encaminhamentos pedagógicos relacionados aos estudantes, além de estudos sobre as demandas impostas pela pandemia. Os coordenadores pedagógicos ficam incumbidos de organizar reuniões virtuais semanais para tratar desses assuntos. Paralelo a isso, a Secretaria Municipal de Educação vem oferecendo momentos formativos através de "lives" (transmissões ao vivo em ambiente virtual) com temáticas variadas ao redor da proposta curricular da rede, além de eventos virtuais, como a Jornada Pedagógica da Educação Infantil. Observa-se que essa foi uma alternativa encontrada pela administração para atender a demanda de formação continuada durante a pandemia, porém, carece de investigação verificar em que medida essas atividades trouxeram contribuições para a formação dos educadores, problematizando ainda o acesso dos professores à equipamentos, conexão e conhecimentos sobre o uso de plataformas virtuais, além de verificar se tais atividades proporcionaram interação aos participantes e dialogaram com as necessidades formativas das escolas.

Palavras-chave: Formação Continuada do Professor; Projeto Especial de Ação; Políticas Públicas.

1 Supervisora Escolar na Rede Municipal de Ensino de São Paulo. Mestre em Educação pela Faculdade de Educação da Universidade de São Paulo. E-mail: renatalivia@hotmail.com. 


\section{TURMA DA MÔNICA EM: A REPRESENTAÇÃO DAS CRIANÇAS COM DEFICIÊNCIA}

Renata Machado da Silva1 ${ }^{1}$ Sayonara Amaral de Oliveira²

Acesse a apresentação deste trabalho

O movimento a favor da inclusão social vem sendo refletido na literaturainfantil, nos mais diversos formatos e suportes. Nas histórias em quadrinhos (HQs) da Turma da Mônica, de Maurício de Sousa, personagens que representam crianças com deficiência mental, motora, visual e auditiva passam a compor o ambiente narrativo. As revistinhas são elaboradas a partir de projetos com instituições parceiras de diferentes áreas, sob o propósito de discutir questões acerca das deficiências, sendo assim distribuídas gratuitamente pelo Instituto Maurício de Sousa em eventos temáticos e escolas públicas. Essas narrativas quadrinizadas merecem um olhar mais minucioso quanto ao desenvolvimento da representação e problematização da inclusão, uma vez que, como todo meio de comunicação, elas transmitem uma ideologia. Ao considerar genuinas as reinvindicações das pessoas com deficiência quanto a uma maior mobilização pelo seu reconhecimento social, deve-se indagar se as HQs da Turma da Mônica colaboram para desconstruir conceitos estigmatizantes de como é ser um sujeito com deficiência, ou contrariamente, se reforçam a invisibilidade e os estereótipos. Partindo dessas reflexões, a pesquisa busca investigar como ocorre a representação da criança com deficiência nas HQs da Turma da Mônica. Afinal, essa produção circula expressivamente no universo da cultura infantil e, ao assumir papel mediador entre o jovem leitor e o mundo social, reverbera efeitos na formação educacional, social e cultural do seu público. Para tanto, o estudo é empreendido metodologicamente através de análise de conteúdo dos exemplares da Turma da Mônica Viva as diferenças (2018) e Um amiguinho diferente (2019). $\mathrm{O}$ aporte teórico utilizado advém dos estudos sobre conceitos de representação, identidade e cultura de Silva (2014) e Hall (2016); as peculiaridades das narrativas dos quadrinhos de McCloud (1995); além das questões acerca das práticas sociais da leitura fundamentadas em Freire (1988) e Chartier (1996).

Palavras-chave: História em quadrinhos. Criança com deficiência. Representação. Leitura.

1 Educadora, Psicopedagoga, Mestranda em Linguagens da Universidade Estadual da Bahia. Email: natamachados@yahoo.com.br

2 Doutora em Letras e Docente Permanente do Programa de Pós-Graduação em Estudo de Linguagens da Universidade do Estado da Bahia. E-mail: sayo22@terra.com.br 


\section{PROGRAMA RESIDÊNCIA PEDAGÓGICA: UM GRANDE DIFERENCIAL NA}

\section{FORMAÇÃO DO PROFESSOR PEDAGOGO}

Rita de Cássia Borges de Magalhães Amaral ${ }^{1}$

Acesse a apresentação deste trabalho

A aprendizagem acadêmica teórico-prática se dá através das Unidades curriculares e do estágio obrigatório busca-se mostrar como a diferença entre o estágio supervisionado e a residência pedagógica, podem agregam conhecimento de forma distinta na formação do Professor. Uma questão atual é que muitos professores chegam ao mercado de trabalho despreparados para lecionarem as unidades curriculares com a aplicação de metodologias ativas, de modo que acompanhar o avanço das questões atuais, fazendo com que tenham mais interesse e se tornem criticos e reflexivos, para saberem viver como plenos cidadãos na sociedade, cumprindo seus direitos, deveres. No estágio supervisionado os acadêmicos iniciam os seus estágios, e geralmente ocorria aquela frustação de ter sido tudo diferente do seu aprendizado, e com poucas oportunidades de terem sidos atuantes na rotina diária, já na residência pedagógica existe uma escola campo onde o acadêmico tem a oportunidade de vivenciar e experenciar o que aprendeu durante a sua formação e utilizar a BNCC. Atualmente a BNCC propõe a unificação do ensino, a fim de que todos os alunos em cada segmento, tenha acesso, seja em escolas públicas ou privadas, a mesma diversidade de conhecimento, o mesmo perfil de alunos que tenham mais autonomia, e isso acontece através das competências e habilidades descritas no documento e que devem ser consultadas no planejamento do Professor. A autora, uma residente pedagógica, norteou seu artigo com a indagação de que concepções e características do programa de residência pedagógica possibilita uma formação de alto nivel dos professores com formação em Pedagogia em relação ao estágio supervisionado que é preconizado pela atual legislação? Para refletir a deficiência das práticas dos acadêmicos nos estágios supervisionados não serem executados pelos mesmos processos, é preciso que apresentar o Programa de Residência Pedagógica, que faz parte da Política Nacional de Formação de Professores, no âmbito de fortalecer o campo da prática, e estreitar a teoria especificamente para o professor-pedagogo, onde adequa a regência de sala, e outras intervenções pedagógicas, segundo as orientações da Base Nacional Comum Curricular e buscar um ensino de qualidade nas escolas de educação básica.

Palavras-chave: Residência Pedagógica, Professor e Estágio Supervisionado. 
O PODCAST ECONVERSA COMO FERRAMENTA DE DIVULGAÇÃO CIENTÍFICA: CONTRIBUIÇÕES À FORMAÇÃO DOCENTE

Sabriny Almeida Rodrigues Souza1, Kenia Silva Severino², Larissa Correia da Silva³, Luan da Silva Lima ${ }^{4}$, Arnaldo Antonio da Silva Junior ${ }^{5}$

Acesse a apresentação deste trabalho

O processo de ensino-aprendizagem é transformador, impacta a sociedade de maneira positiva e, soma-se a isto, a importância da divulgação científica. Nesse sentido, o(a) educador(a) pode assumir um papel fundamental no âmbito da difusão das Ciências, assim como indica o Podcast "ECOnversa", projeto do Observatório de Educação e Sustentabilidade (ObES) da Universidade Federal de São Paulo (UNIFESP), trabalhando com os temas Educação, Ciência, Meio Ambiente e Sustentabilidade. Baseado nesse contexto, o objetivo do presente estudo consiste em identificar e discutir potenciais elementos que podem contribuir com a formação de professoras(es), a partir de análise preliminar de episódios do podcast ECOnversa. Para a confecção do trabalho, utilizou-se os quatro primeiros episódios, publicados até então, além de material presente na literatura, que forneceu apoio e base argumentativa. A análise dos episódios identificou cinco grupos temáticos: (i) o relato das trajetórias das participantes, o que demonstra possibilidades de caminhos na formação acadêmica/científica; (ii) dificuldades e desafios intrínsecos ao momento de distanciamento social da realidade brasileira, sobretudo na região do Grande ABC-SP; (iii) sustentabilidade e valorização da formação docente a partir de projetos desenvolvidos na UNIFESP, além dos cursos superiores, como a Licenciatura em Ciências e o Bacharelado em Ciências Ambientais; (iv) as sinergias entre as artes, principalmente cênicas, e a atuação de professoras(es); (v) representatividade feminina em cargos de coordenação na educação escolar básica e suas consequências no processo de escolarização. Mediante as temáticas e as formas diversas de diálogo com o público, observa-se o alcance e potencial do podcast para além da Universidade. As discussões propostas se apresentam como possibilidades de reflexão para professoras(es), favorecendo a formação docente, além de se configurarem como uma nova alternativa de divulgação do conhecimento.

Palavras-chave: Divulgação do Conhecimento. Ciência. Educação. Formação de Professoras(es). Ensino-Aprendizagem.

1 Licencianda em Ciências pela Universidade Federal de São Paulo. E-mail: almeida.sabriny@unifesp.br

2 Licencianda em Ciências pela Universidade Federal de São Paulo. E-mail: kenia.ss@live.com

3 Licencianda em Ciências pela Universidade Federal de São Paulo. E-mail: larissacorreia_silva@hotmail.com

4 Tecnólogo em Processos Químicos e Licenciando em Ciências pela Universidade Federal de São Paulo. E-mail: luanlimaq@gmail.com

5 Prof. de Química da Rede Pública Estadual de São Paulo e Mestre em Ciências. Observatório de Educação e Sustentabilidade-ObES/Universidade Federal de São Paulo. E-mail: arnald.jr@hotmail.com 


\title{
CINEMA, BULLYNG ESCOLAR E A PRODUÇÃO DE MATERIAIS DIDÁTICO-
}

\section{PEDAGÓGICOS}

\author{
Samira Krupek Donaire 1, Wanessa Gorri de Oliveira², Divania Luiza Rodrigues³
}

Acesse a apresentação deste trabalho

O presente trabalho trata-se de uma pesquisa de iniciação científica, em andamento, desenvolvida junto à Universidade Estadual do Paraná (UNESPAR) campus de Campo Mourão. A proposta de pesquisa intitulada "Cinema, bullying escolar e a produção de materiais didático-pedagógicos", intenta estabelecer interlocuções entre cinema e bullying escolar, mediante a seleção de um filme, que aborde a temática bullying escolar, como um meio para a produção de dois materiais didático-pedagógicos, um voltado aos alunos do primeiro ano do Ensino Fundamental e o outro, aos alunos do segundo ano do Ensino Fundamental. Esses materiais didático-pedagógicos contemplarão a temática bullying escolar e serão articulados ao processo de alfabetização dos alunos. $\mathrm{O}$ trabalho com o cinema na escola, apresenta múltiplos itinerários devido a riqueza da linguagem filmica e das diversas temáticas que podem ser exploradas e/ou desdobradas de uma determinada produção, dentre as quais, destaca-se o bullying escolar. O bullying escolar, recorrente em todas as instituições escolares do mundo, é uma temática que necessita ser problematizada e discutida porque atinge, de distintas formas, inúmeros alunos, sejam eles vítimas, agressores ou testemunhas. A pesquisa em andamento é de cunho bibliográfico e demanda o estudo do uso do cinema em sala de aula, suas contribuições para a abordagem da temática bullying escolar, a seleção de uma produção fílmica e a sistematização de dois materiais didático-pedagógicos. Após a produção dos materiais didático-pedagógicos, iremos divulgá-los para que possam ser utilizados pelos professores junto aos alunos.

Palavras-chave: Educação. Cinema. Bullying escolar. Ensino Fundamental. Materiais didático-pedagógicos.

1 Graduanda do Curso de Pedagogia. Universidade Estadual do Paraná - Campus de Campo Mourão. E- mail: samirakrupek.sk25@gmail.com.

2 Professora do Colegiado de Pedagogia. Universidade Estadual do Paraná - Campus de Campo Mourão. E- mail: wanessa.oliveira@unespar.edu.br.

3 Professora do Colegiado de Pedagogia. Universidade Estadual do Paraná - Campus de Campo Mourão. E- mail: divania.rodrigues@unespar.edu.br. 


\title{
RESIDENCIA PEDAGÓGICA: A PRÁTICA COMO LUGAR DA FORMAÇÃO
}

\section{INICIAL E CONTINUADA PARA A DOCÊNCIA EM EDUCAÇÃO FÍSICA - UM RELATO DE EXPERIÊNCIA}

\author{
Samuel de Souza Neto ${ }^{1}$; Amanda Milani ${ }^{2}$; Maria Carina Fragelli ${ }^{3}$; Rogerio Hatore ${ }^{4}$
}

Acesse a apresentação deste trabalho

\begin{abstract}
Este trabalho trata das profundas mudanças que a formação docente vem passando em relação ao lugar, duração e modalidades de acompanhamento da prática pedagógica na formação inicial. Estas transformações, que estão na base da profissionalização do ensino, exige considerar o ensino como uma atividade profissional de alto nivel, alicerçada sobre uma sólida base de conhecimentos específicos. Os docentes são tomados como profissionais reflexivos, capazes de deliberar sobre suas práticas, de objetivá-las, de inová-las e de torná-las acessiveis aos pares, bem como a prática passa a ser considerada como um espaço original e autônomo de aprendizagem e formação. Neste contexto, buscouse identificar e analisar na avaliação externa, de um projeto de residência pedagógica (RP), os aspectos que foram considerados significativos. Optou-se por um trabalho construtivo-colaborativos, envolvendo: três escolas públicas; uma universidade pública; 24 residentes - licenciatura em Educação Física; três supervisores de escola; um professor orientador; dois colaboradores e um avaliador externo de outra universidade. Como estratégia, o projeto envolveu reuniões pedagógicas na escola e universidade, produção de portfólios, casos de ensino, semanário e seminários de avaliação que foram sintetizadas na apresentação vinculada ao seminário de avaliação. Os seminários de avaliação correram com a presença de avaliador externo, faltando seis para o seu término o que permitiria ajustes depois de 12 meses. Resultados: a) o projeto desenvolveu-se de modo compartilhado entre as instituições; b) RP - foi desenvolvida de forma paralela ao estágio; c) os portfólios e semanário atestam a formação crítica e reflexiva; d) envolvimento do professor de escola; e) falta de discernimento entre estágio e residência; e, f) significativa caminhada na direção de uma formação articulada com o campo profissional.
\end{abstract}

Palavras-chave: Residência Pedagógica; Formação de Professores; Avaliação Externa

1 Universidade Estadual Júlio de Mesquita Filho- campus Rio Claro/SP (Prof. Dr.); samuel.souzaneto@unesp.br.

2 Escola Municipal Prof. Elpidio Mina

3 Escola Municipal Dom Pedro I

4 Escola Eestadual Profa Heloins Lemenhe Marasca 


\title{
CURSO DE LICENCIATURA EM EDUCAÇÃO ESPECIAL INCLUSIVA: AVALIAÇÃO
}

\section{DA DEMANDA DAS PROFESSORAS DAS SRMS DA COMCAM/PR}

\author{
Sandra Garcia Neves¹, Andrea Geraldi Sasso², Gabriele Garcia Neves da Cunha
}

Acesse a apresentação deste trabalho

A matrícula de crianças com necessidades educacionais especiais segundo os Censos Escolares divulgada pelo Inep, aumenta significativamente a cada ano na rede regular de ensino da Educação Básica, bem como, a necessidade de formação inicial e continuada de professoras para o Atendimento Educacional Especializado nas Salas de Recursos Multifuncionais. Nosso objetivo nessa pesquisa é apresentar a demanda pela oferta da formação em licenciatura em Educação Especial Inclusiva na região da Comunidade dos Municípios da Região de Campo Mourão, por meio Unespar-campus de Campo Mourão. Para isso, apresentamos investigação bibliográfica quanti-qualitativa, dos "Relatórios: Salas de Recursos Multifuncionais" da Secretaria Municipal de Educação de Campo Mourão/PR do ano de 2018. As professoras, na "Avaliação da Sala de Recursos Multifuncionais", sugerem três categorias de temas para as formações de 2019. A primeira abarca as sindromes e deficiências específicas: Autismo; Transtorno Opositor Desafiador; Transtornos Globais do Desenvolvimento; Transtorno Funcional Específico; Dislexia; Deficiências Múltiplas. A segunda abarca os métodos de ensino: oficinas de intervenções didáticas e pedagógicas e de práticas adaptativas e flexiveis; Panlexia; alfabetização; formação para as professoras das classes comuns e exclusivas; mediação/intervenção; identificação e diagnósticos; jogos de alfabetização; consciência fonológica; confecção de materiais pedagógicos; confecção de jogos; método fonovisuarticulatório; método Abacada; avaliações semestrais. A terceira abarca aspectos gerais: AEE; Neurociência; trabalho colaborativo como professora regente; práticas de Psicomotricidade; informática e recursos tecnológicos; tecnologia de informação; comunicação acessivel; inteligências múltiplas; enriquecimento curricular; altas habilidades; superdotação. Com a identificação da demanda por formação continuada de professoras consideramos a necessidade da Unespar-campus de Campo Mourão, uma das duas únicas universidades públicas que oferece cursos de licenciatura na região da COMCAM/PR, ofertar o curso de licenciatura em Educação Especial Inclusiva.

Palavras-chave: Formação inicial e continuada, Licenciatura em Educação Especial Inclusiva, professoras das SRMs, Unespar-campus de Campo Mourão.

\footnotetext{
1 Doutora pela Universidade do Estado do Rio de Janeiro, professora adjunta da Unespar-campus de Campo Mourão, coordenadora do Colegiado de Pedagogia. E-mail: sandragarcianeves3@gmail.com.

2 Mestranda do Programa de Pós-graduação Interdisciplinar Sociedade e Desenvolvimento (PPGSeD), graduada em Pedagogia pela Unespar-campus de Campo Mourão, graduanda em Psicologia pela Faculdade União de Campo Mourão (Unicampo) e membro do Grupo de Estudo e Pesquisa em Educação, Diversidade e Cultura (GEPEDIC/CNPq). E-mail: dreasasso@gmail.com.

3 Especialista pela Universidade Estágio de Sá, graduada em Pedagogia pela Unespar-campus de Campo Mourão. E-mail: gabriele9120@hotmail.com.
} 


\title{
FORMAÇÃO DE PROFESSORES PARA AEE NAS SRMS: DEMANDA PELA
}

\author{
FORMAÇÃO CONTINUADA EM ALFABETIZAÇÃO
}

\author{
Andrea Geraldi Sassoํㅡ, Gabriele Garcia Neves da Cunha², Sandra Garcia Neves ${ }^{3}$
}

Acesse a apresentação deste trabalho

A formação continuada de professores para o Atendimento Educacional Especializado nas Salas de Recursos Multifuncionais compreende temáticas específicas das necessidades educacionais dos alunos em inclusão. Nosso objetivo nesse trabalho é apresentarmos informações sobre como é a formação continuada de professores nas SRMs para o processo de alfabetização de crianças. Utilizamos como fonte de pesquisa qualitativa, os Relatórios das SRMs de 2018 quanto as informações sobre as práticas e métodos utilizados pelas professoras alfabetizadoras. Acerca do processo de alfabetização nas SRMs, elencamos três fatores, os recursos, as metodologias e as práticas pedagógicas. Dentre os recursos utilizados estão: fichas de leitura; caixa conversadeira; mercadinho; alfabeto móvel; computador; rodas de conversas; relatos orais; contação de histórias; brinquedos; bingo; jogos de dominós; jogos de memórias; quebra-cabeça; jogos pedagógicos; materiais lúdicos concretos. Como metodologias do processo de alfabetização foram citadas: atividades de intepretação; sequência didática; pesquisas; confecção de cadernos; e, feedback. Dentre as práticas pedagógicas estão: trabalho colaborativo; acompanhamento contínuo nas horas atividades; mediação pedagógica; reforço escolar; orientação e supervisão educacionais continuas; intervenções especificas; formação e trocas de experiências; avaliação complementar, diagnóstica e psicoeducacional; planejamento e atendimento especializado. Como atividades participadas referentes a formação continuada, as professoras elencaram palestras, seminários e cursos. Avaliamos que, por mais que seja requisito legal a formação em nivel de especialização em Educação Especial Inclusiva, as professoras das SRMs do município de Campo Mourão, por meio da Secretaria de Educação Municipal, participam de formações continuadas por meio do acompanhamento colaborativo com as professoras e as orientadoras das escolas que possuem SRMs. Resta destacarmos que a oferta de licenciatura em Educação Especial Inclusiva pela Unespar-campus de Campo Mourão, contribuirá sobremaneira tanto com o acolhimento das crianças com necessidades educacionais especiais quanto com a formação inicial e continuada de professores paras as classes comuns e exclusivas.

Palavras-chave: Alfabetização; Atuação de professores nas SRMs, Formação inicial e continuada.

1 Mestranda do Programa de Pós-graduação Interdisciplinar Sociedade e Desenvolvimento, graduada em Pedagogia pela Unespar-campus de Campo Mourão. E-mail: dreasasso@gmail.com.

2 Especialista pela Universidade Estágio de Sá, graduada em Pedagogia pela Unespar-campus de Campo Mourão. E-mail: gabriele9120@hotmail.com.

3 Doutora pela Universidade do Estado do Rio de Janeiro, professora adjunta da Unespar-campus de Campo Mourão, coordenadora do Colegiado de Pedagogia. E-mail: sandragarcianeves3@gmail.com. 


\title{
UMA EXPERIÊNCIA DE FORMAÇÃO DE PROFESSORES NA EMEI - CEU BUTANTÃ DE FORMA REMOTA NO PERÍODO DE QUARENTENA.
}

\author{
Sandra Cristina Andrade Loiola ${ }^{1}$
}

Acesse a apresentação deste trabalho

Além de preparo de aulas e de materiais para postagem, temos realizado horas de formação continuada durante a semana com nosso grupo escolar. Nesses momentos, além de conversa sobre nosso trabalho, partilhamos experiências do cotidiano e fazemos indicações de livros e filmes. A partir da indicação de leitura do livro de José Saramago "Ensaio sobre a cegueira", sugerida pela coordenadora pedagógica de nossa escola, refleti enquanto lia e percebi o quanto essa leitura se tornou oportuna nesses tempos incertos em que vivemos uma situação de pandemia da covid-19. Permiti-me fazer uma analogia sobre as atitudes e comportamentos dos personagens, enquanto cegos, vivendo uma situação pandêmica catastrófica e nós, que de alguma forma estamos experimentando uma situação estranha e desconhecida, sem muita clareza de perspectivas com relação ao futuro; isso me possibilitou traçar algumas semelhanças e, com uma dose de pessimismo, vi queas formas pelas quais lidamos com situações cotidianas são similares entre a maioria dos seres humanos, bem como a forma como nos adaptamos às situações adversas pode caracterizar o que existe de comum entre nós: nossa dificuldade em perceber e lidar com as mudanças e, ao mesmo tempo, a capacidade de nos reinventar e nos adaptar às mais adversas situações do cotidiano. Pensei sobre nossas escolhas e sobre o aperfeiçoamento das qualidades positivas ou negativas ao longo da vida. Somos quem somos, tanto na rotina cotidiana quanto igualmente na adversidade. Poucos mudam diante das circunstâncias adversas, a menos que se proponham a mudar.O autor distingue os cegos ora pelas suas características físicas, ora por suas profissões. Num dado momento, caracterizou os cegos pelas atitudespositivas e negativas; noutro, pelos grupos aos quais se agregavam e pelas semelhanças e afinidades que possuiam. Referiu-se aos cegos como inseguros, mais confiantes, de espirito rigoroso, covardes e pessoas de mau caráter. Os mais conscientes eram os que estavam dispostos a viver em comunidade e se unirem para o bemcomum. Os outros, os que assumiram atitudes maléficas reproduziam a corrupção político social e perpetuaram a ideologia do opressor sobre o oprimido. Pensei sobre a cegueira física e imagino que deve ser horrivel um ser humano não enxergar, mas acho que pior do que ela é a cegueira intelectual. Acho que a mulher do médico viveu esse dilema. Ela não era cega, mas muitas vezes escolheu viver essa cegueira. Dominada pelo medo,desejou ser cega. Não compreendia o poder que tinha nos olhos. Como muitas vezes fazemos, especialmente se estamos em posição de liderança. Como no mito da caverna, quem mais sabe é quem mais sofre. Ela sofria por enxergar. Semelhante ao filme Matrix, ela preferiu viver na Matrix a sofrer enxergando tudo e discernindo o bem e o mal. Sua posição de privilegiada pelo acaso era ver, mas enxergar era uma decisão dela. Em contrapartida o cego da venda preta, possuía

1 Mestranda na Universidade Mackenzie. Professora de educação infantil e fundamental nas redes municipal e estadual de São Paulo.

ISBN 978-65-88471-05-0 | https://doi.org/10.47247/VV/ENMD/88471.05.0 
a cegueira física, no entanto era dotado de discernimento moral e espiritual. Ele via além do palpável. Sua visão era imaterial, intangivel, intocável. A mulher do médico demorou, mas finalmente se reconheceu singular e por causa desse reconhecimento conseguiu ainda mostrar o caminho para muitos e levou consigo, em segurança, 7 pessoas. Acho que a verdadeira cegueira não é perder a visão física, mas sim perder a capacidade de juízo moral, de discernimento para escolher o certo ao invés do errado, não ter consciência do que significa a ética, a moralidade, a autonomia e o respeito individual e coletivo. A falta de sensibilidade para refletir e investigar as realidades que transcendem a experiencia sensivel é a maior cegueira. A pessoa que não é capaz de compreender o mundo, as relações, os acontecimentos, também não é capaz de exercer influências sobre o pensamento e o comportamento de outras pessoas. Quem somos nós quando ninguém está olhando, o que fazemos quando temos a oportunidade de prejudicar um colega que não simpatizamos, o que escolhemos fazer quando a oportunidade é propícia para expor os defeitos de nossos desafetos? Quanto esforço colocamos, quanta energia desperdiçamos para nos sobrepor ou alcançar reconhecimento em detrimento de outros porque nos sentimos superiores ou porque achamos que não recebemos a consideração que gostariamos de ter? Sentir afeição e admiração por alguém em específico é um direito, mas respeitar e ter consideração por aqueles que temos como inimigos é ser de fato humano. Demonstrar hostilidade em relação a alguém diz muito mais de nós mesmos do que de outros. Ensaio sobre a cegueira nada mais é do que uma demonstração do que os seres humanos são capazes para o bem ou para o mal.

Palavras chave: Espaço de formação, pandemia, cegueira. 


\section{ANÁLISE COMPARATIVA DE DUAS ADAPTAÇÕES PARA HQS DA OBRA DOM} CASMURRO DE MACHADO DE ASSIS

Alcione Sacramento dos Santos ${ }^{1}$

Acesse a apresentação deste trabalho

O presente trabalho tem por objetivo fazer uma análise dos personagens principais da obra de Machado de Assis (Dom Casmurro), adaptadas para duas HQs (Histórias em Qaudrinhos), e mostrar que através desta linguagem pode-se ter novas interpretações do papel desses personagens, e que cada umas das adaptações poderá transmitir para o leitor experiências diferentes vividas por eles, além de apresentar suas principais características, que emergem da verbovisualidade presentes em tal gênero. No artigo é abordado também a capacidade dos autores de se aproximar à obra original. É notável que estes autores de fato tenham demonstrado esta capacidade e ajustado muito bem os personagens tirados de um livro, o qual lido somente de forma verbal, delega ao leitor a incumbência de fazer em sua própria mente a caracterização dos personagens. Contudo, em um quadrinho, essa imagem já chega pronta para o leitor, e para chegar a este resultado os autores precisam superar grandes desafios. Eles precisam chegar o mais perto possivel dos detalhes passados pelo autor da obra que será adaptada, embora os quadrinistas tenham a noção de que ao adaptar um livro, eles podem imaginar seus próprios personagens, interferindo, desde então, na história original. E qual desses autores conseguiu se aproximar mais desse objetivo? Isso foi abordado no desenvolvimento desse trabalho. E para realizar essa análise foi feita uma pesquisa minuciosa que teve como referencial teórico autores como: Will Eisner, Scoot McCloud, Antoine Compagnon, Dan Mazur e Alexander Danner, Patrícia Pina, Taís Diniz.

Palavras-chave: HQ. Adaptação. Dom Casmurro, Machado de Assis.

1 Alcione Sacramento dos Santos. Universidade Estácio de Sá. asacramentodossantos@yahoo.com.br 


\title{
A EVIDÊNCIA DAS DESIGUALDADES SOCIAIS TRAZIDAS PELA PANDEMIA:
}

\author{
UM OLHAR SOBRE AS DIFICULDADES NO ENSINO DA REDE PÚBLICA
}

\author{
DURANTE O LOCKDOWN
}

Camila Barbosa dos Santos ${ }^{1}$ Helmer Aguiar Pinto²

Acesse a apresentação deste trabalho

Desigualdade, palavra formado pelo prefixo "des-", indicando oposição, mais igualdade, proveniente do Latim aequalitas, "aquilo que é igual", de aequalis, "idêntico, uniforme", de aeques, "parelho, justo". Ou seja, desigualdade significa a oposição ao que é igual. Infelizmente, em termos de desigualdade, o Brasil não é estranho. O país encontra-se na sétima colocação do ranking dos países mais desiguais do mundo, de acordo com o relatório divulgado pelo Programa das Nações Unidas para o Desenvolvimento (Pnud), em 2019. Por esse mesmo programa, o país encontra-se no $79^{\circ}$ lugar quanto ao Índice de Desenvolvimento Humano (dados /2018). O grande educador Paulo Freire (1993), afirma que a educação como intervenção, inspira mudanças radicais na sociedade, economia, nas relações humanas e na busca de direitos. Porém, se analisarmos a história do Brasil, desde a época do Brasil Colônia, a educação em si era oferecida em um contexto de exclusão. Apenas os filhos (ressalta-se que aqui tratamos apenas de pessoas do sexo masculino, pois à época, não era bem visto e requerido que mulheres recebessem educação, também excluídos são os negros e indios) dos senhores de engenho tinham possibilidades de receber instrução formal e técnica, pois eram mandados para o exterior para estudar em universidades. Assim percebe-se que a narrativa brasileira é permeada pelo constante desrespeito às diferenças culturais e privilégio de alguns, assim como os recursos educacionais têm uma distribuição regressiva, beneficiando mais quem possui melhores condições. O sistema educacional, fruto de um processo histórico, configura-se no bojo das relações sociais e de produção, que dividiram e ainda dividem a sociedade em grupos econômicos distintos e, ainda mais, estabelece uma relação entre classes sociais antagônicas. Aqui, faremos um recorte acerca da educação a partir da atual situação vivida no mundo, causada pelo coronavírus. De forma a reduzir a curva exponencial de contágio do vírus, como já ocorria em países como Itália, Espanha e Estados Unidos, governos dos estados brasileiros decretaram lockdown, reforçando a necessidade urgente do fechamento de diversos estabelecimentos que não faziam parte da lista de serviços essenciais. Assim, escolas precisaram adaptar suas aulas para o ambiente virutal de aprendizagem (AVA). Para a rede privada de ensino, essas adaptações logo foram implementadas com os privilégios inerentes às classes mais privilegiadas. Contudo, não pode se dizer o mesmo da rede pública, devido a diversos fatores socioculturais como suas condições e disposições econômicas. Evidente assim, que a pandemia escancarou de uma vez por todas o abismo entre as escolas públicas e privadas. Destacaremos aqui os estudos censitários promovido pelo Instituto Brasileira de Geografia e Estatística (IBGE) em 2018,

1 Professora de idiomas. Estudante de pós graduação no Grupo Educacional IBRA. E-mail: camila.bsantosadv@gmail.com

2 Estudante de pós graduação no IPOG. E-mail: helmerap@gmail.com

ISBN 978-65-88471-05-0 | https://doi.org/10.47247/VV/ENMD/88471.05.0 
que afirmam que uma em cada quatro pessoas no Brasil não tem acesso à internet. Significando um total de 46 milhões de brasileiros sem acessam a rede nas grandes cidades, e 53,5\% nas áreas rurais. Objetivando ajudar essas crianças e jovens que não tem acesso à rede, por se encontrarem na margem da sociedade brasileira, a não estagnarem seus estudos nesse momento atual, algumas instituições beneficentes tomaram iniciativas, iniciando campanhas de doação de planos de internet móvel. Por mais que essas ações sejam louváveis e de grande valia, devemos nos perguntar o quão bom e úteis são o uso desses serviços das operadoras de celular para fins educacionais. Devemos iniciar com o fato de que pacotes que fornecem internet móvel com planos pré-pago, exatamente os pacotes sugeridos nos projetos de incentivo, não fornecem uma franquia de uso de qualidade e durabilidade para o fim que será empregado o uso. Antes de mais nada, precisa-se saber que 1 megabyte (MB) equivale a 1024 kilobytes (KB). Estima-se que o consumo de uma chamada de vídeo aula ao-vivo ou o acesso à internet através de aulas gravadas - EAD é de $10 \mathrm{MB}$ por minuto, com isso devemos avaliar que o consumo de 2 horas aula por dia, sendo que o acesso será exclusivamente através de vídeo, será consumido $1.200 \mathrm{MB}$ ou 1,2 GB diários. Com as informações expostas anteriormente, pode-se observar que muitos planos pré-pagos em operadoras de internet móvel no Brasil, disponibilizam apenas plano entre $4 \mathrm{~GB}$ e $8 \mathrm{~GB}$ mensal, o que colabora ao falado anteriormente referente a durabilidade do plano. Podemos concluir que um estudante que necessita de acesso à internet para poder continuar seus estudos durante a pandemia, seria necessário que o mesmo obtivesse acesso a um plano com no mínimo 50 GB mensais, o que não tem um custo barato e de acesso a todos, retornando assim ao nosso problema inicial causado pelas desigualdades sociais. Tendo conhecimento desses dados, caberia ao Governo Federal, juntamente com os governos estaduais, a criação de políticas públicas específicas às classes menos favorecidas, com o intuito de reprimir seu afastamento ao sistema educacional nesse momento, proporcionando ao menos uma constância no ensino e na aprendizagem. Perceptivel que a atual governança não possui sensibilidade, e sendo mais direto, interesse em resolver essas questões, haja vista à demora em perceber a gravidade da crise sanitária e humanitária que nos encontramos, coube à algumas instituições beneficientes tomar iniciativas para ajudar crianças e jovens na margem da sociedade brasileira a não estagnarem seus estudos.

Palavras-chave: Desigualdades sociais; Educação; Pandemia. 


\section{SEPARAÇÃO DE MISTURAS: RECICLAGEM}

Vinicius José da Silva

Acesse a apresentação deste trabalho

A separação de misturas é um conjunto de processos básicos feitos em laboratórios de química para controle de matérias-primas, análise e obtenção de substâncias. Este resumo, atividade elaborada na disciplina didática do curso de ciências-licenciatura da Universidade Federal de São Paulo, tem como cerne estabelecer um plano de aula voltado à temática de separação de misturas, com ênfase na reciclagem. Deve-se trazer aos estudantes a compreensão da separação de misturas, sua colaboração para os processos de reciclagem e o desenvolvimento da consciência crítica sobre as questões da natureza. A separação de misturas se divide em duas partes: separação heterogênea e homogênea. A separação heterogênea compreende processos em que certas misturas apresentam mais de uma fase, sendo possivel identificá-las. Processos de separação heterogênea: catação, levigação, entre outros. A separação homogênea se refere a misturas que apresentam uma única fase, sendo difícil diferenciar uma substância da outra. Técnicas de separação homogênea: fusão fracionada, evaporação, dentre outros. Espera-se que deste modo, os estudantes possam compreender os impactos ambientais e analisar os diferentes processos de reciclagem. São necessárias estratégias que possibilitem a construção deste conhecimento, desenvolvendo a promoção de debates e realização de ações que estimulem atividades práticas de separação de misturas. Portanto, pode-se dizer que a separação de misturas é um processo amplamente utilizado na química para diversos processos que envolvem substâncias. A temática do assunto aborda os principais aspectos da separação de misturas para a promoção da reciclagem e da sustentabilidade. Através das atividades, os estudantes desenvolvem a compreensão deste tema e da necessidade do tratamento de substâncias e da reciclagem de materiais.

Palavras-chaves: separação de misturas; reciclagem; estudantes. 


\section{REVISÃO TEXTUAL NO ENSINO FUNDAMENTAL: UMA ALTERNATIVA COM}

USO DE TECNOLOGIA

Fernanda Sturion da Silva ${ }^{1}$

$\underline{\text { Acesse a apresentação deste trabalho }}$

Pensando em buscar alternativas que ajudassem na revisão textual com os alunos, tornando-a mais atrativa e real, visto que eles a acham cansativa e desinteressante, surgiu a ideia de escrever um texto sobre um personagem/avatar com eles e depois corrigi-lo coletivamente, com o uso da tecnologia. Os alunos de uma turma de terceiro ano do Ensino Fundamental, tiveram a oportunidade de criar um Avatar, ou seja um boneco virtual. Pensando e discutindo sobre as suas características fisicas e de personalidade, para assim, criá-lo. Com o boneco pronto, foi escrito coletivamente, com o uso da lousa, uma ficha com as características do personagem e um pequeno texto de apresentação do mesmo, com seu nome, idade, enfim, falando sobre o boneco e a turma, pois junto à apresentação, foi feito um convite para que os demais alunos, pudessem participar de uma apresentação da turma, na escola. O texto e a ficha com os dados do Avatar foram produzidos em um dia. Um aluno digitou em casa, e enviou para a professora, por email, que em outro momento, fez junto com a turma a revisão do texto e da ficha. Para isso, o notebook e o data show, foram imprescindiveis, visto que, com o auxílio destes equipamentos, foi possível, projetar o texto, ler com a turma e realizar as correções necessárias. Bem como, foi possivel montar o Avatar, seguindo as indicações da ficha, pré definida. Durante todo o processo, os alunos, na sua maioria, se prendeu à atividade, desenvolvendo-a com atenção e interesse. Também, entenderam melhor a função do email. $\mathrm{O}$ uso da tecnologia tornou a atividade de revisão textual mais interessante e motivadora, e ainda tinha uma função social para a turma, que seria a apresentação para os demais alunos. Ao final, os alunos se engajaram, se interessaram e o Avatar, passou a fazer parte da turma.

Palavras-chave: Revisão textual; tecnologia; produção textual. 


\title{
O USO DE (MULTI) MODALIDADES TECNOLÓGICAS EDUCACIONAIS PARA O ENSINO DE PARASITOLOGIA
}

\author{
Shamaya Thilara Leite Lago ${ }^{1}$, Vitoria Pedrozo Rodrigues ${ }^{2}$, \\ Ronaldo Adriano Ribeiro da Silva ${ }^{3}$ \\ Acesse a apresentação deste trabalho
}

Mediante a situação da pandemia do COVID-19, os docentes da educação básica se confrontaram com a situação da suspensão das atividades didáticas pedagógicas. Dessa forma, todos estão vivenciando um momento educacional de desafios e barreiras dos quais não estavam preparados e capacitados para lidar com o cenário atual. Dentro desse contexto, os docentes estão enfrentando inúmeras dificuldades ao terem que utilizar as tecnologias digitais para o ensino remoto emergencial. O objetivo desse projeto é fornecer aos docentes da área de Ciências Naturais do Ensino Fundamental II do município de Altamira/Pará um curso de educação continuada acerca do uso de (multi) modalidades tecnologias educacionais gratuitas (Podcast, Movie maker, Pixton e etc), para facilitar e dinamizar o processo de ensino e aprendizagem ao Ensino de Parasitologia. A natureza da pesquisa é qualitativa. A metodologia se constitui de revisão da literatura acerca de formação continuada de professores e ferramentas de tecnologias educacionais, análise de documentos oficiais Base Nacional Comum Curricular e currículo oficial do município. $\mathrm{Na}$ fase exploratória está sendo utilizados: (1)questionários (online) para diagnosticar concepções relativas ao uso de tecnologias, as ferramentas tecnologias, recursos tecnológicos, metodologias de ensino, propostas de abordagem, dificuldades e obstáculos; (2) apresentação e seleção de plataformas tecnológicas gratuitas; (3) analise de dados coletados utilizando o método de Analise de Bardin ; (4). oficinas; (4) criação de um grupo ( Facebook ) para relatos de experiências e materiais produzidos; (5) avaliação diagnóstica acerca do processo de formação continuada. O projeto surgiu da necessidade de aproximar e estabelecer parceira entre a universidade e escola, na disseminação do conhecimento para a busca de uma melhor qualidade de vida e de educação em saúde da população local no que se referem às principais parasitoses da região amazônica.

Palavras-chave: tecnologia educacional, ensino, parasitoses, educação continuada.

1 Graduanda da Licenciatura
Altamira.shamyathilara@hotmail.com


(M)EU TERRITÓRIO DE IDENTIDADE: RELATO DE PRÁTICA PEDAGÓGICA

\section{COM CRIANÇAS PEQUENAS EM UMA ESCOLA PÚBLICA DE LAURO DE}

FREITAS/BAHIA

Carla Pinheiro, Silvanne Ribeiro

Acesse a apresentação deste trabalho

Por meio da escuta sensivel no levantamento de conhecimentos prévios de crianças pré-escolares, acerca de informações sobre aspectos de seu municipio, houve a percepção de que as mesmas não tinham apropriação do tema. Nesse esteio, noções de pertencimento e identidade confundiam-se com as de territórios vizinhos. Ademais, as formas de representação fundadas em pensamentos espaciais apresentavam desconexões sobre seus espaços de convivência. Assim nasceu a prática "(M)eu território de identidade" que objetivou a construção, ressignificação e fortalecimento da identidade individual e coletiva, da potencialização de/sobre grupos de pertencimento, da construção da imagem positiva de si e do outro. Também objetivou fomentar a consciência de que assim como somos marcados pela história e pela cultura, também imprimimos marcas nos ambientes. A proposta ainda teve por alicerce o senso de cidadania global, a compreensão de dinâmicas pertinentes à mutabilidade do mundo e o empenho à equidade pela garantia dos direitos fundamentais. A experiência educativa contribuiu para o desenvolvimento de competências e habilidades previstas na Base Nacional Comum Curricular (2017), a saber: agir de maneira independente com confiança em suas capacidades; comunicar ideias e sentimentos; usar estratégias pautadas no respeito mútuo para lidar com conflitos e; coordenar habilidades manuais no atendimento adequado a seus interesses e necessidades em situações diversas. Conclui-se que, no entendimento sobre a construção da criança por meio das trocas que realiza com seus pares e com o mundo circundante, e do corpo como elemento central no desenvolvimento integral, as práticas pedagógicas vislumbraram o gerenciamento do conhecimento à emancipação, ao empoderamento e à liberdade. Ressalta-se a importância de problematizações quanto ao formato do currículo escolar cunhado por disciplinas e resistente à defesa dos processos de aprendizagens implicados na valorização da cultura da infância.

Palavras-chave: Prática Pedagógica. Identidade. Território. Educação Infantil. Cultura da Infância. 


\section{PERFIL DOS PROFESSORES QUE EXERCEM A DOCÊNCIA NA EDUCAÇÃO

\author{
INFANTIL NA REDE MUNICIPAL DE ENSINO DE SALVADOR
}

Marlene Oliveira dos Santos' ${ }^{1}$, Silvanne Ribeiro²

$\underline{\text { Acesse a apresentação deste trabalho }}$

A pesquisa Docência na Educação Infantil: um estudo sobre o trabalho pedagógico com bebês e crianças pequenas em escolas de Educação Infantil da rede municipal de ensino de Salvador (2018-2020) objetivou analisar a docência na Educação Infantil no contexto de políticas públicas, traçando o perfil dos professores e explicitando as referências que subsidiam o trabalho pedagógico. A ênfase no exercício da docência com bebês e crianças pequenas deriva de uma escolha político-epistemológica com esse grupo e docentes que começam a ter mais visibilidade no final do século XX. A pesquisa, de abordagem quantitativa e qualitativa, analisou microdados do Censo Escolar de 2018 do Instituto Nacional de Estudos e Pesquisas Educacionais Anísio Teixeira (INEP) e dados de um questionário on-line (2019) respondido por 93 docentes. Os resultados apontaram um perfil de professor com predominância de mulheres, negras, de 28 a 49 anos, nascidas em Salvador, com nível superior em Pedagogia. O tipo de vínculo com o poder público, como o crescimento do número de docentes contratados e/ou terceirizados, e a relação entre a identidade e a função do professor e do Auxiliar de Desenvolvimento Infantil, no exercício da docência, foram alguns dos desafios encontrados. Verificou-se também que os docentes vêm subsidiando suas práticas em fontes on-line e impressas, sites institucionais, canais de YouTube, livros e artigos, documentos legislativos, bem como nas experiências da criança e em conhecimentos próprios. As narrativas explicitaram muitas incertezas relacionadas ao exercício da docência na Educação Infantil, revelando um sentimento de solidão profissional, bem como insatisfação com a distribuição de materiais por parte do poder público. Conclui-se que o perfil de um coletivo de professores está matizado por questões político-econômicas, locais e nacionais, que afetam diretamente o exercício da docência.

Palavras-chave: Educação Infantil. Docência. Perfil docente. Professores.

1 Universidade Federal da Bahia. Faculdade de Educação/Grupo de Estudos e Pesquisas em Educação Infantil, Crianças e Infâncias (GEPEICI). E-mail: dossantos.ufba@gmail.com

2 Universidade Federal da Bahia. Faculdade de Educação/Grupo de Estudos e Pesquisas em Educação Infantil, Crianças e Infâncias (GEPEICI). E-mail: silvanneribeiro@gmail.com 


\title{
FORMAÇÃO DOCENTE DURANTE A COVID-19: EDUCAÇÃO EM VALORES NA
}

\section{ABORDAGEM DA TEORIA DOS CONTEÚDOS}

\author{
Emily Bomfim Souza ${ }^{1}$, Paulo Fraga da Silva ${ }^{2}$
}

Acesse a apresentação deste trabalho

Ao tratar a Teoria dos Conteúdos, é sabido que para a efetivação do processo de ensino-aprendizagem torna-se de suma importância considerar aspectos voltados a normas, valores e atitudes, que por sua vez, compõem o chamado conteúdo atitudinal. $O$ presente relato refere-se à disciplina de Metodologia do Ensino de Ciências, num curso de Pedagogia. Diante do contexto de ensino remoto durante a pandemia da Covid-19, e da necessidade de abordar a importância da educação em valores no curso de Pedagogia para atuação nos anos iniciais do Ensino Fundamental, surgiu a possibilidade de realizar um fórum colaborativo que envolvesse os critérios e discussões abordados no ambiente virtual de aprendizagem. Assim, o primeiro passo dado foi a seleção de algumas questões norteadoras que auxiliassem os educadores em formação, a refletirem sobre o contexto pedagógico e as ações possíveis para o ensino de conteúdos atitudinais, questões como: "Por que alguns autores consideram os conteúdos atitudinais como de "natureza gasosa?" "Que relações existem entre normas, atitudes e valores na aprendizagem dos conteúdos atitudinais?" "O que significa o termo 'autonomia moral'?" "O que nós futuros professores temos a ver com isto?". $\mathrm{Na}$ abordagem do tema, os alunos foram orientados a compilarem em forma argumentativa seus posicionamentos frente às questões levantadas, bem como, deveriam elencar suas ideias de modo colaborativo com as bases levantadas por outros colegas. Como resultado desse fórum, obteve-se um construtivo debate assincrono, que desvelou a compreensão dos graduandos sobre a importância da educação em valores, e, sobretudo garantiu a troca de informações aliadas à formação do educador que contempla a harmonização e interlocução entre teoria e prática, registrando colaborativamente os desafios contemporâneos da profissão e possiveis vestígios de soluções para garantia de um trabalho docente apoiado em valores ético-morais e democráticos na formação cidadã.

Palavras-chave: Ensino Superior. Educação em Valores. Ensino de Ciências.

1 Acadêmica do curso de licenciatura em Pedagogia. Universidade Presbiteriana Mackenzie. emilybonfimsouza@gmail.com.

2 Professor Doutor. Universidade Presbiteriana Mackenzie. paulo.silva1@mackenzie.br 


\title{
O PEQUENO PRÍNCIPE E AS CRIANÇAS NA ERA DA ANSIEDADE
}

\author{
Emily Bomfim Souza ${ }^{1}$
}

\section{Acesse a apresentação deste trabalho}

É evidente que as mudanças na sociedade trouxeram grande impacto na construção da identidade do sujeito criança, mas junto com essa nova construção, uma indagação faz-se presente: As crianças da geração Alpha continuam sendo crianças na percepção colocada por Saint-Exupéry em "O pequeno príncipe"? A importância deste estudo se dá à medida em que serão abordadas questões referentes ao atual cenário em que as crianças vivem e como isso impacta no desfrute da infância em sua plenitude, e reflete direta ou indiretamente no aumento de casos de crianças com problemas voltados a saúde mental, intrinsecamente a ansiedade. Em prol de atingir os objetivos propostos, realizou-se um levantamento bibliográfico referente a infância, criança, saúde mental das crianças e as mudanças na sociedade ao longo dos séculos XX e XXI, a fim de correlacionar as temáticas e identificar quem são as crianças do século XXI e como elas vivenciam a infância. Neste contexto, pode-se aferir que em uma sociedade cada vez mais competitiva e alicerçada na liquidez das informações provocada pelos avanços tecnológicos, tivemos uma significativa mudança na forma em que a criança se coloca no mundo. O acesso a muitas informações revolucionou a forma de se enxergar as coisas, as crianças hoje, pertencentes a chamada geração Alpha, sofrem desde muito cedo influência desse universo digital, o que faz com que elas tenham na palma da mão acesso ao mundo. Se por um lado, isso pode ser uma grande potência para aprendizagens e o protagonismo das crianças, por outro, pode ser um gatilho para o acesso a informações inadequadas a sua idade, e juntamente compor uma disparidade e/ou refúgio da realidade vivida, o que em excesso pode fazer com que a criança não vivencie as experiências próprias da infância e gere uma onda de problemas voltados a saúde mental das crianças. Conclui-se que, o acúmulo de estímulos, o ritmo cada vez mais acelerado das mudanças e as exigências para serem as melhores "competidoras" junto com responsabilidades que vão além de suas idades, levam as crianças a um estresse excessivo e a um verdadeiro assassinato da infância.

Palavras-chave: Criança. Infância. Ansiedade.

1 Acadêmica do curso de licenciatura em Pedagogia. Universidade Presbiteriana Mackenzie. emilybonfimsouza@gmail.com. 


\title{
A DOCÊNCIA NEGADA DAS AUXILIARES DO MUNICÍPIO DE CARAPICUÍBA -SP
}

\author{
Emily Bomfim Souza ${ }^{1}$
}

\section{Acesse a apresentação deste trabalho}

É evidente que a luta por uma educação pública de qualidade perpassa a valorização dos profissionais docentes, mas junto com essa percepção, uma indagação faz-se presente: Existem profissionais da educação que tem seu papel docente negado? A importância deste estudo se dá à medida em que serão abordadas questões referentes ao papel desempenhado no chão da sala de aula, pelas chamadas Auxiliares em escolas públicas de Educação Infantil no Município de Carapicuíba-SP, a fim de dar voz a essas educadoras que não possuem seu papel docente reconhecido. Em prol de atingir os objetivos propostos, realizou-se um levantamento bibliográfico referente a construção histórica da identidade dos profissionais atuantes na Educação Infantil, a relação entre o cuidar e o educar e a precarização da docência dedicada a primeira infância, assim como realizou-se uma entrevista de cunho qualitativo com dez Auxiliares atuantes em creches, para que elas relatassem suas práticas cotidianas e como percebem a própria identidade docente. Neste contexto, podese aferir que historicamente o profissional dedicado a Educação Infantil, intrinsecamente a creche, carrega a desvalorização profissional, por uma ideia restrita de que a atuação com bebês e crianças bem pequenas, limitasse aos cuidados elementares humanos, que por sua vez são considerados como "trabalho sujo" ou inferior. Nas creches as Auxiliares são as profissionais que mais atuam diretamente com as crianças, mas antagonicamente não fazem parte do quadro do magistério, ou recebem incentivo para a formação continuada. Essa realidade revela implícita e explicitamente a importância que os municípios dão a Educação Infantil, pois a desvalorização da docência culmina na desvalorização da Educação. Por meio da entrevista realizada com as Auxiliares no município de Carapicuíba-SP, constatou-se que estas não são profissionais leigas na área pedagógica, tendo como formação de base a licenciatura em pedagogia e que cotidianamente assumem salas para suprir a defasagem de professores titulares. As Auxiliares pontuam que buscam o reconhecimento docente, uma vez que já exercem este papel, assumindo salas de aula e atendem as exigências legais para atuarem como professoras de Educação Infantil. Conclui-se que, a luta das Auxiliares pelo reconhecimento docente é uma luta histórica pela valorização da Educação Infantil.

Palavras-chave: Auxiliares. Docência. Educação Infantil.

1 Acadêmica do curso de licenciatura em Pedagogia. Universidade Presbiteriana Mackenzie. emilybonfimsouza@gmail.com. 


\title{
MODALIDADE DE APRENDIZADO EM ESTUDANTES DO CURSO DE
}

\section{ODONTOLOGIA DA UNIVERSIDADE PÚBLICA E PRIVADA}

\author{
Taís de Souza Barbosa
}

Acesse a apresentação deste trabalho

Cada indivíduo apresenta ao menos uma modalidade de aprendizado e conhecer essas preferências pode auxiliar na escolha dos educadores pela metodologia de ensino mais eficaz. Este estudo teve como objetivo avaliar a relação entre preferência de modalidade de aprendizado e conceito final em alunos de graduação em Odontologia, de uma Universidade pública e uma Universidade privada, os quais foram submetidos ao modelo tradicional de ensino (aula expositiva e avaliação somativa). A amostra consistiu de 32 ( $Q=22$ ) estudantes de Universidade pública e 60 graduandos $(+=47)$ da Universidade privada. Para avaliar as modalidades de aprendizagem, utilizou-se o questionário VARK (Visual, Aural, Reading-writing and Kinesthetic) que considera as modalidades visual, auditiva, leitura/escrita e cinestésica. O conceito final na disciplina Odontopediatria foi obtido pela média de três avaliações somativas sobre o conteúdo teórico ministrado de forma expositiva, sendo considerado aprovado o aluno com conceito igual ou superior a 6,0. Os resultados foram avaliados por análise descritiva, considerando a distribuição dos dados e porcentagem. A modalidade multimodal foi reportada por $50 \%$ dos graduandos do ensino privado e $56,3 \%$ do ensino público. No ensino público, $25 \%$ dos graduandos reportou a modalidade auditiva, $12,5 \%$ cinestésica e $6,3 \%$ visual. No ensino privado, 36\% auditiva, $11,7 \%$ cinestésica e 1,7\% leitura/escrita. O

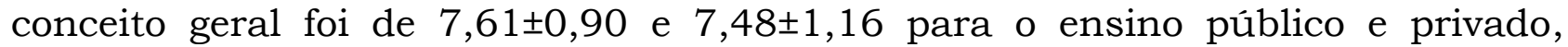
respectivamente, sendo maior nos alunos com preferência tetramodal $(7,91 \pm 0,89$ e $7,64 \pm 0,98$ ) e menor nos bimodais $(7,23 \pm 0,63$ e $7,16 \pm 2,18)$. Concluiu-se que o modelo de ensino tradicional na disciplina ministrada foi compativel com as preferências de aprendizagem dos alunos avaliados, resultando em conceitos finais satisfatórios em ambos os contextos universitários.

Palavras-chave: desempenho acadêmico, estudantes de odontologia, modalidade de aprendizagem 


\title{
VESTIBULÊS: VIDEOAULAS DE LITERATURA
}

\author{
Marianna Schneider¹, Priscila Rabanea², Taisa Robuste ${ }^{3}$
}

Acesse a apresentação deste trabalho

Este trabalho tem como propósito compartilhar experiência de prática de estágio na modalidade remota vivenciada por um grupo de alunos do curso de Letras da Universidade Federal do Paraná (UFPR). Como forma alternativa para o cumprimento das horas de estágio obrigatório da disciplina de Prática de Língua Portuguesa II, em contexto de pandemia, propusemos a criação de um canal no YouTube para discutir as 8 obras literárias avaliadas pelo vestibular da UFPR. Com foco principalmente em estudantes em da rede pública de ensino, foram gravadas 4 videoaulas para cada obra, todas elas acompanhadas de unidade didática e o seu respectivo gabarito, de modo que alunos sem acesso à internet também pudessem usufruir do material. O canal se propõe a preparar o aluno para que seja capaz de realizar a prova de vestibular da universidade, mas, principalmente, visa incentivar a leitura e promover a reflexão, curiosidade, ampliação do conhecimento de mundo e desenvolvimento da habilidade de fazer relações.

Palavras-chave: ensino assincrono; videoaulas; literatura; prática de estágio, vestibular.

1 Graduanda em Letras Português/Italiano pela Universidade Federal do Paraná e uma das professoras do canal Vestibulês. E-mail: mari.schneider.anna@gmail.com

2 Graduanda em Letras Português/Espanhol pela Universidade Federal do Paraná e uma das professoras do canal Vestibulês. E-mail: priscila.rabanea@gmail.com

3 Professora Dra. vinculada ao Departamento de Teoria e Prática de Ensino (DTPEN) da UFPR e orientadora do trabalho. E-mail: taisarobuste@gmail.com 
LINK GAME: DOENÇAS E SISTEMAS DO CORPO HUMANO: PLANO DE AULA

PARA ENSINO REMOTO

Taluan Nogueira1, Marilena Rosalen²

Acesse a apresentação deste trabalho

O período de quarentena, devido ao Covid-19, abriu-nos novas possibilidades de se trabalhar os conceitos de Ciências em casa e ativamente. O presente trabalho foi aplicado em uma escola privada e bilíngue situada na cidade de São Bernardo do Campo. A escola possui fundamental I e ingressou no fundamental II no ano de 2020. As aulas de Ciências são ministradas integralmente em inglês. O plano de aula em questão foi aplicado para os alunos do year 5 , equivalente ao $5^{\circ}$ ano. Os alunos desta sala gostam de práticas dinâmicas, de compartilhar informações, e se expressam bem. A turma se compõe de 12 alunos. Os conteúdos de Ciências relacionados a sistemas do corpo humano já tinham sido aplicados à turma. O novo módulo possuía o tema de "doenças e como elas afetam nossos sistemas". Quando o tema é corpo humano, não podemos deixar de lado o ensino de algumas doenças e como elas afetam o nosso corpo. O ensino remoto dificulta a interação entre os alunos se comparado com as aulas presenciais, por isso a proposta do link game. Este plano de aula trás uma metodologia ativa (aula invertida) onde os alunos são engajados a se comunicarem e trabalharem em grupo para conseguir um resultado significativo. Antes de aplicar esta proposta, os alunos já devem ter estudado no mínimo os sistemas digestivo, excretório, respiratório, circulatório, nervoso e musculoesquelético. Pode-se trabalhar esse plano como um jogo ou não. Os alunos recebem secretamente do professor um sistema do corpo que representa o estudante e uma ou mais doenças que podem afetar seus colegas. Anexado ao email, há a descrição da doença recebida pelo professor. O grupo deve trabalhar em equipe para descobrir quais doenças afetam cada um da turma. A regra mais importante é que todos devem falar e compartilhar suas informações. No final, os discentes devem responder o e-mail do professor afirmando quais doenças o afetaram e como.

Palavras-chave: ensino remoto, doenças, plano de aula, Ciências, grupo.

1 Licenciando em Ciências da Universidade Federal de São Paulo. (UNIFESP). Professor na Escola... E-mail:

2 Profa. Dra. do curso de Ciências e do Programa de Mestrado Ensino de Ciências e Matemática da Universidade Federal de São Paulo (UNIFESP). E-mail: marilena.rosalen@unifesp.br 


\section{O BRINCAR EM TEMPOS DE ISOLAMENTO SOCIAL}

Tatiane Resende Bitencourt

Acesse a apresentação deste trabalho

Este resumo tem como objetivo propiciar a reflexão acerca do papel ocupado pelo brincar e os impactos do isolamento social sobre o mesmo. O brinquedo e o brincar estiveram presentes desde os tempos mais remotos da nossa civilização, antes mesmo dos portugueses chegarem ao Brasil o mesmo já se encontrava entre as crianças indígenas. Com o passar das décadas o brincar, assim como a sociedade, foi se transformando e assumindo novas formas, tamanhos, cores e funções. O brincar, assim como a infância é uma construção social e cultural, desta forma não sendo neutro, com aspectos que influenciam suas interações e objetivos, sendo uma necessidade interior da criança, uma vez que, através dele ela consegue expressar suas emoções e compreender a sociedade em que está inserida. Atualmente, o brincar tem seu papel de destaque na educação, mais fortemente na educação básica. É através do brincar que a criança pode desenvolver capacidades importantes para o seu desenvolvimento integral, o brincar foi e continua sendo tema de diversos estudos de profissionais não apenas da área da educação sempre com a certeza de sua importância como condutor do desenvolvimento de bebês e crianças. Atualmente, o brincar é um direito da criança e um dever das instituições de ensino sendo já ultrapassado o paradigma de ser apenas um "passatempo" para ocupar a ociosidade este direito vem estando presente fortemente na educação a distância com diferentes propostas mesmo durante o isolamento social que atualmente enfrentamos devido a pandemia do novo Corona virus ( Covid-19) . A educação a distância, já tinha seu papel reconhecido em diferentes esferas, muitas vezes escolhida como principal meio para aqueles que não podiam se deslocar a uma instituição de ensino, por diversos fatores, seja pela falta de tempo na rotina, seja pela distância, a educação on-line já fazia parte de nossa sociedade, mas ainda se encontrava destinada fortemente a formação de jovens e adultos, limitadas em sua maioria a aspectos profissionais. Com o decorrer da pandemia aos poucos foi se estreitando cada vez mais locais públicos, parques, comércios e consequentemente escolas, fechados por tempo indeterminado. Com as escolas fechadas, em especial as creches e pré-escolas, muitas famílias se viram diante de uma nova rotina, tendo muitas vezes que conciliar o trabalho doméstico, o trabalho a distância e a educação remota das crianças. A escola precisou se reinventar de uma forma rápida para continuar garantindo o direito a educação e consequentemente ao brincar de milhares de crianças, indo de encontro com a educação remota, que se tornou o principal meio para que ocorresse essa garantia. A questão foi problematizada com um levantamento teórico, utilizando diversos autores que discorrem acerca do brincar, seu impacto no desenvolvimento integral, bem como os efeitos do isolamento social e da educação remota na educação básica, com o foco no brincar e no desenvolvimento integral das crianças em idade pré-escolar. Tendo em vista que a pandemia evidenciou ainda mais a desigualdade em todos os âmbitos sociais, perpassando as condições básicas, como ao acesso à internet. Ainda assim a mesma vem ocorrendo em escolas particulares e públicas de todo o país, os professores, grande parte que não tinham familiaridade com as tecnologias para o ensino a 
distância, se viram obrigados em muito pouco tempo a não apenas gravar suas aulas, bem como editá-las, publicá-las em diferentes plataformas e tendo a consciência que o conteúdo não chegaria a muitas famílias pelos mais variados motivos, devidos aos diferentes contextos como já mencionados. A família que já enfrentava os desafios de nossa atual realidade, com um futuro cheio de dúvidas e incertezas, se viu diante a mais uma dificuldade: o que fazer com as crianças em casa? Como ensiná-las? Como elas iriam brincar? Diante de tantas perguntas e poucas respostas, a escola tem realizado diferentes meios para alcançar cada vez mais suas familias atendendo suas especificidades. Já presente nas rotinas escolares de diferentes formas, o brincar já ocupava um lugar consolidado dentro das instituições escolares, estando presentes nos principais documentos norteadores da educação básica no Brasil, até mesmo na mais recente, a Base Nacional Curricular para a Educação Infantil (2018), que norteia os currículos dos sistemas e redes de ensino das Unidades Federativas, como também as propostas pedagógicas de todas as escolas públicas e privadas de Educação Infantil, Ensino Fundamental e Ensino Médio. O brincar tinha seu papel de suma importância, e cabia a escola continuar garantindo este direito dentro do ensino remoto. Em encontro com as atividades que estão sendo sugeridas pelas escolas as famílias pode-se perceber a concepção de criança, de infância e de educação infantil de cada instituição, através das atividades propostas aproximando mais as famílias do trabalho pedagógico que ficava muitas das vezes limitado a coordenadores, professores e crianças. Em pouco tempo notou-se que os vídeos de atividades tinham que ser característicos para a faixa etária que se destinava, fazendo-se não apenas uma diferenciação de uma formação voltada para adultos, mas também pensando sobre o contexto social das famílias em que a comunidade está inserida e seu alcance, que assim como em uma atividade presencial as atividades tem que ter seus objetivos, sua justificativa sem deixar de ser atrativa, com materiais de fácil acesso, em especial nas escolas públicas. O brincar então voltou a ganhar destaque, já que o uso da tecnologia, além de não ser indicado apara a faixa etária, não era suficiente tanto para o desenvolvimento cognitivo, motor, emotivo e social das crianças. Muitas escolas se alinharam a essa nova demanda, com o cuidado de não tornar a família um espaço de "escolarização" mas sim, optando por oferecer meios e ideias para que a família possa enfrentar este momento com mais leveza e usando este tempo de isolamento para conhecer e brincar com as crianças, o que muitas vezes não era visto como uma prioridade. A escola sempre buscou uma maior interação e participação da família, este momento de isolamento social possibilitou que muitas refletissem não apenas sobre a importância da escola bem como reconheceu a necessidade de serem mais participativos; O brincar está sendo novamente resgatado como a melhor forma seja de educar, garantindo que as crianças não fiquem limitadas a telas de computadores e smartphones, é um momento de garantir o brincar, resgatar as brincadeiras e brinquedos tradicionais da nossa cultura, de aproximar as familias indiferente da plataforma tecnológica utilizada, sendo um lugar de conforto e instrução e não de cobrança pelo o que está ou não sendo feito e proposto. Reconhecendo que as crianças tem que ter suas infâncias garantidas e respeitadas, que a escola continua com o seu papel de garantir uma educação de qualidade, respeitando o desenvolvimento e diferentes contextos dos bebês, crianças e suas famílias.

Palavras-chave: Brincar. Educação. Criança. Reflexão. Isolamento. 


\section{PRÁTICA DOCENTE NO ENSINO SUPERIOR EM TEMPOS DE PANDEMIA: UM RELATO DE EXPERIÊNCIA}

Thalane Souza Santos Silva1, Taiane Gonçalves Novaes², Anne Karoline Pereira Brito ${ }^{3}$, William Santos Silva ${ }^{4}$

Acesse a apresentação deste trabalho

Em consenso com as medidas adotadas pelo poder público para conter o avanço da COVID- 19, ocorreu a suspensão fortuita de aulas presenciais nas Instituições de Ensino Superior, sendo autorizado pelo Ministério da Educação e Cultura a substituição das aulas presenciais por aulas remotas. Neste relato objetiva-se refletir sobre a experiência docente nos cursos de saúde em uma rede de ensino superior privada na Bahia. As aulas foram ministradas remotamente de forma sincrona (ao vivo), nos mesmos dias e horários das aulas presenciais via plataforma digital. A reflexão sobre a proficiência docente quanto ao uso das ferramentas virtuais evidencia inseguranças, principalmente pelo curto período dedicado às capacitações, implementadas pela instituição ou por iniciativa própria, e ao desenvolvimento de habilidades. Houve um aumento substancial da carga horária de trabalho extra aula, com a preparação de materiais e de metodologias ativas, reuniões, correções de atividades e assistência aos discentes. Sendo a sala de aula transferida para o domicílio, destaca-se ainda questões de saúde física relacionadas à ergonomia e tempo de tela em decorrência da sobrecarga no estilo home office. O processo de avaliação, já amplamente discutido na modalidade presencial, emergiu de forma emblemática no ensino remoto. Seriam, então, as avaliações tradicionais efetivas nesse novo contexto de educação? A virtualização da sala de aula acarretou sérias modificações nos processos de ensino-aprendizagem e afetou a subjetividade das relações sociais que antes ali se estabeleciam em múltiplos espaços. Destaca-se ainda o impacto da virtualização com a suspensão das aulas práticas em campo e estágios curriculares. Apesar das estratégias metodológicas na tentativa de mitigar os efeitos negativos, como o uso de casos clínicos fictícios, sabe-se que sua efetividade não é comparável às atividades em campo de prática, reforçando a importância do ensino presencial, especialmente em cursos de saúde.

Palavras-chave: Educação Superior; Docência; Infecções por Coronavirus.

\footnotetext{
1 Docente do curso de Nutrição da Faculdade de Tecnologia e Ciências, Campus Jequié. E-mail: thsouza.jeq@ftc.edu.br

2 Docente do curso de Nutrição da Faculdade de Tecnologia e Ciências, Campus Jequié. E-mail: tgnovaes.jeq@ftc.edu.br.

3 Docente do curso de Nutrição da Faculdade de Tecnologia e Ciências, Campus Jequié. E-mail: akpereira.jeq@ftc.edu.br

4 Coordenador do curso de Nutrição da Faculdade de Tecnologia e Ciências, Campus Jequié. Email: wsilva.jeq@ftc.edu.br.
} 
NEUROFIBROMATOSE TIPO 1 E ESCOLARIZAÇÃO: ENTRE A INVISIBILIDADE E POSSIBILIDADES EDUCACIONAIS.

Thomas Pontes P. Chequettoํ․ Amália Neide Covic ${ }^{2}$

Acesse a apresentação deste trabalho

A neurofibromatose tipo 1(NF1) é uma enfermidade genética, crônica e progressiva, que está potencialmente ligada à prejuízos cognitivos, sociais e psicológicos. Apesar de ser considerada uma doença rara tem significativa prevalência na população em geral (1:3000). Não faltam, na literatura médica, relatos de déficits cognitivos relacionados ao diagnóstico de NF1. Muitos desses possiveis déficits podem se manifestar em uma série de questões de aprendizagem e escolarização. Essa revisão bibliográfica, do tipo narrativa, pretende responder a seguinte pergunta: Como são tratadas as questões escolares dos sujeitos com NF1? Vaucheret Paz (2017) afiram que, em média, $80 \%$ das crianças com NF1 apresentam algum problema cognitivo e de aprendizagem. Pride \& North (2012) corroboram esse dado, por meio de testes psicométricos, encontrando alterações neuropsicológicas, em especial nas funções executivas, em 70\% das pessoas com NF1. Batista (2014), encontra maiores déficits de processamento auditivo temporal na população com NF1 em comparação com população livre de doença. Violante (2015) encontra níveis mais baixos de GABA e da expressão de receptores de GABAA, neurotransmissor inibidor essencial no plano sensorial, cognitivo e motor, na população com NF1, independente da idade. Farias (2013) busca sistematizar hipóteses que apontam para maior dificuldade no desenvolvimento das capacidades leitoras de alunos com NF1. Apesar desse panorama, não encontramos, até o momento pesquisado, dados seguros na área da Educação sobre os processos de escolarização de pessoas com NF1. Contudo, empiricamente, percebemos que dificuldades de aprendizagem, são parte da vida dessa população. Encontramos, desse modo, a invisibilidade (Honneth, 2001) das questões escolares e de aprendizagem das pessoas com NF1 no campo da Educação. Recomendamos como orientações futuras a construção de dados educacionais mais sólidos sobre a população com NF1.

Palavras-chave: escolarização; neurofibromatose tipo-1; déficits cognitivos; dificuldade de aprendizagem.

1 Aluno de doutorado do Programa de Pós-graduação Educação e Saúde na Infância e Adolescência. Universidade Federal de São Paulo. Chequetto.pontes@gmail.com

2 Professara Doutora do Programa de Pós-graduação Educação e Saúde na Infância e Adolescência. Universidade Federal de São Paulo. Amalia.covic@gmail.com 


\section{ESCRITA CURSIVA: CÓDIGO SECRETO DA ESCOLA}

\section{Tírza Porto Azambuja Verri ${ }^{1}$}

\section{$\underline{\text { Acesse a apresentação deste trabalho }}$}

Professora há 26 anos em cidades da Região Metropolitana de Porto Alegre - RS, atuando nos Anos Iniciais do Ensino Fundamental, me foi possivel vivenciar facilitadores e entraves no processo de alfabetização. Dentre os entraves, destaco a exigência de transposição do tipo de letra, entre o segundo e terceiro ano. Nas escolas da região, a alfabetização se dá com o uso da letra script (maiúscula e minúscula) e com a progressão nos estudos, acontece a transposição para a letra cursiva. Esse processo ocorre no momento em que a criança, começa a consolidar sua escrita dando asas a criatividade, produzindo textos amplos, coerentes, revelando prazer em se comunicar através da escrita. É necessário considerar aqui as descobertas das Neurociências que implicam o foco atencional como um vetor essencial para a aprendizagem. Contrariando essa a afirmativa, no momento em que a atenção deveria ser focada na ampliação do letramento, observamos o emprego de funções cognitivas nobres para o ato mecânico de transposição caligráfica. Há de se considerar também a necessidade de empenho das crianças em atividades de desenvolvimento motor, na coordenação espacial, a correlação entre as grafias, a correção no traçado para garantia de funcionalidade na escrita cursiva o que acarreta menos tempo de investimento noutras aprendizagens, mais relevantes. Destaco, por fim o momento atual, onde a letra cursiva se estabelece como um código secreto do universo escolar, visto que não a encontramos em espaços alheios a escola. O mundo usa a letra script para comunicação nas mais diversas linguas, sendo a cursiva cada vez mais rara no nosso dia a dia. Não defendo o descarte completo da letra cursiva, mas que ela seja tratada como mais um conhecimento, uma possibilidade de escolha, que respeite as características de cada escritor e seu tempo de desenvolvimento.

Palavras-chave: Neurociências - transposição gráfica - atenção - código

1 Graduada em Pedagogia, especialista em Psicopedagogia e Educação Especial, concluinte especialização em Neuropsicopedagogia Clínica. CENSUPEG- RS. tirzaverri@gmail.com 


\section{O USO DOS VÍDEOS EM UM CURSO NA MODALIDADE EDUCAÇÃO A DISTÂNCIA (EAD) ONLINE: ANÁLISE DO POTENCIAL PEDAGÓGICO E TECNOLÓGICO}

Ubiratan Pereira dos Santos ${ }^{1}$

Acesse a apresentação deste trabalho

Esta pesquisa buscou analisar os aspectos pedagógicos e técnicos dos vídeos, identificando como essa mídia está sendo utilizada para a aprendizagem de pessoas adultas em instituições públicas e privadas de ensino que ofertam cursos EAD on-line. A pesquisa é sobre gestão estratégica em EAD, por isso optou-se em contemplar profissionais da área com os seguintes perfis: gestor, coordenador de cursos e designer instrucional. Foi utilizada metodologia de pesquisa de caráter exploratório de cunho qualitativo, utilizando o questionário de questões estruturadas como instrumento de coleta de dados. As respostas da maioria dos gestores entrevistados sinalizaram que os vídeos estão sendo utilizados na sua forma mais tradicional, ou seja, como mídia distributiva de aulas mais expositivas sem engendrar inovação pedagógica. Do ponto de vista técnico, as respostas também sugerem que os recursos tecnológicos explorados estão abaixo do atual estágio de desenvolvimento das tecnologias de criação e distribuição de vídeos digitais em Sistemas de Gerenciamento de Aprendizagem. De modo geral, foi demostrado um descompasso entre as potencialidades anunciadas pelos autores estudados e a prática vigente nessas instituições.

Palavras-chave: Educação a Distância. Gestão Estratégica da EAD. Design instrucional. Mídia. Vídeos.

1 Pós-graduando lato sensu especialização em Gestão Estratégica em Educação a Distância Centro Universitário Senac de Educação a Distância - Santo Amaro - São Paulo. E-mail: ups696@gmail.com 
DIMENSÕES PEDAGÓGICAS E ADMINISTRATIVAS DA SUPERVISÃO ESCOLAR:

UM ESTUDO NA PERSPECTIVA DAS REPRESENTAÇÕES SOCIAIS

Valdete Pereira da Silva Nascimento ${ }^{1}$

Acesse a apresentação deste trabalho

Esta pesquisa, de abordagem qualitativa, teve como objeto de estudo a ação supervisora na Rede Municipal de Ensino de São Paulo. Seu objetivo geral foi analisar as Representações Sociais dos Supervisores Escolares sobre o que consideram uma boa ação supervisora. Assumimos o percurso teóricometodológico da Representação Social baseada na Psicologia Social europeia postulada por Serge Moscovici dentre outros, como uma possibilidade de desvelar os discursos dos Supervisores Escolares. Para o embasamento teórico sobre a supervisão escolar, recorreu-se aos autores contemporâneos que apresentam análise sobre esse tema. Para o aprofundamento da discussão optou-se pela realização da análise bibliográfica e documental da legislação relacionada aos Supervisores Escolares que atuam nesta Rede de Ensino. O estudo teve como campo empírico uma Diretoria Regional de Educação da zona sul da cidade de São Paulo. Os participantes da pesquisa foram 18 Supervisores Escolares que atuam na referida Diretoria. Utilizamos para coleta e geração dos dados um questionário com perguntas abertas e fechadas. Os dados das questões abertas foram submetidos à análise de conteúdo proposta por Maria Laura Barbosa Franco. Os resultados da pesquisa indicaram que os Supervisores gostariam de realizar as ações de cunho pedagógico, todavia relatam que o excesso de afazeres burocráticos impede a realização do trabalho pedagógico, que é posto em segundo plano. Consideram ainda, uma boa ação supervisora aquela que é acolhedora, orientadora, reflexiva e que está preocupada com a melhoria da qualidade da aprendizagem dos estudantes. A partir dos resultados alcançados inferimos na importância do fortalecimento do coletivo da supervisão escolar, na busca de melhores condições de trabalho, rompendo com uma ação supervisora acrítica em prol da supervisão centrada na escola, que valorize a comunidade educativa e mantenha o equilíbrio entre as atividades administrativas e pedagógicas.

Palavras-chave: Representações Sociais. Supervisão Escolar. Ação Supervisora. Supervisão Pedagógica.

1 Mestra em Educação - Pontificia Universidade Católica de São Paulo. Supervisora Escolar. Secretaria Municipal de Educação de São Paulo. valdetecarvalho@yahoo.com.br.

ISBN 978-65-88471-05-0 | https://doi.org/10.47247/VV/ENMD/88471.05.0 


\section{A PRÁTICA PEDAGÓGICA E SUAS INTENCIONALIDADES NA FORMAÇÃO DOCENTE}

Veronica Ester Tapiaํ, Luciano Pereira Marotto², Bruna Gabriela Marques ${ }^{3}$

Acesse a apresentação deste trabalho

O estudo pretende relatar a experiência pedagógica dos pesquisadores associada a Feira de Atividades Acadêmicas e Culturais realizada semestralmente na Faculdade Diadema, tendo como foco os cursos de licenciatura em Educação Física e Pedagogia. O espaço de formação da faculdade compartilha performances pedagógicas, artísticas, culturais e esportivas em uma semana de vivências práticas elaborada pelos próprios estudantes, mas com mediação dos professores, onde são divididos em espaços de experimentações práticas recebendo a comunidade e escolas convidadas. A ação traz temas ligados a cultura popular, diversidade, corpo e movimento, literatura infanto-juvenil, jogos e brincadeiras, jogos de alfabetização e letramento, atividades para deficientes físicos, auditivos e visuais e problemas de aprendizagem na perspectiva da educação popular defendida por Paulo Freire e um Sarau Cultural "Diversidades" que fecha o evento recebendo a comunidade como protagonistas das apresentações, compartilhando experiências artísticas e culturais muito significativas que nos remete a descolonização do pensamento, desta forma, a academia vem ao encontro dos saberes populares no olhar de Boaventura de Souza Santos. O projeto surgiu da necessidade de colocar em prática todo o conhecimento adquirido pelos estudantes nas disciplinas com a intencionalidade de qualificálos ainda mais para o atendimento nos espaços educativos, constituindo uma rica forma de experimentação de mundo, experiências colaborativas de acesso ao novo, à pluralidade de conhecimentos culturais, entendidos como patrimônio humano e coletivo de experiências e saberes, como tempo e espaço de circulação da cultura. Assim, pode-se evidenciar que é nas relações de aproximação, seja nas atividades de formação inicial ou da própria atuação profissional que a identidade docente vai se constituindo num intercâmbio de conhecimentos e culturas, buscando uma particularidade educacional para os novos docentes.

Palavras-chave: Educação popular, Experiências pedagógicas, Cultura e educação.

1 Mestranda em Educação Física. Universidade São Judas Tadeu. veronicatappia@gmail.com.

2 Mestre em Ciências. UNIFESP. Lucianomarotto@icloud.com

3 Dra. do Programa de Pós Graduação Stricto Sensu em Educação Física. Universidade São Judas Tadeu. bruna.marques@saojudas.br 


\section{CONSCIÊNCIA POLÍTICA: A INFLUÊNCIA DA TECNOLOGIA DA INFORMAÇÃO}

NA FORMAÇÃO DOS CONCEITOS DE POLITIZAÇÃO E DEMOCRACIA

Vinicius Camargo Chiquito', Valéria Scomparim²

Acesse a apresentação deste trabalho

O estudo da política como ciência nos proporciona uma reflexão exata e imparcial sobre o contexto e acontecimentos atuais. A politização inserida na sociedade e a formação de opinião obtida através dela é o objeto de estudo deste trabalho que através de leituras contextualizadas e uma revisão bibliográfica resultam numa análise a partir de um recorte histórico, partindo dos governos de Getúlio Vargas, golpe militar de 64, a redemocratização até chegarmos no cenário político da deposição, impedimento ou golpe de 2016. Como pano de fundo, estudamos como a evolução e desenvolvimento de tecnologias da informação e a popularização da internet, facilitaram e influenciaram a absorção das informações para a formação de opiniões que é demonstrada e debatida de forma polêmica pela sociedade atual. Finalmente, considerando as várias evidências empíricas avaliou-se e analisou-se tanto o contexto político atual, bem como a polarização política gerada através desses estudos. Metodologicamente, este estudo foi exploratório quanto aos objetivos e de delineamento descritivo.

Palavras-chave: Educação, Democracia, Tecnologia da Informação, Política.

1 Aluno do Curso de Especialização em Tecnologia da Informação e Comunicação na Educação. IFSP/Capivari.v.c.chiquito@gmail.com

2 Professora/Orientadora do Curso de Especialização em Tecnologia da Informação e Comunicação na Educação. IFSP/Capivari. vslima67@gmail.com 


\section{BANDA ESCOLAR}

Vitória Regina Ramos Bitiano ${ }^{1}$

$\underline{\text { Acesse a apresentação deste trabalho }}$

Em processo de formação docente, tenho refletido a minha trajetória escolar enquanto aluna e nesse trabalho relato um projeto que fez diferença na minha vida e na de muitos outros adolescentes: a banda escolar. Ela gerou nos alunos não apenas a iniciação e o gosto musical, mas um senso de coletivo, com vínculos colaborativos e afetivos. Para os alunos da banda, o projeto passou a ter uma importância maior que a própria instituição em que estudavam. A banda ganhou mais força quando alguns alunos que recebiam reclamações de professores passaram a integrar a banda e isso mudou o comportamento e o desempenho deles. A vontade de estar no projeto se tornou algo tão grande que apresentações tidas como exaustivas pelo tempo que os alunos utilizavam desde a preparação até a apresentação, como o desfile cívico de aniversário da cidade de São Bernardo do Campo, eram as mais esperadas pelos alunos, pois eram os momentos em que a interação era maior, com brincadeiras, danças e improvisação de músicas no espaço de concentração, onde cada um era o que era de verdade, sem fingimentos. Durante esses períodos de espera, geralmente um aluno iniciava uma música do repertório e em pouco tempo uma roda se formava com vários alunos tocando, o que chamava a atenção dos que estavam ao redor, inclusive dos professores. As grandes apresentações também foram responsáveis por gerar mais interesse nos alunos, que sempre buscavam melhorar, para que a apresentação da banda a qual pertenciam se tornasse a melhor dentre as demais de apresentações coletivas. O carinho dos alunos ao projeto é tamanha que, mesmo após concluírem o ensino médio, eles recebem convites para os eventos e respondem positivamente, prontamente.

Palavras-chave: Banda escolar; música; afetividade; identidade.

1 Licencianda em Ciências na Universidade Federal de São Paulo (UNIFESP). E-mail: vbitiano@unifesp.br. 


\section{ATIVIDADE DE ENSINO DE CIÊNCIAS NOS ANOS FINAIS}

Lucas Marino Vivot ${ }^{1}$

Acesse a apresentação deste trabalho

O ser humano, sujeito histórico, se relaciona com o meio físico e social, mediado por instrumentos e signos. A atividade de ensino se estabelece no agrupamento social, no espaço de aprendizagem e na apropriação da cultura humana, de forma a criar ferramentas para o desenvolvimento integral dos sujeitos. O planejamento das atividades de ensino de ciências deve estar associado ao ensino investigativo, à familiarização dos conteúdos científicos e na compreensão de fenômenos presente no cotidiano dos estudantes. Objetivou-se desenvolver uma atividade para o ensino de ciências capaz de proporcionar aos alunos uma visão global dos conteúdos envolvidos e as relações entre o saber científico e o cotidiano. O presente artigo foi realizado na instituição privada Colégio Américas, localizado em São Paulo, Brasil. A atividade foi desenvolvida e aplicada em uma turma de $8^{\circ}$ ano dos anos finais do ensino fundamental, relacionada ao tema "Sistema Circulatório", totalizando três aulas de 50 minutos cada, contudo descreverei aqui apenas as atividades relacionadas à primeira aula. Os tópicos abordados foram: sistema cardiovascular humano; vasos sanguíneos e coração; pressão arterial; doenças relacionadas ao sistema circulatório humano. Iniciei a aula utilizando as músicas: "Coração bobo" (Alceu Valença) e "Eu sei" (Negra Li) e, em seguida realizei um levantamento prévio sobre o tema. Em exposição dialogada foram definidos os conceitos e finalizei a aula com uma atividade prática individual utilizando um aplicativo de celular, que permite aos alunos medir os batimentos cardíacos. $\mathrm{Na}$ avaliativa os estudantes deveriam buscar, em casa, explicações sobre as seguintes doenças: pressão alta, aterosclerose e AVC para serem apresentadas, em seminários, na próxima aula. O professor deve ter um papel de mediador do conhecimento, de modo que os alunos sejam participativos, e a educação seja construída para se tornar transformadora.

Palavras-chave: alfabetização científica, práticas de ciências, ensino de biologia, didática das ciências

1 Biólogo, Mestre em Ecologia e Evolução pela Universidade Federal de São Paulo. Licenciando em Biologia pela mesma Universidade. lucasmvivot@gmail.com 


\section{RELATOS DO PIBID-UFPR: O TEXTO DRAMÁTICO EM SALA DE AULA}

Carolyne Dornelles Meloํ, Wagner José Negrelo Biscaia²

Acesse a apresentação deste trabalho

Dentro das regências mensais que os bolsistas do Programa Institucional de Bolsas de Iniciação à Docência (PIBID) exerciam, um dos conteúdos trabalhados foi o texto dramático. Este trabalho versa sobre duas regências acontecidas no ano de 2019, uma de cada um dos autores, em turmas do $8^{\circ}$ Ano do Colégio Estadual do Paraná, na disciplina de Língua Portuguesa. Em uma das regências, o tema da aula foi $O$ Auto da Compadecida, de Ariano Suassuna, do qual foi feita leitura em conjunto de um trecho e exibida cena do filme homônimo que correspondia ao que fora lido, de forma a observar a transposição do texto e a importância da forma deste para a criação da cena. A outra regência teve como temas a peça "O Rico Avarento", de Ariano Suassuna, e o conto de narrativa dramatizada "Moral Quotidiana", de Mário de Andrade. Entre a forma mais livre e temática cômica daquele e a forma mais tradicional e temática trágica deste, procurou-se apresentar, inicialmente, características do gênero aos estudantes, seus autores, mas, principalmente, trabalhar com o texto, levado impresso, e sua interpretação. Ambas as regências propuseram como atividade avaliativa a criação, pelos alunos, de um pequeno texto dramático, no qual deveriam aplicar o que fora abordado na aula. No geral, em ambas as regências os alunos, majoritariamente, apresentaram textos muito presos ao diálogo, sem usar, de fato, o gênero dramático. O objetivo deste trabalho é demonstrar como programas tais como o PIBID são importantes para a formação docente, uma vez que propiciam a reflexão sobre a prática em sala de aula a partir da interação professor-aluno. Além disso, com os resultados obtidos nas regências, abre-se espaço para olhar criticamente para a forma como conteúdos são abordados e quais seriam outros caminhos possiveis para o trabalho em sala.

Palavras-chave: Pibid, UFPR, texto dramático, docência.

${ }^{1}$ Graduanda em Letras. Universidade Federal do Paraná (UFPR). carolynedornelles@ufpr.br

2 Graduando em Letras. Universidade Federal do Paraná (UFPR). wagnerbiscaia@gmail.com ISBN 978-65-88471-05-0 | https://doi.org/10.47247/VV/ENMD/88471.05.0 


\section{COMO O ISOLAMENTO NOS UNIU: A CONSTRUÇÃO DE UMA COLETIVIDADE}

\section{REFLEXIVA}

Willian Vinicius Silva

Acesse a apresentação deste trabalho

O momento pandêmico chegou inesperada e compulsoriamente a todas e todos. É inevitável refletir sobre as consequências advindas da impossibilidade de permanecermos ser e estar em uma sociedade baseada em abismos sociais, econômicos e culturais. Perante este cenário, como construir ações educacionais que possam dar início a um percurso de transformação em torno da comunidade onde está inserida uma escola de educação infantil? Foi a partir desta realidade que surgiu um projeto político pedagógico de construção coletiva fundamentado na escuta ativa e atenta de professoras, crianças e comunidade, registros críticosreflexivos individuais e coletivos, desenvolvimento de potencialidades internas e externas ao grupo de professoras e a comunidade escolar e a construção de práticas pedagógicas significativas possíveis. Para a construção desta trajetória, foi imprescindivel priorizar o protagonismo infantil, sem desconsiderar o uso excessivo de telas pelas crianças, tomar consciência sobre o acesso limitado às tecnologias pelas comunidades periféricas e a tímida intimidade das professoras com as ferramentas da internet. Assim, surgiram nossas primeiras demandas de pesquisas, estudos, formações, encontros, debates e diferentes formas de construir criticamente conhecimentos para iniciarmos nosso planejamento e práticas pedagógicas reflexivas formando e transformando nossa comunidade de aprendizagem. Desde o surgimento da quarentena, foram realizados 1 questionário diagnóstico da realidade de cada família, 24 encontros entre professoras e a coordenação pedagógica, 110 propostas de atividades para as crianças, 2 encontros virtuais com as famílias, 18 momentos formativos, contatos telefônicos com as famílias mais vulneráveis e um imenso sentimento de responsabilidade crítica, reflexiva e coletiva de toda nossa comunidade de aprendizagem. O desafio é sempre envolver mais familias e crianças em todo esse processo e não perdê-lo em meio a rotina escolar presencial.

Palavras-chave: Educação, comunidade de aprendizagem, formação docente, coletividade. 


\title{
COMO NASCEM AS PLANTAS? O DESAFIO DE ENSINAR CIÊNCIAS PARA
}

\section{CRIANÇAS EM CARÁTER REMOTO}

\author{
Angélica Nunes da Rochaํ, Aparecida Adriana Galdino², \\ Márcia César ${ }^{3}$ Margarida Antunes ${ }^{4}$
}

$\underline{\text { Acesse a apresentação deste trabalho }}$

\begin{abstract}
Este trabalho trata-se de um relato de experiência de uma atividade de ensino em ciências nos anos iniciais, intitulada Ciclo de Desenvolvimento das Plantas, realizada remotamente no contexto da pandemia Covid-19. Está sendo realizada por professoras envolvidas em um projeto de parceria universidade/escola, inscrito no Programa Melhoria do Ensino Público da Fapesp (218/16585-1). O Grupo de Trabalho colaborativo constituido entre professoras da escola e pesquisadores da universidade reúne-se semanalmente para planejar e refletir sobre as ações que vão sendo realizadas pelas crianças e suas famílias. A comunicação tem ocorrido por meio de plataformas digitais como WhatsApp e Google Meet. O estudo do ciclo de vida das plantas foi escolhido com a intenção de proporcionar a "elaboração do conceito de semente, germinação, partes das plantas e, sobretudo, o conceito de ciclo, como estruturante da área de ciências" (Ata do $6^{\circ}$ encontro, 2020). Todas as ações realizadas pelas crianças foram documentadas pelas famílias, registradas em vídeos, fotos, registros escritos e enviadas para as professoras. Ações realizadas até o presente momento: reconhecimento do meio ambiente no entorno da criança com visita a uma praça, orientada por um adulto; levantamento de hipótese sobre a questão: "Como nascem as plantas?"; experimentação com o plantio de uma semente de feijão em papel toalha inserida em um vidro de boca larga. Esse plantio foi orientado por um vídeo gravado pelas professoras; registros do acompanhamento da germinação em um "diário do pé de feijão"; leituras de livros infantis e poesias com gravação de áudios, entre outras ações em processo de desenvolvimento. Resultados preliminares: empenho das docentes; envolvimento das crianças e familiares; aproximações com a orientação investigativa no ensino de ciências e com a alfabetização científica e articulações com a alfabetização na língua materna.
\end{abstract}

Palavras-chave: Ensino de Ciências para crianças; ensino remoto; orientação investigativa; alfabetização científica; 


\title{
EDUCAÇÃO, CULTURA E DEMOCRACIA: UMA RELAÇÃO DE
}

\section{INTERDEPENDÊNCIA.}

\author{
Evelyn Elen Alves de Brito Cabral1, Idelma Izabel de Camargo Silva²
}

Acesse a apresentação deste trabalho

Introdução: A formação de uma cultura democrata nasce do conhecimento enquanto instrumento politico de libertação. A educação permitirá em partes que cada aluno - cidadão no meio social que vive, desenvolverá um potencial para sua libertação. A ideia de educação deve estar intimamente ligada às de liberdade, democracia e cidadania. Entretanto, a educação não pode preparar nada para a democracia a não ser também que seja democrática, seria contraditório ensinar à democracia no meio de instituições de caráter autoritário. O domínio moral da educação freiriana é relembrado com a expressão "manifestação ética", e o âmbito estético. Educação seria, ainda, habilitação científica e técnica, ou seja, capacitaria o educando para prática da ciência e para os estudos e trabalhos tecnológicos. Além disso, a educação seria uma atividade imprescindível aos humanos e pertenceria a eles de modo específico: "na História como movimento, como luta". Assim, a História, segundo Freire, seria dinâmica, dotada de mobilidade, de mudança, seria luta empenho, esforço, conflito. O processo constante de criação do conhecimento e de busca da transformação reinvenção da realidade pela ação-reflexão humana, além de ser um processo político, seria uma prática específica dos humanos no "movimento" e na "luta" própria da História conforme a concepção freiriana. Objetivos: Tensiona-se com este trabalho: refletir sobre a importância da interferência impar de cada autor no cenário educativo, onde cada um do seu jeito contribuiu para uma educação que nos dias atuais podem ser vistas como um norte no processo de ensino na educação brasileira. Identificar e discutir o processo de ensino-aprendizagem, segundo o pensamento de Paulo Freire, pautado com base no sentimento de transformação da realidade. O intuito do autor era promover a inclusão na educação dos indivíduos marginalizados e Anísio Teixeira, o defensor da escola pública brasileira, onde seu compromisso era com a causa da escola pública, desde os primórdios de sua atuação na área educacional. Objetiva-se também ao estudar sobre os ícones da educação, destacar que ambos tiveram de forma ativa e significativa um papel para a formação dos modelos educacional brasileiro. Cada um do seu jeito e perfil trabalhou e procurou dar sua contribuição para as gerações anteriores e atuais, lutando contra vários "poderes" explícitos ou ocultos para realizar seu trabalho. Metodologia: O percurso metodológico utilizado neste trabalho definiu-se a pesquisa de natureza básica bibliográfica como principal instrumento de investigação, aplicando uma abordagem qualitativa descritiva. Considerações finais: Este trabalho se propôs como objetivo geral elaborar de forma sintética, a partir de recortes bibliográficos, um estudo que confirma que o caráter apenas instrutivo da educação brasileira vem se dissolvendo ao longo do tempo. Essa evolução poderá ser atribuida a alguns fatores: novo paradigma de

1 Evelyn Elen Alves de Brito Cabral. Pontificia Universidade Católica de Goiás. evelynelenalves@gmail.com

2 Idelma Izabel de Camargo Silva. Pontificia Universidade Católica de Goiás. idelmaizabel@hotmail.com 
homem e de sociedade, novas concepções de educação, novas teorias de ensino e de aprendizagem, novos pensadores e, creio que ainda mais importantes novos pensamentos, desta vez críticos, nas mentes da maioria dos cidadãos desse país, até mesmo daqueles com pouca instrução escolar. É fato que a educação escolar tem com uma de suas funções a construção ou o despertar do pensamento crítico nos seus discentes. Independente dos motivos ou motivadores da queda do modelo de educação voltada apenas à instrução é importante que saibamos um pouco mais sobre essa (ré) evolução, que muito contribuiu para a democracia do ensino público, assim como da abolição da discriminação da oferta do ensino brasileiro.

Palavras- chaves: Educação, Cultura, Democracia. 


\title{
MATERIAL BIOLÓGICO DA COLEÇÃO DIDÁTICA COMO FERRAMENTA PARA O ENSINO DA ICTIOLOGIA NA EDUCAÇÃO BÁSICA
}

\author{
Josiney Farias de Araújoํ, Erival Gonçalves Prata², Renan Ferreira de Sousa ${ }^{3}$, \\ Leandro Marques Correia ${ }^{4}$, Adriana de Almeida Sanches ${ }^{5}$
}

Acesse a apresentação deste trabalho

Introdução: O ensino de biologia a partir de material biológico que compõe a coleção didática é um excelente recurso na ministração de aulas práticas. Isso porque facilita a compreensão das estruturas morfológicas, possibilitando a assimilação de conceitos teóricos vistos em sala de aula. Esta forma de ensino pode ser aplicada em diferentes niveis da educação e tem demonstrado excelentes resultados no processo de ensino-aprendizagem dos discentes. Objetivo: Desenvolver uma aprendizagem teórica e prática dos conteúdos da biologia de vida dos peixes nas aulas de Zoologia no ensino de Ciências. Material e métodos: Foi apresentado aos discentes do Clube de Ciências o material biológico de ictiologia que está conservado em frascos de vidros com álcool no laboratório de Ciências da Universidade Federal do Pará - Campus Universitário Marajó Breves (CUMB). Assim sendo, foram ministrados aos discentes aulas teóricas e práticas a respeito das características morfológicas, interações ecológicas e hábitos alimentares dos peixes. Resultados: No total participaram destas atividades aproximadamente 20 discentes do ensino fundamental de diferentes escolas do municipio de Breves que participam do Clube de Ciências no período vespertino. Através dessa estratégia de ensino podemos observar processos educativos relevantes que foram desenvolvidos, como a situação pedagógica de ensino por investigação nas aulas de Ciências. Deste modo, o debate e participação elevada dos discentes envolvidos em atividades propostas no ensino da Zoologia em aulas de Ciências foram fundamentais para o processo de ensino-aprendizagem. Conclusão: A utilização de material biológico como ferramenta didática em Zoologia no ensino de Ciências possui diversos benefícios como o desenvolvimento de um ensino mais contextualizado aos discentes e a união do conhecimento teórico e prático. Nesta perspectiva o ensino de Ciências por investigação pode propiciar soluções para diversas práticas da cultura científica, resolução de problemas, participação ativa dos discentes e outros.

Palavras-chave: Didática, Zoologia, Investigação, Ensino.

1 Universidade Federal do Pará. E-mail. josineyaraujo@yahoo.com.br

2 Universidade Federal do Pará. E-mail. erival.gprata@gmail.com

3 Universidade Federal do Pará. E-mail. renansous.26@gmail.com

4 Universidade Federal do Cariri. E-mail.1mcleleufac@gmail.com

5 Faculdade Integrada de Goiás. E-mail. adriana.sanches@ymail.com 
METODOLOGIAS MISTAS DE ENSINO EM UM PROCESSO DE COMPETIÇÃO EM ESCOLA TÉCNICA DE MINAS GERAIS

\author{
Fabiano Henrique Oliveira Sabino ${ }^{1}$, Elisângela Aparecida de Almeida Alves², \\ Luciana Jerônimo de Almeida Silva ${ }^{3}$, Pedro Henrique da Silva Santos ${ }^{4}$
}

Acesse a apresentação deste trabalho

INTRODUÇÃO: O ensino técnico traz consigo a objetividade voltada às práticas de trabalho com a aproximação com a realidade, perpassando pelas entrelinhas dos processos educacionais baseados em ações. Uma barreira tradicional é o modelo biomédico que muitas vezes fragmenta o indivíduo que necessita de um cuidado em saúde. Afim de quebrar estes paradigmas, práticas pedagógicas alternativas são essências para o processo ensino aprendizagem em saúde, dentre elas: sala de aula invertida, problematização e a gamificação. Somado a isto, a atualidade traz o desafio da manutenção da qualidade do ensino com a complexidade da educação em saúde em tempos de aulas remotas por plataformas digitais. OBJETIVO: Relatar a experiência dos autores na condução de uma competição de conhecimentos técnicos e educação em saúde de alunos do curso técnico em enfermagem de uma escola de cursos técnicos profissionalizantes. MÉTODO: A competição foi realizada via Webconferência através de plataforma digital, no período de 24 a 30/06/2020; envolveu cerca de 20 profissionais em 6 municipios mineiros e contou com estudos de casos direcionados aos cuidados em saúde voltados para doenças crônicas e primeiros socorros. RESULTADOS: Através das práticas apresentadas o aluno que conseguiu articular o conhecimento teórico-prático na condução dos estudos de casos propostos conforme critérios estabelecidos, foi consagrado o campeão da competição. A gamificação como estratégia possibilitou a conexão com a prática de futuros profissionais de saúde transformando o momento em um atendimento remoto. CONCLUSÃO: Entende-se que para o bom desempenho na atividade de cuidar, o profissional precisa de fato de conhecimentos que podem ser desenvolvidos a partir dos indicadores baseados em habilidades e competências. $\mathrm{O}$ uso de metodologias mistas de ensino, incluindo as metodologias ativas, contempla boa parte da abrangência de um profissional de saúde, tornando-o crítico, reflexivo e empoderado de seu conhecimento.

Palavras-chave: Enfermagem Prática; Educação Técnica em Enfermagem; Ensino.

1 Enfermeiro, mestrando do programa de pós-graduação em enfermagem pela Universidade Federal de São Carlos. fabianooliveira163@gmail.com

2 Enfermeira. Superintendência educacional do SENAC-MG

3 Enfermeira, mestre em enfermagem pela Universidade Federal de Alfenas.

4 Enfermeiro. Instrutor de formação profissional. Eixo saúde. SENAC-MG 
DESAFIOS E POSSIBILIDADES DO ENSINO EM SAÚDE EM AULAS REMOTAS: UM RELATO DE EXPERIÊNCIA

\author{
Fabiano Henrique Oliveira Sabino1; Lucas Fernando Antunes Gomes², \\ Silmara Elaine Malaguti Toffano ${ }^{3}$, Diene Monique Carlos ${ }^{4}$
}

Acesse a apresentação deste trabalho

INTRODUÇÃO: Dentre as mais diversas modalidades de ensino, as mais populares são o ensino presencial e o ensino à distância. Em tempos de pandemia e distanciamento social a transição entre estes modelos foi obrigatória ao modo que emergiu um novo modelo de ensino: o ensino remoto e com ele, várias possibilidades e inúmeros desafios e nuances inesperadas. Quando este ensino se traduz para a saúde multiplicam-se as potencialidades e nuances do processo. OBJETIVO: Relatar a experiência de um docente do curso técnico da área da saúde. MÉTODO: Trata-se de um relato de experiência sobre o ensino remoto em uma instituição de ensino técnico, situada no interior de Minas Gerais. As aulas remotas, que ocorrem por meio de uma plataforma de aulas remotas, tiveram início em abril e ainda permanecem nesta modalidade de ensino. RESULTADOS: No período descrito o docente perpassou por diversas disciplinas, as quais possuíam temas diferentes e que também necessitavam de abordagens diferentes. A metodologia para conduzir a aula foi escolhida a partir da temática a ser abordada, visando maior aproximação dos alunos. CONCLUSÃO: Percebe-se que os desafios são inerentes a qualquer modalidade de ensino, contudo, cabe ao docente articular a melhor forma de abordar o conteúdo, levando sempre em consideração a demanda de seus alunos. Apesar da modalidade de ensino remoto ser um método de aprendizado de maior destaque no presente momento e as dificuldades que lhe acarreta, verifica-se que as oportunidades do seu uso também são diversas. Ainda em um momento de constante aprendizado, entende-se que é necessário um constante aperfeiçoamento nos diversos eixos do saber para que, dessa forma, a educação possa se aperfeiçoar gradativa e concomitantemente.

Palavras-chave: Educação Técnica em Enfermagem; Educação a Distância; Prática do Docente de Enfermagem.

1 Enfermeiro, mestrando do programa de pós-graduação em enfermagem pela Universidade Federal de São Carlos. fabianooliveira163@gmail.com

2 Discente do curso de Enfermagem. Instituto de Ciências da Saúde. Universidade Federal do Triângulo Mineiro

3 Docente, Departamento de Enfermagem. Universidade Federal de São Carlos.

4 Docente. Departamento de Enfermagem na Assistência Hospitalar. Universidade Federal do Triângulo Mineiro. 


\section{PROFESSORES NO CONTEXTO DA PANDEMIA: UM ESTUDO DAS EMOÇÕES À}

\section{LUZ DOS PRESSUPOSTOS TEÓRICOS DE MATURANA}

Marise Rodrigues Guedes ${ }^{1}$

$\underline{\text { Acesse a apresentação deste trabalho }}$

O novo coronavírus imergiu os professores num contexto de ensino que, mais que nunca, evidencia a importância das emoções para o agir humano. Desse modo, partindo principalmente dos pressupostos de Humberto Maturana, cuja teoria discute o entrelaçamento entre as emoções e as ações - isto é, as conversações - como fundamentos que movem os seres vivos, essa pesquisa consiste em conhecer como as conversações de professores são veiculadas em notícias de portais on line baianos, durante a pandemia. Como objetivos específicos, traçamos: identificar e agrupar as conversações relativas aos docentes veiculadas pelas notícias em estudo; descrever aspectos negativos e positivos concernentes às emoções dos professores; discutir sobre o entrelaçamento entre as emoções e as ações desses profissionais; e, compreender os impactos das demandas educacionais atuais nas suas emoções. Esta pesquisa documental possui abordagem qualitativa e percorre os caminhos da Análise de Conteúdo, consistindo nas seguintes etapas: revisão bibliográfica; levantamento de notícias sobre emoções de professores em portais on line baianos; leitura, seleção e codificação dos documentos encontrados; seleção, agrupamento, codificação e categorização das unidades obtidas das notícias; descrição das categorias e análise interpretativa do conteúdo. As notícias revelaram que a forma de conviver atual potencializou o adoecimento dos docentes durante o periodo da pandemia, uma vez que a grande maioria das emoções apresentadas nos documentos denotam sentimentos negativos dos professores, no que tange à sua relação com as instituições, com a sociedade e com a sua própria profissão, demonstrando a realidade de dominação, exploração e subserviência a que estão expostos os docentes, cujos impactos negativos atravessam a prática e a saúde desses profissionais.

Palavras-chave: Emoções. Pandemia. Professores. Notícias.

1 Discente do Doutorado em Letras: Linguagens e Representações. Universidade Estadual de Santa Cruz. mariseguedess@hotmail.com 
(RE) INVENÇÃO DA PRÁTICA DOCENTE DE NÍVEL SUPERIOR NO PERÍODO DE PANDEMIA

Rose Manuela Marta Santos ${ }^{1}$, Rosana Daily Marta Santos ${ }^{2}$

Acesse a apresentação deste trabalho

Introdução: a pandemia impôs desafios a todos os setores da sociedade e, a educação também foi afetada, apresentando aos docentes e discentes o desafio do ensino remoto. Objetivo: relatar a experiência de (re) invenção da prática de uma docente de nivel superior no período de pandemia. Método: trata-se de um relato de experiência da prática docente em período de pandemia ocorrido em uma Instituição de Nivel Superior. A vivência iniciou-se em 24 de março e ocorre até o momento em turmas do $4^{\circ}$ ao $8^{\circ}$ semestre do curso de enfermagem, nos turnos matutino e noturno. Resultados: a adaptação: a pandemia apresentou um momento de incertezas e uma nova realidade aos docentes, formados e capacitados para o ensino presencial. As mudanças foram bruscas e a adaptação ao modelo de ensino remoto foi desafiador, além de cansativo. A adaptação aos ambientes virtuais apontou momentos de sofrimento mental pela necessidade de desenvolver novas habilidades em curto prazo. Os desafios: o momento vivenciado exige uma compreensão mútua: docente e discente, pois vários fatores influenciam no processo ensino e aprendizagem. O trabalho em home office torna-se uma barreira por ser um ambiente desfavorável pela rotina dos familiares e afazeres da casa e ocasiona a dispersão e a falta de interação na aula. O período remete a incerteza, medo e angustia e influencia na saúde mental dos docentes e discentes, originando insegurança e desmotivação. Ademais, este ensino exige instrumentos essenciais como computadores e/ou celulares, conexão com internet de qualidade e habilidade. A (re)invenção: foi necessário a reavaliação do planejamento inicial do semestre. Assim, foi realizado a aproximação do ensino remoto na literatura, busca de capacitações com vistas a instrumentalização imprescindivel para o momento. Foram adotadas estratégias: estímulo a gravação de vídeos com a demonstração prática do conteúdo estudado, criação de mapas metais, exibição de vídeos demonstrativos, direcionamento de estudo de casos e discussão, relatos de experiência de profissionais da área, aula invertida, incentivo ao condução de lives em rede social e utilização de jogos virtuais. Considerações finais: a interação remota apresenta papel fundamental neste periodo, principalmente pela continuidade da rotina de estudos, pelo apoio aos discentes e o fomento à esperança.

Palavras-chave: Ensino superior; Distanciamento Social; Ensino Remoto; Covid 19.

1 Enfermeira. Doutora em Ciências da Saúde e docente do Curso de Enfermagem da Faculdade Maria Milza (FAMAM). E-mail: rmms9@hotmail.com.

2 Pedagoga. Pós-graduada em Metodologia do Ensino Superior e em Educação a Distância. Coordenadora Pedagógica do Colégio Estadual Democrático Professor Romulo Galvão. E-mail: rosanauesb@hotmail.com. 


\section{PAPÉIS DE GÊNERO}

\section{Cibele Santos Oliveira Martins 1, Giovanna Marrochelli Guimarães²}

Quando se fala sobre sexualidade na escola conteúdos como IST's, gravidez na adolescência e métodos contraceptivos são os mais recorrentes, deixando de lado outros tópicos relacionados. É imprescindivel abordá-los na escola, visto que "a educação é uma das áreas prioritárias de intervenção para a promoção de uma sociedade mais inclusiva e respeitadora da diversidade." (Ferreira, 2011 p. 11). Como uma forma de promover a discussão dessa temática, foi proposto um plano de aula para que os alunos compreendessem o que é Gênero e seus papéis em nossa sociedade, assim como a construção social destes. Utilizou-se a metodologia construtivista, partindo do conhecimento prévio dos alunos. O público alvo foram duas turmas do $1^{\circ}$ ano do Ensino Médio de uma Escola Estadual em Diadema, e teve duração de duas aulas. Nas duas aulas abordamos alguns conceitos como identidade de gênero, orientação sexual e sexo biológico, além de uma atividade de "Caça-Estereótipos", onde os meninos e as meninas fizeram um levantamento de palavras, e comportamentos que são tipicamente relacionados aos dois sexos. Para as mulheres apareceram termos como "descontrole emocional" e "exibidas", enquanto para os homens citaram "machismo" e "assédio". Essas palavras mostram como a divisão entre os sexos é arraigada, arcaica (BARRETO et al. 2014) e preconceituosa. Nosso projeto foi além do que esperávamos, pois as discussões saíram do âmbito da biologia e foram para o lado social, estabelecendo relações entre o conhecimento formal (acadêmico) e a vivência dos alunos.

Palavras-chave: Gênero; biologia; educação.

1 Licencianda de Ciências. UNIFESP. Cibele.maartins@gmail.com

2 Licencianda de Ciências. UNIFESP. Giovanna.marrochelli@gmail.com 
Querida leitora e querido leitor,

Agradecemos por ter feito o download desse e-book. Decerto que despertar seu interesse pela obra, para nós, editores, organizadores e autores, é uma alegria imensa. Por isso, agradecemos.

Caso tenha alguma dúvida ou sugestão, entre em contato conosco pelo e-mail contato@vveditora.com

PUBLIQUE CONOSCO!

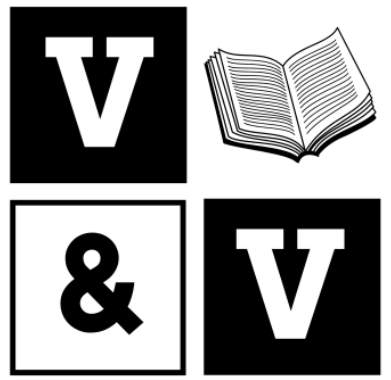

EDITORA

Biografias, poesias e textos literários.

Trabalhos de Conclusão de Curso, Dissertações e Teses.

Artigos e textos de Grupos de Pesquisas e Coletâneas.

Acompanhe nosso site e redes sociais e também nossos eventos.

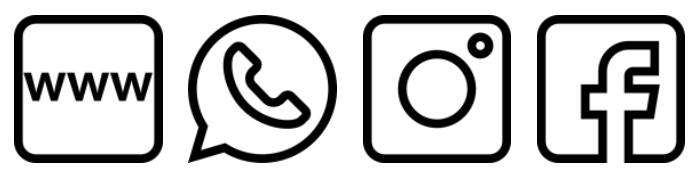


Comunidade Movimentos Docentes Comunidade Movimentos Docentes Comunidade Movimentos Docentes Comunidade Movimentos Docentes Comunidade Movimentos Docentes Comunidade Movimentos Docentes Comunidade Movimentos Docentes Comunidade Movimentos Docentes Comunidade Movimentos Docentes Comunidade Movimentos Docentes Comunidade Movimentos Docentes Comunidade Movimentos Docentes Comunidade Movimentos Docentes Comunidade Movimentos Docentes Comunidade Movimentos Docentes Comunidade Movimentos Docentes Comunidade Movimentos Docentes Comunidade Movimentos Docentes Comunidade Movimentos Docentes Comunidade Movimentos Docentes Comunidade Movimentos Docentes Comunidade Movimentos Docentes Comunidade Movimentos Docentes Comunidade Movimentos Docentes Comunidade Movimentos Docentes Comunidade Movimentos Docentes Comunidade Movimentos Docentes Comunidade Movimentos Docentes Comunidade Movimentos Docentes Comunidade Movimentos Docentes Comunidade Movimentos Docentes Comunidade Movimentos Docentes Comunidade Movimentos Docentes Comunidade Movimentos Docentes Comunidade Movimentos Docentes Comunidade Movimentos Docentes Comunidade Movimentos Docentes Comunidade Movimentos Docentes Comunidade Movimentos Docentes Comunidade Movimentos

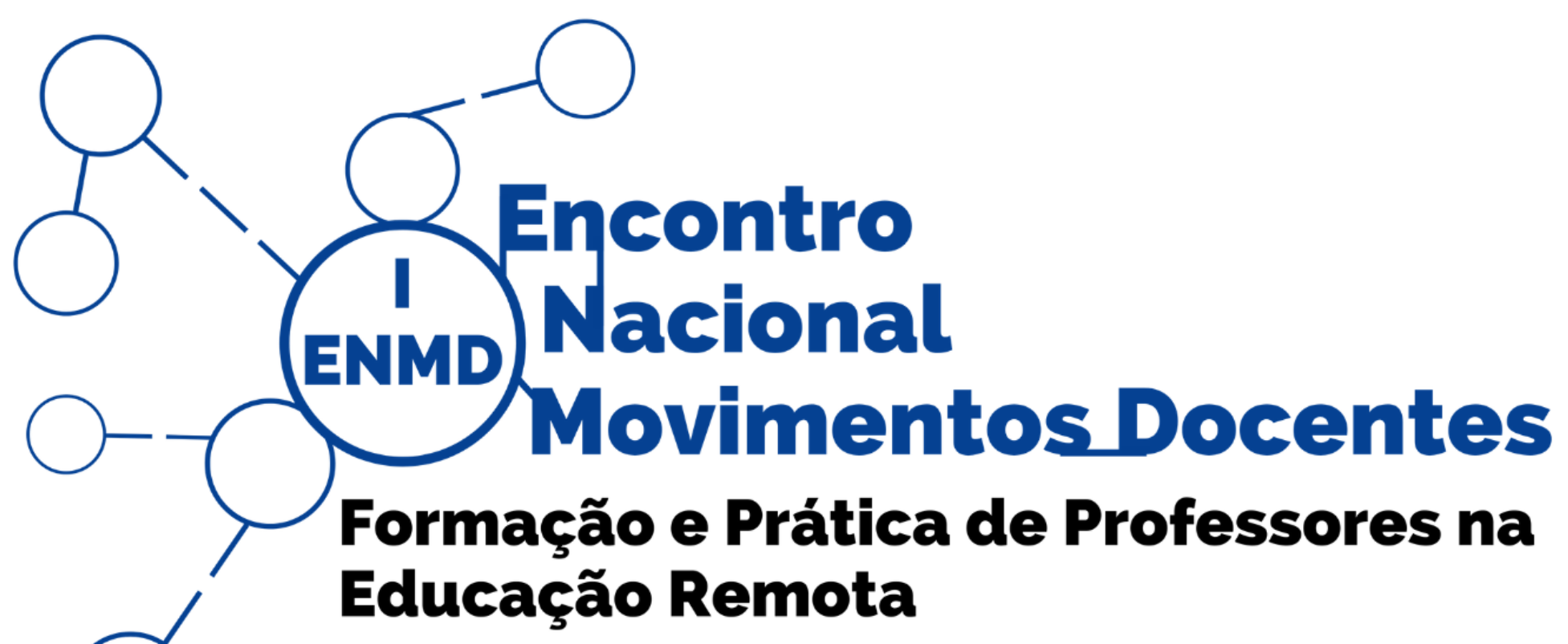

Docentes Comunidade Movimentos Docentes Comunidade Movimentos Docentes Comunidade Movimentos Docentes Comunidade Movimentos Docentes Comunidade Movimentos Docentes Comunidade Movimentos Docentes Comunidade Movimentos Docentes Comunidade Movimentos Docentes Comunidade Movimentos Docentes Comunidade Movimentos Docentes Comunidade Movimentos Docentes Comunidade Movimentos Docentes Comunidade Movimentos Docentes Comunidade Movimentos Docentes Comunidade Movimentos Docentes Comunidade Movimentos Docentes Comunidade Movimentos Docentes Comunidade Movimentos Docentes Comunidade Movimentos Docentes Comunidade Movimentos Docentes Comunidade Movimentos Docentes Comunidade Movimentos Docentes Comunidade Movimentos Docentes Comunidade Movimentos Docentes Comunidade Movimentos Docentes Comunidade 